\title{
Aneurysmal subarachnoid hemorrhage: imaging strategies and cost-effectiveness aspects in diagnostic work-up and post-therapeutic follow-up
}

Citation for published version (APA):

van Zwam, W. H. (2013). Aneurysmal subarachnoid hemorrhage: imaging strategies and costeffectiveness aspects in diagnostic work-up and post-therapeutic follow-up. [Doctoral Thesis, Maastricht University]. Maastricht University. https://doi.org/10.26481/dis.20130628wz

Document status and date:

Published: 01/01/2013

DOI:

10.26481/dis.20130628wz

Document Version:

Publisher's PDF, also known as Version of record

Please check the document version of this publication:

- A submitted manuscript is the version of the article upon submission and before peer-review. There can be important differences between the submitted version and the official published version of record.

People interested in the research are advised to contact the author for the final version of the publication, or visit the DOI to the publisher's website.

- The final author version and the galley proof are versions of the publication after peer review.

- The final published version features the final layout of the paper including the volume, issue and page numbers.

Link to publication

\footnotetext{
General rights rights.

- You may freely distribute the URL identifying the publication in the public portal. please follow below link for the End User Agreement:

www.umlib.nl/taverne-license

Take down policy

If you believe that this document breaches copyright please contact us at:

repository@maastrichtuniversity.nl

providing details and we will investigate your claim.
}

Copyright and moral rights for the publications made accessible in the public portal are retained by the authors and/or other copyright owners and it is a condition of accessing publications that users recognise and abide by the legal requirements associated with these

- Users may download and print one copy of any publication from the public portal for the purpose of private study or research.

- You may not further distribute the material or use it for any profit-making activity or commercial gain

If the publication is distributed under the terms of Article $25 \mathrm{fa}$ of the Dutch Copyright Act, indicated by the "Taverne" license above, 


\section{Aneurysmal subarachnoid hemorrhage:}

Imaging strategies and cost-effectiveness aspects in diagnostic work-up and post-therapeutic follow-up 


$\begin{array}{ll}\text { Lay-out: } & \text { Thum Aarts } \\ \text { Glass Art: } & \text { Nataliya Vladychko (www.vladychko.nl) } \\ \text { Art design: } & \text { Jan Besseling } \\ \text { Printed by: } & \text { Grafische Dienst MUMC + } \\ & \\ \text { ISBN: } & 978-90-817958-4\end{array}$

Some of the studies in this thesis were financially supported by the 'profileringsfonds' Maastricht UMC+. Financial support for printing has been kindly provided by, among others: Angiocare, St Jude Medical, Lamepro, Bard Benelux, Abbott Vascular, Toshiba Medical Systems Nederland, Bayer B.V. 


\section{Aneurysmal subarachnoid hemorrhage:}

Imaging strategies and cost-effectiveness aspects in diagnostic work-up and post-therapeutic follow-up

\section{PROEFSCHRIFT}

ter verkrijging van de graad van doctor aan de Universiteit Maastricht, op gezag van de Rector Magnificus, Prof dr. L.L.G. Soete volgens het besluit van het College van Decanen,

in het openbaar te verdedigen

op vrijdag 28 juni 2013 om 14.00 uur

door 


\section{Promotores}

Prof. dr. J.T. Wilmink,

Prof. dr. J.E. Wildberger

\section{Copromotor}

Dr. P.A.M. Hofman

\section{Beoordelingscommissie}

Prof. dr. J.J. van Overbeeke (voorzitter)

Prof. dr. C.B.L.M. Majoie (AMC, Amsterdam)

Dr. J.E.A. Staals

Prof. dr. G.E. Wilms (U.Z. Leuven, België) 



\section{Contents}

- Chapter 1

Introduction and historical background

- Chapter 2

Performance of Contrast Enhanced Magnetic Resonance Angiography in patients presenting with Subarachnoid Hemorrhage. Part 1: detection of aneurysms.

- Chapter 3

Performance of Contrast Enhanced Magnetic Resonance Angiography in patients presenting with Subarachnoid

Hemorrhage. Part 2: assessing feasibility of coiling.

- Chapter 4

Simulation study employing different scenarios using contrastenhanced MRA and digital subtraction angiography in patients presenting with a subarachnoid hemorrhage. 


\section{- Chapter 5}

Single center experience of surgical and endovascular treatment of ruptured cerebral aneurysms.

\section{- Chapter 6}

Follow-up of coiled intracranial aneurysms with contrast enhanced MRA with digital subtraction angiography as standard of reference.

\section{- Chapter 7}

Late recanalization of adequately coiled intracranial aneurysms.

\section{- Chapter 8}

Cost-effectiveness of CTA, MRA and DSA in patients with nontraumatic subarachnoid hemorrhage.

\section{- Chapter 9}

General discussion.

Summary 

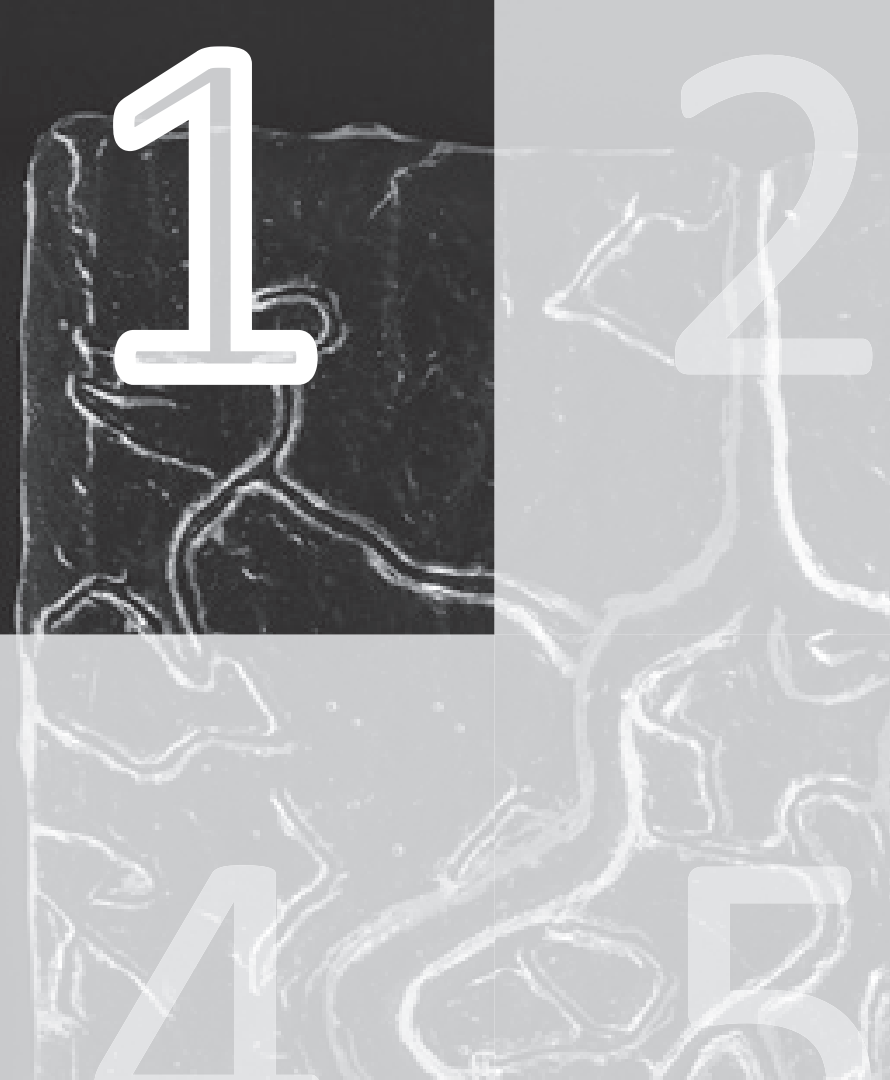


\section{Chapter 1}

Introduction and historical background

W.H. van Zwam 
In 1765, Biumi of Milan provided the first clinical account and autopsy description of an aneurysmal subarachnoid hemorrhage $(\mathrm{SAH})^{1}$. $\mathrm{SAH}$ is a devastating neurologic disorder leading to a high mortality rate, permanent disability in $50 \%$ of surviving patients, and estimated lifetime costs amounting to more than double those of an ischemic stroke..$^{2-4}$

A patient showing signs and symptoms indicating a possible SAH poses several diagnostic challenges:

At first the clinical presentation of SAH is not always straightforward and the classic symptomatic "thunderclap headache" characterizing SAH may be absent or caused by another disease. ${ }^{5}$ A definite diagnosis therefore, can only be established through imaging or laboratory tests of the cerebrospinal fluid (CSF). A rapid and accurate diagnosis is crucial since one of the possible underlying causes of SAH is a potentially fatal, but treatable, intracranial aneurysm. Thus, once the diagnosis SAH has been confirmed, the second challenge is to detect or exclude an aneurysm as the cause of hemorrhage. If an aneurysm is found, the third challenge is to select the most appropriate treatment: endovascular or neurosurgical.

The aim of the treatment is to prevent a new bleed from the aneurysm, the risk of which is greatest in the period immediately following the first bleed.

After treatment a follow-up strategy is needed to detect possible aneurysm recurrence. Finding the optimal follow-up strategy is the fourth challenge.

In the last decennia, much research has been carried out and many articles have been published on the ways in which these challenges can be met. This thesis contributes to our understanding and overcoming of those challenges.

\section{Epidemiology of Intracranial aneurysms}

From a meta-analysis of 68 studies it was calculated that the prevalence of intracranial aneurysms was $3.2 \%$ in a hypothetical population with no co-morbidity, a mean age of 50 years and a $1: 1$ sex ratio (95\% Cl 1.9-5.2). ${ }^{6}$ Other studies found a prevalence of intracranial aneurysms ranging from 2 to $3 \%$. $^{7-9}$ The prevalence is higher in patients with connective tissue disorders such as autosomal dominant polycystic kidney disease (ADPKD) or Ehlers-Danlos disease, and in patients with a family history of one or more known intracranial aneurysms: prevalence is estimated to be $4-10 \%$ for patients with a case in one first-degree relative, and $20 \%$ for patients with more than one case in their family history. ${ }^{6,7}$ Even though nowadays more and more aneurysms are being detected through screening or as incidental findings, the majority of aneurysms manifest themselves through rupturing into the subarachnoid space surrounding the intracranial arteries.

Retrospective calculations on the average risk of aneurysm rupture have been carried out in the International Study of Unruptured Intracranial Aneurysms (ISUIA) ${ }^{10,11}$ and other investigations. ${ }^{12-14}$ These have led to estimates of annual risk of rupture ranging from $0.3 \%$ for small $(<7 \mathrm{~mm})$ anterior circulation aneurysms, to $13.0 \%$ for large $(>25 \mathrm{~mm})$ posterior circulation aneurysms ${ }^{10}$, and even to $43.1 \%$ for large aneurysms in the Japanese population. ${ }^{12}$

Worldwide incidence of aneurysmal SAH is approximately 9/100,000 patient years (PY), with a wide range of variability per region from 2.0 and 4.2/100,000 PY in China and Central \& South America, to 19.7 and 22.7/100,000 PY in Finland and Japan. ${ }^{15,16}$ Incidence of aneurysmal SAH in the Netherlands is 3.78 / 100,000 PY (2.98-4.72). ${ }^{17}$ The high incidence of SAH in Finland and Japan is not associated with a 
higher prevalence of intracranial aneurysms, ${ }^{6}$ which leads to the conclusion that there must be a higher risk for rupture of the aneurysms in these countries. Several factors have been found to predict the risk of rupture: smoking, hypertension and heavy alcohol use all appear to be independent risk factors. ${ }^{18-21}$ Incidence of rupture increases with age and is 1.24 times higher in women than in men; the exception being the Central \& South American population in which the incidence of rupture was found to be slightly higher in men. ${ }^{15}$ Size, location and morphological characteristics of the aneurysm itself are also predictors of risk of rupture. ${ }^{12,22-25}$ Other investigations have focused on flow dynamics and wall shear stress factors ${ }^{26-29}$ in order to predict risk of rupture, and some report seasonal variations due to meteorological factors, ${ }^{30,31}$ whereas others find no such correlation. ${ }^{32}$

Apart from aneurysm rupture, any of the following may cause non-traumatic SAH: rupture of an intracranial arteriovenous (AV) malformation or fistula, dissection of an intracranial artery, a bleeding disorder or drug abuse. In two thirds of the patients in whom no aneurysm can be found after SAH, computed tomographic (CT) imaging reveals a perimesencephalic pattern of hemorrhage, with the bleed confined to the CSF spaces around the midbrain. ${ }^{33,34}$ These patients invariably have a good prognosis regarding the risk of rebleeding. ${ }^{35,36}$

Patients suffering a SAH due to aneurysm rupture have high rates of morbidity and mortality. Although case fatality rates have improved markedly over the past years, ${ }^{15,37,38}$ there is still a 30 -day mortality rate of more than $20 \%{ }^{16,17,37}$

The risk of a rebleed from an aneurysm, especially in the period shortly after the first rupture, is much higher than the average risk of initial rupture: the case fatality rate of patients suffering from a rebleed is up to $70 \% .{ }^{16}$ Timely discovery and treatment of the causative aneurysm therefore, is vital.

\section{Confirmation of Subarachnoid Hemorrhage}

When a patient presents to the hospital with acute-onset headache, the first step is to exclude or confirm a SAH. This can be achieved through CT or magnetic resonance imaging (MRI), or through the examination of CSF obtained by lumbar puncture (LP). The usual diagnostic strategy is to perform noncontrast enhanced CT (NECT), followed by a LP if the CT is negative. ${ }^{16,34,39-41}$ NECT is highly sensitive for the detection of SAH in the first 12 hours after the onset of symptoms, with sensitivities ranging from 93 $-100 \%,{ }^{42-47}$ but this decreases steadily in the ensuing hours and days, until sensitivity is no more than $50 \%$ after one week. ${ }^{48}$ On the other hand, CSF examination is not reliable in the first 12 hours after SAH due to the fact that bilirubin is not formed until $9-15$ hours after a bleed. ${ }^{39}$ The role of LP is under debate $^{45,47,49,50}$ due to its potential complication rate ${ }^{51}$ and due to the higher sensitivity of newer generation CT scanners. ${ }^{52}$ An alternative diagnostic strategy may be the combination of NECT and CT angiography (CTA), in which CTA functions as a diagnostic back-up to detect an intracranial aneurysm as possible cause of SAH in case of a negative NECT. ${ }^{47,52,53}$ After all, the absolute diagnostic priority in a patient with a possible SAH lies in establishing the presence of an aneurysm. If diagnostic emphasis lies on aneurysm detection by CTA, a (false) negative NECT finding in the absence of an aneurysm becomes less relevant. ${ }^{52,54}$ The risk of missing an aneurysmal SAH with the combination NECT and CTA is small, ranging from $0.2 \%-0.8 \%$, depending on the assumed dependency of the two tests. ${ }^{47}$

The role of MRI in detecting SAH has always been under discussion. ${ }^{55-58}$ In the early years of MRI it was thought that this modality was insensitive for detecting acute SAH. ${ }^{58}$ Explanations for this lack of 
sensitivity were sought in the absence of paramagnetic methaemoglobin in the first days after the bleed ${ }^{59}$ or in the restrictions on the generation of paramagnetic deoxyhaemoglobin due to the local oxygen tension of cerebrospinal fluid..$^{60}$ In the same period however, superiority of MRI over CT in the detection of SAH in the later phase (after 4 days) was reported in literature, especially with proton density weighted sequences. ${ }^{61}$ Later publications also reported a high sensitivity in the acute phase: most worked with fluid attenuated inversion recovery (FLAIR) sequences ${ }^{62-64}$ while others found T2* gradient-echo sequences to be the most sensitive. ${ }^{56}$ However, doubt about the practical value of MRI for the detection of subarachnoid blood remains, ${ }^{55,57}$ and even if MRI were to be equally sensitive to CT in detecting SAH in the acute phase, MRI would be impracticable: MRI systems are less readily available than $\mathrm{CT}$ scanners, and the lengthier MRI acquisitions make MRI images more sensitive to movement artefacts than $\mathrm{CT} .36,65$

\section{Detection and evaluation of intracranial aneurysms: DSA}

Once the diagnosis of SAH has been established a causative aneurysm must be detected or excluded. Currently, three main diagnostic tools exist: digital subtraction angiography (DSA), CTA and MRA.

Until recently, the standard tool used for the identification of the source of a bleed was conventional (catheter) angiography. This technique has evolved to the currently used DSA techniques using non-ionic contrast material. ${ }^{16,66-69}$ The 'Guidelines for the Management of Aneurysmal Subarachnoid Hemorrhage : A Statement for Healthcare Professionals From a Special Writing Group of the Stroke Council, American Heart Association' of 2009 give the following recommendations:

- Selective cerebral angiography should be performed in patients with SAH to document the presence and anatomic features of aneurysms (Class I, Level of Evidence B).

- MRA and CTA may be considered when conventional angiography cannot be performed in a timely fashion (Class IIb, Level of Evidence B). ${ }^{16}$

DSA is an invasive, labor-intensive and relatively expensive technique. It involves the placement of a catheter in the cervical internal carotid arteries and in the vertebral arteries. Therefore it carries a small but potentially significant risk of neurological complications. Permanent neurologic complication is reported to occur in 0.12 to $2.3 \%$ of cases. ${ }^{70-77}$

Before the introduction of rotational DSA, the sensitivity of DSA for cerebral aneurysm detection was estimated to be greater than $90 \%$; in the setting of acute SAH sensitivity decreased to slightly over $80 \%{ }^{41,78,79}$ Since then, the introduction of rotational DSA with 3D reconstruction has increased diagnostic sensitivity even further. This technique has been used for detecting and evaluating cerebral aneurysms $s^{80-83}$ ever since the first reports of rotational roentgenography $y^{84,85}$ and the application of rotational angiography to imaging of the cerebral vessels ${ }^{86-89}$ were first published. The 3D reconstructions provided by rotational angiography have consistently shown a strong correlation with intraoperative findings ${ }^{90}$ and have proven helpful in evaluating possibilities for endovascular treatment. ${ }^{91-94}$ There are several advantages to 3D rotational angiography over conventional 2D angiography: first, the spatial resolution which can be achieved using 3D DSA is $0.15 \mathrm{~mm}$, whereas this is limited to ca. $0.2 \mathrm{~mm}$ for 2D DSA. ${ }^{95}$ Thus 3D DSA allows the detection of more aneurysms, especially those of smaller size. ${ }^{96-100}$ Second, in 2D DSA multiple acquisitions are usually required for detailed evaluation of the cerebral vessels, whereas in 3D DSA a single acquisition per vessel usually suffices. 
Consequently, 3D DSA leads to a reduction in patient radiation and iodinated contrast material exposure. $^{101}$

Due to these advantages, many now consider 3D DSA the gold standard for detection and evaluation of cerebral aneurysms. ${ }^{68,83,102}$ The standard 2D DSA images should not be dismissed entirely however: 3D reconstructed DSA images may cause the dome-to-neck ratio to be underestimated ${ }^{103}$ and pseudostenosis in the parent vessel to be observed. ${ }^{104}$

The true diagnostic accuracy of DSA for detecting intracerebral aneurysms is difficult to determine due to the lack of an alternate standard of reference. Indeed, initial DSA may be negative in 10-20\% of cases, sometimes falsely-negative due to small aneurysm size, aneurysm thrombosis, local vasospasm, or simply due to incomplete imaging. Repeat angiography has traditionally been recommended within 1 to 2 weeks. If this repeat DSA is negative it is concluded that an aneurysm is not present and the cause of the SAH should be sought elsewhere. However, the estimated additional diagnostic yield of this procedure is only $1 \%-2 \%$, and its cost effectiveness and benefit-risk balance are topics of debate. ${ }^{16}$

Repeat DSA may not be functional in several identifiable patient subpopulations. Different bleeding patterns in $\mathrm{SAH}$, for example, may give an indication of the presence or absence of an aneurysm. ${ }^{105} \mathrm{It}$ is known that a perimesencephalic or pretruncal distribution pattern is not usually caused by an aneurysm. ${ }^{106,107}$ And in patients exhibiting such patterns not only does repeat DSA have a very low diagnostic yield, ${ }^{108-111}$ but the clinical course is favorable with very few rebleeds. ${ }^{112,113}$ On the other hand, when the bleeding distribution pattern is not typical for a perimesencephalic SAH, repeat angiography reveals an aneurysm in up to $45 \%$ of cases. ${ }^{114-118}$ Another category is the group of patients with a clinical presentation of SAH, with a CT study negative for SAH but a positive CSF finding at LP. In all studies where this patient group was examined separately, repeat DSA did not reveal a single aneurysm. ${ }^{108,114,116,117,119,120}$

Introducing a second repeat DSA after a longer period proved of little value in the aforementioned subgroups. ${ }^{109,121}$

Based on the above information the following strategy appears to be most practical for patients with a DSA-negative SAH:

- If the diagnosis of SAH is based on clinical presentation with positive CSF findings but a negative CT study, repeat DSA is not recommended

- If the bleeding pattern in SAH has a typical perimesencephalic distribution on CT, repeat DSA is not recommended

- If the SAH has a non-perimesencephalic distribution pattern on CT, repeat DSA within the first week is recommended

\section{Detection and evaluation of intracranial aneurysms: CTA}

CTA is an alternative to DSA for the detection of aneurysms in patients with a SAH.

Since the first description of axial computed tomography was published by Hounsfield and Ambrose in $1973,{ }^{122-125}$ CT has become a valuable tool in imaging of the brain. Early CT units produced crude images on a 64x64 matrix and early computers took all night to process these images. ${ }^{126}$

The main technological advance that led to the development of extended coverage CT and CTA was the introduction of spiral CT in 1989, which allowed continuous tube-detector rotation and transport of the 
patient without pausing for each section. ${ }^{127-129}$ The first results of studies assessing the possibility of diagnosing intracranial aneurysms with CTA were reported in the early 1990s. ${ }^{130-134}$

Since then, many articles have described the performance of CTA in detecting intracranial aneurysms, and the first meta-analysis was published in 2000 by White and Wardlaw. ${ }^{135}$ Studies that evaluated noninvasive angiographic techniques against DSA as the standard of reference were included in this metaanalysis and a total of sixteen studies with CTA as the non-invasive diagnostic modality comprising a total of 677 patients were analyzed. The overall sensitivity of CTA for detecting aneurysms was found to be $92 \%$ (95\% Confidence Interval (Cl): $89-95 \%)$, but this sensitivity decreased sharply for smaller aneurysms: sensitivity for aneurysms larger than $3 \mathrm{~mm}$ was $96 \%$ (95\% Cl: $94-98 \%)$, and only $61 \%$ (95\% Cl: $51-70 \%$ ) for aneurysms smaller than $3 \mathrm{~mm}$. It should be noted that not all sixteen studies employed spiral technique (in 2 of 16 studies sequential CT scans were used). The meta-analysis of White and Wardlaw ${ }^{135}$ was updated in $2002^{136}$ with special focus on the effect of aneurysm size on diagnostic performance. Nine studies with a total of 619 individual cases were included. The sensitivity of CTA found in this meta-analysis ranged from $53 \%$ (95\% Cl 44-62\%) for aneurysms $2 \mathrm{~mm}$ or less in size to $95 \%$ (95\% Cl 92-97\%) for aneurysms larger than $7 \mathrm{~mm}$. Another meta-analysis was published at about the same time ${ }^{137}$ including some of the same studies used by White and Wardlaw. Twenty-one studies met the inclusion criteria for this meta-analysis and 1251 patients were evaluated, resulting in a mean sensitivity of $93.3 \%$ and specificity of $87.8 \%$. When the studies were weighted for the number of patients in each study, the sensitivity decreased slightly, to $92.7 \%$ and the specificity to $77.2 \%$. The authors concluded that DSA should remain the standard method for detecting intracranial aneurysms, but that CTA could be used as the first diagnostic modality followed by DSA in cases where an aneurysm was not identified or clearly delineated.

In the meantime, spiral or helical computed tomographic technology kept improving with faster gantry rotation, more powerful $\mathrm{X}$-ray tubes and improved interpolation algorithms. However, the greatest advance came with the introduction of multi-detector-row computed tomography scanners which provided similar scan quality at speeds 3-6 times greater than single-detector-row scanners. This improvement had a profound impact on the performance of CT angiography, resulting in greater anatomic coverage, lower iodinated contrast doses, and images with higher spatial resolution ${ }^{138-140}$. Needless to say these multi-slice or multi-detector CT (MDCT) scanners were a welcome new tool, and they were immediately implemented for intracranial aneurysm imaging. ${ }^{141-147}$

Another great improvement in CT scanning was the introduction of subtraction techniques. ${ }^{148-155}$ Aneurysms near the skull base are sometimes difficult to detect because the contrast-filled vessels and aneurysms have approximately the same attenuation coefficient (Hounsfield Units) as bone; effective subtraction of bony structures solves this problem.

Recent meta-analyses including studies using multi-detector-row CT scanners report significantly better diagnostic accuracies. ${ }^{156,157}$ Westerlaan et al. included 50 studies with 4,097 patients in their metaanalysis, ${ }^{157}$ and found a pooled sensitivity of $98 \%$ (95\% Cl: $\left.97-99 \%\right)$ and a pooled specificity of $100 \%$ (95\% Cl: $97-100 \%)$. The authors stated that multi-detector-row scanners were used in all included studies, 34 of which using 4-row scanners. However, closer inspection reveals that at least 20 of the aforementioned 34 studies appear to have been performed using single-detector-row scanners. ${ }^{158-177}$ In five studies distal pericalossal and posterior inferior cerebellar aneurysms were missed because they 
were outside the area of coverage. The authors stated that these studies had been performed with fourdetector-row scanners, but in fact in only one of these five a four-row scanner was used. ${ }^{178}$ The other four were studies in which single-row scanners were used. This nicely illustrates one of the main drawbacks of the older, single-row scanners, which is the limited coverage within a certain time window. Larger coverage would require longer scan times which would lead to more motion artefacts, as well as to more undesired enhancement of venous structures.

Another improvement of modern multi-detector scanners is the higher spatial resolution. Even though spatial resolution depends on the collimation of the scanner and not necessarily on the number of detector rows, modern scanners with more detector rows use smaller collimation and therefore have better spatial resolution. In the meta analysis of Menke et al $^{156}$ a subgroup analysis based on scanner type was carried out. They reviewed 45 studies with 3,643 patients, 26 of which have previously been included in the meta-analysis by Westerlaan et al. and 9 of which were used in older meta-analyses. ${ }^{135-}$ 137 Sixteen of the studies reviewed by Menke et al. utilized single-detector-row scanners; the other 29 utilized four to 64 detector row scanners. Pooled sensitivity and specificity were found to be 95.0 and $96.2 \%$ respectively. When stratified to the number of detector rows however, the pooled sensitivities ranged from $91.2 \%$ for single-row scanners to $97.8 \%$ for 64 -row scanners and specificity ranged from $90.8 \%$ for 4 -row-scanners to $97.7 \%$ for 64-row scanners (pooled specificity for single-row scanner studies was 94.0\%). Sub-millimeter slice thickness was only achieved in 16- and 64-detector-row scanners: the 16 studies in Menke's meta-analyses using sub-millimeter slice thickness had significantly better results in detecting aneurysms than the studies using a slice thickness of 1 millimeter or more: sensitivity $98.8 \%$ vs. $95.9 \%$ ( $p=0.006$ ) and specificity $99.4 \%$ vs. $96.4 \%$ ( $p=0.029)$.

A few more studies have been published since these meta-analyses appeared, using 16-, ${ }^{179-181}$ 64-182,183 and even 320 detector-row scanners. ${ }^{184,185}$ One of these studies reported detection of aneurysms smaller than $3 \mathrm{~mm}$ with a sensitivity of more than $95 \% .{ }^{183}$ Another new CT scanning technique currently under investigation is dual energy $\mathrm{CT}^{186}$ which allows for automatic bone subtraction. ${ }^{187-190}$ The results so far look promising, but further evaluation of this technique with larger study population is necessary. The studies mentioned above consistently use DSA as the standard of reference, sometimes in combination with perioperative findings. A few studies report aneurysms missed by DSA that were discovered with CTA and confirmed during treatment, ${ }^{179,191,192}$ and one study reports a false-positive DSA finding with true-negative CTA, confirmed at surgery. ${ }^{193}$ Some claim that, for the detection of small aneurysms, 3D CTA has a superior sensitivity than conventional DSA ${ }^{192}$ or even rotational DSA. ${ }^{183}$ Considering these reports we are probably justified in stating that the accuracy of CTA with modern multi-slice scanners at least approaches that of DSA in the detection of intracranial aneurysms.

The development of new techniques to treat aneurysms has influenced the requirements of aneurysmal detection and evaluation tools. In the last decade, and especially since the publication of the results of the International Subarachnoid Aneurysm Trial (ISAT), ${ }^{194}$ the new endovascular treatment technique of intracranial aneurysms using platinum Guglielmi detachable coils (GDC) ${ }^{195,196}$ has gained acceptance and become the primary treatment mode in many centers. As a consequence of this new treatment, not only must a diagnostic tool detect the aneurysm but it must also be able to assess the feasibility of endovascular treatment. ${ }^{197,198}$ Thus, studies assessing the performance of non-invasive diagnostic tools in patients suspected of harboring an intracranial aneurysm now focus on both its detection accuracy as 
well as its ability to detail anatomic features and predict whether endovascular treatment is feasible. ${ }^{120,159,160,173,175,179,191-193,199-203}$ In order to accomplish these feats, the diagnostic tool must permit accurate measurement of the neck width and neck-to-dome ratios, as well as visualization of possible arterial branches originating from the neck of the aneurysm. The latter is important because, for aneurysms with a wide neck or large neck-to-dome ratio, or with branches originating from the neck of the aneurysm, surgical instead of endovascular treatment is preferred in most cases. Some authors report an overestimation of neck-to-dome ratio by $\mathrm{CTA}^{141,202}$ which potentially leads to a choice for surgical treatment where endovascular treatment might have been possible. However, most authors assessing CTA as a diagnostic tool for SAH conclude that, in the majority of cases, CTA is able to fulfill the requirements for optimal treatment planning ${ }^{120,159,179,193,201,203}$ limiting the need for DSA. ${ }^{160,199}$ Others still consider DSA the first line imaging modality for patients presenting with $\mathrm{SAH} .{ }^{66,68,204}$

There are on-going heated debates on this issue as exemplified by the following quotes: ${ }^{205-207}$

"However, in the vast majority of patients with aneurysmal SAH, it (CTA) seems redundant. Perhaps we should, as has been suggested before, "dispense with the CTA altogether and just get on with the appropriate test"68,204

and

"When reading the editorial by Kallmes et al, one cannot help conclude that their protests are the obligatory last spasms of a dying, outclassed, antiquated way of practice that is the "diagnostic" catheter angiogram."205

We suggest that an appropriate diagnostic strategy following the detection of an aneurysm through CTA could be as follows:

- If CTA clearly depicts the neck of the aneurysm, and side branches can be identified properly, treatment planning can be done using CTA alone.

- If doubt exists about these characteristics an additional (preferably rotational) DSA examination should be performed.

It is important to note that, in these recommendations, cost-effectiveness of the different diagnostic strategies was not taken into consideration.

\section{Detection and evaluation of intracranial aneurysms: MRA}

A third alternative tool in the search for aneurysms in patients presenting with a SAH is magnetic resonance angiography (MRA).

After the detection of 'magnetic resonance' by Bloch and Purcell in the 1940's, ${ }^{208,209}$ Paul Lauterbur was the first to write a paper about imaging using this technique in $1973^{210}$ which he called zeugmatography. Lauterbur realized what potential the new technique had for medical imaging and speculated that: "a possible application of considerable interest at this time would be to the in vivo study of malignant tumors, which have been shown to give proton nuclear magnetic resonance signals with much longer water spin-lattice relaxation times than those in corresponding normal tissues." The possibility to discriminate between malignant tumors and normal tissue using spin echo nuclear magnetic resonance measurements had already been described by Damadian in $1971 .{ }^{211}$ The first clinical applications of magnetic resonance imaging (MRI) were described by Mansfield and Maudsley in $1977^{212}$ and the development of magnetic resonance angiography (MRA) began in the early to middle 1980 s. $^{213,214}$ 
In 1985 Wedeen et al first described the possibility of using magnetic resonance to image arteries noninvasively. ${ }^{215}$ Although a variety of early techniques were investigated, the most promising techniques were based on the phase change experienced by moving spins in the presence of a bipolar magnetic field gradient (phase contrast, PC) or on the saturation of stationary tissue and the bright signal obtained from the inflow of fresh unsaturated magnetization in blood. The latter technique is most commonly called time-of-flight (TOF) MRA but has been more recently referred to as inflowenhancement MRA. ${ }^{216}$

The same period that saw the development of flow dependent MRA techniques, also saw the publication of the first reports on a contrast medium for MRI. ${ }^{217-219}$ Contrast-enhanced MRA allows for better background suppression and shorter acquisition times as the Gadolinium-based contrast agents shorten the T1 value of inflowing blood. This was initially combined with TOF MRA sequences. ${ }^{220,221}$ Due to the presence of a blood-brain barrier, contrast media do not enter the normal brain tissue, thus enhancing the contrast between brain tissue and blood vessels. More recently, first-pass dynamic subtraction angiography was developed, further reducing acquisition times. ${ }^{222-224}$ First-pass dynamic subtraction angiography requires a gradient system with high slew rates for ultrafast acquisitions and additional tools for the proper timing of the scan sequence initiation to coincide with the contrast bolus arrival, $^{225}$ feasible with modern scanners. Due to the short arteriovenous transit time in the cerebral circulation, early enhancement of venous structures limits the time window for scan acquisition, and a trade-off is therefore necessary between scan time, volume coverage and spatial resolution. ${ }^{226}$ Subtraction of an unenhanced data set from the contrast enhanced data set is performed to delete residual high signal of nonvascular structures. ${ }^{227,228}$ Further improvements in contrast-enhanced MRA were accomplished through optimized k-space filling:229-231 the principle that the center of k-space determines the contrast and the periphery resolution of the image is used to manipulate the order in which k-space is filled with the acquired signal. The technique which uses automatic triggered first-pass contrast acquisitions with centric ordered k-space filling (called 'ATECO' by Farb et $\mathrm{al}^{232,233}$ ) is employed in this thesis, and is henceforth referred to as contrast-enhanced MRA (CEMRA).

In the first report of MRI of intracranial aneurysms, the aneurysms were visualized by using flow voids on standard T1- and T2-weighted spin echo images, ${ }^{234}$ and it was concluded that 'MRI was able to show aneurysms of $5 \times 5 \mathrm{~mm}$ or larger'. The use of specific flow-dependent MRA sequences for imaging of the cerebral vessels was described a few years later ${ }^{235-237}$ and the first reports on the application of this technique to the detection of intracranial aneurysms appeared in the early $1990 \mathrm{~s}^{238-240} \mathrm{~A}$ multitude of publications followed, evaluating the different MRA techniques and comparing them with each other, ${ }^{240-}$ ${ }^{244}$ with CTA, ${ }^{132,133}$ or with DSA, ${ }^{245-253}$ which in all cases was considered the standard of reference. PC MRA proved to be inferior to TOF MRA in most studies ${ }^{242,243,254}$ and was soon abandoned as a technique for aneurysm detection. ${ }^{228}$ All authors concluded that MRA could not replace DSA in the detection of cerebral aneurysms due to insufficient sensitivity, especially for smaller aneurysms, but that it could be useful as a screening tool in patients at higher risk of harboring intracranial aneurysms. ${ }^{239,245,251}$

The first, and to date the only, meta-analysis on evaluating MRA in detecting intracranial aneurysms is the previously mentioned review of White and Wardlaw. ${ }^{135}$ In this analysis, besides the 16 CTA studies, 20 studies using MRA were evaluated, comprising 926 patients. All these studies used TOF MRA acquisition sequences and three of them ${ }^{247,253,255}$ used both TOF and PC sequences. Pooled MRA 
sensitivity was slightly lower than CTA: $87 \%$ (95\% Cl: $84-90 \%)$, but the difference in MRA sensitivity between large and small aneurysms was even greater than CTA: $94 \%(95 \% \mathrm{Cl}: 90-97 \%)$ for aneurysms larger than $3 \mathrm{~mm}$ versus $38 \%(95 \% \mathrm{Cl}: 25-53 \%)$ for aneurysms smaller than $3 \mathrm{~mm}$. There were no contrast enhanced MRA studies included in this meta-analysis, and the authors expected improved outcomes with these newer techniques.

From 1998 to 2004 the department of Radiology of Maastricht University Medical Centre (MUMC) performed several studies with CEMRA in other areas of vascular imaging such as imaging of peripheral ${ }^{256-260}$ and renal arteries. ${ }^{261,262}$ In continuation of this line of research a study was designed to assess the performance of CEMRA in the detection of cerebral aneurysms in patients with a SAH: Magnetic resonance Angiography with Contrast in Cerebral Aneurysms (MACCA).

This study is described in Chapter 2: Performance of Contrast Enhanced Magnetic Resonance Angiography in patients presenting with Subarachnoid Hemorrhage. Part 1: detection of aneurysms

To define the true value of MRA in the diagnosis and treatment of SAH it is important not only to determine its diagnostic sensitivity but also to evaluate its performance in assessing the feasibility of endovascular treatment. This has been done in a few studies, but the lack of a good standard of reference poses a problem in assessments of this kind. Feasibility of endovascular treatment, or "coilability", of an aneurysm, depends on many factors -of which a few have been mentioned above- but assessment of coilability appears to be very subjective. In most studies evaluating the efficiency of noninvasive techniques in the assessment of coilability of an aneurysm, the neck-to-dome ratio was measured and sometimes compared to measurements made using DSA, and shape or lobulation of the aneurysm as well as parent and branch vessels were described and evaluated. ${ }^{263-266}$ In these studies TOF MRA was used. The main limitation of TOF MRA in the assessment of aneurysm morphology lies in the fact that high intravascular signal represents flow rather than the true boundaries of the aneurysm. In TOF MRA, slow flow within the aneurysm may not be registered, and thus an incomplete and incorrect image of aneurysm morphology may be presented. ${ }^{228}$ Unlu et al. evaluated the performance of CEMRA in the assessment of aneurysm morphology with a 1 Tesla MRI scanner, and concluded that: 'the mean grade of aneurysm depiction, depending on morphology of the aneurysm, the shape of the neck and relationship of the aneurysm with parent and branch vessels, was significantly greater with CEMRA than with TOF MRA'. However, these same authors also concluded that: 'CEMRA cannot yet safely replace DSA in the diagnostic work-up of patients with acute SAH'. ${ }^{267}$ Neal et al, who used CEMRA in a 3 Tesla system, concluded that CEMRA 'is reliable for evaluation and characterization of intracranial aneurysms, and that the results are comparable with those of MDCT'. ${ }^{268}$ In comparison with TOF MRA they found that: 'TOF and CEMRA perform comparably at 3T for evaluation of intracranial aneurysms. CEMRA can generate sub-millimeter voxels without the sensitivity to saturation or flow effects characteristic of TOF techniques'. ${ }^{269}$ Their study population was too small to draw strong conclusions however, and Neal et al. stressed the need for larger studies. Two studies evaluated MRA as the only diagnostic modality before surgical treatment. ${ }^{270,271}$ In both studies a considerable number of patients still required additional DSA imaging ( 30 and $35.1 \%$ respectively), because MRA was inconclusive or no aneurysm was found. Despite 
this, the authors of both studies concluded that MRA could be used as the primary, and in most cases, the only modality before surgical treatment. It must be noted that both studies used TOF MRA and failed to evaluate the feasibility of endovascular treatment.

It is clear that a study evaluating the efficiency of a non-invasive modality to assess coilability of an aneurysm was needed, and we carried out such a study upon the group of patients described in Chapter 2.

This study is described in Chapter 3: Performance of Contrast Enhanced Magnetic Resonance Angiography in patients presenting with Subarachnoid Hemorrhage. Part 2: predicting suitability of aneurysm for endovascular coiling.

The true value of a non-invasive modality to assess the coilability of an aneurysm is difficult to determine, firstly because coilability is a largely subjective criterion, ${ }^{272-274}$ and secondly because the possibilities for endovascular treatment are rapidly evolving. ${ }^{275}$ Thus aneurysms that were not suitable for endovascular treatment ten years ago can now be treated with the aid of balloons ${ }^{276}$ or stents, ${ }^{277,278}$ or with so-called flow diverters. ${ }^{279,280}$ Only recently was the clinical value of TOF MRA for therapeutic planning in patients with SAH investigated using DSA as the gold standard. ${ }^{272} \mathrm{~A}$ treatment plan based on the TOF MRA was made for 165 patients, who subsequently underwent DSA: only 10 treatment strategies were altered as a consequence of DSA findings.

We used the data from the group of patients described in Chapters 2 and 3 to simulate CEMRA as the sole modality used to select patients for endovascular treatment and evaluated diagnostic, therapeutic and financial consequences of different diagnostic strategies.

This study is described in Chapter 4: Simulation employing different scenarios using contrast-enhanced MRA (CEMRA) and digital subtraction angiography (DSA) in patients presenting with a subarachnoid hemorrhage (SAH).

\section{Treatment}

Reports of neurosurgical treatments of intracranial aneurysms first appeared in the late $19^{\text {th }}$ century, and mostly involved ligation of the parent vessel. ${ }^{281,282}$ The first planned intracranial aneurysm operation was carried out in 1931 by Dott, during which he successfully wrapped an aneurysm that had bled three times. ${ }^{283}$ Six years later the first aneurysm clipping procedure was performed by Dandy. ${ }^{284}$ Subsequent advances in neurosurgical techniques (such as the development of operating microscopes, microsurgical instruments, improved clips, neuroanaesthesia, and perioperative management for complications) enabled neurosurgeons to treat most cerebral aneurysms, and surgical aneurysm clipping remained the predominant treatment for almost four decades. ${ }^{285}$

In the second half of the $19^{\text {th }}$ century, aortic aneurysms were treated by metal wiring. ${ }^{286}$ Wire, the theory stipulated, would promote thrombus formation and reduce flow into the aneurysm sac. Moore introduced 26 yards of coil into a thoracic aorta aneurysm in his first such operation in $1864 .{ }^{287}$ In the same period other physicians experimented with electrothrombosis (electropuncture or 
Galvanopuncture) of aneurysms. In 1866 a 50\% success rate in a series of 50 cases involving electropuncture was reported, including four carotid, one 'temporal' and one ophthalmic aneurysm. ${ }^{288}$ In 1879, Corradi suggested that an electrical current applied to a permanently inserted metallic coil would combine the dual benefits of wire insertion and electrothrombosis. The merger of Moore's original wire work with the application of electrical current became widely referred to as the MooreCorradi method. ${ }^{286}$ The method we use nowadays, inserting coils in a cerebral aneurysm and detaching them with an electrical current, resembles this 150-year-old technique and was developed more than a century later. ${ }^{196}$

The first successful report of (silver) wiring and electrothermic thrombosis of an intracranial aneurysm through direct access via the orbit was made by Werner in $1941 .^{289}$ Few more attempts were made using this technique, ${ }^{290}$ but complication rates were high. It was not until the early 1970 s, when the Russian neurosurgeon Serbinenko developed a detachable balloon that an exclusively endovascular approach to the treatment of intracranial aneurysms became possible. ${ }^{291}$ Balloon placement within aneurysms proved not to be the best endovascular solution however, and after the introduction of endovascular embolization coils in $1975,{ }^{292}$ focus shifted towards coil occlusion of cerebral aneurysms. ${ }^{293}$ Because coils behave unpredictably and are not retrievable once advanced into the aneurysm, the technique did not gain widespread acceptance. This changed when Guido Guglielmi observed accidental electrolytic detachment of the electrode tip while applying current to a stainless steel electrode introduced into an experimental aneurysm, and so developed the detachable coil which later became known as the Guglielmi Detachable Coil (GDC; Boston Scientific/Target Therapeutics, Fremont CA). ${ }^{195,196}$

Aneurysm treatment with these GDC's was rapidly accepted by interventional radiologists and neurosurgeons, and by 2004, more than 125,000 patients with ruptured and unruptured aneurysms had been treated with the GDC system. ${ }^{294}$

Initially, endovascular treatment was used solely in patients considered poor candidates for surgical treatment ${ }^{295}$ such as patients with severe neurological deficits; an aneurysm in the posterior circulation or in the cavernous segment of internal carotid artery; patients aged 75 years or over; or patients presenting to the hospital during the high-risk period for cerebral vasospasm i.e. 3-10 days after aneurysm rupture. Furthermore, coiling was limited to aneurysms with narrow necks. Wide-necked aneurysms, defined from an endovascular standpoint as those with a dome-to-neck ratio of less than 2 or a neck diameter greater than $4 \mathrm{~mm}$, were not considered suitable for coil embolization until technological advances were made in the late 1990s and early 2000 s. $^{294}$

Three major advances have expanded the indications for coil embolization of these wide-necked aneurysms. First, the introduction of three-dimensional coils has allowed complex framing configurations to be achieved with less coil protrusion into the parent artery. ${ }^{296}$ Second, the development of balloon assisted coil embolization by Moret et al has allowed for improved packing density of coils and also reduces the risk of coil protrusion into the parent vessel. ${ }^{297}$ In this technique, a compliant balloon is navigated and inflated across the neck of an aneurysm as coils are introduced into the aneurysm through the microcatheter. A welcome advantage is that the balloon can also arrest flow in the parent artery in the event of an intraprocedural aneurysm rupture. This 'remodeling technique', as Moret called the balloon assisted coiling, became widely accepted even though higher complication 
rates were reported. ${ }^{298-300}$ Other authors, however, reported no difference in outcome with or without the use of balloons, ${ }^{276,301}$ this still being a subject of dispute in the neuro-interventional community. ${ }^{302,303}$ Third, stent-assisted coil embolization has made treatment of very wide-necked aneurysms and diffusely diseased segments of arteries possible. ${ }^{304,305}$ The microcatheter can be navigated through the pores of the stent into the aneurysm or can be trapped between the artery wall and the stent. It must be noted that the use of stents results in a higher complication rate ${ }^{306,307}$ and is therefore restricted to aneurysms which cannot be treated in any other way. ${ }^{277,308}$

Controversy exists about which is the best treatment for aneurysms that could in principle be treated by either neurosurgical clipping or endovascular coiling. ${ }^{309}$ An important study that tried to find a solution for this controversy was the International Subarachnoid Aneurysm Trial (ISAT). ${ }^{310}$ The initial findings of this trial, which were published in the Lancet in 2002, indicated that patients with a ruptured aneurysm and treated with endovascular coiling had lower mortality rate and better outcome after one year as compared to those treated with surgical clipping. ${ }^{194,311}$ The first reactions following these publications were critical, mainly addressing the selection of patients and the question of long-term results. ${ }^{312-320}$ For example, only a very small proportion of posterior circulation aneurysms were included in ISAT and critics warned that therefore the results of ISAT could not be extrapolated to the posterior circulation. However, the reason that so few posterior circulation aneurysms were included in the randomized study lay in the fact that endovascular treatment was already the preferred mode of treatment for these aneurysms. ${ }^{321,322}$ Furthermore, the results of endovascular coiling appeared to be sustained after five years: even though there was no longer a difference in outcome between the survivors of the two groups (endovascular and surgical), a small but significant difference in mortality remained. ${ }^{323,324}$ Several subgroup analyses were published establishing the advantages of endovascular treatment in most cases. $^{325-329}$ Only in young patients were the advantages of coiling possibly offset by the higher rebleed rates observed in the coiled group, ${ }^{330,331}$ whereas in older patients with a middle cerebral artery aneurysm, clipping appeared to yield better outcomes. ${ }^{329,332,333}$ Despite the controversy the results of this trial had an enormous impact on the treatment of intracranial aneurysms and caused a shift to primary endovascular treatment ${ }^{273,334-342}$ to a variable degree in different regions and different hospitals. $^{343-345}$

A Cochrane database review, largely based on data extracted from the ISAT study, led to the conclusion that: 'we now have firm evidence that if the aneurysm is considered suitable for both surgical clipping and endovascular treatment, coiling is associated with a better outcome'. ${ }^{346}$ Apart from the randomized studies evaluated in the Cochrane database review, many observational and nonrandomized prospective studies were published; two reviews exist giving a practical overview of most of these. ${ }^{285,347}$ Later studies with various outcome parameters supported the results of ISAT. ${ }^{348-350}$ One of the latest additions is the Barrow Ruptured Aneurysm Trial (BRAT). ${ }^{351,352}$ In this study 472 patients were randomly assigned to a group that had clipping as the preferred treatment and a group that had coiling as the preferred treatment. If the assigned treatment was considered impossible or high risk, cross-over to the other treatment was allowed. When analyzed on 'intention-to-treat' as well as on actual treatment, endovascular treatment had a better one year outcome than clipping. 
This study supports the general opinion that, although coiling is the preferred treatment for cerebral aneurysms, the decision to treat by clipping or coiling should be made on a case-by-case basis. A few guidelines are given by recent publications, such as:

- Wide necked aneurysms, aneurysms with arterial branches originating from the base of the aneurysm, patients with intracerebral hematoma, dissected vessels or acute brainstem compression, are better candidates for surgery.

- Aneurysms closer to the midline and in the posterior circulation, or in patients with high age, poor neurological condition, medical comorbidity or vasospasm, are better candidates for coiling. ${ }^{347,353}$

Attempts have been made to design a paradigm for selecting treatment, ${ }^{354}$ but this selection remains subjective, often being based on preference and experience of the treating physician.

Nowadays, in most centers in Western Europe and the US, the preferred treatment of intracranial aneurysms is coiling. ${ }^{343,344,355,356}$ As mentioned above, patients entering a hospital with a SAH in the last decade have better outcomes than in previous times, ${ }^{37,38}$ but it is difficult to say if this is the result of an increase in endovascular treatment. ${ }^{357-359}$ Brinjikji et al found that endovascular treatment of unruptured aneurysms increased the odds for better outcome. ${ }^{360}$ The same authors mentioned that, in the US, high-volume centers for treatment of intracranial aneurysms tend to perform endovascular treatment more frequently and have better outcomes in treating unruptured aneurysms, ${ }^{361}$ which leads us to another important question in the treatment of intracranial aneurysms. Should we preferably treat intracranial aneurysms in high-volume centers, where more endovascular procedures are performed and treatment delays are presumably shorter? Most authors, especially those in the US, declare that high-volume centers have better outcome in treating patients with aneurysmal SAH. ${ }^{362-368}$ The arguments for centralizing intracranial aneurysm treatment or management of patients with SAH are convincing. One such argument is that treatment in high-volume centers can be performed 24/7, an important advantage where timing is crucial for successful treatment, the reason to treat aneurysms in patients with $\mathrm{SAH}$ being the prevention of rebleeding of the ruptured aneurysm. The rate of rebleeding in untreated aneurysms is approximately $4 \%$ within the first $24 \mathrm{~h}, 1-2 \%$ per day over the next 14 days and $50 \%$ overall during the first 6 months. ${ }^{369}$ Very early rebleeds are near impossible to prevent due to the logistic unfeasibility of direct treatment after the first bleed as well as the risk of surgical morbidity when operating early on an acutely injured brain. ${ }^{370}$ The latter does not hold true for coiling. ${ }^{371}$ It was already noted in the ISAT study that the average time between rupture of the aneurysm and treatment was shorter in the endovascular than in the surgical group. ${ }^{194}$ For clipping, recent studies show that the advantage of preventing early rebleeding outweighs the disadvantage of early surgery. ${ }^{372,373}$ The present opinion is that aneurysm treatment should be performed as soon as possible to prevent rebleeding, which is more likely to be accomplished in high-volume centers. ${ }^{16,371,372,374-376}$

Although the positive effect of increased experience in endovascular treatment on patient outcome has been described ${ }^{377}$ the authors of the ATENA trial, which is concerned with treatment of unruptured aneurysms, found no difference in patient outcome after coiling between low and high volume centers, $^{378}$ and several reports from small centers present outcome figures comparable with ISAT or other larger studies. ${ }^{379-385}$

In 2011 we presented the results of treating ruptured aneurysms in our relatively low-volume center, ${ }^{386}$ where we currently perform ca. 50 coiling and 20 clipping procedures a year. 
This report is described in Chapter 5: Single-center experience of surgical and endovascular treatment of ruptured intracranial aneurysms.

\section{Recurrence and rebleed after treatment}

Although the aim of treating aneurysms after a SAH is to prevent rebleeds, these do occur, mostly in the first weeks after treatment. Early rebleed incidence (within 30 days after endovascular treatment of ruptured aneurysms) is reported to be between 1.1 and 3.6\%. ${ }^{387-389}$ The main risk factors for early rebleed are larger aneurysms and the presence of intracerebral hematoma (ICH), incomplete aneurysm occlusion by coils being a lesser factor. ${ }^{387-389}$ Late rebleed incidence is lower, with an annual rate between 0.1 and $0.3 \%, 323,390,391$ and incomplete aneurysm occlusion is a strong predictor of late rebleed. ${ }^{323,390-393}$ Since repeat treatment of recurrences involves relatively little risk, ${ }^{391,394-396}$ it is recommended that patients with treated aneurysms be followed in order to detect recurrences, and that these recurrences should be treated. ${ }^{392}$

\section{Follow-up of coiled aneurysms}

Until recently, DSA was the established post-coiling standard of reference for aneurysm evaluation. Whereas it is true that CTA images suffer too much from beam hardening artefacts caused by the coil mesh, ${ }^{397}$ MRA is potentially a good alternative: the platinum coils are compatible with MR imaging in terms of safety and do not produce image artefacts at magnetic field strengths up to 3 Tesla. ${ }^{398-400}$ The $^{3}$ first reports on the use of MRA for coiled aneurysm follow-up were published at the end of the last century. ${ }^{401-405}$ These first studies were all performed with flow-dependent MRA sequences incurring the potential disadvantages described in the aneurysm detection section above. Studies using contrast enhanced TOF sequences followed, but this did not improve performance. ${ }^{406-409}$ First-pass or ultra-fast CEMRA sequences appeared in few studies to be superior to flow-dependent MRA, ${ }^{410-412}$ but in another study no such superiority was found. ${ }^{413}$

Two meta-analyses on the diagnostic accuracy of MRA in the detection of recurrences after endovascular coiling were published one shortly after the other: Kwee and Kwee ${ }^{414}$ and Weng et al. ${ }^{415}$ Kwee and Kwee evaluated 16 studies, all with DSA as standard of reference, and evaluated TOF MRA and CEMRA data separately. However, the CEMRA data included studies using contrast-enhanced TOF as well as true first pass CEMRA: of the seven studies providing CEMRA data, only two ${ }^{410,411}$ used firstpass CEMRA. Pooled estimates of sensitivity and specificity were found to be 83.3 and $90.6 \%$ for nonenhanced TOF MRA, and 86.6 and 91.9\% for the mixed "CEMRA" group. Thus Kwee and Kwee found slightly but not significantly better results for the mixed "CEMRA" group than for non-enhanced TOF MRA.

Weng et al $^{415}$ also evaluated 16 studies, largely overlapping with Kwee and Kwee's meta-analysis. They performed the same analysis on TOF and CEMRA data, using the same mix of CEMRA data as Kwee and Kwee: from the six studies providing CEMRA data, only three had used true first-pass CEMRA. ${ }^{410,411,413}$ The authors found pooled sensitivity and specificity of 90 and $95 \%$ for non-enhanced TOF MRA, and 92 and $96 \%$ for CE-TOF/CEMRA. Again the difference was not significant. 
In both meta-analyses very heterogeneous studies were included, and recanalization rate was not standardized: a small neck remnant and a recurrence within the coil mesh were both regarded as a positive finding, whereas complete occlusion was considered a negative. Most studies evaluating treatment-results in intracranial aneurysms use the difference between complete occlusion, neck remnant and recurrence as described by Roy and Raymond (R\&R) ${ }^{416}$ (Fig 1). More refined grading scales have been proposed, ${ }^{417}$ but observer variability was found to be substantially better in scales that offer fewer gradations in observer responses. ${ }^{418}$ Of greatest value in clinical practice is the distinction between neck remnant and residual or recurrent aneurysm, because this last category most likely needs retreatment whereas neck remnant does not.

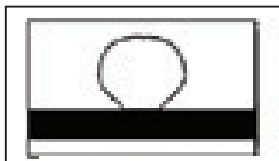

Complete

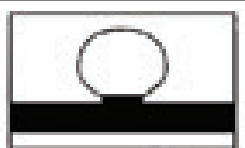

Residual neck

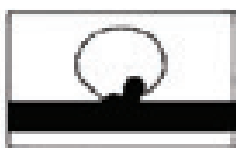

Residual aneurysm

Figure 1. Aneurysm occlusion classification by Roy and Raymond

Recent studies reporting the accuracy of MRA in follow-up of coiled aneurysms use the R\&R aneurysm occlusion classification. ${ }^{419-426}$ If a dichotomization was made between class 1 and 2 of the R\&R classification ("complete occlusion" versus "incomplete occlusion") sensitivity ranged between 72 and $90 \%$ and specificity between 52 and 86\%; if, on the other hand, a dichotomization was made between class 2 and 3 ("adequately coiled" versus "inadequately coiled") sensitivity ranged from 50 to $80 \%$ and specificity from 84 to $93 \% .{ }^{420-422,426}$ Thus sensitivity appears to decrease and specificity to increase when a decision is based on adequately versus inadequately coiled as compared to complete versus incomplete occlusion. For an inadequately coiled aneurysm retreatment will usually be considered, but not for an adequately coiled aneurysm.

Daugherty et al showed that a substantial variability exists when a group of five experienced neurointerventional radiologists and interventional neurosurgeons are asked whether a recurrent aneurysm should be retreated: ${ }^{427}$ After giving their decision to retreat on a five-point scale based on DSA images of 27 coiled aneurysms with recurrence at follow-up, the median Kappa was only 0.27 ! This reflects the difficulty of establishing a standard of reference for this kind of study.

Although not all authors are yet convinced that MRA can replace DSA as the primary modality for followup, $^{426}$ in our hospital, as in many others, ${ }^{423,425,428}$ it is standard practice.

The additional value of CEMRA is still disputed. Advocates of the technique see clear advantages especially in the larger recurrences, where differentiation between class 2 and 3 of the R\&R classification, or between retreatment or not, is important. ${ }^{410,422,429-431}$ Other authors, however, find no additional value. ${ }^{413,420,421,432-435}$ Recently the advantage of CEMRA over TOF MRA in the follow-up of stent assisted coil embolization was described. ${ }^{436-439}$ Perhaps at present the best advice is to use both TOF MRA and CEMRA in the follow-up of coiled aneurysms. ${ }^{422}$

The advantage of 3T MRA over 1.5T for the follow-up of coiled aneurysms is another subject under investigation. In the meta-analyses by Kwee \& $\mathrm{Kwee}^{414}$ and Weng et al ${ }^{415}$ only one study, included in both meta-analyses, used a $3 \mathrm{~T} \mathrm{MRI}{ }^{440}$ In more recent publications some find a clear advantage in using 
$3 \mathrm{~T}^{422,430,435,441}$ even though increased coil artefacts at 3T are reported. ${ }^{442}$ Other investigators did not find any difference between 1.5T and 3T. ${ }^{420,443}$ Anzalone et al found better results with TOF-MRA at 3T than at 1.5T, but both were still inferior to CEMRA at 1.5T. ${ }^{430}$

We performed a study evaluating the accuracy of CEMRA at 1.5T in the follow-up of coiled aneurysms.

This report is described in Chapter 6: Follow-up of coiled intracranial aneurysms with Contrast Enhanced MRA with DSA as standard of reference.

\section{Long term follow-up}

The optimal strategy for monitoring the stability of ruptured aneurysms following coil embolization in terms of duration and time intervals is still unclear. ${ }^{444,445}$ As mentioned above, the annual rebleed rate of ruptured aneurysms after the first month is low, between 0.1 and $0.3 \%,{ }^{323,390,391}$ and incomplete occlusion is a strong predictor of late rehemorrhage. ${ }^{392,393}$ Recanalization occurs in approximately $20 \%$ of coiled aneurysms and half of these aneurysms are retreated. ${ }^{445-449}$

A strategy in which patients with incomplete occlusion at six months are selected for retreatment or longer follow-up leads to a low incidence of late adverse events. ${ }^{394}$ The question is how long and in which frequency surveillance should continue after an aneurysm has been adequately occluded at six months.

In order to answer this question, two factors need to be assessed: the risk of reopening of adequately occluded aneurysms at six months, and the risk of rebleed - from the treated aneurysm or from another aneurysm - in patients that have undergone adequate coiling at six months. In a cohort of 283 patients with aneurysms that were adequately coiled at six months, Schaafsma et al found three SAH's occurring in the following eight years, which results in a cumulative incidence of recurrent SAH of $0.4 \%$. This was lower than, but did not differ significantly from, the incidence they found in a cohort of 776 clipped aneurysms: $17 \mathrm{SAH}^{\prime}$ s recurred in eight years leading to a cumulative incidence of recurrent $\mathrm{SAH}$ of $2.6 \%{ }^{450}$ In the coiled group the hemorrhage probably occurred from rupture of the treated aneurysm. In the clipped group 13 of 17 hemorrhages were probably from an associated aneurysm in a different location. The incidence of recurrent SAH found was higher than that found by the CARAT investigators. ${ }^{391}$ The annual re-rupture rate of coiled aneurysms after more than one year in the CARAT study was $0.11 \%$, but they did not focus on aneurysms that were adequately occluded at first followup. $^{391}$ Other studies found slightly higher rates of SAH after coiling, but again they did not focus on adequately occluded aneurysms at early follow-up, and the timing of follow-up varied widely. $323,390,451,452$ In a study by Sprengers et al, including a small group of 104 patients with 111 aneurysms that were adequately occluded at six months, the risk of aneurysm recanalization was found to be approximately $3.6 \%$ in the first six years. ${ }^{453}$ This low incidence of late recurrences is in concordance with a previous observational study by Sluzewski et al. ${ }^{449}$ Other studies found more first time recurrences at longer follow-up periods, ${ }^{446-448}$ however, these studies used a wide variety of follow-up intervals and often it was not clear when the recurrence had actually taken place.

A large multicenter study (LOTUS study) was set up in order to further investigate this risk of late recanalization: 400 patients with 439 aneurysms that were adequately coiled at six months were imaged 
with MRA. ${ }^{454}$ In the mean follow-up period of six years (range $4.5-12.9$ years), recanalization was found in 11 aneurysms (2.5\%), three of which were retreated. Treatment of the other eight aneurysms was not performed due to the recanalization being too small, co-morbidity, unfavorable morphology or because the patient refused retreatment. Independent predictors for late reopening were found to be aneurysm size greater than $10 \mathrm{~mm}$ (OR 4.7; 95\% Cl, 1.3-16.3), and location of aneurysm on basilar tip (OR 3.9; 95\% $\mathrm{Cl}, 1.1-14.6)$. This confirms findings of other studies in which an aneurysm size of more than $10 \mathrm{~mm}$ was found to be a strong predictor of aneurysm recurrence. ${ }^{393,447}$

In order to assess the rate of late recanalization in the subgroup of patients from our own hospital we performed a sub analysis on the LOTUS data from this group.

The results of the patient subgroup analysis from the Maastricht University Medical Centre are described in Chapter 7: Late reopening of adequately coiled intracranial aneurysms.

Apart from the risk of rebleed of treated aneurysms, the risk of a bleed from de novo aneurysms or from already existing additional aneurysms elsewhere necessitates monitoring of patients with treated intracranial aneurysms. ${ }^{455,456}$ These patients are thought to have a higher risk of new aneurysm formation, ${ }^{455}$ although a recent study from Sprengers et al showed most de novo aneurysms to be very small and not requiring treatment. ${ }^{457}$ In a literature review, Ferns et al found an annual incidence of de novo aneurysm formation between 0.3 and $1.8 \%{ }^{458}$ In their cohort of 276 patients they found two de novo aneurysms at five year follow-up after treatment of another aneurysm, or a cumulative five-year incidence of $0.75 \%$. Regrowth of additional aneurysms, identified the time of treatment of the index aneurysm, had a cumulative five-year incidence of $7.9 \%$ (five of 63 previously known but untreated aneurysms were seen to have grown at the five-years follow-up). In their literature review Ferns et al. reported annual risk of growth of additional aneurysms to be ranging from 1.5 to $22.7 \%$.

The annual incidence of SAH from unruptured aneurysms is low, ranging from 0.6 to $1.3 \%{ }^{24,459}$ Results of long-term follow-up data from the ISAT study suggest an annual rupture rate from de novo and known additional aneurysms in patients with a coiled aneurysm of $0.036 \%$ each $^{323}$ and an older study found an incidence of rupture of de novo aneurysms to be $0.06 \%$ per patient-year in patients with a clipped aneurysm. ${ }^{460}$ Ferns et al concluded that: 'the risk of de novo aneurysm formation and significant enlargement of additional untreated aneurysms is low, with a subsequent extremely low risk of subarachnoid hemorrhage from these aneurysms .... especially in the first five years.' And: 'screening of all patients within the first five years after aneurysm treatment does not seem beneficial in terms of preventing subarachnoid hemorrhage or for detection of aneurysms that need treatment' ${ }^{458}$ However, even if long term follow-up has a low yield in terms of hemorrhage prevention or aneurysm detection, it is advisable if disadvantages are minimal. Disadvantages in terms of side effects or complications have been reduced since MRA has become the accepted modality for follow-up, but other aspects, like psychology and finance, have hardly been investigated. One study did assess the impact of long term follow-up with MRA on mood and anxiety of the patient and concluded that, even though long term follow-up did not induce a temporary major increase in anxiety or depression at the time of follow-up, 
patients with a history of aneurysm coiling are more anxious or depressed than the general population ${ }^{461}$ which is not alleviated by a reassuring outcome of the follow-up study.

\section{Cost-effectiveness}

Evaluations of diagnostic strategies cannot be complete without cost-effectiveness analyses. ${ }^{462-464}$ In the various schemes used to describe the requisites for complete assessment of a diagnostic method, costeffectiveness always is the completing last step. ${ }^{462,463,465,466}$ Cost-effectiveness studies compute a cost per unit of effect measured. Any diagnostic test characteristic can be used as an output parameter: for example, cost per surgery avoided, cost per appropriately treated patient, cost per life-year gained, or cost per quality adjusted life year (QALY). ${ }^{462}$ Different models can be used, but the validity of the model's input parameters is crucial for its credibility. The validity of all input variables must be based on solid evidence from literature or, when such evidence is lacking, any uncertainties pertaining to the value of the different parameters should be incorporated into the model. The Markov model, where a patient can go from one defined health state to another based on several interventions or decisions, is often used. ${ }^{467-469}$ The Monte Carlo method incorporates a degree of uncertainty into the Markov model in order to simulate the outcomes for a larger group of patients. ${ }^{470}$

In the setting of SAH diagnosis and treatment, different facets can be evaluated in cost-effectiveness analyses. Most cost-effectiveness studies to date have focused on treatment. Thus studies assessing general costs of treatment, ${ }^{471}$ and whom to treat ${ }^{472-476}$ which treatment to use, ${ }^{477-486}$ and where to treat $^{487}$ have been published in the literature. Only two studies assessed cost-effectiveness of screening for aneurysms. The first concerned MRA in patients with a positive family history for aneurysms, and concluded that screening in this particular group was recommended with a cost-effectiveness threshold of $€ 20,000 / Q A L Y .{ }^{488}$ The other study concerned CTA in patients who had suffered a SAH and had been clipped in the past. The authors concluded that screening in this group is not recommended from a costeffectiveness perspective. ${ }^{489}$

Cost-effectiveness studies comparing different imaging modalities in patients with aneurysmal SAH hardly exist. One study compared DSA and MRA in the follow-up of coiled aneurysms and concluded that MRA provided equivalent health benefits compared to DSA, and was cost-saving. ${ }^{490}$

We performed a cost-effectiveness analysis comparing three different imaging modalities - CEMRA, CTA and DSA - in patients with a SAH, and tested different scenarios in a Markov decision model. The data presented in Chapters 2 and 3 were used as input parameters in the model.

The results of this study are described in Chapter 8: Cost-effectiveness of CTA, MRA and DSA in patients with suspected ruptured intracranial aneurysms: a decision model.

In cost-effectiveness studies, all steps in evaluating diagnostic tests in patients with an aneurysmal SAH are addressed, whether it be the hierarchical steps as described by Fryback ${ }^{465}$ (1.Technical efficacy, 2. Diagnostic accuracy, 3. Impact on diagnostic reasoning, 4. Impact on patient management, 5. Impact on patient outcome, 6. Cost-effectiveness), or those in the stepwise approach by Van den Bruel ${ }^{462}$ (1. 
Technical accuracy, 2. Place in clinical pathway, 3. Diagnostic accuracy, 4. Impact on patient outcome,

5. Cost-effectiveness). We believe that there is room for improvement however, because:

- not all steps are as yet fully addressed in the currently available literature;

- many studies do not comply with the Standards for Reporting of Diagnostic Accuracy(STARD) published in 2003; 491,492

- going through all the steps takes time, and technical developments in imaging are evolving rapidly. ${ }^{493}$

These suggested improvements and other recommendations will be discussed in Chapter 9: Discussion.

\section{References}

1 Holmes, T. Aneurysms of the internal carotid artery in the cavernous sinus. Trans Pathol Soc London 12, 61, (1860).

2 Taylor, T. N. et al. Lifetime cost of stroke in the United States. Stroke 27, 1459-1466, (1996).

3 le Roux, A. A. \& Wallace, M. C. Outcome and cost of aneurysmal subarachnoid hemorrhage. Neurosurg Clin N Am 21, 235-246, (2010).

4 Dodel, R. et al. Cost of illness in subarachnoid hemorrhage: a German longitudinal study. Stroke 41, 29182923, (2010).

5 van Gijn, J., Kerr, R. S. \& Rinkel, G. J. Subarachnoid haemorrhage. Lancet 369, 306-318, (2007).

6 Vlak, M. H., Algra, A., Brandenburg, R. \& Rinkel, G. J. Prevalence of unruptured intracranial aneurysms, with emphasis on sex, age, comorbidity, country, and time period: a systematic review and meta-analysis. Lancet Neurol 10, 626-636, (2011).

7 Fiehler, J. [Unruptured brain aneurysms: when to screen and when to treat?]. Rofo 184, 97-104, (2012).

8 Rinkel, G. J. Intracranial aneurysm screening: indications and advice for practice. Lancet Neurol 4, 122-128, (2005).

9 Rinkel, G. J., Djibuti, M., Algra, A. \& van Gijn, J. Prevalence and risk of rupture of intracranial aneurysms: a systematic review. Stroke 29, 251-256, (1998).

10 Wiebers, D. O. et al. Unruptured intracranial aneurysms: natural history, clinical outcome, and risks of surgical and endovascular treatment. Lancet 362, 103-110, (2003).

11 Wiebers, D. O. Unruptured intracranial aneurysms--risk of rupture and risks of surgical intervention. International Study of Unruptured Intracranial Aneurysms Investigators. N Engl J Med 339, 1725-1733, (1998).

12 Ishibashi, T. et al. Unruptured intracranial aneurysms: incidence of rupture and risk factors. Stroke 40, 313316, (2009).

13 Juvela, S. Natural history of unruptured intracranial aneurysms: risks for aneurysm formation, growth, and rupture. Acta Neurochir Suppl 82, 27-30, (2002).

14 Tsutsumi, K., Ueki, K., Morita, A. \& Kirino, T. Risk of rupture from incidental cerebral aneurysms. J Neurosurg 93, 550-553, (2000)

15 de Rooij, N. K., Linn, F. H., van der Plas, J. A., Algra, A. \& Rinkel, G. J. Incidence of subarachnoid haemorrhage: a systematic review with emphasis on region, age, gender and time trends. J Neurol Neurosurg Psychiatry 78, 1365-1372, (2007).

16 Bederson, J. B. et al. Guidelines for the management of aneurysmal subarachnoid hemorrhage: a statement for healthcare professionals from a special writing group of the Stroke Council, American Heart Association. Stroke 40, 994-1025, (2009).

17 Risselada, R. et al. Incidence, treatment, and case-fatality of non-traumatic subarachnoid haemorrhage in the Netherlands. Clin Neurol Neurosurg 113, 483-487, (2011).

18 Juvela, S., Hillbom, M., Numminen, H. \& Koskinen, P. Cigarette smoking and alcohol consumption as risk factors for aneurysmal subarachnoid hemorrhage. Stroke 24, 639-646, (1993).

19 Qureshi, A. I. et al. Risk factors for subarachnoid hemorrhage. Neurosurgery 49, 607-612; discussion 612-603, (2001).

20 Teunissen, L. L., Rinkel, G. J., Algra, A. \& van Gijn, J. Risk factors for subarachnoid hemorrhage: a systematic review. Stroke 27, 544-549, (1996).

21 van der Schaaf, I. C., Ruigrok, Y. M., Rinkel, G. J., Algra, A. \& van Gijn, J. Study design and outcome measures in studies on aneurysmal subarachnoid hemorrhage. Stroke 33, 2043-2046, (2002). 
22 Rahman, M. et al. Size ratio correlates with intracranial aneurysm rupture status: a prospective study. Stroke 41, 916-920, (2010).

23 Amenta, P. S. et al. Analysis of Non-Modifiable Risk Factors for Intracranial Aneurysm Rupture in A Large, Retrospective Cohort. Neurosurgery, (2011).

24 Wermer, M. J., van der Schaaf, I. C., Algra, A. \& Rinkel, G. J. Risk of rupture of unruptured intracranial aneurysms in relation to patient and aneurysm characteristics: an updated meta-analysis. Stroke 38, 14041410, (2007).

25 Dhar, S. et al. Morphology parameters for intracranial aneurysm rupture risk assessment. Neurosurgery 63, 185-196; discussion 196-187, (2008).

26 Xiang, J. et al. Newtonian viscosity model could overestimate wall shear stress in intracranial aneurysm domes and underestimate rupture risk. J Neurointerv Surg, (2011).

27 Tremmel, M., Dhar, S., Levy, E. I., Mocco, J. \& Meng, H. Influence of intracranial aneurysm-to-parent vessel size ratio on hemodynamics and implication for rupture: results from a virtual experimental study. Neurosurgery 64, 622-630; discussion 630-621, (2009).

28 Mut, F. et al. Computational Hemodynamics Framework for the Analysis of Cerebral Aneurysms. Int j numer method biomed eng 27, 822-839, (2011).

29 Jou, L. D., Lee, D. H., Morsi, H. \& Mawad, M. E. Wall shear stress on ruptured and unruptured intracranial aneurysms at the internal carotid artery. AJNR Am J Neuroradiol 29, 1761-1767, (2008).

30 Hughes, M. A., Grover, P. J., Butler, C. R., Elwell, V. A. \& Mendoza, N. D. A 5-year retrospective study assessing the association between seasonal and meteorological change and incidence of aneurysmal subarachnoid haemorrhage. Br J Neurosurg 24, 396-400, (2010).

31 Inagawa, T. Seasonal variation in the incidence of aneurysmal subarachnoid hemorrhage in hospital- and community-based studies. J Neurosurg 96, 497-509, (2002).

32 Cowperthwaite, M. C. \& Burnett, M. G. The association between weather and spontaneous subarachnoid hemorrhage: an analysis of 155 US hospitals. Neurosurgery 68, 132-138; discussion 138-139, (2011).

33 Rinkel, G. J., van Gijn, J. \& Wijdicks, E. F. Subarachnoid hemorrhage without detectable aneurysm. A review of the causes. Stroke 24, 1403-1409, (1993).

34 Provenzale, J. M. \& Hacein-Bey, L. CT evaluation of subarachnoid hemorrhage: a practical review for the radiologist interpreting emergency room studies. Emerg Radiol 16, 441-451, (2009).

35 Maslehaty, H., Barth, H., Petridis, A. K., Doukas, A. \& Maximilian Mehdorn, H. Special features of subarachnoid hemorrhage of unknown origin: a review of a series of 179 cases. Neurol Res 34, 91-97, (2012).

36 van Gijn, J. \& Rinkel, G. J. Subarachnoid haemorrhage: diagnosis, causes and management. Brain 124, 249278, (2001).

37 Lovelock, C. E., Rinkel, G. J. \& Rothwell, P. M. Time trends in outcome of subarachnoid hemorrhage: Population-based study and systematic review. Neurology 74, 1494-1501, (2010).

38 Nieuwkamp, D. J. et al. Changes in case fatality of aneurysmal subarachnoid haemorrhage over time, according to age, sex, and region: a meta-analysis. Lancet Neurol 8, 635-642, (2009).

39 Cruickshank, A. et al. Revised national guidelines for analysis of cerebrospinal fluid for bilirubin in suspected subarachnoid haemorrhage. Ann Clin Biochem 45, 238-244, (2008).

40 Horstman, P., Linn, F. H., Voorbij, H. A. \& Rinkel, G. J. Chance of aneurysm in patients suspected of SAH who have a 'negative' CT scan but a 'positive' lumbar puncture. J Neurol 259, 649-652, (2012).

41 ACR / Appropriateness Criteria / Expert Panel on Neurologic Imaging / Cerebrovascular Disease, $<$ http://www.acr.org/SecondaryMainMenuCategories/quality_safety/app_criteria/pdf/ExpertPanelonNeurolo giclmaging/CerebrovascularDiseaseDoc2.aspx> (2011).

42 Byyny, R. L. et al. Sensitivity of noncontrast cranial computed tomography for the emergency department diagnosis of subarachnoid hemorrhage. Ann Emerg Med 51, 697-703, (2008).

43 Cortnum, S., Sorensen, P. \& Jorgensen, J. Determining the sensitivity of computed tomography scanning in early detection of subarachnoid hemorrhage. Neurosurgery 66, 900-902; discussion 903, (2010).

44 Perry, J. J. et al. Sensitivity of computed tomography performed within six hours of onset of headache for diagnosis of subarachnoid haemorrhage: prospective cohort study. BMJ 343, d4277, (2011).

45 van der Wee, N., Rinkel, G. J., Hasan, D. \& van Gijn, J. Detection of subarachnoid haemorrhage on early CT: is lumbar puncture still needed after a negative scan? J Neurol Neurosurg Psychiatry 58, 357-359, (1995).

46 Sames, T. A., Storrow, A. B., Finkelstein, J. A. \& Magoon, M. R. Sensitivity of new-generation computed tomography in subarachnoid hemorrhage. Acad Emerg Med 3, 16-20, (1996).

47 McCormack, R. F. \& Hutson, A. Can computed tomography angiography of the brain replace lumbar puncture in the evaluation of acute-onset headache after a negative noncontrast cranial computed tomography scan? Acad Emerg Med 17, 444-451, (2010). 
48 Edlow, J. A., Malek, A. M. \& Ogilvy, C. S. Aneurysmal subarachnoid hemorrhage: update for emergency physicians. J Emerg Med 34, 237-251, (2008).

49 Boesiger, B. M. \& Shiber, J. R. Subarachnoid hemorrhage diagnosis by computed tomography and lumbar puncture: are fifth generation CT scanners better at identifying subarachnoid hemorrhage? J Emerg Med 29, 23-27, (2005).

50 Perry, J. J. et al. Is the combination of negative computed tomography result and negative lumbar puncture result sufficient to rule out subarachnoid hemorrhage? Ann Emerg Med 51, 707-713, (2008).

51 Williams, J., Lye, D. C. \& Umapathi, T. Diagnostic lumbar puncture: minimizing complications. Intern Med J 38, 587-591, (2008).

52 Gee, C. et al. Sensitivity of Newer-generation Computed Tomography Scanners for Subarachnoid Hemorrhage: A Bayesian Analysis. J Emerg Med, (2012).

53 Carstairs, S. D. et al. Computed tomographic angiography for the evaluation of aneurysmal subarachnoid hemorrhage. Acad Emerg Med 13, 486-492, (2006).

54 Lin, N. et al. Angiogram-Negative Subarachnoid Hemorrhage: Relationship Between Bleeding Pattern and Clinical Outcome. Neurocrit Care, (2012).

55 Shimoda, M., Hoshikawa, K., Shiramizu, H., Oda, S. \& Matsumae, M. Problems with diagnosis by fluidattenuated inversion recovery magnetic resonance imaging in patients with acute aneurysmal subarachnoid hemorrhage. Neurol Med Chir (Tokyo) 50, 530-537, (2010).

56 Mitchell, P. et al. Detection of subarachnoid haemorrhage with magnetic resonance imaging. J Neurol Neurosurg Psychiatry 70, 205-211, (2001).

57 Mohamed, M., Heasly, D. C., Yagmurlu, B. \& Yousem, D. M. Fluid-attenuated inversion recovery MR imaging and subarachnoid hemorrhage: not a panacea. AJNR Am J Neuroradiol 25, 545-550, (2004).

58 Atlas, S. W. MR imaging is highly sensitive for acute subarachnoid hemorrhage ... not! Radiology 186, 319322; discussion 323, (1993).

59 Bradley, W. G., Jr. \& Schmidt, P. G. Effect of methemoglobin formation on the MR appearance of subarachnoid hemorrhage. Radiology 156, 99-103, (1985).

60 Grossman, R. I. et al. Importance of oxygenation in the appearance of acute subarachnoid hemorrhage on high field magnetic resonance imaging. Acta Radiol Suppl 369, 56-58, (1986).

61 Ogawa, T. et al. MR diagnosis of subacute and chronic subarachnoid hemorrhage: comparison with CT. AJR Am J Roentgenol 165, 1257-1262, (1995).

62 Noguchi, K. et al. Subacute and chronic subarachnoid hemorrhage: diagnosis with fluid-attenuated inversionrecovery MR imaging. Radiology 203, 257-262, (1997).

63 Bakshi, R. et al. Fluid-attenuated inversion-recovery MR imaging in acute and subacute cerebral intraventricular hemorrhage. AJNR Am J Neuroradiol 20, 629-636, (1999).

64 Wiesmann, M. et al. Detection of hyperacute subarachnoid hemorrhage of the brain by using magnetic resonance imaging. J Neurosurg 96, 684-689, (2002).

65 Maslehaty, H., Petridis, A. K., Barth, H. \& Mehdorn, H. M. Diagnostic value of magnetic resonance imaging in perimesencephalic and nonperimesencephalic subarachnoid hemorrhage of unknown origin. J Neurosurg 114, 1003-1007, (2011).

66 Moran, C. J. Aneurysmal subarachnoid hemorrhage: DSA versus CT angiography--is the answer available? Radiology 258, 15-17, (2011).

67 Meyers, P. M. et al. Reporting standards for endovascular repair of saccular intracranial cerebral aneurysms. Stroke 40, e366-379, (2009).

68 Kallmes, D. F., Layton, K., Marx, W. F. \& Tong, F. Death by nondiagnosis: why emergent CT angiography should not be done for patients with subarachnoid hemorrhage. AJNR Am J Neuroradiol 28, 1837-1838, (2007).

69 JM, U. K.-I. et al. Current diagnostic approaches to subarachnoid haemorrhage. Eur Radiol 15, 1135-1147, (2005).

70 Cloft, H. J., Joseph, G. J. \& Dion, J. E. Risk of cerebral angiography in patients with subarachnoid hemorrhage, cerebral aneurysm, and arteriovenous malformation: a meta-analysis. Stroke 30, 317-320, (1999).

71 Dawkins, A. A. et al. Complications of cerebral angiography: a prospective analysis of 2,924 consecutive procedures. Neuroradiology 49, 753-759, (2007).

$72 \mathrm{Fifi}, \mathrm{J}$. T. et al. Complications of modern diagnostic cerebral angiography in an academic medical center. J Vasc Interv Radiol 20, 442-447, (2009).

73 Grzyska, U., Freitag, J. \& Zeumer, H. Selective cerebral intraarterial DSA. Complication rate and control of risk factors. Neuroradiology 32, 296-299, (1990).

74 Leffers, A. M. \& Wagner, A. Neurologic complications of cerebral angiography. A retrospective study of complication rate and patient risk factors. Acta Radiol 41, 204-210, (2000). 
75 Willinsky, R. A. et al. Neurologic complications of cerebral angiography: prospective analysis of 2,899 procedures and review of the literature. Radiology 227, 522-528, (2003).

76 Moran, C. J. et al. Randomized controlled trial of sheaths in diagnostic neuroangiography. Radiology 218, 183187, (2001).

77 Kaufmann, T. J. et al. Complications of diagnostic cerebral angiography: evaluation of 19,826 consecutive patients. Radiology 243, 812-819, (2007).

78 Adams, H. P., Jr., Kassell, N. F., Torner, J. C., Nibbelink, D. W. \& Sahs, A. L. Early management of aneurysmal subarachnoid hemorrhage. A report of the Cooperative Aneurysm Study. J Neurosurg 54, 141-145, (1981).

79 Black, P. M. Hydrocephalus and vasospasm after subarachnoid hemorrhage from ruptured intracranial aneurysms. Neurosurgery 18, 12-16, (1986).

80 Anxionnat, R. et al. 3D angiography. Clinical interest. First applications in interventional neuroradiology. J Neuroradiol 25, 251-262, (1998).

81 Heautot, J. F. et al. Analysis of cerebrovascular diseases by a new 3-dimensional computerised X-ray angiography system. Neuroradiology 40, 203-209, (1998).

82 Ishihara, S. et al. 3D Rotational Angiography: Recent Experience in the Evaluation of Cerebral Aneurysms for Treatment. Interv Neuroradiol 6, 85-94, (2000).

83 Castano-Duque, C. H. et al. Early Experience Studying Cerebral Aneurysms with Rotational and Threedimensional Angiography and Review of CT and MR Angiography Literature. Interv Neuroradiol 8, 377 391, (2002).

84 Cornelis, G., Bellet, A., van Eygen, B., Roisin, P. \& Libon, E. Rotational multiple sequence roentgenography of intracranial aneurysms. Acta Radiol Diagn (Stockh) 13, 74-76, (1972).

85 Voigt, K., Stoeter, P. \& Petersen, D. Rotational cerebral roentgenography. I. Evaluation of the technical procedure and diagnostic application with model studies. Neuroradiology 10, 95-100, (1975).

86 Thron, A. \& Voigt, K. Rotational cerebral angiography: procedure and value. AJNR Am J Neuroradiol 4, $289-$ 291, (1983).

87 Schumacher, M., Kutluk, K. \& Ott, D. Digital rotational radiography in neuroradiology. AJNR Am J Neuroradiol 10, 644-649, (1989).

$88 \mathrm{Tu}, \mathrm{R}$. K. et al. Digital subtraction rotational angiography for aneurysms of the intracranial anterior circulation: injection method and optimization. AJNR Am J Neuroradiol 17, 1127-1136, (1996).

89 Hoff, D. J., Wallace, M. C., terBrugge, K. G. \& Gentili, F. Rotational angiography assessment of cerebral aneurysms. AJNR Am J Neuroradiol 15, 1945-1948, (1994).

90 Tanoue, S. et al. Three-dimensional reconstructed images after rotational angiography in the evaluation of intracranial aneurysms: surgical correlation. Neurosurgery 47, 866-871, (2000).

91 Albuquerque, F. C., Spetzler, R. F., Zabramski, J. M. \& McDougall, C. G. Effects of three-dimensional angiography on the coiling of cerebral aneurysms. Neurosurgery 51, 597-605; discussion 605-596, (2002).

92 Anxionnat, R. et al. Intracranial aneurysms: clinical value of 3D digital subtraction angiography in the therapeutic decision and endovascular treatment. Radiology 218, 799-808, (2001).

93 Abe, $T$. et al. Clinical benefits of rotational 3D angiography in endovascular treatment of ruptured cerebral aneurysm. AJNR Am J Neuroradiol 23, 686-688, (2002).

94 Missler, U., Hundt, C., Wiesmann, M., Mayer, T. \& Bruckmann, H. Three-dimensional reconstructed rotational digital subtraction angiography in planning treatment of intracranial aneurysms. Eur Radiol 10, 564-568, (2000).

95 Hacein-Bey, L. \& Provenzale, J. M. Current imaging assessment and treatment of intracranial aneurysms. AJR Am J Roentgenol 196, 32-44, (2011).

96 Hochmuth, A., Spetzger, U. \& Schumacher, M. Comparison of three-dimensional rotational angiography with digital subtraction angiography in the assessment of ruptured cerebral aneurysms. AJNR Am J Neuroradiol 23, 1199-1205, (2002).

97 Sugahara, T. et al. Comparison of 2D and 3D digital subtraction angiography in evaluation of intracranial aneurysms. AJNR Am J Neuroradiol 23, 1545-1552, (2002).

98 van Rooij, W. J., Peluso, J. P., Sluzewski, M. \& Beute, G. N. Additional value of 3D rotational angiography in angiographically negative aneurysmal subarachnoid hemorrhage: how negative is negative? AJNR Am J Neuroradiol 29, 962-966, (2008).

99 Shi, W. Y. et al. 3D rotational angiography with volume rendering: the utility in the detection of intracranial aneurysms. Neurol India 58, 908-913, (2010).

100 Ishihara, H. et al. Angiogram-negative subarachnoid hemorrhage in the era of three dimensional rotational angiography. J Clin Neurosci 14, 252-255, (2007).

101 Bridcut, R. R., Murphy, E., Workman, A., Flynn, P. \& Winder, R. J. Patient dose from 3D rotational neurovascular studies. Br J Radiol 80, 362-366, (2007). 
102 van Rooij, W. J., Sprengers, M. E., de Gast, A. N., Peluso, J. P. \& Sluzewski, M. 3D rotational angiography: the new gold standard in the detection of additional intracranial aneurysms. AJNR Am J Neuroradiol 29, 976-979, (2008).

103 Brinjikji, W., Cloft, H., Lanzino, G. \& Kallmes, D. F. Comparison of 2D digital subtraction angiography and 3D rotational angiography in the evaluation of dome-to-neck ratio. AJNR Am J Neuroradiol 30, 831-834, (2009).

104 Kucukay, F. et al. Three-dimensional volume rendering digital subtraction angiography in comparison with two-dimensional digital subtraction angiography and rotational angiography for detecting aneurysms and their morphological properties in patients with subarachnoid hemorrhage. Eur J Radiol, (2011).

105 Rinkel, G. J. et al. Nonaneurysmal perimesencephalic subarachnoid hemorrhage: CT and MR patterns that differ from aneurysmal rupture. AJNR Am J Neuroradiol 12, 829-834, (1991).

106 van Gijn, J., van Dongen, K. J., Vermeulen, M. \& Hijdra, A. Perimesencephalic hemorrhage: a nonaneurysmal and benign form of subarachnoid hemorrhage. Neurology 35, 493-497, (1985).

107 Rinkel, G. J. et al. The clinical course of perimesencephalic nonaneurysmal subarachnoid hemorrhage. Ann Neurol 29, 463-468, (1991).

108 Agid, R. et al. Negative CT angiography findings in patients with spontaneous subarachnoid hemorrhage: When is digital subtraction angiography still needed? AJNR Am J Neuroradiol 31, 696-705, (2010).

109 Delgado Almandoz, J. E. et al. Diagnostic Yield of Repeat Catheter Angiography in Patients with Catheter and CT Angiography Negative Subarachnoid Hemorrhage. Neurosurgery, (2011).

110 Huttner, H. B. et al. Repeated digital substraction angiography after perimesencephalic subarachnoid hemorrhage? J Neuroradiol 33, 87-89, (2006).

111 Cruz, J. P., Sarma, D. \& Noel de Tilly, L. Perimesencephalic subarachnoid hemorrhage: when to stop imaging? Emerg Radiol 18, 197-202, (2011).

112 Brilstra, E. H., Hop, J. W. \& Rinkel, G. J. Quality of life after perimesencephalic haemorrhage. J Neurol Neurosurg Psychiatry 63, 382-384, (1997).

113 Boswell, S., Thorell, W., Gogela, S., Lyden, E. \& Surdell, D. Angiogram-Negative Subarachnoid Hemorrhage: Outcomes Data and Review of the Literature. J Stroke Cerebrovasc Dis, (2012).

114 Jung, J. Y., Kim, Y. B., Lee, J. W., Huh, S. K. \& Lee, K. C. Spontaneous subarachnoid haemorrhage with negative initial angiography: a review of 143 cases. J Clin Neurosci 13, 1011-1017, (2006).

115 Andaluz, N. \& Zuccarello, M. Yield of further diagnostic work-up of cryptogenic subarachnoid hemorrhage based on bleeding patterns on computed tomographic scans. Neurosurgery 62, 1040-1046; discussion 1047, (2008).

116 Little, A. S. et al. Evaluation of patients with spontaneous subarachnoid hemorrhage and negative angiography. Neurosurgery 61, 1139-1150; discussion 1150-1131, (2007).

117 Topcuoglu, M. A. et al. Subarachnoid hemorrhage without evident cause on initial angiography studies: diagnostic yield of subsequent angiography and other neuroimaging tests. J Neurosurg 98, 1235-1240, (2003).

118 Houben, M. P., van Rooij, W. J., Sluzewski, M. \& Tijssen, C. C. [Subarachnoid hemorrhage without aneurysm on the angiogram: the value of repeat angiography]. Ned Tijdschr Geneeskd 146, 804-808, (2002).

119 Rogg, J. M. et al. Assessment of the value of MR imaging for examining patients with angiographically negative subarachnoid hemorrhage. AJR Am J Roentgenol 172, 201-206, (1999).

120 Westerlaan, H. E. et al. Multislice CT angiography in the selection of patients with ruptured intracranial aneurysms suitable for clipping or coiling. Neuroradiology 49, 997-1007, (2007).

121 Hashimoto, H., lida, J., Hironaka, Y., Okada, M. \& Sakaki, T. Use of spiral computerized tomography angiography in patients with subarachnoid hemorrhage in whom subtraction angiography did not reveal cerebral aneurysms. J Neurosurg 92, 278-283, (2000).

122 Ambrose, J. Computerized transverse axial scanning (tomography). 2. Clinical application. Br J Radiol 46, 1023-1047, (1973).

123 Ambrose, J. Computerized transverse axial scanning of the brain. Proc R Soc Med 66, 833-834, (1973).

124 Ambrose, J. \& Hounsfield, G. Computerized transverse axial tomography. Br J Radiol 46, 148-149, (1973).

125 Hounsfield, G. N. Computerized transverse axial scanning (tomography). 1. Description of system. Br J Radiol 46, 1016-1022, (1973).

126 Bradley, W. G. History of medical imaging. Proc Am Philos Soc 152, 349-361, (2008).

127 Kalender, W. A., Vock, P., Polacin, A. \& Soucek, M. [Spiral-CT: a new technique for volumetric scans. I. Basic principles and methodology]. Rontgenpraxis 43, 323-330, (1990).

128 Soucek, M., Vock, P., Daepp, M. \& Kalender, W. A. [Spiral-CT: a new technique for volumetric scans. II. Potential clinical applications]. Rontgenpraxis 43, 365-375, (1990).

129 Kalender, W. A., Seissler, W., Klotz, E. \& Vock, P. Spiral volumetric CT with single-breath-hold technique, continuous transport, and continuous scanner rotation. Radiology 176, 181-183, (1990). 
130 Napel, S. et al. CT angiography with spiral CT and maximum intensity projection. Radiology 185, 607-610, (1992).

131 Aoki, S., Sasaki, Y., Machida, T., Ohkubo, T. \& Minami, M. Cerebral aneurysms: detection and delineation using 3-D-CT angiography. AJNR Am J Neuroradiol 13, 1115-1120, (1992).

132 Schwartz, R. B., Tice, H. M., Hooten, S. M., Hsu, L. \& Stieg, P. E. Evaluation of cerebral aneurysms with helical CT: correlation with conventional angiography and MR angiography. Radiology 192, 717-722, (1994).

133 Tsuchiya, K., Makita, K. \& Furui, S. 3D-CT angiography of cerebral aneurysms with spiral scanning: comparison with 3D-time-of-flight MR angiography. Radiat Med 12, 161-166, (1994).

134 Rieger, J. et al. [Cerebral aneurysms: their 3-dimensional imaging with spiral CT]. Rofo 160, 204-209, (1994).

135 White, P. M., Wardlaw, J. M. \& Easton, V. Can noninvasive imaging accurately depict intracranial aneurysms? A systematic review. Radiology 217, 361-370, (2000).

136 van Gelder, J. M. Computed tomographic angiography for detecting cerebral aneurysms: implications of aneurysm size distribution for the sensitivity, specificity, and likelihood ratios. Neurosurgery 53, 597-605; discussion 605-596, (2003).

137 Chappell, E. T., Moure, F. C. \& Good, M. C. Comparison of computed tomographic angiography with digital subtraction angiography in the diagnosis of cerebral aneurysms: a meta-analysis. Neurosurgery 52, 624-631; discussion 630-621, (2003).

138 Jones, T. R., Kaplan, R. T., Lane, B., Atlas, S. W. \& Rubin, G. D. Single- versus multi-detector row CT of the brain: quality assessment. Radiology 219, 750-755, (2001).

139 Rubin, G. D. et al. Computed tomographic angiography: historical perspective and new state-of-the-art using multi detector-row helical computed tomography. J Comput Assist Tomogr 23 Suppl 1, S83-90, (1999).

140 Skutta, B., Furst, G., Eilers, J., Ferbert, A. \& Kuhn, F. P. Intracranial stenoocclusive disease: double-detector helical CT angiography versus digital subtraction angiography. AJNR Am J Neuroradiol 20, 791-799, (1999).

141 Wintermark, M. et al. Multislice computerized tomography angiography in the evaluation of intracranial aneurysms: a comparison with intraarterial digital subtraction angiography. J Neurosurg 98, 828-836, (2003).

142 Ertl-Wagner, B., Hoffmann, R. T., Bruning, R., Dichgans, M. \& Reiser, M. F. [Diagnostic evaluation of the craniocervical vascular system with a 16-slice multi-detector row spiral CT. Protocols and first experiences]. Radiologe 42, 728-732, (2002).

143 Ertl-Wagner, B., Hoffmann, R. T., Bruning, R. \& Reiser, M. F. [CT-angiographic evaluation of intracranial aneurysms - a review of the literature and first experiences with 4- and 16-slice multi detector CT scanners]. Radiologe 42, 892-897, (2002).

144 Jayaraman, M. V. et al. Detection of intracranial aneurysms: multi-detector row CT angiography compared with DSA. Radiology 230, 510-518, (2004).

145 Kato, Y. et al. Multi-slice 3D-CTA - an improvement over single slice helical CTA for cerebral aneurysms. Acta Neurochir (Wien) 144, 715-722, (2002).

146 Klingebiel, R. et al. Multi-slice CT angiography in the evaluation of patients with acute cerebrovascular disease--a promising new diagnostic tool. J Neurol 249, 43-49, (2002).

147 Klingebiel, R. et al. Assessment of the arteriovenous cerebrovascular system by multi-slice CT. A single-bolus, monophasic protocol. Acta Radiol 42, 560-562, (2001).

148 Imakita, S. et al. Subtraction CT angiography with controlled-orbit helical scanning for detection of intracranial aneurysms. AJNR Am J Neuroradiol 19, 291-295, (1998).

149 Jayakrishnan, V. K. et al. Subtraction helical CT angiography of intra- and extracranial vessels: technical considerations and preliminary experience. AJNR Am J Neuroradiol 24, 451-455, (2003).

150 Romijn, M. et al. Diagnostic accuracy of CT angiography with matched mask bone elimination for detection of intracranial aneurysms: comparison with digital subtraction angiography and 3D rotational angiography. AJNR Am J Neuroradiol 29, 134-139, (2008).

151 Venema, H. W., Hulsmans, F. J. \& den Heeten, G. J. CT angiography of the circle of Willis and intracranial internal carotid arteries: maximum intensity projection with matched mask bone elimination-feasibility study. Radiology 218, 893-898, (2001).

$152 \mathrm{Li}, \mathrm{Q}$. et al. Subtraction CT angiography for evaluation of intracranial aneurysms: comparison with conventional CT angiography. Eur Radiol 19, 2261-2267, (2009).

153 Lu, L. et al. Digital subtraction CT angiography for detection of intracranial aneurysms: comparison with three-dimensional digital subtraction angiography. Radiology 262, 605-612, (2012).

154 Hwang, S. B., Kwak, H. S., Han, Y. M. \& Chung, G. H. Detection of intracranial aneurysms using threedimensional multidetector-row CT angiography: is bone subtraction necessary? Eur J Radiol 79, e18-23, (2011).

155 Tomandl, B. F. et al. Bone-subtraction CT angiography for the evaluation of intracranial aneurysms. AJNR Am J Neuroradiol 27, 55-59, (2006). 
156 Menke, J., Larsen, J. \& Kallenberg, K. Diagnosing cerebral aneurysms by computed tomographic angiography: meta-analysis. Ann Neurol 69, 646-654, (2011).

157 Westerlaan, H. E. et al. Intracranial aneurysms in patients with subarachnoid hemorrhage: CT angiography as a primary examination tool for diagnosis--systematic review and meta-analysis. Radiology 258, 134-145, (2011).

158 Anderson, G. B., Steinke, D. E., Petruk, K. C., Ashforth, R. \& Findlay, J. M. Computed tomographic angiography versus digital subtraction angiography for the diagnosis and early treatment of ruptured intracranial aneurysms. Neurosurgery 45, 1315-1320; discussion 1320-1312, (1999).

159 Dehdashti, A. R., Rufenacht, D. A., Delavelle, J., Reverdin, A. \& de Tribolet, N. Therapeutic decision and management of aneurysmal subarachnoid haemorrhage based on computed tomographic angiography. $\mathrm{Br} J$ Neurosurg 17, 46-53, (2003).

160 Gonzalez-Darder, J. M., Pesudo-Martinez, J. V. \& Feliu-Tatay, R. A. Microsurgical management of cerebral aneurysms based in CT angiography with three-dimensional reconstruction (3D-CTA) and without preoperative cerebral angiography. Acta Neurochir (Wien) 143, 673-679, (2001).

161 Karamessini, M. T. et al. CT angiography with three-dimensional techniques for the early diagnosis of intracranial aneurysms. Comparison with intra-arterial DSA and the surgical findings. Eur J Radiol 49, 212-223, (2004).

162 Lenhart, M. et al. Cerebral CT angiography in the diagnosis of acute subarachnoid hemorrhage. Acta Radiol 38, 791-796, (1997).

163 Lukosevicius, S. \& Vaitkevicius, G. [Brain computed tomography angiography in case of subarachnoid hemorrhage]. Medicina (Kaunas) 38, 140-146, (2002).

164 Matsumoto, M. et al. Acute aneurysm surgery using three-dimensional CT angiogrphy without conventional catheter angiography. Fukushima J Med Sci 48, 63-73, (2002).

165 Nakajima, Y. et al. Computerized tomography angiography of ruptured cerebral aneurysms: factors affecting time to maximum contrast concentration. J Neurosurg 88, 663-669, (1998).

166 Pedersen, H. K. et al. CTA in patients with acute subarachnoid haemorrhage. A comparative study with selective, digital angiography and blinded, independent review. Acta Radiol 42, 43-49, (2001).

167 Rajagopal, K. V., Lakhkar, B. N. \& Acharya, D. K. Three-dimensional CT angiography in the evaluation of cerebral arteries in acute hemorrhage. Neurol India 51, 206-207, (2003).

168 Rohnert, W., Hanig, V., Hietschold, V. \& Abolmaali, N. [Detection of aneurysm in subarachnoid hemorrhage-CT angiography vs. digital subtraction angiography]. Aktuelle Radiol 8, 63-70, (1998).

169 Santos, N., Machado, E., Carvalho, S., Barbosa, M. \& Martins, F. [Subarachnoid hemorrhage and computerized tomography cerebral angiography]. Acta Med Port 14, 43-47, (2001).

170 Sasiadek, M. et al. Efficiency of CT-angiography in the diagnosis of intracranial aneurysms. Med Sci Monit 8, MT99-MT104, (2002).

171 Seruga, T., Bunc, G. \& Klein, G. E. Helical high-resolution volume-rendered 3-dimensional computer tomography angiography in the detection of intracranial aneurysms. J Neuroimaging 11, 280-286, (2001).

172 Uysal, E., Yanbuloglu, B., Erturk, M., Kilinc, B. M. \& Basak, M. Spiral CT angiography in diagnosis of cerebral aneurysms of cases with acute subarachnoid hemorrhage. Diagn Interv Radiol 11, 77-82, (2005).

173 Velthuis, B. K. et al. Subarachnoid hemorrhage: aneurysm detection and preoperative evaluation with CT angiography. Radiology 208, 423-430, (1998).

174 Velthuis, B. K., Rinkel, G. J., Ramos, L. M., Witkamp, T. D. \& van Leeuwen, M. S. Perimesencephalic hemorrhage. Exclusion of vertebrobasilar aneurysms with CT angiography. Stroke 30, 1103-1109, (1999).

175 Velthuis, B. K. et al. Computerized tomography angiography in patients with subarachnoid hemorrhage: from aneurysm detection to treatment without conventional angiography. J Neurosurg 91, 761-767, (1999).

176 White, P. M., Teasdale, E. M., Wardlaw, J. M. \& Easton, V. Intracranial aneurysms: CT angiography and MR angiography for detection prospective blinded comparison in a large patient cohort. Radiology 219, 739-749, (2001).

177 Zouaoui, A. et al. Three-dimensional computed tomographic angiography in detection of cerebral aneurysms in acute subarachnoid hemorrhage. Neurosurgery 41, 125-130, (1997).

178 Kouskouras, C. et al. Intracranial aneurysms: evaluation using CTA and MRA. Correlation with DSA and intraoperative findings. Neuroradiology 46, 842-850, (2004).

179 Chen, W., Yang, Y., Xing, W., Qiu, J. \& Peng, Y. Application of multislice computed tomographic angiography in diagnosis and treatment of intracranial aneurysms. Clin Neurol Neurosurg 112, 563-571, (2010).

180 Donmez, H. et al. Comparison of 16-row multislice CT angiography with conventional angiography for detection and evaluation of intracranial aneurysms. Eur J Radiol, (2010).

181 Prestigiacomo, C. J. et al. Three dimensional CT angiography versus digital subtraction angiography in the detection of intracranial aneurysms in subarachnoid hemorrhage. J Neurointerv Surg 2, 385-389, (2010). 
182 Franklin, B., Gasco, J., Uribe, T., VonRitschl, R. H. \& Hauck, E. Diagnostic accuracy and inter-rater reliability of 64-multislice 3D-CTA compared to intra-arterial DSA for intracranial aneurysms. J Clin Neurosci 17, 579-583, (2010).

183 Xing, W. et al. Sixty-four-row multislice computed tomographic angiography in the diagnosis and characterization of intracranial aneurysms: comparison with 3D rotational angiography. World Neurosurg 76, 105-113, (2011).

184 Luo, Z. et al. Comparison of the accuracy of subtraction CT angiography performed on 320-detector row volume CT with conventional CT angiography for diagnosis of intracranial aneurysms. Eur J Radiol 81, 118122, (2012).

185 Sun, G. et al. Comparison of standard- and low-tube voltage 320-detector row volume CT angiography in detection of intracranial aneurysms with digital subtraction angiography as gold standard. Acad Radiol 19, 281-288, (2012).

186 Johnson, T. R. et al. Material differentiation by dual energy CT: initial experience. Eur Radiol 17, 1510-1517, (2007).

187 Morhard, D. et al. Cervical and cranial computed tomographic angiography with automated bone removal: dual energy computed tomography versus standard computed tomography. Invest Radiol 44, 293-297, (2009).

188 Hegde, A., Chan, L. L., Tan, L., Illyyas, M. \& Lim, W. E. Dual Energy CT and its use in neuroangiography. Ann Acad Med Singapore 38, 817-820, (2009).

189 Zhang, L. J. et al. Dual-energy CT angiography in the evaluation of intracranial aneurysms: image quality, radiation dose, and comparison with 3D rotational digital subtraction angiography. AJR Am J Roentgenol 194, 23-30, (2010).

190 Zhang, L. J. et al. Automatic bone removal dual-energy CT angiography for the evaluation of intracranial aneurysms. J Comput Assist Tomogr 34, 816-824, (2010).

$191 \mathrm{Li}, \mathrm{Q}$. et al. Evaluation of 64-section CT angiography for detection and treatment planning of intracranial aneurysms by using DSA and surgical findings. Radiology 252, 808-815, (2009).

192 Villablanca, J. P. et al. Detection and characterization of very small cerebral aneurysms by using 2D and 3D helical CT angiography. AJNR Am J Neuroradiol 23, 1187-1198, (2002).

193 Papke, K. et al. Intracranial aneurysms: role of multidetector CT angiography in diagnosis and endovascular therapy planning. Radiology 244, 532-540, (2007).

194 Molyneux, A. et al. International Subarachnoid Aneurysm Trial (ISAT) of neurosurgical clipping versus endovascular coiling in 2143 patients with ruptured intracranial aneurysms: a randomised trial. Lancet 360, 1267-1274, (2002).

195 Guglielmi, G., Vinuela, F., Dion, J. \& Duckwiler, G. Electrothrombosis of saccular aneurysms via endovascular approach. Part 2: Preliminary clinical experience. J Neurosurg 75, 8-14, (1991).

196 Guglielmi, G., Vinuela, F., Sepetka, I. \& Macellari, V. Electrothrombosis of saccular aneurysms via endovascular approach. Part 1: Electrochemical basis, technique, and experimental results. J Neurosurg 75, 17, (1991).

197 Brown, J. H., Lustrin, E. S., Lev, M. H., Ogilvy, C. S. \& Taveras, J. M. Characterization of intracranial aneurysms using CT angiography. AJR Am J Roentgenol 169, 889-893, (1997).

198 Goddard, A. J., Tan, G. \& Becker, J. Computed tomography angiography for the detection and characterization of intra-cranial aneurysms: current status. Clin Radiol 60, 1221-1236, (2005).

199 Hoh, B. L. et al. Results of a prospective protocol of computed tomographic angiography in place of catheter angiography as the only diagnostic and pretreatment planning study for cerebral aneurysms by a combined neurovascular team. Neurosurgery 54, 1329-1340; discussion 1340-1322, (2004).

200 Uysal, E. et al. Detection and evaluation of intracranial aneurysms with 16-row multislice CT angiography: comparison with conventional angiography. Emerg Radiol 15, 311-316, (2008).

201 Villablanca, J. P. et al. Aneurysms of the posterior circulation: detection and treatment planning using volume-rendered three-dimensional helical computerized tomography angiography. J Neurosurg 103, 10181029, (2005).

202 Yoon, D. Y. et al. Detection and characterization of intracranial aneurysms with 16-channel multidetector row CT angiography: a prospective comparison of volume-rendered images and digital subtraction angiography. AJNR Am J Neuroradiol 28, 60-67, (2007).

203 Agid, R., Lee, S. K., Willinsky, R. A., Farb, R. I. \& terBrugge, K. G. Acute subarachnoid hemorrhage: using 64slice multidetector CT angiography to "triage" patients' treatment. Neuroradiology 48, 787-794, (2006).

204 Jayaraman, M. V., Haas, R. A., Do, H. M. \& Meyers, P. M. Should CT Angiography Be Routinely Used in Patients Suspected of Having Aneurysmal Subarachnoid Hemorrhage? No! Radiology 254, 314-315, (2010). 
205 Agid, R., Willinsky, R. A., Farb, R. I. \& Terbrugge, K. G. Life at the end of the tunnel: why emergent CT angiography should be done for patients with acute subarachnoid hemorrhage. AJNR Am J Neuroradiol 29, e45; author reply e46-47, (2008).

206 Fox, A. J., Symons, S. P. \& Aviv, R. I. CT angiography is state-of-the-art first vascular imaging for subarachnoid hemorrhage. AJNR Am J Neuroradiol 29, e41-42; author reply e46-47, (2008).

207 Livingston, R. R. Regarding the risk of death from CT angiography in patients with subarachnoid hemorrhage. AJNR Am J Neuroradiol 29, e44; author reply e46-47, (2008).

208 Bloch, F., Hanssen, W. \& Packard, M. Nuclear induction. Physical Review 69, (1946).

209 Purcell, E., Torrey, H. \& Pound, R. Resonance absorption by nuclear magnetic moments in a solid. Physical Review 69, 37 - 38, (1946).

210 Lauterbur, P. C. Image Formation by induced local interactions: Example employing nuclear magnetic resonance. Nature 242, 190 - 191, (1973).

211 Damadian, R. Tumor detection by nuclear magnetic resonance. Science 171, 1151-1153, (1971).

212 Mansfield, I. \& Maudsley, A. Medical imaging by NMR. Br J Radiol 50, 188 - 194, (1977).

213 Bradley, W. G., Jr., Waluch, V., Lai, K. S., Fernandez, E. J. \& Spalter, C. The appearance of rapidly flowing blood on magnetic resonance images. AJR Am J Roentgenol 143, 1167-1174, (1984).

214 George, C. R. et al. Magnetic resonance signal intensity patterns obtained from continuous and pulsatile flow models. Radiology 151, 421-428, (1984).

215 Wedeen, V. J. et al. Projective imaging of pulsatile flow with magnetic resonance. Science 230, 946-948, (1985).

216 Parker, D. L., Tsuruda, J. S., Goodrich, K. C., Alexander, A. L. \& Buswell, H. R. Contrast-enhanced magnetic resonance angiography of cerebral arteries. A review. Invest Radiol 33, 560-572, (1998).

217 Caille, J. M., Lemanceau, B. \& Bonnemain, B. Gadolinium as a contrast agent for NMR. AJNR Am J Neuroradiol 4, 1041-1042, (1983).

218 Weinmann, H. J., Brasch, R. C., Press, W. R. \& Wesbey, G. E. Characteristics of gadolinium-DTPA complex: a potential NMR contrast agent. AJR Am J Roentgenol 142, 619-624, (1984).

219 Laniado, M., Weinmann, H. J., Schorner, W., Felix, R. \& Speck, U. First use of GdDTPA/dimeglumine in man. Physiol Chem Phys Med NMR 16, 157-165, (1984).

220 Lin, W., Haacke, E. M., Smith, A. S. \& Clampitt, M. E. Gadolinium-enhanced high-resolution MR angiography with adaptive vessel tracking: preliminary results in the intracranial circulation. J Magn Reson Imaging 2, 277284, (1992).

221 Creasy, J. L. et al. Gadolinium-enhanced MR angiography. Radiology 175, 280-283, (1990).

222 Levy, R. A. \& Prince, M. R. Arterial-phase three-dimensional contrast-enhanced MR angiography of the carotid arteries. AJR Am J Roentgenol 167, 211-215, (1996).

223 Watanabe, Y. et al. Dynamic subtraction contrast-enhanced MR angiography: technique, clinical applications, and pitfalls. Radiographics 20, 135-152; discussion 152-133, (2000).

224 Watanabe, Y. et al. Dynamic subtraction MR angiography: first-pass imaging of the main arteries of the lower body. AJR Am J Roentgenol 170, 357-360, (1998).

225 Bosmans, H., Wilms, G., Dymarkowski, S. \& Marchal, G. Basic principles of MRA. Eur J Radiol 38, 2-9, (2001).

226 Gottschalk, S. et al. [Contrast-enhanced intracranial 3 D MR angiography (CE-MRA) in assessing arterial stenoses and aneurysms]. Rofo 174, 704-713, (2002).

227 Lee, V. S., Flyer, M. A., Weinreb, J. C., Krinsky, G. A. \& Rofsky, N. M. Image subtraction in gadoliniumenhanced MR imaging. AJR Am J Roentgenol 167, 1427-1432, (1996).

228 Papke, K. \& Brassel, F. Modern cross-sectional imaging in the diagnosis and follow-up of intracranial aneurysms. Eur Radiol 16, 2051-2066, (2006).

229 Maki, J. H., Prince, M. R., Londy, F. J. \& Chenevert, T. L. The effects of time varying intravascular signal intensity and k-space acquisition order on three-dimensional MR angiography image quality. J Magn Reson Imaging 6, 642-651, (1996).

230 Riedy, G., Golay, X. \& Melhem, E. R. Three-dimensional isotropic contrast-enhanced MR angiography of the carotid artery using sensitivity-encoding and random elliptic centric k-space filling: technique optimization. Neuroradiology 47, 668-673, (2005).

231 Lee, H. M. \& Wang, Y. Dynamic k-space filling for bolus chase 3D MR digital subtraction angiography. Magn Reson Med 40, 99-104, (1998).

232 Farb, R. I. et al. Intracranial venous system: gadolinium-enhanced three-dimensional MR venography with auto-triggered elliptic centric-ordered sequence--initial experience. Radiology 226, 203-209, (2003).

233 Farb, R. I. et al. Intracranial arteriovenous malformations: real-time auto-triggered elliptic centric-ordered 3D gadolinium-enhanced MR angiography--initial assessment. Radiology 220, 244-251, (2001). 
234 Zimmerman, R. A. et al. Magnetic resonance imaging of cerebral aneurysm. Acta Radiol Suppl 369, 107-109, (1986).

235 Masaryk, T. J. et al. Intracranial circulation: preliminary clinical results with three-dimensional (volume) MR angiography. Radiology 171, 793-799, (1989).

236 Pernicone, J. R. et al. Three-dimensional phase-contrast MR angiography in the head and neck: preliminary report. AJNR Am J Neuroradiol 11, 457-466, (1990).

237 Ruggieri, P. M., Laub, G. A., Masaryk, T. J. \& Modic, M. T. Intracranial circulation: pulse-sequence considerations in three-dimensional (volume) MR angiography. Radiology 171, 785-791, (1989).

238 Ross, J. S. et al. Intracranial aneurysms: evaluation by MR angiography. AJR Am J Roentgenol 155, 159-165, (1990).

239 Sevick, R. J., Tsuruda, J. S. \& Schmalbrock, P. Three-dimensional time-of-flight MR angiography in the evaluation of cerebral aneurysms. J Comput Assist Tomogr 14, 874-881, (1990).

240 Huston, J., 3rd, Rufenacht, D. A., Ehman, R. L. \& Wiebers, D. O. Intracranial aneurysms and vascular malformations: comparison of time-of-flight and phase-contrast MR angiography. Radiology 181, 721-730, (1991).

241 Huston, J., 3rd \& Ehman, R. L. Comparison of time-of-flight and phase-contrast MR neuroangiographic techniques. Radiographics 13, 5-19, (1993).

242 Araki, Y., Kohmura, E. \& Tsukaguchi, I. A pitfall in detection of intracranial unruptured aneurysms on threedimensional phase-contrast MR angiography. AJNR Am J Neuroradiol 15, 1618-1623, (1994).

243 Huston, J., 3rd et al. Blinded prospective evaluation of sensitivity of MR angiography to known intracranial aneurysms: importance of aneurysm size. AJNR Am J Neuroradiol 15, 1607-1614, (1994).

244 Bontozoglou, N. P., Spanos, H., Lasjaunias, P. \& Zarifis, G. Intracranial aneurysms: endovascular evaluation with three-dimensional-display MR angiography. Radiology 197, 876-879, (1995).

245 Gouliamos, A. et al. Magnetic resonance angiography compared to intra-arterial digital subtraction angiography in patients with subarachnoid haemorrhage. Neuroradiology 35, 46-49, (1992).

246 Auffray, E. et al. Contribution of MR-angiography to the diagnosis and the therapeutic indication and followup of intracranial aneurysms. J Neuroradiol 21, 17-29, (1994).

247 Horikoshi, T., Fukamachi, A., Nishi, H. \& Fukasawa, I. Detection of intracranial aneurysms by threedimensional time-of-flight magnetic resonance angiography. Neuroradiology 36, 203-207, (1994).

248 Anzalone, N., Triulzi, F. \& Scotti, G. Acute subarachnoid haemorrhage: 3D time-of-flight MR angiography versus intra-arterial digital angiography. Neuroradiology 37, 257-261, (1995).

249 Felber, S. et al. [Magnetic resonance angiography of intracranial aneurysms after subarachnoid hemorrhage]. Radiologe 35, 822-829, (1995).

250 Stock, K. W., Radue, E. W., Jacob, A. L., Bao, X. S. \& Steinbrich, W. Intracranial arteries: prospective blinded comparative study of MR angiography and DSA in 50 patients. Radiology 195, 451-456, (1995).

251 Futatsuya, R. et al. Clinical utility of three-dimensional time-of-flight magnetic resonance angiography for the evaluation of intracranial aneurysms. Clin Imaging 18, 101-106, (1994).

252 Schuierer, G., Huk, W. J. \& Laub, G. Magnetic resonance angiography of intracranial aneurysms: comparison with intra-arterial digital subtraction angiography. Neuroradiology 35, 50-54, (1992).

253 Gasparotti, R. et al. [Subarachnoid hemorrhage: assessment in the acute phase with angiography, with highresolution magnetic resonance (angio-MR)]. Radiol Med 87, 219-228, (1994).

254 Metens, T. et al. Intracranial aneurysms: detection with gadolinium-enhanced dynamic three-dimensional MR angiography-initial results. Radiology 216, 39-46, (2000).

255 Wilcock, D., Jaspan, T., Holland, I., Cherryman, G. \& Worthington, B. Comparison of magnetic resonance angiography with conventional angiography in the detection of intracranial aneurysms in patients presenting with subarachnoid haemorrhage. Clin Radiol 51, 330-334, (1996).

256 Leiner, T., Ho, K. Y., Nelemans, P. J., de Haan, M. W. \& van Engelshoven, J. M. Three-dimensional contrastenhanced moving-bed infusion-tracking (MoBl-track) peripheral MR angiography with flexible choice of imaging parameters for each field of view. J Magn Reson Imaging 11, 368-377, (2000).

257 Ho, V. B. et al. Automated bolus chase peripheral MR angiography: initial practical experiences and future directions of this work-in-progress. J Magn Reson Imaging 10, 376-388, (1999).

258 Ho, K. Y. et al. Peripheral vascular tree stenoses: evaluation with moving-bed infusion-tracking MR angiography. Radiology 206, 683-692, (1998).

259 Leiner, T. et al. Comparison of treatment plans for peripheral arterial disease made with multi-station contrast medium-enhanced magnetic resonance angiography and duplex ultrasound scanning. J Vasc Surg 37, 1255-1262, (2003).

260 Planken, R. N. et al. Stenosis detection in forearm hemodialysis arteriovenous fistulae by multiphase contrastenhanced magnetic resonance angiography: preliminary experience. J Magn Reson Imaging 17, 54-64, (2003). 
261 Vasbinder, G. B. et al. Accuracy of computed tomographic angiography and magnetic resonance angiography for diagnosing renal artery stenosis. Ann Intern Med 141, 674-682; discussion 682, (2004).

262 Vasbinder, G. B. et al. Motion of the distal renal artery during three-dimensional contrast-enhanced breathhold MRA. J Magn Reson Imaging 16, 685-696, (2002).

263 Adams, W. M., Laitt, R. D. \& Jackson, A. The role of MR angiography in the pretreatment assessment of intracranial aneurysms: a comparative study. AJNR Am J Neuroradiol 21, 1618-1628, (2000).

264 Chung, T. S., Joo, J. Y., Lee, S. K., Chien, D. \& Laub, G. Evaluation of cerebral aneurysms with high-resolution MR angiography using a section-interpolation technique: correlation with digital subtraction angiography. AJNR Am J Neuroradiol 20, 229-235, (1999).

265 Mallouhi, A. et al. Detection and characterization of intracranial aneurysms with MR angiography: comparison of volume-rendering and maximum-intensity-projection algorithms. AJR Am J Roentgenol 180, 55-64, (2003).

266 Debrun, G. M. et al. Selection of cerebral aneurysms for treatment using Guglielmi detachable coils: the preliminary University of Illinois at Chicago experience. Neurosurgery 43, 1281-1295; discussion 1296-1287, (1998).

267 Unlu, E., Cakir, B., Gocer, B., Tuncbilek, N. \& Gedikoglu, M. The role of contrast-enhanced MR angiography in the assessment of recently ruptured intracranial aneurysms: a comparative study. Neuroradiology 47, 780791, (2005).

268 Nael, K. et al. 3-T contrast-enhanced MR angiography in evaluation of suspected intracranial aneurysm: comparison with MDCT angiography. AJR Am J Roentgenol 190, 389-395, (2008).

269 Nael, K. et al. Contrast-enhanced MR angiography at 3T in the evaluation of intracranial aneurysms: a comparison with time-of-flight MR angiography. AJNR Am J Neuroradiol 27, 2118-2121, (2006).

270 Keogh, A. J. \& Sankhla, S. K. Magnetic resonance angiography for anterior midline aneurysms. Br J Neurosurg 10, 143-147, (1996).

271 Westerlaan, H. E. et al. Magnetic resonance angiography in the selection of patients suitable for neurosurgical intervention of ruptured intracranial aneurysms. Neuroradiology 46, 867-875, (2004).

272 Chen, Y. C. et al. The clinical value of MRA at 3.0 T for the diagnosis and therapeutic planning of patients with subarachnoid haemorrhage. Eur Radiol, (2012).

273 Broderick, J. Clipping or coiling: the first step for ruptured aneurysms. Lancet Neurol 8, 414-415, (2009).

274 Broderick, J. P. Coiling, clipping, or medical management of unruptured intracranial aneurysms: time to randomize? Ann Neurol 48, 5-6, (2000).

275 Currie, S., Mankad, K. \& Goddard, A. Endovascular treatment of intracranial aneurysms: review of current practice. Postgrad Med J 87, 41-50, (2011).

276 Shapiro, M., Babb, J., Becske, T. \& Nelson, P. K. Safety and efficacy of adjunctive balloon remodeling during endovascular treatment of intracranial aneurysms: a literature review. AJNR Am J Neuroradiol 29, 1777-1781, (2008).

277 Bodily, K. D. et al. Stent-assisted coiling in acutely ruptured intracranial aneurysms: a qualitative, systematic review of the literature. AJNR Am J Neuroradiol 32, 1232-1236, (2011).

278 Shapiro, M., Becske, T., Sahlein, D., Babb, J. \& Nelson, P. K. Stent-supported aneurysm coiling: a literature survey of treatment and follow-up. AJNR Am J Neuroradiol 33, 159-163, (2012).

279 Pierot, L. Flow diverter stents in the treatment of intracranial aneurysms: Where are we? J Neuroradiol 38, 40-46, (2011).

280 Wong, G. K., Kwan, M. C., Ng, R. Y., Yu, S. C. \& Poon, W. S. Flow diverters for treatment of intracranial aneurysms: current status and ongoing clinical trials. J Clin Neurosci 18, 737-740, (2011).

281 Stein, S. C. Brief history of surgical timing: surgery for ruptured intracranial aneurysms. Neurosurg Focus 11, E3, (2001).

282 Louw, D. F., Asfora, W. T. \& Sutherland, G. R. A brief history of aneurysm clips. Neurosurg Focus 11, E4, (2001).

283 Dott, N. Intracranial aneurysms: cerebral arterioradiography: surgical treatment. Edinburgh Med J 40, 219 240, (1933).

284 Dandy, W. E. Intracranial Aneurysm of the Internal Carotid Artery: Cured by Operation. Ann Surg 107, 654659, (1938).

285 Qureshi, A. I., Janardhan, V., Hanel, R. A. \& Lanzino, G. Comparison of endovascular and surgical treatments for intracranial aneurysms: an evidence-based review. Lancet Neurol 6, 816-825, (2007).

286 Siddique, K., Alvernia, J., Fraser, K. \& Lanzino, G. Treatment of aneurysms with wires and electricity: a historical overview. J Neurosurg 99, 1102-1107, (2003). 
287 Moore, C. H. \& Murchison, C. On a new method of procuring the consolidation of Fibrin in certain incurable Aneurisms: With the Report of a case in which an Aneurism of the ascending Aorta was treated by the insertion of Wire. Med Chir Trans 47, 129-149, (1864).

288 Duncan, J. On the galvano-puncture of aneurisms. Edinb Med J 11, 920 - 933, (1866).

289 Werner, S., Blakemore, A. \& King, B. Aneurysm of the internal carotid artery within the skull: Wiring and electrothermic coagulation. JAMA 116, 578 - 582, (1941).

290 Hopkins, L. N., Lanzino, G. \& Guterman, L. R. Treating complex nervous system vascular disorders through a "needle stick": origins, evolution, and future of neuroendovascular therapy. Neurosurgery 48, 463-475, (2001).

291 Serbinenko, F. A. Balloon catheterization and occlusion of major cerebral vessels. J Neurosurg 41, 125-145, (1974).

292 Gianturco, C., Anderson, J. H. \& Wallace, S. Mechanical devices for arterial occlusion. Am J Roentgenol Radium Ther Nucl Med 124, 428-435, (1975).

293 Hilal, S. K. \& Solomon, R. A. Endovascular treatment of aneurysms with coils. J Neurosurg 76, 337-339, (1992).

294 Seibert, B. et al. Intracranial aneurysms: review of current treatment options and outcomes. Front Neurol 2, 45, (2011).

295 Johnston, S. C. et al. Recommendations for the endovascular treatment of intracranial aneurysms: a statement for healthcare professionals from the Committee on Cerebrovascular Imaging of the American Heart Association Council on Cardiovascular Radiology. Stroke 33, 2536-2544, (2002).

296 Cloft, H. J., Joseph, G. J., Tong, F. C., Goldstein, J. H. \& Dion, J. E. Use of three-dimensional Guglielmi detachable coils in the treatment of wide-necked cerebral aneurysms. AJNR Am J Neuroradiol 21, 1312-1314, (2000).

297 Moret, J., Cognard, C., Weill, A., Castaings, L. \& Rey, A. The "Remodelling Technique" in the Treatment of Wide Neck Intracranial Aneurysms. Angiographic Results and Clinical Follow-up in 56 Cases. Interv Neuroradiol 3, 21-35, (1997).

298 Henkes, H. et al. Endovascular coil occlusion of 1811 intracranial aneurysms: early angiographic and clinical results. Neurosurgery 54, 268-280; discussion 280-265, (2004).

299 Sluzewski, M., van Rooij, W. J., Beute, G. N. \& Nijssen, P. C. Balloon-assisted coil embolization of intracranial aneurysms: incidence, complications, and angiography results. J Neurosurg 105, 396-399, (2006).

300 Gonzalez, L. F., McDougall, C. G., Albuquerque, F. C., Kim, L. J. \& Spetzler, R. F. Balloon-assisted coil embolization. J Neurosurg 106, 733-734; author reply 734, (2007).

301 Pierot, L. et al. Endovascular treatment of unruptured intracranial aneurysms: comparison of safety of remodeling technique and standard treatment with coils. Radiology 251, 846-855, (2009).

302 Sluzewski, M., van Rooij, W. J. \& Cloft, H. Is the risk of balloon assistance underinflated? AJNR Am J Neuroradiol 29, 1782, (2008).

303 Meyer, F. B. Balloon-assisted coil embolization of intracranial aneurysms. J Neurosurg 105, 392; discussion 394-395, (2006).

304 Bracard, S. et al. Combined endovascular stenting and endosaccular coiling for the treatment of a widenecked intracranial vertebral aneurysm. Technical case report. Interv Neuroradiol 5, 245-249, (1999).

305 Wakhloo, A. K., Lanzino, G., Lieber, B. B. \& Hopkins, L. N. Stents for intracranial aneurysms: the beginning of a new endovascular era? Neurosurgery 43, 377-379, (1998).

306 Piotin, M. et al. Stent-assisted coiling of intracranial aneurysms: clinical and angiographic results in 216 consecutive aneurysms. Stroke 41, 110-115, (2010).

307 Amenta, P. S. et al. Stent-Assisted Coiling of Wide-Necked Aneurysms in the Setting of Acute Subarachnoid Hemorrhage: Experience in 65 Patients. Neurosurgery, (2011).

308 van Rooij, W. J., Sluzewski, M. \& Peluso, J. P. Alarmingly high serious complication rate of stent-assisted coiling in unruptured intracranial aneurysms: the need for reflection and reconsideration. Stroke 41, e191; author reply e192, (2010).

309 Chang, S. D. \& Steinberg, G. K. Management of intracranial aneurysms. Vasc Med 3, 315-326, (1998).

310 Molyneux, A. \& Kerr, R. International Subarachnoid Aneurysm Trial. J Neurosurg 91, 352-353, (1999).

311 Molyneux, A. J. et al. International subarachnoid aneurysm trial (ISAT) of neurosurgical clipping versus endovascular coiling in 2143 patients with ruptured intracranial aneurysms: a randomised comparison of effects on survival, dependency, seizures, rebleeding, subgroups, and aneurysm occlusion. Lancet 366, 809817, (2005).

312 Barrow, D. L. Bad science ISAT: the impact on neurosurgical practice. Clin Neurosurg 51, 126-131, (2004).

313 Ausman, J. I. ISAT study: is coiling better than clipping? Surg Neurol 59, 162-165; discussion 165-173; author reply $173-165,(2003)$. 
314 Nichols, D. A., Brown, R. D., Jr. \& Meyer, F. B. Coils or clips in subarachnoid haemorrhage? Lancet 360, 12621263, (2002).

315 Leung, C. H., Poon, W. S. \& Yu, L. M. The ISAT trial. Lancet 361, 430-431; author reply 432, (2003).

316 Harbaugh, R. E., Heros, R. C. \& Hadley, M. N. More on ISAT. Lancet 361, 783-784; author reply 784, (2003).

317 Kirkpatrick, P. J., Kirollos, R. W., Higgins, N. \& Matta, B. Lessons to be learnt from the International Subarachnoid Haemorrhage Trial (ISAT). Br J Neurosurg 17, 5-7, (2003).

318 Ogilvy, C. S. Neurosurgical clipping versus endovascular coiling of patients with ruptured intracranial aneurysms. Stroke 34, 2540-2542, (2003).

319 Tait, M. J., Critchley, G. R. \& Norris, J. S. How much can be concluded from the International Subarachnoid Aneurysm Trial (ISAT)? Br J Neurosurg 21, 3-6, (2007).

320 Javadpour, M. ISAT: Will the results stand the test of time? Br J Neurosurg 21, 7-8, (2007).

321 Nichols, D. A. et al. Endovascular treatment of ruptured posterior circulation aneurysms using electrolytically detachable coils. J Neurosurg 87, 374-380, (1997).

322 Lusseveld, E. et al. Endovascular coiling versus neurosurgical clipping in patients with a ruptured basilar tip aneurysm. J Neurol Neurosurg Psychiatry 73, 591-593, (2002).

323 Molyneux, A. J. et al. Risk of recurrent subarachnoid haemorrhage, death, or dependence and standardised mortality ratios after clipping or coiling of an intracranial aneurysm in the International Subarachnoid Aneurysm Trial (ISAT): long-term follow-up. Lancet Neurol 8, 427-433, (2009).

324 Bakker, N. A., Metzemaekers, J. D., Groen, R. J., Mooij, J. J. \& Van Dijk, J. M. International subarachnoid aneurysm trial 2009: endovascular coiling of ruptured intracranial aneurysms has no significant advantage over neurosurgical clipping. Neurosurgery 66, 961-962, (2010).

325 Dorhout Mees, S. M., Kerr, R. S., Rinkel, G. J., Algra, A. \& Molyneux, A. J. Occurrence and impact of delayed cerebral ischemia after coiling and after clipping in the International Subarachnoid Aneurysm Trial (ISAT). J Neurol 259, 679-683, (2012).

326 Hart, Y. et al. Epilepsy after subarachnoid hemorrhage: the frequency of seizures after clip occlusion or coil embolization of a ruptured cerebral aneurysm: results from the International Subarachnoid Aneurysm Trial. J Neurosurg 115, 1159-1168, (2011).

327 Risselada, R. et al. Prediction of 60 day case-fatality after aneurysmal subarachnoid haemorrhage: results from the International Subarachnoid Aneurysm Trial (ISAT). Eur J Epidemiol 25, 261-266, (2010).

328 Rivero-Arias, $\mathrm{O}$. et al. The costs and prognostic characteristics of ischaemic neurological deficit due to subarachnoid haemorrhage in the United Kingdom. Evidence from the MRC International Subarachnoid Aneurysm Trial. J Neurol 256, 364-373, (2009).

329 Ryttlefors, M., Enblad, P., Kerr, R. S. \& Molyneux, A. J. International subarachnoid aneurysm trial of neurosurgical clipping versus endovascular coiling: subgroup analysis of 278 elderly patients. Stroke 39, 27202726, (2008).

330 Mitchell, P., Kerr, R., Mendelow, A. D. \& Molyneux, A. Could late rebleeding overturn the superiority of cranial aneurysm coil embolization over clip ligation seen in the International Subarachnoid Aneurysm Trial? J Neurosurg 108, 437-442, (2008).

331 Campi, A. et al. Retreatment of ruptured cerebral aneurysms in patients randomized by coiling or clipping in the International Subarachnoid Aneurysm Trial (ISAT). Stroke 38, 1538-1544, (2007).

332 van Dijk, J. M. et al. Surgical clipping as the preferred treatment for aneurysms of the middle cerebral artery. Acta Neurochir (Wien) 153, 2111-2117, (2011).

333 Carter, B. S. ISAT subgroups: is aneurysm clipping better for some patients? Neurosurgery 63, 14, (2008).

334 Lanzino, G., Fraser, K., Kanaan, Y. \& Wagenbach, A. Treatment of ruptured intracranial aneurysms since the International Subarachnoid Aneurysm Trial: practice utilizing clip ligation and coil embolization as individual or complementary therapies. J Neurosurg 104, 344-349, (2006).

335 Maurice-Williams, R. S. Aneurysm surgery after the International Subarachnoid Aneurysm Trial (ISAT). J Neurol Neurosurg Psychiatry 75, 807-808, (2004).

336 Crocker, M., Corns, R., Hampton, T., Deasy, N. \& Tolias, C. M. Vascular neurosurgery following the International Subarachnoid Aneurysm Trial: modern practice reflected by subspecialization. J Neurosurg 109, 992-997, (2008).

337 Qureshi, A. I. et al. Impact of International Subarachnoid Aneurysm Trial results on treatment of ruptured intracranial aneurysms in the United States. Clinical article. J Neurosurg 114, 834-841, (2011).

338 Lindsay, K. W. The impact of the International Subarachnoid Aneurysm Treatment Trial (ISAT) on neurosurgical practice. Acta Neurochir (Wien) 145, 97-99, (2003).

339 van den Berg, R., Rinkel, G. J. \& Vandertop, W. P. Treatment of ruptured intracranial aneurysms: implications of the ISAT on clipping versus coiling. Eur J Radiol 46, 172-177, (2003). 
340 Lubicz, B. et al. Endovascular treatment of intracranial aneurysms as the first therapeutic option. J Neuroradiol 34, 250-259, (2007).

341 Derdeyn, C. P. et al. The International Subarachnoid Aneurysm Trial (ISAT): a position statement from the Executive Committee of the American Society of Interventional and Therapeutic Neuroradiology and the American Society of Neuroradiology. AJNR Am J Neuroradiol 24, 1404-1408, (2003).

342 Gnanalingham, K. K., Apostolopoulos, V., Barazi, S. \& O'Neill, K. The impact of the international subarachnoid aneurysm trial (ISAT) on the management of aneurysmal subarachnoid haemorrhage in a neurosurgical unit in the UK. Clin Neurol Neurosurg 108, 117-123, (2006).

343 Smith, G. A., Dagostino, P., Maltenfort, M. G., Dumont, A. S. \& Ratliff, J. K. Geographic variation and regional trends in adoption of endovascular techniques for cerebral aneurysms. J Neurosurg 114, 1768-1777, (2011).

344 Bradac, O., Hide, S., Mendelow, D. A. \& Benes, V. Aneurysm treatment in Europe 2010: an internet survey. Acta Neurochir (Wien) 154, 971-978, (2012).

345 Grigoryan, M., Chaudhry, S. A., Hassan, A. E., Suri, F. K. \& Qureshi, A. I. Neurointerventional procedural volume per hospital in United States: implications for comprehensive stroke center designation. Stroke 43, 1309-1314, (2012).

346 van der Schaaf, I. et al. Endovascular coiling versus neurosurgical clipping for patients with aneurysmal subarachnoid haemorrhage. Cochrane Database Syst Rev, CD003085, (2005).

347 Raja, P. V. et al. Microsurgical clipping and endovascular coiling of intracranial aneurysms: a critical review of the literature. Neurosurgery 62, 1187-1202; discussion 1202-1183, (2008).

348 Alshekhlee, A. et al. Hospital mortality and complications of electively clipped or coiled unruptured intracranial aneurysm. Stroke 41, 1471-1476, (2010).

349 Scott, R. B. et al. Improved cognitive outcomes with endovascular coiling of ruptured intracranial aneurysms: neuropsychological outcomes from the International Subarachnoid Aneurysm Trial (ISAT). Stroke 41, 1743$1747,(2010)$.

350 Vieira, A. C. et al. Cognitive Changes in Patients with Aneurysmal Subarachnoid Hemorrhage Before and Early Posttreatment: Differences Between Surgical and Endovascular. World Neurosurg, (2011).

351 McDougall, C. G. et al. The Barrow Ruptured Aneurysm Trial. J Neurosurg 116, 135-144, (2012).

352 Lanzino, G. The Barrow Ruptured Aneurysm Trial. J Neurosurg 116, 133-134; discussion 134, (2012).

353 Guimond, J. G., Chagnon, P. M. \& Bojanowski, M. W. Clipping vs. coiling in acute aneurysmal subarachnoid haemorrhage: Should the patient's medical condition influence treatment modality? Neurochirurgie 58, 115119, (2012).

354 Fraser, J. F. et al. Principles in case-based aneurysm treatment: approaching complex lesions excluded by International Subarachnoid Aneurysm Trial (ISAT) criteria. World Neurosurg 75, 462-475, (2011).

355 Spiotta, A. M., Hui, F. K. \& Moskowitz, S. I. Trends in device-assisted aneurysm treatment at a single highvolume tertiary care center. J Neurointerv Surg, (2012).

356 Cognard, C., Pierot, L., Anxionnat, R. \& Ricolfi, F. Results of embolization used as the first treatment choice in a consecutive nonselected population of ruptured aneurysms: clinical results of the Clarity GDC study. Neurosurgery 69, 837-841; discussion 842, (2011).

357 Al-Shahi Salman, R. \& Sudlow, C. L. Case fatality after subarachnoid haemorrhage: declining, but why? Lancet Neurol 8, 598-599, (2009).

358 Karamanakos, P. N. et al. The impact of endovascular management on the outcome of aneurysmal subarachnoid hemorrhage in the elderly in eastern Finland. Acta Neurochir (Wien) 152, 1493-1502, (2010).

359 Shojima, M. \& Saito, N. Has the introduction of coiling improved therapeutic outcomes for subarachnoid hemorrhage? A report from the Japanese PRESAT Group. World Neurosurg 76, 394-395, (2011).

360 Brinjikji, W. et al. Better outcomes with treatment by coiling relative to clipping of unruptured intracranial aneurysms in the United States, 2001-2008. AJNR Am J Neuroradiol 32, 1071-1075, (2011).

361 Brinjikji, W., Rabinstein, A. A., Lanzino, G., Kallmes, D. F. \& Cloft, H. J. Patient outcomes are better for unruptured cerebral aneurysms treated at centers that preferentially treat with endovascular coiling: a study of the national inpatient sample 2001-2007. AJNR Am J Neuroradiol 32, 1065-1070, (2011).

362 Andaluz, N. \& Zuccarello, M. Recent trends in the treatment of cerebral aneurysms: analysis of a nationwide inpatient database. J Neurosurg 108, 1163-1169, (2008).

363 Bardach, N. S., Zhao, S., Gress, D. R., Lawton, M. T. \& Johnston, S. C. Association between subarachnoid hemorrhage outcomes and number of cases treated at California hospitals. Stroke 33, 1851-1856, (2002).

364 Cross, D. T., 3rd et al. Mortality rates after subarachnoid hemorrhage: variations according to hospital case volume in 18 states. J Neurosurg 99, 810-817, (2003).

365 Komotar, R. J., Zacharia, B. E., Mocco, J. \& Connolly, E. S., Jr. Controversies in the surgical treatment of ruptured intracranial aneurysms: the First Annual J. Lawrence Pool Memorial Research Symposium-- 
controversies in the management of cerebral aneurysms. Neurosurgery 62, 396-407; discussion 405-397, (2008).

366 Krishna, V. et al. Impact of integrated cerebrovascular program on outcomes in patients with intracranial aneurysms. J Neurointerv Surg, (2012).

367 Leake, C. B., Brinjikji, W., Kallmes, D. F. \& Cloft, H. J. Increasing treatment of ruptured cerebral aneurysms at high-volume centers in the United States. J Neurosurg 115, 1179-1183, (2011).

368 Vespa, P. \& Diringer, M. N. High-volume centers. Neurocrit Care 15, 369-372, (2011).

369 Starke, R. M. \& Connolly, E. S., Jr. Rebleeding after aneurysmal subarachnoid hemorrhage. Neurocrit Care 15, 241-246, (2011).

370 Ross, N., Hutchinson, P. J., Seeley, H. \& Kirkpatrick, P. J. Timing of surgery for supratentorial aneurysmal subarachnoid haemorrhage: report of a prospective study. J Neurol Neurosurg Psychiatry 72, 480-484, (2002).

371 Gu, D. Q., Zhang, X., Luo, B., Long, X. A. \& Duan, C. Z. Impact of ultra-early coiling on clinical outcome after aneurysmal subarachnoid hemorrhage in elderly patients. Acad Radiol 19, 3-7, (2012).

372 Wong, G. K. et al. Ultra-Early (within 24 Hours) Aneurysm Treatment After Subarachnoid Hemorrhage. World Neurosurg 77, 311-315, (2012).

373 Laidlaw, J. D. \& Siu, K. H. Ultra-early surgery for aneurysmal subarachnoid hemorrhage: outcomes for a consecutive series of 391 patients not selected by grade or age. J Neurosurg 97, 250-258; discussion 247-259, (2002).

374 Weil, A. G. \& Zhao, J. Z. Treatment of Ruptured Aneurysms: Earlier is Better. World Neurosurg 77, 263-265, (2012).

375 Phillips, T. J., Dowling, R. J., Yan, B., Laidlaw, J. D. \& Mitchell, P. J. Does treatment of ruptured intracranial aneurysms within 24 hours improve clinical outcome? Stroke 42, 1936-1945, (2011).

376 Gooderham, P. A. \& Steinberg, G. K. Reflections on the benefits and pitfalls of ultra-early aneurysm treatment after subarachnoid hemorrhage. World Neurosurg 77, 261-262, (2012).

377 Singh, V. et al. The learning curve for coil embolization of unruptured intracranial aneurysms. AJNR Am J Neuroradiol 23, 768-771, (2002).

378 Pierot, L., Spelle, L. \& Vitry, F. Similar safety in centers with low and high volumes of endovascular treatments for unruptured intracranial aneurysms: evaluation of the analysis of treatment by endovascular approach of nonruptured aneurysms study. AJNR Am J Neuroradiol 31, 1010-1014, (2010).

379 Standhardt, H. et al. Endovascular treatment of unruptured intracranial aneurysms with Guglielmi detachable coils: short- and long-term results of a single-centre series. Stroke 39, 899-904, (2008).

380 Bunc, G., Ravnik, J. \& Seruga, T. Treatment of ruptured intracranial aneurysms: report from a low-volume center. Wien Klin Wochenschr 118 Suppl 2, 6-11, (2006).

381 Lindekleiv, H. M. et al. Introduction of endovascular embolization for intracranial aneurysms in a low-volume institution. Acta Radiol 50, 555-561, (2009).

382 Lozano, A. M., Lazaro, R. C. \& Andres, J. M. [Endovascular treatment of cerebral aneurysms: review of a ten year experience]. Neurologia 24, 797-803, (2009).

383 Bonafe, A. et al. [Acutely ruptured intracranial aneurysms treated with GDC coils. Results from a single center over a period of 5 years]. Neurochirurgie 51, 155-164, (2005).

384 Friedman, J. A. et al. Guglielmi detachable coil treatment of ruptured saccular cerebral aneurysms: retrospective review of a 10-year single-center experience. AJNR Am J Neuroradiol 24, 526-533, (2003).

385 Consoli, A. et al. Five to ten years follow-up after coiling of 241 patients with acutely ruptured aneurysms. A single centre experience. Interv Neuroradiol 18, 5-13, (2012).

386 Klompenhouwer, E. G. et al. Single-center experience of surgical and endovascular treatment of ruptured intracranial aneurysms. AJNR Am J Neuroradiol 32, 570-575, (2011).

387 Sluzewski, M. \& van Rooij, W. J. Early rebleeding after coiling of ruptured cerebral aneurysms: incidence, morbidity, and risk factors. AJNR Am J Neuroradiol 26, 1739-1743, (2005).

388 Cho, Y. D. et al. Early recurrent hemorrhage after coil embolization in ruptured intracranial aneurysms. Neuroradiology, (2011).

389 Jartti, P. et al. Early rebleeding after coiling of ruptured intracranial aneurysms. Acta Radiol 51, 1043-1049, (2010).

390 Sluzewski, M., van Rooij, W. J., Beute, G. N. \& Nijssen, P. C. Late rebleeding of ruptured intracranial aneurysms treated with detachable coils. AJNR Am J Neuroradiol 26, 2542-2549, (2005).

391 CARAT-investigators. Rates of delayed rebleeding from intracranial aneurysms are low after surgical and endovascular treatment. Stroke 37, 1437-1442, (2006).

392 Johnston, S. C. et al. Predictors of rehemorrhage after treatment of ruptured intracranial aneurysms: the Cerebral Aneurysm Rerupture After Treatment (CARAT) study. Stroke 39, 120-125, (2008). 
393 Ries, T. et al. Long-term follow-up of cerebral aneurysms after endovascular therapy prediction and outcome of retreatment. AJNR Am J Neuroradiol 28, 1755-1761, (2007).

394 Ferns, S. P., Majoie, C. B., Sluzewski, M. \& van Rooij, W. J. Late adverse events in coiled ruptured aneurysms with incomplete occlusion at 6-month angiographic follow-up. AJNR Am J Neuroradiol 31, 464-469, (2010).

395 Slob, M. J., Sluzewski, M., van Rooij, W. J., Roks, G. \& Rinkel, G. J. Additional coiling of previously coiled cerebral aneurysms: clinical and angiographic results. AJNR Am J Neuroradiol 25, 1373-1376, (2004).

396 Renowden, S. A. et al. Retreatment of previously embolized cerebral aneurysms: the risk of further coil embolization does not negate the advantage of the initial embolization. AJNR Am J Neuroradiol 29, 14011404, (2008).

397 Masaryk, A. M., Frayne, R., Unal, O., Rappe, A. H. \& Strother, C. M. Utility of CT angiography and MR angiography for the follow-up of experimental aneurysms treated with stents or Guglielmi detachable coils. AJNR Am J Neuroradiol 21, 1523-1531, (2000).

398 Hartman, J., Nguyen, T., Larsen, D. \& Teitelbaum, G. P. MR artifacts, heat production, and ferromagnetism of Guglielmi detachable coils. AJNR Am J Neuroradiol 18, 497-501, (1997).

399 Shellock, F. G., Detrick, M. S. \& Brant-Zawadski, M. N. MR compatibility of Guglielmi detachable coils. Radiology 203, 568-570, (1997).

400 Hennemeyer, C. T., Wicklow, K., Feinberg, D. A. \& Derdeyn, C. P. In vitro evaluation of platinum Guglielmi detachable coils at 3 T with a porcine model: safety issues and artifacts. Radiology 219, 732-737, (2001).

401 Kahara, V. J. et al. MR angiography with three-dimensional time-of-flight and targeted maximum-intensityprojection reconstructions in the follow-up of intracranial aneurysms embolized with Guglielmi detachable coils. AJNR Am J Neuroradiol 20, 1470-1475, (1999).

402 Gonner, F. et al. MR angiography with ultrashort echo time in cerebral aneurysms treated with Guglielmi detachable coils. AJNR Am J Neuroradiol 19, 1324-1328, (1998).

403 Brunereau, L. et al. Prospective evaluation of time-of-flight MR angiography in the follow-up of intracranial saccular aneurysms treated with Guglielmi detachable coils. J Comput Assist Tomogr 23, 216-223, (1999).

404 Derdeyn, C. P., Graves, V. B., Turski, P. A., Masaryk, A. M. \& Strother, C. M. MR angiography of saccular aneurysms after treatment with Guglielmi detachable coils: preliminary experience. AJNR Am J Neuroradiol 18, 279-286, (1997).

405 Adams, W. M., Laitt, R. D. \& Jackson, A. Time of Flight 3D Magnetic Resonance Angiography in the Follow-up of Coiled Cerebral Aneurysms. Interv Neuroradiol 5, 127-137, (1999).

406 Boulin, A. \& Pierot, L. Follow-up of intracranial aneurysms treated with detachable coils: comparison of gadolinium-enhanced 3D time-of-flight MR angiography and digital subtraction angiography. Radiology 219, 108-113, (2001).

407 Leclerc, X., Navez, J. F., Gauvrit, J. Y., Lejeune, J. P. \& Pruvo, J. P. Aneurysms of the anterior communicating artery treated with Guglielmi detachable coils: follow-up with contrast-enhanced MR angiography. AJNR Am J Neuroradiol 23, 1121-1127, (2002).

408 Anzalone, N. et al. Three-dimensional time-of-flight MR angiography in the evaluation of intracranial aneurysms treated with Guglielmi detachable coils. AJNR Am J Neuroradiol 21, 746-752, (2000).

409 Cottier, J. P. et al. Intracranial aneurysms treated with Guglielmi detachable coils: is contrast material necessary in the follow-up with 3D time-of-flight MR angiography? AJNR Am J Neuroradiol 24, 1797-1803, (2003).

410 Farb, R. I. et al. Surveillance of intracranial aneurysms treated with detachable coils: a comparison of MRA techniques. Neuroradiology 47, 507-515, (2005)

411 Gauvrit, J. Y. et al. Intracranial aneurysms treated with Guglielmi detachable coils: imaging follow-up with contrast-enhanced MR angiography. Stroke 37, 1033-1037, (2006).

412 Lubicz, B., Levivier, M., Sadeghi, N., Emonts, P. \& Baleriaux, D. Immediate intracranial aneurysm occlusion after embolization with detachable coils: a comparison between MR angiography and intra-arterial digital subtraction angiography. J Neuroradiol 34, 190-197, (2007).

413 Pierot, L. et al. Follow-up of intracranial aneurysms selectively treated with coils: Prospective evaluation of contrast-enhanced MR angiography. AJNR Am J Neuroradiol 27, 744-749, (2006).

414 Kwee, T. C. \& Kwee, R. M. MR angiography in the follow-up of intracranial aneurysms treated with Guglielmi detachable coils: systematic review and meta-analysis. Neuroradiology 49, 703-713, (2007).

415 Weng, H. H., Jao, S. Y., Yang, C. Y. \& Tsai, Y. H. Meta-analysis on Diagnostic Accuracy of MR Angiography in the Follow-Up of Residual Intracranial Aneurysms Treated with Guglielmi Detachable Coils. Interv Neuroradiol 14 Suppl 2, 53-63, (2008).

416 Roy, D., Milot, G. \& Raymond, J. Endovascular treatment of unruptured aneurysms. Stroke 32, 1998-2004, (2001). 
417 Meyers, P. M. et al. Reporting standards for endovascular repair of saccular intracranial cerebral aneurysms. AJNR Am J Neuroradiol 31, E12-24, (2010).

418 Cloft, H. J., Kaufmann, T. \& Kallmes, D. F. Observer agreement in the assessment of endovascular aneurysm therapy and aneurysm recurrence. AJNR Am J Neuroradiol 28, 497-500, (2007).

419 Serafin, Z., Strzesniewski, P., Lasek, W. \& Beuth, W. Follow-up after embolization of ruptured intracranial aneurysms: A prospective comparison of two-dimensional digital subtraction angiography, three-dimensional digital subtraction angiography, and time-of-flight magnetic resonance angiography. Neuroradiology, (2012).

420 Schaafsma, J. D. et al. Intracranial aneurysms treated with coil placement: test characteristics of follow-up MR angiography--multicenter study. Radiology 256, 209-218, (2010).

421 Pierot, L., Portefaix, C., Boulin, A. \& Gauvrit, J. Y. Follow-up of coiled intracranial aneurysms: comparison of 3D time-of-flight and contrast-enhanced magnetic resonance angiography at $3 \mathrm{~T}$ in a large, prospective series. Eur Radiol, (2012).

422 Kaufmann, T. J. et al. A prospective trial of 3T and 1.5T time-of-flight and contrast-enhanced MR angiography in the follow-up of coiled intracranial aneurysms. AJNR Am J Neuroradiol 31, 912-918, (2010).

423 Shankar, J. J., Lum, C., Parikh, N. \& dos Santos, M. Long-term prospective follow-up of intracranial aneurysms treated with endovascular coiling using contrast-enhanced MR angiography. AJNR Am J Neuroradiol 31, 1211$1215,(2010)$.

424 Ferre, J. C. et al. Time-of-flight MR angiography at 3T versus digital subtraction angiography in the imaging follow-up of 51 intracranial aneurysms treated with coils. Eur J Radiol 72, 365-369, (2009).

425 Bakker, N. A. et al. Feasibility of magnetic resonance angiography (MRA) follow-up as the primary imaging modality after coiling of intracranial aneurysms. Acta Radiol 51, 226-232, (2010).

426 Lavoie, P. et al. Residual flow after cerebral aneurysm coil occlusion: diagnostic accuracy of MR angiography. Stroke 43, 740-746, (2012).

427 Daugherty, W. P. et al. Observer agreement regarding the necessity of retreatment of previously coiled recurrent cerebral aneurysms. AJNR Am J Neuroradiol 32, 566-569, (2011).

428 Agid, R., Willinsky, R. A., Lee, S. K., Terbrugge, K. G. \& Farb, R. I. Characterization of aneurysm remnants after endovascular treatment: contrast-enhanced MR angiography versus catheter digital subtraction angiography. AJNR Am J Neuroradiol 29, 1570-1574, (2008).

429 Anzalone, N. et al. Follow-up of coiled cerebral aneurysms at 3T: comparison of 3D time-of-flight MR angiography and contrast-enhanced MR angiography. AJNR Am J Neuroradiol 29, 1530-1536, (2008).

430 Anzalone, N. et al. Follow-up of coiled cerebral aneurysms: comparison of three-dimensional time-of-flight magnetic resonance angiography at 3 tesla with three-dimensional time-of-flight magnetic resonance angiography and contrast-enhanced magnetic resonance angiography at 1.5 Tesla. Invest Radiol 43, 559-567, (2008).

431 Wallace, R. C., Karis, J. P., Partovi, S. \& Fiorella, D. Noninvasive imaging of treated cerebral aneurysms, part I: MR angiographic follow-up of coiled aneurysms. AJNR Am J Neuroradiol 28, 1001-1008, (2007).

432 Wikstrom, J., Ronne-Engstrom, E., Gal, G., Enblad, P. \& Tovi, M. Three-dimensional time-of-flight (3D TOF) magnetic resonance angiography (MRA) and contrast-enhanced MRA of intracranial aneurysms treated with platinum coils. Acta Radiol 49, 190-196, (2008).

433 Nakiri, G. S. et al. A comparison between magnetic resonance angiography at 3 Teslas (time-of-flight and contrast-enhanced) and flat-panel digital subtraction angiography in the assessment of embolized brain aneurysms. Clinics (Sao Paulo) 66, 641-648, (2011).

434 Sprengers, M. E. et al. Evaluation of the occlusion status of coiled intracranial aneurysms with MR angiography at 3T: is contrast enhancement necessary? AJNR Am J Neuroradiol 30, 1665-1671, (2009).

435 Ramgren, B. et al. Follow-up of intracranial aneurysms treated with detachable coils: comparison of 3D inflow MRA at 3T and 1.5T and contrast-enhanced MRA at 3T with DSA. Neuroradiology 50, 947-954, (2008).

436 Agid, R., Schaaf, M. \& Farb, R. CE-MRA for Follow-up of Aneurysms Post Stent-Assisted Coiling. Interv Neuroradiol 18, 275-283, (2012).

437 Lovblad, K. O. et al. Intracranial aneurysm stenting: follow-up with MR angiography. J Magn Reson Imaging 24, 418-422, (2006)

438 Takayama, K. et al. Usefulness of contrast-enhanced magnetic resonance angiography for follow-up of coil embolization with the enterprise stent for cerebral aneurysms. J Comput Assist Tomogr 35, 568-572, (2011).

439 Lubicz, B., Neugroschl, C., Collignon, L., Francois, O. \& Baleriaux, D. Is digital substraction angiography still needed for the follow-up of intracranial aneurysms treated by embolisation with detachable coils? Neuroradiology 50, 841-848, (2008).

440 Majoie, C. B. et al. MR angiography at $3 T$ versus digital subtraction angiography in the follow-up of intracranial aneurysms treated with detachable coils. AJNR Am J Neuroradiol 26, 1349-1356, (2005). 
441 Pierot, L., Portefaix, C., Gauvrit, J. Y. \& Boulin, A. Follow-Up of Coiled Intracranial Aneurysms: Comparison of 3D Time-of-Flight MR Angiography at 3T and 1.5T in a Large Prospective Series. AJNR Am J Neuroradiol, (2012).

$442 \mathrm{Lu}, \mathrm{H}$. et al. Routine clinical brain MRI sequences for use at 3.0 Tesla. J Magn Reson Imaging 22, 13-22, (2005).

443 Buhk, J. H., Kallenberg, K., Mohr, A., Dechent, P. \& Knauth, M. No advantage of time-of-flight magnetic resonance angiography at 3 Tesla compared to 1.5 Tesla in the follow-up after endovascular treatment of cerebral aneurysms. Neuroradiology 50, 855-861, (2008).

444 Tailor, J. et al. Stability of ruptured intracranial aneurysms treated with detachable coils: is delayed follow-up angiography warranted? Br J Neurosurg 24, 405-409, (2010).

445 van Rooij, W. J. \& Sluzewski, M. Opinion: imaging follow-up after coiling of intracranial aneurysms. AJNR Am J Neuroradiol 30, 1646-1648, (2009).

446 Raymond, J. et al. Long-term angiographic recurrences after selective endovascular treatment of aneurysms with detachable coils. Stroke 34, 1398-1403, (2003).

447 Cognard, C. et al. Long-term angiographic follow-up of 169 intracranial berry aneurysms occluded with detachable coils. Radiology 212, 348-356, (1999).

448 Piotin, M. et al. Intracranial aneurysms: treatment with bare platinum coils--aneurysm packing, complex coils, and angiographic recurrence. Radiology 243, 500-508, (2007).

449 Sluzewski, M., van Rooij, W. J., Rinkel, G. J. \& Wijnalda, D. Endovascular treatment of ruptured intracranial aneurysms with detachable coils: long-term clinical and serial angiographic results. Radiology 227, 720-724, (2003).

450 Schaafsma, J. D. et al. Long-term recurrent subarachnoid hemorrhage after adequate coiling versus clipping of ruptured intracranial aneurysms. Stroke 40, 1758-1763, (2009).

451 Byrne, J. V., Sohn, M. J., Molyneux, A. J. \& Chir, B. Five-year experience in using coil embolization for ruptured intracranial aneurysms: outcomes and incidence of late rebleeding. J Neurosurg 90, 656-663, (1999).

452 Murayama, Y. et al. Guglielmi detachable coil embolization of cerebral aneurysms: 11 years' experience. J Neurosurg 98, 959-966, (2003).

453 Sprengers, M. E. et al. Stability of intracranial aneurysms adequately occluded 6 months after coiling: a 3T MR angiography multicenter long-term follow-up study. AJNR Am J Neuroradiol 29, 1768-1774, (2008).

454 Ferns, S. P. et al. Late reopening of adequately coiled intracranial aneurysms: frequency and risk factors in 400 patients with 440 aneurysms. Stroke 42, 1331-1337, (2011).

455 Bruneau, M. et al. Long-term follow-up survey reveals a high yield, up to $30 \%$ of patients presenting newly detected aneurysms more than 10 years after ruptured intracranial aneurysms clipping. Neurosurg Rev 34, 485-496, (2011).

456 Plowman, R. S., Clarke, A., Clarke, M. \& Byrne, J. V. Sixteen-year single-surgeon experience with coil embolization for ruptured intracranial aneurysms: recurrence rates and incidence of late rebleeding. Clinical article. J Neurosurg 114, 863-874, (2011).

457 Sprengers, M. E. et al. MR angiography follow-up 5 years after coiling: frequency of new aneurysms and enlargement of untreated aneurysms. AJNR Am J Neuroradiol 30, 303-307, (2009).

458 Ferns, S. P. et al. De novo aneurysm formation and growth of untreated aneurysms: a 5-year MRA follow-up in a large cohort of patients with coiled aneurysms and review of the literature. Stroke 42, 313-318, (2011).

459 Juvela, S., Porras, M. \& Poussa, K. Natural history of unruptured intracranial aneurysms: probability of and risk factors for aneurysm rupture. J Neurosurg 108, 1052-1060, (2008).

460 Miller, C. A., Hill, S. A. \& Hunt, W. E. "De novo" aneurysms. A clinical review. Surg Neurol 24, 173-180, (1985).

461 Ferns, S. P., Nieuwkerk, P. T., van Rooij, W. J., Rinkel, G. J. \& Majoie, C. B. Long-term MRA follow-up after coiling of intracranial aneurysms: impact on mood and anxiety. Neuroradiology 53, 343-348, (2011).

462 Van den Bruel, A., Cleemput, I., Aertgeerts, B., Ramaekers, D. \& Buntinx, F. The evaluation of diagnostic tests: evidence on technical and diagnostic accuracy, impact on patient outcome and cost-effectiveness is needed. J Clin Epidemiol 60, 1116-1122, (2007).

463 Schaafsma, J. D., van der Graaf, Y., Rinkel, G. J. \& Buskens, E. Decision analysis to complete diagnostic research by closing the gap between test characteristics and cost-effectiveness. J Clin Epidemiol 62, 12481252, (2009).

464 Gazelle, G. S., McMahon, P. M., Siebert, U. \& Beinfeld, M. T. Cost-effectiveness analysis in the assessment of diagnostic imaging technologies. Radiology 235, 361-370, (2005).

465 Fryback, D. G. \& Thornbury, J. R. The efficacy of diagnostic imaging. Med Decis Making 11, 88-94, (1991).

466 Sackett, D. L. \& Haynes, R. B. The architecture of diagnostic research. BMJ 324, 539-541, (2002).

467 Bala, M. V. \& Mauskopf, J. A. Optimal assignment of treatments to health states using a Markov decision model: an introduction to basic concepts. Pharmacoeconomics 24, 345-354, (2006). 
468 Briggs, A. \& Sculpher, M. An introduction to Markov modelling for economic evaluation. Pharmacoeconomics 13, 397-409, (1998).

469 Sonnenberg, F. A. \& Beck, J. R. Markov models in medical decision making: a practical guide. Med Decis Making 13, 322-338, (1993).

470 Rouder, J. N. \& Lu, J. An introduction to Bayesian hierarchical models with an application in the theory of signal detection. Psychon Bull Rev 12, 573-604, (2005).

471 Malmivaara, K., Juvela, S., Hernesniemi, J., Lappalainen, J. \& Siironen, J. Health-related quality of life and costeffectiveness of treatment in subarachnoid haemorrhage. Eur J Neurol, (2012).

472 Greving, J. P., Rinkel, G. J., Buskens, E. \& Algra, A. Cost-effectiveness of preventive treatment of intracranial aneurysms: new data and uncertainties. Neurology 73, 258-265, (2009).

473 Koffijberg, H., Buskens, E. \& Rinkel, G. J. Aneurysm occlusion in elderly patients with aneurysmal subarachnoid haemorrhage: a cost-utility analysis. J Neurol Neurosurg Psychiatry 82, 718-727, (2011).

474 Takao, H., Nojo, T. \& Ohtomo, K. Cost-effectiveness of treatment of unruptured intracranial aneurysms in patients with a history of subarachnoid hemorrhage. Acad Radiol 15, 1126-1132, (2008).

475 Takao, H. \& Nojo, T. Treatment of unruptured intracranial aneurysms: decision and cost-effectiveness analysis. Radiology 244, 755-766, (2007).

476 Johnston, S. C., Gress, D. R. \& Kahn, J. G. Which unruptured cerebral aneurysms should be treated? A costutility analysis. Neurology 52, 1806-1815, (1999).

477 Ballet, A. C. et al. [Neurosurgical and endovascular treatment of intracranial aneurysms: a cost analysis of two different strategies at the University Hospital of Bordeaux (France)]. Neurochirurgie 48, 419-425, (2002).

478 Brinjikji, W., Kallmes, D. F., Lanzino, G. \& Cloft, H. J. Hospitalization costs for endovascular and surgical treatment of unruptured cerebral aneurysms in the United States are substantially higher than medicare payments. AJNR Am J Neuroradiol 33, 49-51, (2012).

479 Hoh, B. L., Chi, Y. Y., Dermott, M. A., Lipori, P. J. \& Lewis, S. B. The effect of coiling versus clipping of ruptured and unruptured cerebral aneurysms on length of stay, hospital cost, hospital reimbursement, and surgeon reimbursement at the university of Florida. Neurosurgery 64, 614-619; discussion 619-621, (2009).

480 Javadpour, M. et al. Analysis of cost related to clinical and angiographic outcomes of aneurysm patients enrolled in the international subarachnoid aneurysm trial in a North American setting. Neurosurgery 56, 886894; discussion 886-894, (2005).

481 Lawson, M. F. \& Hoh, B. L. Clipping versus coiling: the total hospital cost of aneurysm treatment. World Neurosurg 73, 430-431, (2010).

482 Maud, A. et al. Cost-effectiveness analysis of endovascular versus neurosurgical treatment for ruptured intracranial aneurysms in the United States. J Neurosurg 110, 880-886, (2009).

483 Wolstenholme, J. et al. Treatment pathways, resource use, and costs of endovascular coiling versus surgical clipping after aSAH. Stroke 39, 111-119, (2008).

484 Zubair Tahir, M., Enam, S. A., Pervez Ali, R., Bhatti, A. \& ul Haq, T. Cost-effectiveness of clipping vs coiling of intracranial aneurysms after subarachnoid hemorrhage in a developing country--a prospective study. Surg Neurol 72, 355-360; discussion 360-351, (2009).

485 Halkes, P. H., Wermer, M. J., Rinkel, G. J. \& Buskens, E. Direct costs of surgical clipping and endovascular coiling of unruptured intracranial aneurysms. Cerebrovasc Dis 22, 40-45, (2006).

486 Bairstow, P., Dodgson, A., Linto, J. \& Khangure, M. Comparison of cost and outcome of endovascular and neurosurgical procedures in the treatment of ruptured intracranial aneurysms. Australas Radiol 46, 249-251, (2002).

487 Bardach, N. S. et al. Regionalization of treatment for subarachnoid hemorrhage: a cost-utility analysis. Circulation 109, 2207-2212, (2004).

488 Bor, A. S., Koffijberg, H., Wermer, M. J. \& Rinkel, G. J. Optimal screening strategy for familial intracranial aneurysms: a cost-effectiveness analysis. Neurology 74, 1671-1679, (2010).

489 Wermer, M. J., Koffijberg, H. \& van der Schaaf, I. C. Effectiveness and costs of screening for aneurysms every 5 years after subarachnoid hemorrhage. Neurology 70, 2053-2062, (2008).

490 Schaafsma, J. D. et al. Cost-effectiveness of magnetic resonance angiography versus intra-arterial digital subtraction angiography to follow-up patients with coiled intracranial aneurysms. Stroke 41, 1736-1742, (2010).

491 Bossuyt, P. M. STARD statement: still room for improvement in the reporting of diagnostic accuracy studies. Radiology 248, 713-714, (2008).

492 Bossuyt, P. M. et al. Towards complete and accurate reporting of studies of diagnostic accuracy: the STARD initiative. AJR Am J Roentgenol 181, 51-55, (2003).

493 Hunink, M. G. \& Krestin, G. P. Study design for concurrent development, assessment, and implementation of new diagnostic imaging technology. Radiology 222, 604-614, (2002). 


\section{Chapter 2}

Performance of Contrast Enhanced Magnetic Resonance Angiography in patients presenting with Subarachnoid Hemorrhage. Part 1: detection of aneurysms

W.H. van Zwam

P.A.M. Hofman

A.G. Kessels

T.K. Oei

R.J Heijboer

J.T. Wilmink

Published in the European Journal of Minimally Invasive Neurological Therapies: EJMINT Original Article, 2012: 1240000078 (4 $4^{\text {th }}$ October 2012) 


\section{Abstract}

Background and purpose: Most centers use computed tomographic angiography (CTA) as the primary diagnostic tool in patients presenting with a subarachnoid hemorrhage (SAH). Contrast enhanced magnetic resonance angiography (CEMRA) might be an alternative technique.

In this study the ability to detect cerebral aneurysms with CEMRA in patients presenting with a SAH is investigated and compared with CTA.

Methods: In 75 consecutive patients, two experienced neuroradiologists evaluated CEMRA and CTA images. Digital Subtraction Angiography (DSA) served as standard of reference. The diagnostic performance in detection of aneurysms, in terms of sensitivity, specificity and interobserver variability, was calculated for both modalities and a comparison was made between the two.

Results: No significant difference was found between the two modalities for the detection of aneurysms: sensitivities for the two observers were 96.6 and 93.8 respectively for CEMRA and 90.8 and 92.3 for CTA; specificities were 77.8 and 88.9 for CEMRA and 94.4 in both observers for CTA. Kappa values for interobserver variability were 0.82 for CEMRA and 0.85 for CTA.

Conclusion: The diagnostic accuracy of CEMRA and CTA in the work-up of patients presenting with a $\mathrm{SAH}$ does not differ significantly. The choice to use either CEMRA or CTA depends on preference or availability. 


\section{Introduction}

Magnetic resonance angiography (MRA) has some advantages over computed tomographic angiography (CTA): no harmful ionizing radiation or iodinated contrast agent and no image degradation arising from vascular calcifications and surrounding bony structures. Therefore, MRA might be a preferable diagnostic tool in the detection of intracranial aneurysms in patients presenting with a subarachnoid hemorrhage (SAH).

Few direct comparisons between the two modalities have been published. White et al. described the performance of CTA and MRA ten years ago in a meta-analysis. ${ }^{1}$ The results of their review did not allow direct comparison between CTA and MRA because few studies included patients who underwent both CTA and MRA.

In a prospective study White et al $^{2}$ performed CTA as well as MRA in 142 patients. The diagnostic performance of both modalities did not differ significantly and was not better than in the review performed by the same group. The sensitivity was low, especially for detection of small aneurysms: $57 \%$ for CTA and 35\% for MRA for aneurysms smaller than $5 \mathrm{~mm}$. It was expected that future improvements in scan technique would lead to better performance, and that the addition of contrast enhanced MRA especially would contribute to this improved performance.

All MRA studies in the review as well as their own study used non-contrast-enhanced sequences such as time-of-flight (TOF)-MRA or phase contrast (PC)-MRA.

First-pass or contrast enhanced magnetic resonance angiography (CEMRA) has shorter acquisition times than flow dependent MRA sequences and does not suffer from signal loss due to turbulent or slow flow or as a result from spin saturation in larger scan volumes. ${ }^{3-5}$ It might therefore be advantageous in the depiction of intracranial aneurysms.

Only a few studies have been performed to evaluate the diagnostic performance of CEMRA in the detection of cerebral aneurysms, ${ }^{3-8}$ involving only small numbers of patients (4-41 patients) and aneurysms (4-25 aneurysms). The largest series was published by Nael et al ${ }^{7}$ with 25 aneurysms in 41 patients. In this study CEMRA was compared with CTA for the detection and characterization of cerebral aneurysms, without digital subtraction angiography (DSA) as the reference standard. Therefore, the diagnostic accuracy of the two techniques could not be assessed. The performance of both techniques was excellent in terms of interobserver agreement and of correlation between the two modalities. In the smaller studies of Metens et $\mathrm{al}^{4}$, Suzuki et $\mathrm{al}^{8}$ and Unlu et $\mathrm{al}^{5}$, both CEMRA and DSA were performed. All aneurysms in these three studies, except for one small $(2 \mathrm{~mm})$ aneurysm, ${ }^{5}$ were detected by CEMRA. All three groups concluded that CEMRA performed better than TOF-MRA. Specificity could not be defined in these studies because only patients harboring at least one aneurysm were included, so no false positive scores were possible.

In view of the sparse data about the performance of CEMRA in the detection of cerebral aneurysms in patients presenting with a SAH, and the lack of data about the compariitive accuracy of CEMRA and CTA, we undertook a prospective study to assess the accuracy of CEMRA in comparison with CTA. We recognize that diagnostic accuracy is not the only factor determining the practical utility of a technique in a demanding clinical situation. Because catheter DSA is an integral part of the coiling procedure, and 
still the standard of reference for the detection of cerebral aneurysms, DSA is used as gold standard in our study.

If CEMRA were to perform better than CTA in the detection of intracranial aneurysms this would be an argument to add CEMRA to the work-up protocol of patients presenting with a SAH.

\section{Materials and Methods}

\section{Study design}

Patients admitted with the diagnosis of a non-traumatic SAH between 2004 and 2006 were included in the study. All patients underwent CTA for detection of a possible cerebral aneurysm. Diagnostic catheter DSA was performed as an additional diagnostic procedure in case of an initially negative CTA study, or where there was uncertainty about the preferred treatment strategy. Moreover, DSA is an essential part of the endovascular coiling procedure (see flow chart in figure 1). If endovascular treatment was not considered feasible on the basis of the CTA images the patient was referred to the neurosurgeon. Diagnostic DSA was performed at the request of the neurosurgeon if more detailed information was required about the aneurysm and its surrounding arterial branches.

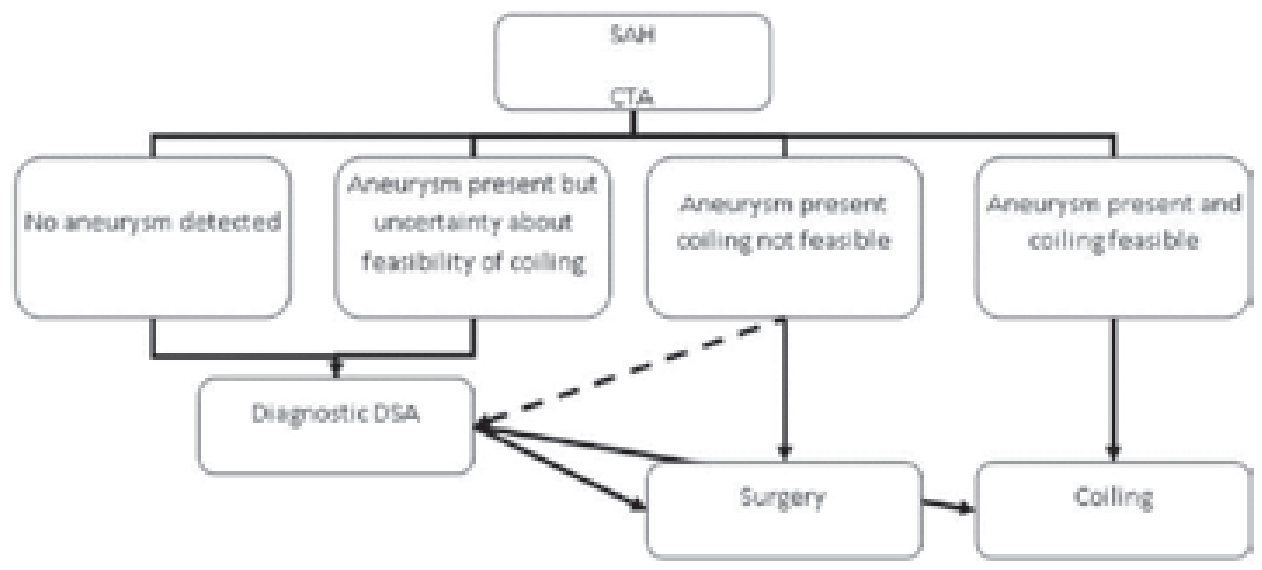

Figure 1. Flow chart of the work up of a patient presenting with a SAH.

Within 48 hours of CTA, patients meeting the inclusion criteria for the study underwent an additional CEMRA study before endovascular or surgical treatment. Inclusion of the patient was only allowed, however, if the performance of the additional CEMRA study would not delay treatment. Informed consent was obtained from all patients or, in unresponsive patients, from a legally responsible person. DSA served as standard of reference in included patients.

The Institutional Review Board of our center approved the study. Approval was also given by the national center for patient related research (CCMO) because of the anticipated inclusion of patients unable to give informed consent. 


\section{Patients}

All consecutive adult patients presenting with the diagnosis of a non-traumatic SAH were eligible to enter the study. The diagnosis SAH was established by CT or lumbar puncture.

Exclusion criteria were as follows: patients in whom there was a contraindication for MRI or in whom no further treatment was considered. A poor clinical condition was no contraindication for inclusion, but if no reasonable chance of survival was expected by the treating physician, then no further diagnostic or treatment procedures would be undertaken and the patient would not be included in the study.

\section{Techniques}

CTA:

CTA was performed on a two-slice (Elscint Dual; Elscint, Haifa, Israel) or on a four-slice multidetectorrow spiral CT scanner (Toshiba Aquilion; Toshiba, Tokyo, Japan). Scan parameters for the two-slice scanner were: 120 kVp, 250 mAs, collimation width 1,3 mm, pitch 0,7; FOV $250 \mathrm{~mm}$, matrix 340; ${ }^{2}$ and for the four-slice scanner: $120 \mathrm{kV}, 200 \mathrm{mAs}$, collimation width 0,9 mm, pitch 0,67; FOV 230mm, matrix $512{ }^{2}$ Reconstruction on both scanners to $0,5 \mathrm{~mm}$ slices. Contrast: iobitridol $350 \mathrm{mg} / \mathrm{ml}$ (Xenetix ${ }^{\circledR}$, Guerbet, Villepinte, France), IV at $4 \mathrm{ml} / \mathrm{s}$, total volume $125 \mathrm{ml}$, flushed with $40 \mathrm{ml} \mathrm{NaCl}$ 0,9\% at $4 \mathrm{ml} / \mathrm{s}$. For the Elscint scanner a test contrast bolus of $20 \mathrm{ml}$ was injected to determine the optimal interval between the start of contrast injection and the start of the scan. For the Toshiba scanner a detection slice through the internal carotid arteries was made; scanning began upon arrival of contrast in this slice. Scan direction in both scanners was from caudal to cranial.

In most cases a semi-automatic bone subtraction method, Matched Mask Bone Elimination (MMBE), was used. In this method a low dose-mask is acquired of the bony skull, after which the bone-containing voxels are extracted from the post-contrast images, using a computer algorithm that compensates for movements between the scans. ${ }^{9,10}$ In cases where the patient was too restless to undergo a mask CT scan before the contrast scan or in cases where the contrast scan could not be matched with the mask due to excessive movement between the scans, the contrast scan was evaluated using manual segmentation to remove the bony structures.

MRA:

MRA was performed on a 1.5 Tesla Philips scanner using a dedicated head coil (Intera; Philips, Best, The Netherlands). The scan protocol included an ultra-short first-pass CEMRA with concentric k-space filling. The scan parameters were: parallel imaging (SENSE, factor 2), TR 5.4 / TE 1.68 ms, flip angle 35 deg, FOV $256 \mathrm{~mm}$ (rectangular FOV 65\%), matrix 512, slice thickness $0.4 \mathrm{~mm}$, coronal orientation (parallel to basilar artery), one stack, 120 slices. Voxel size $0.5 \times 0.8 \times 0.4 \mathrm{~mm}$. Contrast: gadopentetate dimeglumine (Magnevist ${ }^{\circledR}$, Bayer Schering Pharma, Leverkusen, Germany) $35 \mathrm{ml} \mathrm{IV}, 3 \mathrm{ml} / \mathrm{s}$ (2 ml for a timing sequence and $33 \mathrm{ml}$ for the CE-MRA sequence), flushed with $25 \mathrm{ml} \mathrm{NaCl} \mathrm{0,9 \%} \mathrm{at} 3 \mathrm{ml} / \mathrm{s}$.

\section{DSA:}

All patients underwent conventional catheter DSA (Integris; Philips Medical Systems, Best, the Netherlands). All four feeding arteries to the brain were catheterized and imaged, except for two patients in whom, due to patient unrest, only the vessel which contained the suspected aneurysm was 
catheterized. A 4 or 5F catheter system was used for diagnostic DSA and a 6F system in cases of anticipated immediate endovascular treatment. Automatic contrast injections were performed by power injector (Medrad Inc., Warrendale PA, USA), of $9 \mathrm{ml}$ iobitridol $350 \mathrm{mg} / \mathrm{ml}$ (Xenetix ${ }^{\circledR}$, Guerbet, Villepinte, France) at $5 \mathrm{ml} / \mathrm{s}$ for the carotid arteries and $8 \mathrm{ml}$ at $4 \mathrm{ml} / \mathrm{s}$ for the vertebral arteries. Internal carotid arteries were imaged in antero-posterior, lateral and oblique projections and vertebrobasilar arteries in antero-posterior and lateral projections. Additional angiographic projections were obtained, if necessary, of the vessels harboring an aneurysm, for better visualization of the aneurysm, its neck and its surrounding arteries.

\section{Image interpretation and statistical analysis}

The CTA and MRA studies were retrospectively evaluated by two independent observers on a dedicated workstation (Vitrea; Vital Images, Minnetonka, Minnesota, USA). Observers were able to use source images and interactively view volume rendered or maximum intensity projection (MIP) reconstructions. Observers evaluated both modalities in random order, with an interval of at least 12 months between each modality. The DSA images were analyzed by two independent observers; discordant results were settled by a third observer.

Scoring criteria included: quality of images, presence of aneurysm, size of aneurysm and diagnostic confidence. Quality of images and confidence in scoring were rated on a three point scale: 'poor', 'moderate' and 'good'. Size was given in millimeters in two directions.

Sensitivity and specificity for the detection of aneurysms were calculated and compared with McNemar's test. ROC curves for the two modalities and two observers were calculated and the areas under the curve were compared. For ROC curve calculations the confidence scoring was transferred to a negative value if no aneurysm was found. The resultant values were used for cut-off points.

Cohen's Kappa was calculated for interobserver agreement.

\section{Results}

During an approximate three-year period, a total of 189 patients entered our hospital with a SAH diagnosis. Of these 189 patients 114 (60.3\%) could not be included in the study for reasons set out in Table 1.

Table 1. Reason for exclusion

\begin{tabular}{|lr|}
\hline & N \\
\hline - Not enough time between CTA and treatment to perform MRA & 57 \\
- Declined additional MRA & 22 \\
- Condition too poor to plan further treatment & 11 \\
- Contra-indication for MRI & 10 \\
- Patient distress, MRA not possible & 6 \\
- Died before MRA & 4 \\
- No informed consent before treatment (no MRA made) & 2 \\
- Died before DSA and treatment, after MRA & 1 \\
- Transferred to other hospital for treatment & 1 \\
\hline Total excluded & $\mathbf{1 1 4}$ \\
\hline
\end{tabular}


The characteristics of the total group of 189 eligible and of the 75 (39.7\%) included patients are given in Table 2. The parameters of the included patients did not differ significantly from the total group of eligible patients. All patients included in the study underwent DSA as part of their endovascular treatment or during diagnostic work-up, and these DSA studies were used as the standard of reference.

Table 2. Characteristics of the total group of eligible patients and the included patients.

\begin{tabular}{|l|l|l|l|}
\hline & Total eligible pt & Included pt & P-value \\
\hline $\mathrm{N}$ & 189 & 75 & \\
\hline Female (\%) & $138(73)$ & $54 \quad(72)$ & 0.88 \\
\hline Mean age & 54.5 & 54.0 & \\
\hline SD age & 13.9 & 15.1 & \\
\hline Pt without aneurysm (\%) & $40(21.2)$ & $18 \quad(24.0)$ & 0.62 \\
\hline Total aneurysms & 189 & 65 & \\
\hline
\end{tabular}

The quality of CTA images was rated as good in 62.7\% (47/75) by Observer 1 and 72\% (54/75) by Observer 2, and that of the CEMRA images as good in $82.7 \%$ (62/75) by Observer 1 and 86.7\% (65/75) by Observer 2. The confidence rating of their final scoring per aneurysm (and per patient with no aneurysm) was 'good' in respectively $84.3 \%$ (70/83, Observer 1 ) and 91.6\% (76/83, Observer 2) for CTA; and $88.0 \%$ (73/83, Observer 1$)$ and $94 \%$ (78/83, Observer 2) for CEMRA.

There were 18 patients without an aneurysm. Fifty patients harbored one aneurysm, six patients had two aneurysms and one patient harbored three aneurysms, making a total of 65 aneurysms. Locations of the aneurysms are given in Table 3.

Table 3. Location of the aneurysms

\begin{tabular}{|l|l|}
\hline $\begin{array}{l}|c| \\
\text { Internal carotid artery, including posterior communicating artery, carotid tip and } \\
\text { ophtalmic artery }\end{array}$ & 14 \\
\hline Anterior cerebral artery, including anterior communicating artery & 19 \\
\hline Middle cerebral artery & 20 \\
\hline Vertebrobasilar complex, (basilar tip) & $12(8)$ \\
\hline
\end{tabular}

Scoring results of the two observers for CTA and CEMRA are given in 2x2-tables (Tables $4 \mathrm{a}$ and $4 \mathrm{~b}$ ).

Table 4a. $2 \times 2$ table of both observers assessing the CTA images.

\begin{tabular}{|c|c|c|c|c|c|c|}
\hline & & & \multicolumn{4}{|c|}{ CTA } \\
\hline & & & \multicolumn{2}{|c|}{ Observer 1} & \multicolumn{2}{|c|}{ Observer 2} \\
\hline & & & - & + & - & + \\
\hline \multirow{2}{*}{ DSA } & $18^{a}$ & - & 17 & 1 & 17 & 1 \\
\hline & $65^{b}$ & + & 6 & 59 & 5 & 60 \\
\hline & & Total & 23 & 60 & 22 & 61 \\
\hline
\end{tabular}

\footnotetext{
${ }^{a}$ Number of patients without an aneurysm. ${ }^{b}$ Total number of aneurysms.
} 
Table 4b. $2 \times 2$ table of both observers assessing the MRA images.

\begin{tabular}{|c|c|c|c|c|c|c|}
\hline & & & \multicolumn{4}{|c|}{ MRA } \\
\hline & & & \multicolumn{2}{|c|}{ Observer 1} & \multicolumn{2}{|c|}{ Observer 2} \\
\hline & & & - & + & - & + \\
\hline \multirow{3}{*}{ DSA } & $18^{a}$ & - & 14 & 4 & 16 & 2 \\
\hline & $65^{b}$ & + & 2 & 63 & 4 & 61 \\
\hline & & Total & 16 & 67 & 20 & 63 \\
\hline
\end{tabular}

${ }^{a}$ Number of patients without an aneurysm. ${ }^{b}$ Total number of aneurysms.

The sensitivity and specificity for the detection of an aneurysm by CTA and CEMRA with their 95\% Confidence Intervals ( $\mathrm{Cl}^{\prime} \mathrm{s}$ ) are given in Table 5. There was no significant difference between the sensitivity and specificity of CTA and CEMRA tested with McNemar's test. Cohen's Kappa inter-observer agreement in rating CEMRA and CTA was 0.82 and 0.85 respectively for the detection of an aneurysm. ROC curves are given in Figure 2. The areas under the curve $(95 \% \mathrm{Cl}$ ) are $0.94(0.90-0.99)$ and 0.96 (0.93-1) for CTA and 0.89 (0.79-0.99) and 0.91 (0.83-0.99) for CEMRA. The areas of CTA and CEMRA are not significantly different ( $p=0.30$ for Observer 1 and $p=0.24$ for Observer 2 ).

Table 5. Sensitivity and specificity $(95 \% \mathrm{Cl})$ of CTA and CEMRA for the detection of aneurysms.

\begin{tabular}{|c|c|c|c|}
\hline & & CTA & CEMRA \\
\hline \multirow{2}{*}{ Sensitivity } & Obs 1 & $90.8(81.0-96.5)$ & $96.9(89.3-99.6)$ \\
& Obs 2 & $92.3(83.0-97.5)$ & $93.8(85.0-98.3)$ \\
\hline \multirow{2}{*}{ Specificity } & Obs 1 & $94.4(72.7-99.9)$ & $77.8(52.4-93.6)$ \\
& Obs 2 & $94.4(72.7-99.9)$ & $88.9(65.3-98.6)$ \\
\hline
\end{tabular}

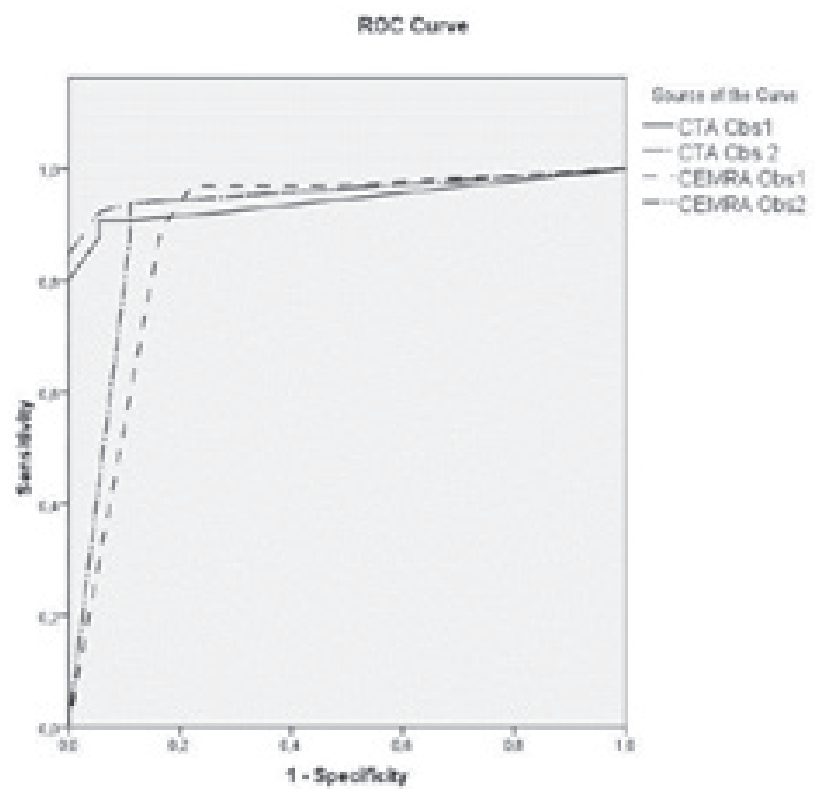

Figure 2. ROC curve for the detection of aneurysms by CTA and CEMRA by both observers. 
No relationship between aneurysm location and accuracy of detection was found.

One observer reported 4 aneurysms at CEMRA -all very small- that were not confirmed at DSA. One of these aneurysms, which was reported by both observers, appeared to be an infundibular widening of the origin of the left posterior communicating artery (Figure 3). One other aneurysm unconfirmed by DSA was (temporarily) thrombosed at the time DSA was performed. Because the study protocol states that DSA is the standard of reference, considering this finding as a true aneurysm would be a violation of the study protocol. The other two aneurysms were seen only by Observer 1 , located on the basilar tip $(1.5 \times 1.5 \mathrm{~mm})$ and right middle cerebral artery $(2 \times 2 \mathrm{~mm})$ respectively. These false positive findings represent either artifacts or irregularities of the vessel wall. None of these four false positive aneurysms was registered by CTA. At CTA both observers scored one false positive aneurysm, both located at the PICA, but in two different patients. In one of these two cases there was a dysplastic vertebral artery, rather than a true aneurysm. This was not considered as the bleeding source, but was reported by Observer 2 as an aneurysm. The other false-positive PICA aneurysm reported at CTA was not seen on CEMRA or DSA.
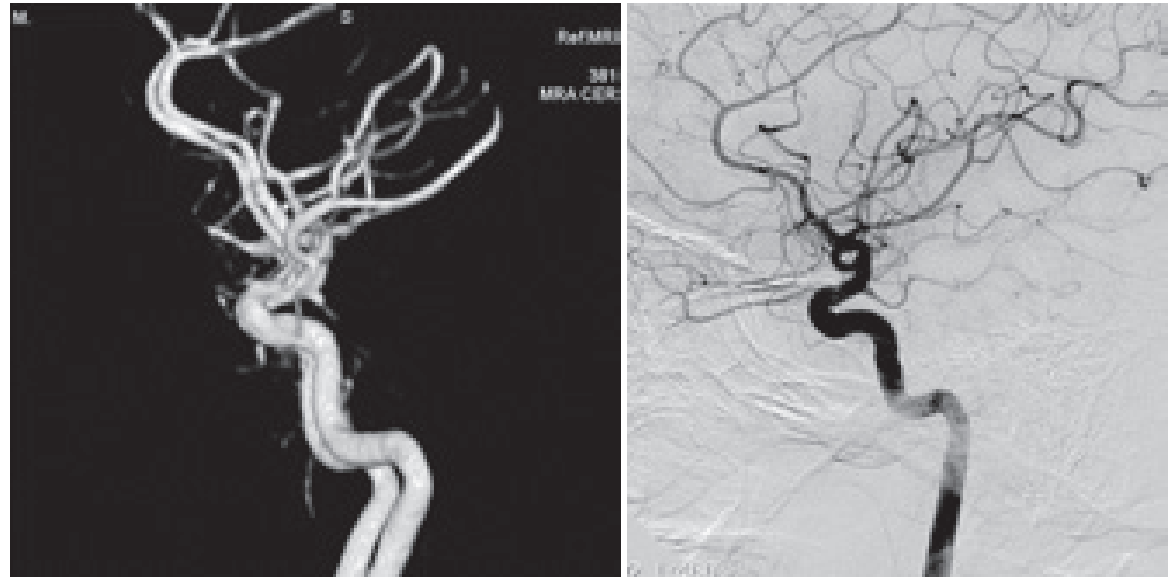

Figure 3 a. Lateral projection of a volume rendered reconstruction of the CEMRA scan of a patient presenting with an SAH. Both observers described a small left posterior communicating artery aneurysm. b. Lateral projection of the left internal carotid artery made by DSA of the same patient as in figure 3a. It shows a posterior communicating artery with an infundibular widening.

In our study population $50.8 \%(33 / 65)$ of the aneurysms were smaller than $5 \mathrm{~mm}$ and $18.5 \%(12 / 65)$ were smaller than $3 \mathrm{~mm}$. The sensitivities for detection of these small aneurysms are given in Table 6.

Table 6. Sensitivity of CTA and CEMRA for the detection of small aneurysms

\begin{tabular}{|c|c|c|c|c|c|}
\hline \multirow{2}{*}{ CTA } & & \multicolumn{2}{|c|}{ All } & $<5 \mathbf{m m}$ & $<3 \mathbf{m m}$ \\
& & Obs1 & 90.8 & 84.8 & 75 \\
\hline \multirow{2}{*}{ CEMRA } & Obs2 & 92.3 & 84.8 & 75 \\
\hline & Obs1 & 96.9 & 96.9 & 91.7 \\
\hline
\end{tabular}


For both observers sensitivity of detecting small aneurysms was slightly better with CEMRA than with CTA; however, this difference was not significant.

\section{Discussion}

This was the first report that directly compares the accuracy of CEMRA with CTA in the detection of cerebral aneurysms with a relevant number of consecutive patients. Scans of lesser quality due to patient movement or bolus timing problems were also included, reflecting the clinical situation.

We found no significant difference between CTA and CEMRA in the detection of intracranial aneurysms. In their meta-analysis White et al ${ }^{1}$ calculated a pooled sensitivity and specificity (with $95 \% \mathrm{Cl}$ ) for detection of an aneurysm of 90\% (88-92) and 86\% (79-91) for CTA and 87\% (84-90) and 95\% (91-97) for MRA respectively. These results are in line with our study, even though our population contained a high percentage of small aneurysms (Figure 4 is an example of such a small aneurysm).
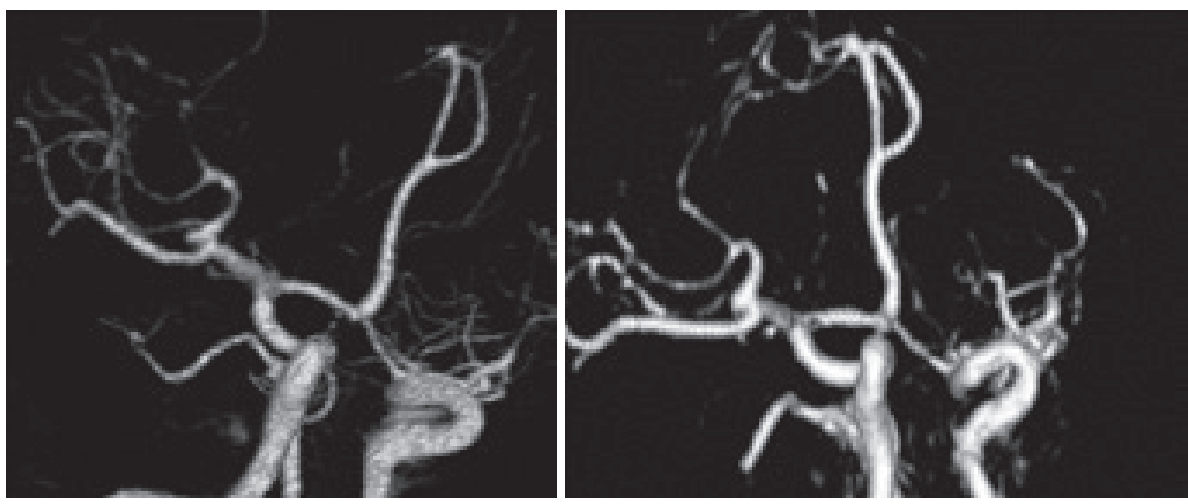

Figure 4. a. Oblique projection of a volume rendered reconstruction of the CTA scan of a patient with a small right middle cerebral artery aneurysm. The aneurysm was properly described by both observers. b. Oblique projection of a volume rendered reconstruction of the CEMRA scan of the same patient as in Figure 4(a). The right middle cerebral artery aneurysm was not detected by both observers.

In the meta-analysis of White et al. sensitivity decreased to $61 \%$ and $38 \%$ for CTA and MRA respectively for aneurysms smaller than $3 \mathrm{~mm}$. In their own prospective study, the sensitivity for small aneurysms was even lower: $57 \%$ for CTA and 35\% for MRA for aneurysms smaller than $5 \mathrm{~mm}$. In our series sensitivity for small aneurysms was considerably better for both modalities (Table 6).

Therefore, it seems that the improvement in scan techniques has led to better detection of small aneurysms, especially with MRA.

The sensitivity and specificity figures in our study are not as high as in previously published articles on the diagnostic performance of CEMRA in the detection of cerebral aneurysms, ${ }^{3-8}$ but because all acquisitions performed were included (no exclusions because of poor quality (Figure 5)), it likely reflects a more realistic expression of the performance of CEMRA in daily clinical practice. It shows that the 
performance of CEMRA is not significantly different from that of CTA; moreover, it appears to be better than in the published studies using TOF-MRA. ${ }^{1,2}$
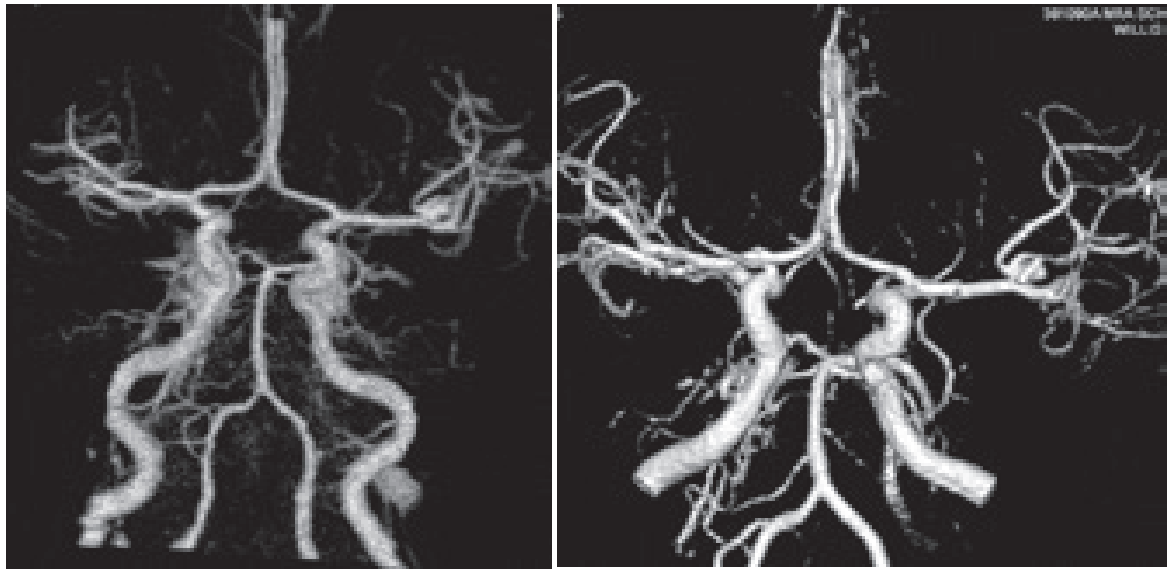

Figure 5. a. Anteroposterior projection of a volume rendered reconstruction of the CTA scan of a patient with a left middle cerebral artery aneurysm. Despite suboptimal image quality due to venous contamination and movement artefacts both observers correctly described the aneurysm. b. Anteroposterior projection of a volume rendered reconstruction of the CEMR scan of the same patient as in Figure 5 a. The left middle cerebral artery aneurysm was properly described by both observers.

In clinical practice where patients with negative CTA or CEMRA will undergo diagnostic DSA, specificity is of more importance than sensitivity. A false-positive result may ultimately lead to an unnecessary surgical intervention ${ }^{11}$ or a DSA examination at the start of a coiling procedure under general anesthesia which is then aborted when no aneurysm is found. In our series the specificity for CEMRA is lower than for CTA, although not significantly so.

In most hospitals MRI is less easily available than CT. Transporting the patient from the CT scanner, where the diagnosis of SAH is ideally made, to the MRI scanner for aneurysm detection and classification by CEMRA is cumbersome, and patient monitoring is more difficult in the MRI room.

Furthermore patient motion is more likely to degrade image quality with MRI than with CT. In our population only six patients were too restless to go into the MRI scanner, though they had already been able to undergo CTA. Contraindications such as implanted pacemakers, intraocular metal fragments and claustrophobia will exclude another group (ten patients in our population). These MRI drawbacks make this modality less popular even though it has the advantage of not employing iodinated contrast media and ionizing radiation. ${ }^{12}$

The use of gadolinium chelates as a contrast agent for CEMRA involves the risk of inducing nephrogenic systemic fibrosis. ${ }^{13}$ In the patient population included in our study this is normally not an issue: most $\mathrm{SAH}$ patients are relatively young and healthy, and the risk of contrast-induced nephropathy from iodinated contrast media is higher. ${ }^{14}$ In our population there were no patients with severe renal insufficiency. Additionally, the risk of other adverse reactions is higher with iodinated contrast material than with gadolinium based contrast agents. ${ }^{14}$ 


\section{Study limitations:}

Only $39.7 \%$ of all eligible patients presenting during the study period were finally included, mainly due to logistical problems (lack of time for the informed consent procedure and performance of the additional CEMRA study). The patient characteristics and the prevalence of aneurysms, however, did not differ significantly between the total group of 189 presenting patients and the 75 included patients.

When patient inclusion for this study commenced it was not yet common practice to employ 3D rotational DSA. Therefore it was decided to use conventional 2D DSA as the standard of reference in all patients. In our practice, all patients with non-perimesencephalic and non-traumatic SAH, in whom the DSA study does not show an aneurysm, are studied by a second or even a third DSA. In the study population, these repeat DSA studies were performed with the knowledge of the CTA and CEMRA findings but no additional aneurysms were found with these repeat DSA studies (except for the one case described above where the thrombosed aneurysm was revealed on a second DSA some days later). Although this is not a guarantee that no additional aneurysms would be found if 3D DSA was used, this would not lead to difference in performance between CTA and CEMRA.

1.5T MRI scanners are still the systems mostly used. The use of 3T scanners has led to better results in the follow-up of coiled aneurysms, ${ }^{15,16}$ but this improvement has not yet been confirmed for the detection of aneurysms in patients presenting with a $\mathrm{SAH}$.

The evolution in CT technique, on the other hand, from the two- and four-detector-row scanners used in our study to 16-, 64- and even 320-detector-row scanners, has definitely led to improved accuracy in the detection of intracranial aneurysms. ${ }^{17-20}$ It is therefore likely that at the present time CTA with state-ofthe-art CT-scanners performs significantly better than MRA in the detection of intracranial aneurysms.

\section{Conclusion}

Using the techniques available at the time of the study, our results indicate that CEMRA does not appear to provide superior diagnostic performance compared to CTA for the detection of cerebral aneurysm in this patient population. Improvements in CTA technique make it unlikely that with present state of the art equipment CEMRA will gain preference over CTA.

\section{References}

1 White, P. M., Wardlaw, J. M. \& Easton, V. Can noninvasive imaging accurately depict intracranial aneurysms? A systematic review. Radiology 217, 361-370, (2000).

2 White, P. M., Teasdale, E. M., Wardlaw, J. M. \& Easton, V. Intracranial aneurysms: CT angiography and MR angiography for detection prospective blinded comparison in a large patient cohort. Radiology 219, 739-749, (2001).

3 Jager, H. R. et al. Contrast-enhanced MR angiography of intracranial giant aneurysms. AJNR Am J Neuroradiol 21, 1900-1907, (2000).

4 Metens, T. et al. Intracranial aneurysms: detection with gadolinium-enhanced dynamic three-dimensional MR angiography-initial results. Radiology 216, 39-46, (2000). 
5 Unlu, E., Cakir, B., Gocer, B., Tuncbilek, N. \& Gedikoglu, M. The role of contrast-enhanced MR angiography in the assessment of recently ruptured intracranial aneurysms: a comparative study. Neuroradiology 47, 780791, (2005).

6 Gottschalk, S. et al. [Contrast-enhanced intracranial 3 D MR angiography (CE-MRA) in assessing arterial stenoses and aneurysms]. Rofo 174, 704-713, (2002).

7 Nael, K. et al. 3-T contrast-enhanced MR angiography in evaluation of suspected intracranial aneurysm: comparison with MDCT angiography. AJR Am J Roentgenol 190, 389-395, (2008).

8 Suzuki, I. M. et al. Contrast-enhanced MR angiography (enhanced 3-D fast gradient echo) for diagnosis of cerebral aneurysms. Neuroradiology 44, 17-20, (2002).

9 Romijn, M. et al. Diagnostic accuracy of CT angiography with matched mask bone elimination for detection of intracranial aneurysms: comparison with digital subtraction angiography and 3D rotational angiography. AJNR Am J Neuroradiol 29, 134-139, (2008).

10 Venema, H. W., Hulsmans, F. J. \& den Heeten, G. J. CT angiography of the circle of Willis and intracranial internal carotid arteries: maximum intensity projection with matched mask bone elimination-feasibility study. Radiology 218, 893-898, (2001).

11 Westerlaan, H. E. et al. Magnetic resonance angiography in the selection of patients suitable for neurosurgical intervention of ruptured intracranial aneurysms. Neuroradiology 46, 867-875, (2004).

12 Hacein-Bey, L. \& Provenzale, J. M. Current imaging assessment and treatment of intracranial aneurysms. AJR Am J Roentgenol 196, 32-44, (2011).

13 Kuo, P. H., Kanal, E., Abu-Alfa, A. K. \& Cowper, S. E. Gadolinium-based MR contrast agents and nephrogenic systemic fibrosis. Radiology 242, 647-649, (2007).

14 Halvorsen, R. A. Which study when? lodinated contrast-enhanced CT versus gadolinium-enhanced MR imaging. Radiology 249, 9-15, (2008).

15 Kaufmann, T. J. et al. A prospective trial of 3T and 1.5T time-of-flight and contrast-enhanced MR angiography in the follow-up of coiled intracranial aneurysms. AJNR Am J Neuroradiol 31, 912-918, (2010).

16 Pierot, L., Portefaix, C., Gauvrit, J. Y. \& Boulin, A. Follow-Up of Coiled Intracranial Aneurysms: Comparison of 3D Time-of-Flight MR Angiography at 3T and 1.5T in a Large Prospective Series. AJNR Am J Neuroradiol, (2012).

17 Donmez, H. et al. Comparison of 16-row multislice CT angiography with conventional angiography for detection and evaluation of intracranial aneurysms. Eur J Radiol, (2010).

18 Franklin, B., Gasco, J., Uribe, T., VonRitschl, R. H. \& Hauck, E. Diagnostic accuracy and inter-rater reliability of 64-multislice 3D-CTA compared to intra-arterial DSA for intracranial aneurysms. J Clin Neurosci 17, 579-583, (2010).

19 Luo, Z. et al. Comparison of the accuracy of subtraction CT angiography performed on 320-detector row volume CT with conventional CT angiography for diagnosis of intracranial aneurysms. Eur J Radiol 81, 118122, (2012)

20 Menke, J., Larsen, J. \& Kallenberg, K. Diagnosing cerebral aneurysms by computed tomographic angiography: meta-analysis. Ann Neurol 69, 646-654, (2011). 


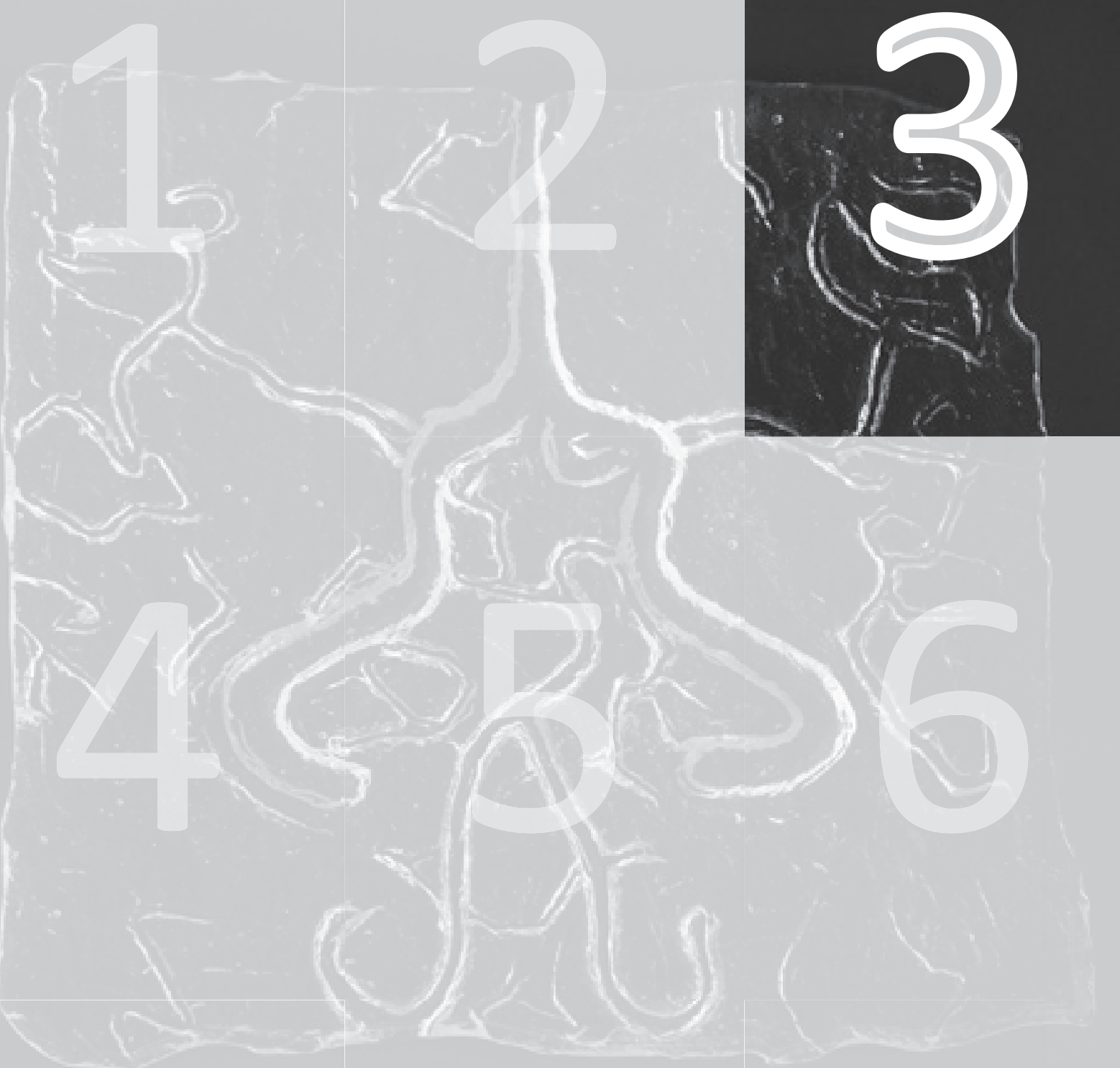




\section{Chapter 3}

Performance of Contrast Enhanced Magnetic Resonance Angiography in patients presenting with Subarachnoid Hemorrhage. Part 2: assessing feasibility of coiling

W.H. van Zwam

P.A.M. Hofman

A.G. Kessels

T.K. Oei

R.J Heijboer

J.T. Wilmink

Adapted from the article submitted to the European Journal of Minimally Invasive Neurological Therapies. 


\begin{abstract}
Background and purpose: Computed tomographic angiography (CTA) is used in our center as the primary diagnostic tool to detect and characterize intracranial aneurysms in patients presenting with a subarachnoid hemorrhage (SAH). Contrast enhanced magnetic resonance angiography (CEMRA) might be a possible alternative technique.

In this study assessment by CEMRA of the feasibility of endovascular treatment of intracranial aneurysms with platinum coils, their "coilability", is evaluated and compared to similar assessment using CTA.

Materials and Methods: In 75 consecutive patients with a SAH two experienced neuroradiologists evaluated CEMRA and CTA images. Accuracy in predicting the coilability and determining the size of the aneurysms was calculated for both modalities and compared. Digital subtraction angiography (DSA) served as standard of reference.
\end{abstract}

Results: 65 aneurysms were detected in 57 patients. No significant difference was found between the two modalities with respect to accuracy in assessing the feasibility of endovascular treatment: sensitivity and specificity for both were rather low (52.8-72.2 and 80.9-89.4 respectively) and Kappa was only 0.49 for both. Both modalities showed a little oversizing in the measurements of cerebral aneurysms. The intraclass correlation coefficient in size measurement was good for both modalities (0.93 and 0.91).

Conclusion: The diagnostic performance of CEMRA does not differ significantly from that of CTA in the work up to endovascular treatment of patients presenting with an SAH. The choice to use either CEMRA or CTA can depend on personal preference and availability. 


\section{Introduction}

If a non-invasive imaging technique is to be employed in the work up of patients presenting with a subarachnoid hemorrhage (SAH), accurate detection of a possible intracranial aneurysm is of primary importance. In addition however, the technique in question should permit an assessment of the possibility of endovascular treatment: its 'coilability'. ${ }^{1,2}$ In Chapter 2 the accuracy of contrast enhanced MRA (CEMRA) in detecting an aneurysm in patients presenting with a SAH is described and compared to that of CT angiography (CTA). ${ }^{3}$ In this chapter the capability of CEMRA and CTA to predict the coilability of an intracranial aneurysm and the respective accuracies of the two modalities in aneurysm size measurement are evaluated, using DSA as standard of reference.

The capability of selecting the appropriate mode of treatment for intracranial aneurysms using CTA, has been studied and described in several papers. ${ }^{4-12}$ Most authors conclude that in the majority of cases CTA is able to guide treatment planning, thus limiting the need for additional digital subtraction angiography (DSA). ${ }^{4,5,11}$

Only few studies have appeared describing the use of MRA to assess the feasibility of endovascular treatment, $^{13-16}$ and no direct comparison with CTA was made in these studies. The conclusions of these studies varied from 'MRA appears to be an effective treatment planning tool for most patients with $\mathrm{SAH}^{13}$ to 'MRA cannot replace DSA in treatment planning'. ${ }^{16}$

Important criteria determining the feasibility of endovascular coiling are the neck-to-dome ratio of the aneurysm and the absolute size of the neck and of the aneurysm. In vivo studies have been performed to assess the reliability of aneurysm volume measurement with CTA and MRA ${ }^{17,18}$ reporting good correlation with DSA. Some authors report overestimation of neck-to-dome ratio by CTA. ${ }^{19,20}$

The advantages of MRA over CTA have been pointed out in Chapter 2: there is no use of harmful ionizing radiation or iodinated contrast agents, and bony structures or vessel calcifications do not hinder evaluation of the vascular structures. Signal loss due to turbulent or slow flow, which may degrade the image in flow dependent MRA sequences, do not occur in CEMRA. ${ }^{16,21,22}$ There are logistical limitations involved in performing a MRA study in the acute setting of a patient with a SAH. Frequently there is no immediate availability of an MRI system, and there is the necessity of transporting the patient from the CT scanner, used in diagnosing SAH, to the MRI system. Furthermore there may be problems related to patient unrest and poor patient monitoring inside the bore of the magnet. These drawbacks make MRA a less attractive alternative. Therefore CEMRA could be a preferable diagnostic tool in the patient work up only if it were to perform better than CTA in detecting intracranial aneurysms or predicting the feasibility of endovascular treatment. 


\section{Materials and Methods}

\section{Study design}

Patient selection and additional information about the study design are described in Chapter 2.

The two observers who reviewed the CEMRA and CTA data of the 75 included patients in the first part of this study (Chapter 2) were asked to assess the "coilability" of the aneurysms which had been detected by CEMRA or CTA, and to measure the size of the aneurysms.

\section{Techniques}

CTA was performed on a two-slice (Elscint Dual; Elscint, Haifa, Israel) or on a four-slice multidetectorrow spiral CT scanner (Toshiba Aquilion; Toshiba, Tokyo, Japan). In most cases a semi-automatic bone subtraction method, Matched Masked Bone Elimination (MMBE), was used.

MRA was performed on a 1.5 Tesla Philips system using a dedicated head coil (Intera; Philips, Best, The Netherlands). The scan protocol included an ultra-short first-pass CEMRA sequence with concentric kspace filling. All patients underwent catheter DSA examinations (Integris; Philips Medical Systems, Best, the Netherlands)

A detailed description of the scan techniques can be found in Chapter 2.

\section{Image interpretation and statistical analysis}

The CTA and MRA data were post-processed and interactively evaluated on a workstation (Vitrea; Vital Images, Minnetonka, Minnesota, USA). Both observers blindly evaluated the images acquired by both modalities, in random order.

Quality of images, feasibility of endovascular treatment and diagnostic confidence were used as scoring criteria. Quality of images and confidence in scoring were both rated on a three point scale: 'poor', 'moderate' and 'good'.

Size was given in millimeters in two directions. Calculations were done on the product of the two measurements.

Sensitivity, specificity and ROC curves were calculated to evaluate the capability of each modality to predict the feasibility of endovascular treatment as well as Cohen's Kappa for interobserver agreement. For ROC curve calculations the confidence scoring was transferred to a negative value if the aneurysm was considered not coilable. The resultant values were used for cut-off points.

The actual coilability of the aneurysm during the endovascular coiling procedure was used as standard of reference. In the cases where no coiling procedure was performed, the diagnostic DSA served as standard of reference.

The performance of CEMRA and CTA in aneurysm size measurement was described with linear regression analysis and $95 \%$ predictive intervals. Interobserver variability was calculated using the Intraclass Correlation Coefficient.

DSA findings served as the standard of reference for size measurement. Aneurysm size in the DSA images was estimated by comparison with known diameters of adjacent intracranial arteries. 


\section{Results}

In 18 patients (24\%) no aneurysm was found. Fifty patients harbored one aneurysm, six patients had two aneurysms and one patient had three aneurysms, adding up to a total of 65 aneurysms.

Thirty three out of sixty five (50.8\%) of the aneurysms in our study population were smaller than $5 \mathrm{~mm}$ and $12 / 65$ (18.5\%) were smaller than $3 \mathrm{~mm}$.

Sensitivity and specificity of the CEMRA and CTA assessments for the verdict whether an aneurysm could be treated by endovascular coiling or not, are given in table 1a. Calculations were done on all 75 cases, where the 18 cases with 'no aneurysm present' were regarded as 'coiling not feasible'.

Table 1a. Sensitivity and specificity $(95 \% \mathrm{Cl}$ ) of CTA and CEMRA for assessing the feasibility of endovascular treatment of the aneurysm, calculated for all 75 cases. Obs = Observer.

\begin{tabular}{|c|c|cc|}
\hline & & CTA & CEMRA \\
\hline \multirow{2}{*}{ Sensitivity } & Obs 1 & $58.8(40.7-75.4)$ & $52.9(35.5-69.1)$ \\
& Obs 2 & $73.5(55.6-87.1)$ & $61.8(43.6-77.8)$ \\
\cline { 2 - 4 } Specificity & Obs 1 & $89.8(77.8-96.6)$ & $87.8(75.2-95.4)$ \\
\hline \multirow{2}{*}{ Obs 2 } & $79.6(65.7-89.8)$ & $79.6(65.7-89.8)$ \\
\hline
\end{tabular}

There is no significant difference between the sensitivity and specificity of CTA and CEMRA tested with McNemar's test statistics. Cohen's Kappa for inter-observer agreement is 0.49 for both CEMRA and CTA for assessing the feasibility of endovascular treatment. ROC curves for the feasibility of endovascular treatment are given in figure 1. The areas under the curve are: 0.73 (0.62-0.83) and 0.78 (0.69-0.88) for CTA and $0.71(0.60-0.81)$ and 0.77 (0.67-0.86) for CEMRA. The areas of CTA and CEMRA are not significantly different ( $p=0.75$ for obs 1 and $p=0.83$ for obs 2 ).

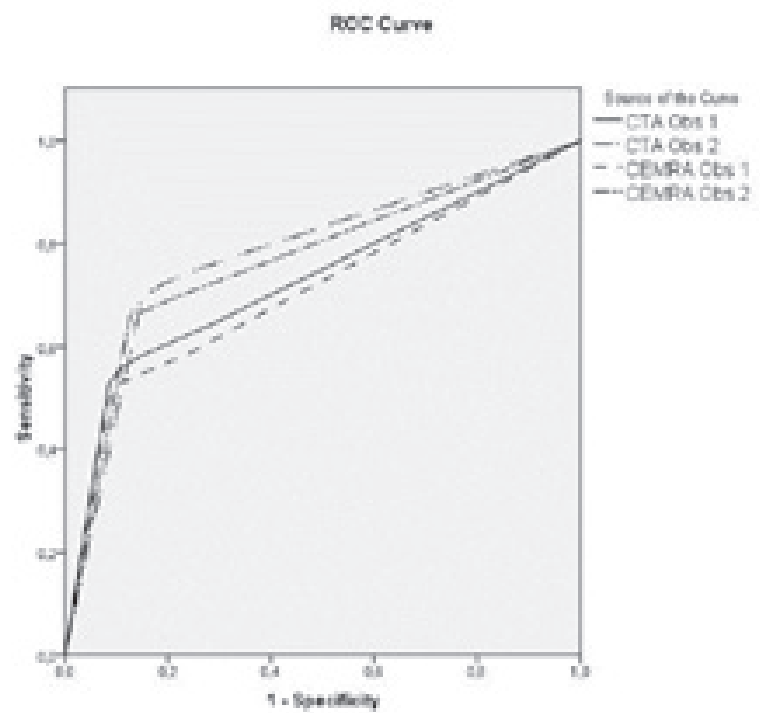

Figure 1. ROC curves for feasibility of coiling by both observers for CTA and CEMRA. 
Sensitivity and specificity for prediction of feasibility of endovascular treatment, calculated only for those cases where an aneurysm was detected by the observer, are given in table $1 \mathrm{~b}$.

Table 1b. Sensitivity and specificity of CTA and CEMRA for assessing the feasibility of endovascular treatment of the aneurysm if only the patients harboring aneurysms (as scored by the observer) are considered. Obs = Observer.

\begin{tabular}{|c|c|c|c|}
\hline & & CTA & CEMRA \\
\hline Sensitivity & $\begin{array}{l}\text { Obs } 1 \\
\text { Obs } 2\end{array}$ & $\begin{array}{l}64.5(45.4-80.2) \\
80.6(61.9-91.9)\end{array}$ & $\begin{array}{l}52.9(35.5-69.1) \\
63.6(45.1-79.0)\end{array}$ \\
\hline Specificity & $\begin{array}{l}\text { Obs } 1 \\
\text { Obs } 2\end{array}$ & $\begin{array}{l}82.8(63.5-93.5) \\
66.7(47.1-82.1)\end{array}$ & $\begin{array}{l}81.8(63.9-92.4) \\
70.0(50.4-84.6)\end{array}$ \\
\hline
\end{tabular}

If Cohen's Kappa for feasibility of endovascular treatment is calculated for these cases only, this value decreases to 0.38 for CTA and to 0.46 for CEMRA.

The accuracy for measuring the size of an aneurysm is given by the regression lines with the $95 \%$ predictive interval in figure $2 a-d$.

Using the regression equation DSA $=\alpha+\beta \times($ CTA or MRA), the regression coefficients $\beta$ with $95 \% \mathrm{Cl}$ are given in table $2 . \alpha$ is small (zero is in the $95 \% \mathrm{Cl}$ in all cases) and therefore is of no importance.

Table 2. Regression coefficients $\beta(95 \% \mathrm{Cl})$ for size measurement of aneurysms for CTA and CEMRA with DSA as standard of reference.

\begin{tabular}{|c|c|c|}
\hline & CTA $(\mathbf{9 5} \% \mathbf{C I})$ & MRA (95\% CI) \\
\hline Obs 1 & $0.84(0.72-0.96)$ & $0.80(0.72-0.88)$ \\
\hline Obs 2 & $0.83(0.72-0.95)$ & $0.83(0.73-0.92)$ \\
\hline
\end{tabular}



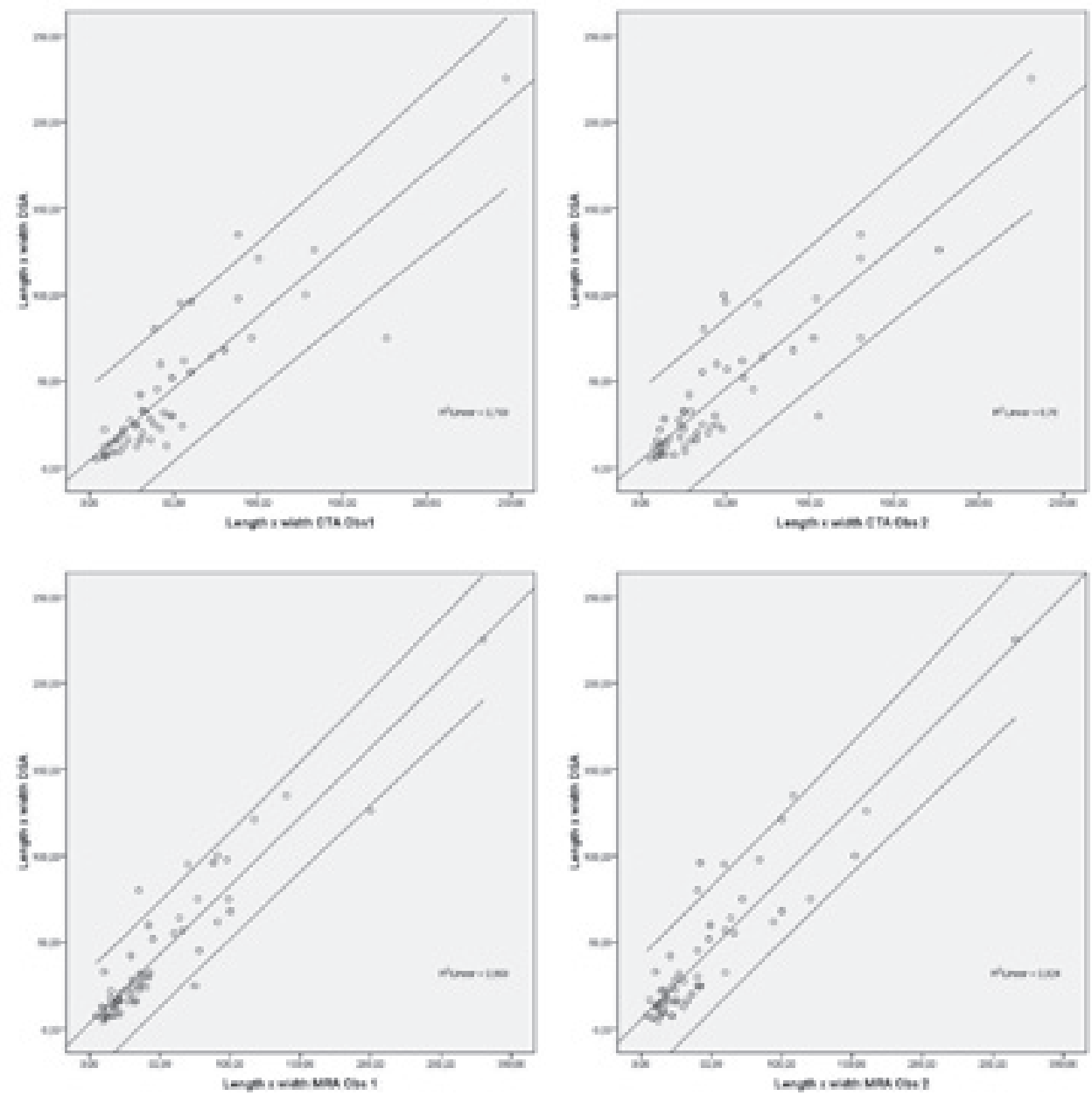

Figure 2 a-d. Size correlation between CTA and DSA and between CEMRA and DSA for both observers, with regression line and $95 \%$ predictive interval.

The Intraclass Correlation Coefficient $(95 \% \mathrm{Cl})$ between the two observers for size measurement is 0.91 (0.85-0.95) for CTA and 0.93 (0.89-0.96) for CEMRA.

\section{Discussion}

Beside its role in aneurysm detection CTA also has the potential for assessing the possibility of endovascular aneurysm treatment. Although most aneurysms can be treated by endovascular coiling with the aid of balloons and stents, there is still a place for surgical treatment in aneurysms with a wide neck, or with vessels originating from the base of the aneurysm that might become occluded if 
endovascular treatment were to be undertaken. These patients will be referred to the neurosurgeon for clipping of the aneurysm.

The percentage of aneurysms that are coiled in our department has increased from less than $50 \%$ ten years ago to more than $70 \%$ at present.

In the present study 36 of the 65 aneurysms appeared to be suitable for endovascular treatment on the basis of the DSA findings in the diagnostic phase. In two of these patients an endovascular procedure was initiated, but during the procedure it proved that coiling was not possible. The procedure was aborted and the patients were referred for surgery. In our analysis these aneurysms are considered as not suitable for endovascular treatment, reflecting the findings during the endovascular procedure. Thus 34 of the 65 aneurysms (52.3\%) were treated by endovascular coiling, which is less than average in our general population of patients with an aneurysmal SAH (see Chapter 5). ${ }^{23}$

If there is doubt about the coilability of an aneurysm on the basis of the CTA findings, diagnostic DSA is performed. In some of the cases presented to the neurosurgeon for clipping on the basis of the CTA findings, an additional DSA study is requested by the neurosurgeon. If CEMRA were to perform better than CTA in the selection of aneurysms suitable for coiling or clipping, then this might prevent a number of additional diagnostic DSA studies with their inherent risks and costs. ${ }^{24}$

There are hardly any reports in the literature describing the accuracy of noninvasive techniques in deciding whether endovascular treatment of an aneurysm will be possible. In one study that used CTA as the only pretreatment modality for detection and treatment planning, the authors state that in only $18 \%(41 / 223)$ of patients with an aneurysm was an additional DSA study needed for treatment planning. ${ }^{5}$ The report does not mention however whether all these decisions on treatment selection made on the basis of CTA were correct. A second study reports the results of a strategy in which CTA was the primary modality to select the appropriate mode of treatment. ${ }^{8}$ Only in cases in which CTA findings left room for doubt, was a diagnostic DSA study performed. This was the case in in 31 of 224 patients (13.8\%). In two of these cases a reversal of the initial treatment decision, which had been based on the CTA findings, took place. In this study there is no direct comparison however with a gold standard (DSA or intra operative findings) in all cases. Other studies report strategies using CTA as a pretreatment modality, ${ }^{25-29}$ but none specify the accuracy of CTA in assessing the feasibility of endovascular treatment of an intracranial aneurysm

The decision whether an aneurysm can be treated by endovascular coiling depends on many factors such as the configuration of the aneurysm, dome to neck ratio and presence of vessels emerging from the base of the aneurysm. Even using these criteria however the decision is largely subjective, depending on the insights and experience of the observer. To investigate this aspect we asked two experienced neurointerventionists from two different hospitals to give their opinion on the feasibility of endovascular treatment on the basis of the DSA findings in our patients with an aneurysm. The Kappa value for interobserver agreement was only 0.41. Of the 65 aneurysms evaluated, the first observer considered 46 aneurysms to be suitable for endovascular coiling, while the second observer agreed with this verdict in only 33 aneurysms (table 3). This indicates that an aspect of the standard of reference the DSA findings in the cases in which endovascular treatment was considered not possible- depends significantly on subjective criteria. 
Table 3. Results of two experienced neurointerventionists on the feasibility of endovascular treatment of intracerebral aneurysms on the basis of the DSA's.

\begin{tabular}{|c|c|c|c|c|}
\hline & & \multicolumn{2}{|c|}{ Coiling feasible obs 2} & \\
\hline & & no & yes & \\
\hline Coiling feasible & no & 16 & 3 & 19 \\
\hline Obs 1 & yes & 16 & 30 & 46 \\
\hline \multicolumn{2}{|c|}{ Total } & 32 & 33 & 65 \\
\hline
\end{tabular}

Size measurement is very consistent and robust for both modalities with an Intraclass Correlation Coefficient between two observers of 0.91 and 0.93 for CTA and CEMRA respectively.

Both CTA and CEMRA appear to overestimate the size of the aneurysms by nearly $20 \%$ compared to DSA. One of the possible explanations for this discrepancy regarding MRA could be that this technique also generates a high signal in intraluminal thrombus, whereas DSA only displays the contrast-filled vascular lumen. ${ }^{30}$ Another reason for this discrepancy can be that with CTA and MRA the window/ level settings can be adjusted by the observer. These levels are often set in such a fashion that small aneurysms will be detected as well, thereby probably including more voxels with partial volume in the detected aneurysms. Size itself is not an important parameter for the assessment of feasibility of endovascular treatment, but this finding indicates a limitation in the accuracy of the non-invasive techniques. It could be of importance for very small aneurysms, because we consider aneurysms of $2 \mathrm{~mm}$ or smaller as not suitable for endovascular treatment. In these very small aneurysms oversizing is not a significant factor however, because it is always proportional to the size of the aneurysm ( $\beta$ in the equation DSA $=\alpha+\beta \times($ CTA or MRA)), and not an absolute overestimation in size ( $\alpha)$. For selecting the right size of the coils for a coiling procedure measurement of the diameter of the aneurysm is necessary. This is normally done on the DSA images made at the beginning of the coiling procedure.

Although aneurysm size, ${ }^{31}$ size relative to vessel diameter ${ }^{32}$ or growth of the aneurysm ${ }^{33}$ might be predictors of the risk of rupture in as yet unruptured aneurysms, this was not the focus of this study. These aspects will play a role in screening for aneurysms and in follow-up of treated aneurysms. In vitro studies have shown that volumetric measurements with CTA and MRA are not very accurate. ${ }^{18,34}$

\section{Conclusion}

There is no significant difference in the performance of CTA and CEMRA in guiding the decision whether or not to treat an intracranial aneurysm by endovascular coiling. This is an important function of noninvasive imaging in patients presenting with a SAH shown to harbor an intracranial aneurysm. If this performance could be improved, the need for additional diagnostic DSA studies would decrease.

CTA and CEMRA both overestimate the size of intracranial aneurysms. 


\section{References}

Brown, J. H., Lustrin, E. S., Lev, M. H., Ogilvy, C. S. \& Taveras, J. M. Characterization of intracranial aneurysms using CT angiography. AJR Am J Roentgenol 169, 889-893, (1997).

Goddard, A. J., Tan, G. \& Becker, J. Computed tomography angiography for the detection and characterization of intra-cranial aneurysms: current status. Clin Radiol 60, 1221-1236, (2005).

Zwam, W. H. v. et al. Diagnostic performance of contrast enhanced magnetic resonance angiography in detecting intracranial aneurysms in patients presenting with subarachnoid haemorrhage. EJMINT, 1240000078, (2012).

Gonzalez-Darder, J. M., Pesudo-Martinez, J. V. \& Feliu-Tatay, R. A. Microsurgical management of cerebral aneurysms based in CT angiography with three-dimensional reconstruction (3D-CTA) and without preoperative cerebral angiography. Acta Neurochir (Wien) 143, 673-679, (2001).

Hoh, B. L. et al. Results of a prospective protocol of computed tomographic angiography in place of catheter angiography as the only diagnostic and pretreatment planning study for cerebral aneurysms by a combined neurovascular team. Neurosurgery 54, 1329-1340; discussion 1340-1322, (2004).

Li, Q. et al. Evaluation of 64-section CT angiography for detection and treatment planning of intracranial aneurysms by using DSA and surgical findings. Radiology 252, 808-815, (2009).

Papke, K. et al. Intracranial aneurysms: role of multidetector CT angiography in diagnosis and endovascular therapy planning. Radiology 244, 532-540, (2007).

Westerlaan, H. E. et al. Multislice CT angiography in the selection of patients with ruptured intracranial aneurysms suitable for clipping or coiling. Neuroradiology 49, 997-1007, (2007).

Chen, W., Yang, Y., Xing, W., Qiu, J. \& Peng, Y. Application of multislice computed tomographic angiography in diagnosis and treatment of intracranial aneurysms. Clin Neurol Neurosurg 112, 563-571, (2010).

Dehdashti, A. R., Rufenacht, D. A., Delavelle, J., Reverdin, A. \& de Tribolet, N. Therapeutic decision and management of aneurysmal subarachnoid haemorrhage based on computed tomographic angiography. Br J Neurosurg 17, 46-53, (2003).

Agid, R., Lee, S. K., Willinsky, R. A., Farb, R. I. \& terBrugge, K. G. Acute subarachnoid hemorrhage: using 64slice multidetector CT angiography to "triage" patients' treatment. Neuroradiology 48, 787-794, (2006).

Villablanca, J. P. et al. MDCT angiography for detection and quantification of small intracranial arteries: comparison with conventional catheter angiography. AJR Am J Roentgenol 188, 593-602, (2007).

Chen, Y. C. et al. The clinical value of MRA at 3.0 T for the diagnosis and therapeutic planning of patients with subarachnoid haemorrhage. Eur Radiol, (2012).

Nael, K. et al. 3-T contrast-enhanced MR angiography in evaluation of suspected intracranial aneurysm: comparison with MDCT angiography. AJR Am J Roentgenol 190, 389-395, (2008).

Nael, K. et al. Contrast-enhanced MR angiography at 3T in the evaluation of intracranial aneurysms: a comparison with time-of-flight MR angiography. AJNR Am J Neuroradiol 27, 2118-2121, (2006).

Unlu, E., Cakir, B., Gocer, B., Tuncbilek, N. \& Gedikoglu, M. The role of contrast-enhanced MR angiography in the assessment of recently ruptured intracranial aneurysms: a comparative study. Neuroradiology 47, 780-791, (2005).

7 Doerfler, A. et al. Multimodal imaging in the elastase-induced aneurysm model in rabbits: a comparative study using serial DSA, MRA and CTA. Rofo 176, 590-596, (2004).

Piotin, M. et al. CT angiography, MR angiography and rotational digital subtraction angiography for volumetric assessment of intracranial aneurysms. An experimental study. Neuroradiology 45, 404-409, (2003).

Wintermark, M. et al. Multislice computerized tomography angiography in the evaluation of intracranial aneurysms: a comparison with intraarterial digital subtraction angiography. J Neurosurg 98, 828-836, (2003).

Yoon, D. Y. et al. Detection and characterization of intracranial aneurysms with 16-channel multidetector row CT angiography: a prospective comparison of volume-rendered images and digital subtraction angiography. AJNR Am J Neuroradiol 28, 60-67, (2007).

Jager, H. R. et al. Contrast-enhanced MR angiography of intracranial giant aneurysms. AJNR Am J Neuroradiol 21, 1900-1907, (2000).

Metens, T. et al. Intracranial aneurysms: detection with gadolinium-enhanced dynamic three-dimensional MR angiography-initial results. Radiology 216, 39-46, (2000).

3 Klompenhouwer, E. G. et al. Single-center experience of surgical and endovascular treatment of ruptured intracranial aneurysms. AJNR Am J Neuroradiol 32, 570-575, (2011). 
24 Kaufmann, T. J. et al. Complications of diagnostic cerebral angiography: evaluation of 19,826 consecutive patients. Radiology 243, 812-819, (2007).

25 Anderson, G. B., Steinke, D. E., Petruk, K. C., Ashforth, R. \& Findlay, J. M. Computed tomographic angiography versus digital subtraction angiography for the diagnosis and early treatment of ruptured intracranial aneurysms. Neurosurgery 45, 1315-1320; discussion 1320-1312, (1999).

26 Boet, R., Poon, W. S., Lam, J. M. \& Yu, S. C. The surgical treatment of intracranial aneurysms based on computer tomographic angiography alone--streamlining the acute mananagement of symptomatic aneurysms. Acta Neurochir (Wien) 145, 101-105; discussion 105, (2003).

27 Matsumoto, M. et al. Three-dimensional computerized tomography angiography-guided surgery of acutely ruptured cerebral aneurysms. J Neurosurg 94, 718-727, (2001).

28 Velthuis, B. K. et al. Subarachnoid hemorrhage: aneurysm detection and preoperative evaluation with CT angiography. Radiology 208, 423-430, (1998).

29 Zouaoui, A. et al. Three-dimensional computed tomographic angiography in detection of cerebral aneurysms in acute subarachnoid hemorrhage. Neurosurgery 41, 125-130, (1997).

30 Adams, W. M., Laitt, R. D. \& Jackson, A. The role of MR angiography in the pretreatment assessment of intracranial aneurysms: a comparative study. AJNR Am J Neuroradiol 21, 1618-1628, (2000).

31 Wiebers, D. O. et al. Unruptured intracranial aneurysms: natural history, clinical outcome, and risks of surgical and endovascular treatment. Lancet 362, 103-110, (2003).

32 Rahman, M. et al. Size ratio correlates with intracranial aneurysm rupture status: a prospective study. Stroke 41, 916-920, (2010).

33 Burns, J. D., Huston, J., 3rd, Layton, K. F., Piepgras, D. G. \& Brown, R. D., Jr. Intracranial aneurysm enlargement on serial magnetic resonance angiography: frequency and risk factors. Stroke 40, 406-411, (2009).

34 Hanley, M., Zenzen, W. J., Brown, M. D., Gaughen, J. R. \& Evans, A. J. Comparing the Accuracy of Digital Subtraction Angiography, CT Angiographyand MR Angiography at Estimating the Volume of Cerebral Aneurysms. Interv Neuroradiol 14, 173-177, (2008). 


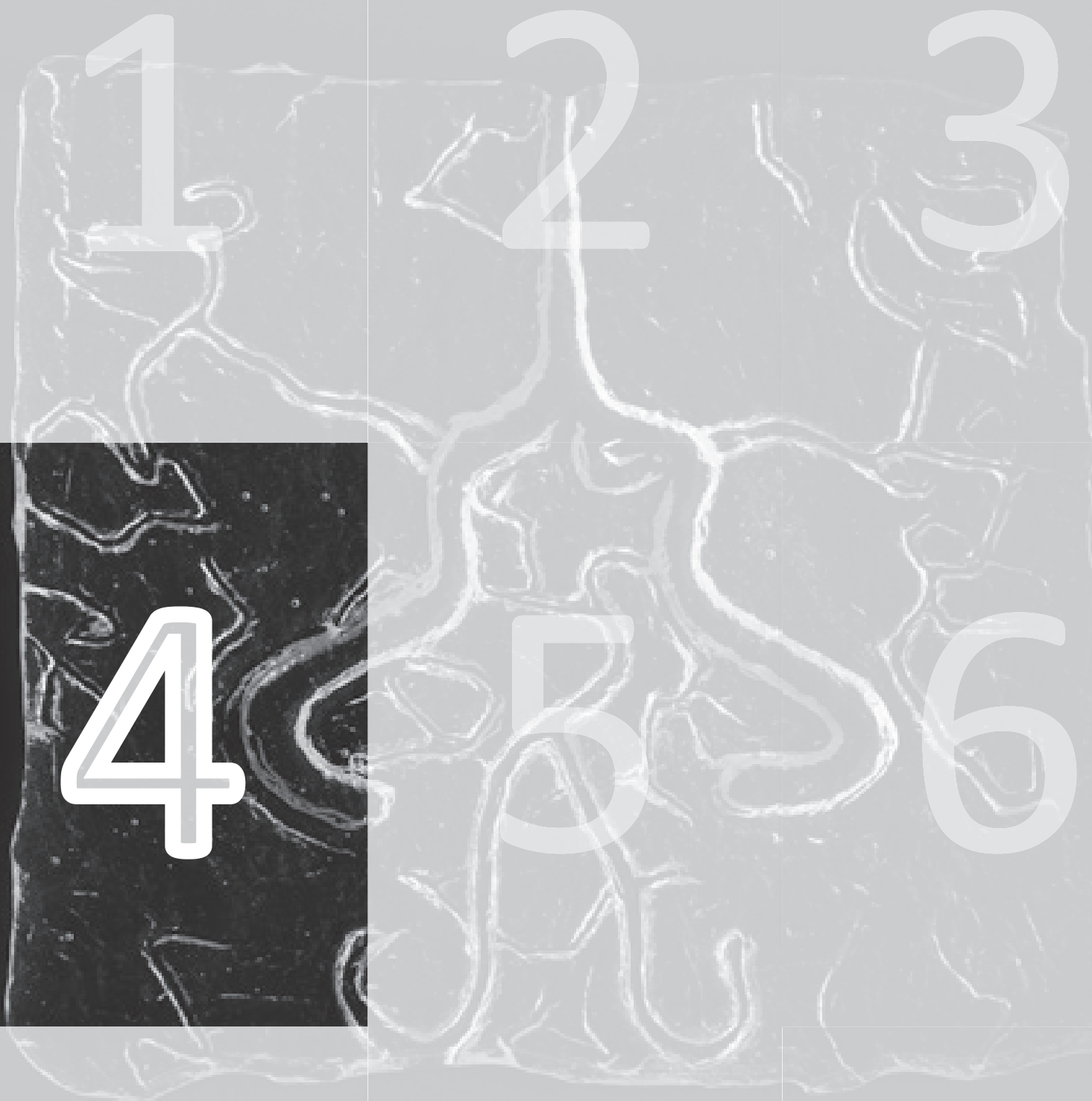




\section{Chapter 4}

Simulation study employing different scenarios using contrast-enhanced MRA and digital subtraction angiography in patients presenting with a subarachnoid hemorrhage.

W.H. van Zwam

P.A.M. Hofman

A.G. Kessels

T.K. Oei

G.H.J.J Spincemaille

J.T. Wilmink 


\section{Abstract}

Background and purpose: Contrast enhanced magnetic resonance angiography (CEMRA) can be used to detect intracranial aneurysms and plan treatment in patients presenting with a subarachnoid hemorrhage (SAH). In Chapters 2 and 3 it is shown that the diagnostic accuracy of CEMRA is not sufficient to replace digital subtraction angiography (DSA) completely, but the use of CEMRA in the work up of patients with SAH might avoid the more invasive and expensive DSA in selected cases, reducing risks and costs.

In this study the diagnostic accuracy and costs of four scenarios combining CEMRA with DSA in varying degrees, are compared.

Methods: Seventy-five patients consecutively presenting with a SAH had all undergone CEMRA and DSA. In this group 65 aneurysms in 58 patients were found, and two observers were asked to assess retrospectively and in consensus, the feasibility of endovascular treatment (the "coilability") of the aneurysms. Observers were also asked to indicate the need for an additional DSA study in case of uncertainty about their decision based on CEMRA.

All DSA images had been evaluated by the same observers in a separate session, blinded for the CEMRA results. These DSA findings served as the standard of reference.

Four scenarios which employed various combinations of CEMRA and DSA, were analyzed with regard to diagnostic accuracy and costs.

Results: Sensitivity of CEMRA for predicting coilability, by the two observers in consensus, was $84.2 \%$ and specificity $88.9 \%$. The diagnostic costs for these 75 patients in the four scenarios varied from $€$ 30,500 to $€ 54,375$. Limiting the number of DSA studies reduces costs and risks, but also the reliability of determining optimal treatment mode. In one of the simulated scenarios a reduction of 46 DSA studies would have led to one unsuccessful coiling attempt and one clipping of an aneurysm that could have been coiled.

Conclusion: Acceptable results can be achieved by performing CEMRA as the first study in patients presenting with a SAH, and reserving additional DSA for cases in which CEMRA does not show an aneurysm, and for patients with aneurysms who are to be referred for surgical clipping, but in whom the CEMRA verdict of non-coilability of the aneurysm leaves room for doubt. 


\section{Introduction}

At the present time the gold standard for imaging the cerebral vessels in patients suspected of harboring an intracranial aneurysm is digital subtraction angiography (DSA). The risk of complications associated with cerebral DSA, although low, is not negligible. ${ }^{1-4}$ Therefore a search is ongoing for an adequate non-invasive alternative for imaging the cerebral vessels and aneurysms originating from these vessels.

Alternative techniques presently in use are computed tomographic angiography (CTA) and magnetic resonance angiography (MRA).

MRA is a less invasive technique than DSA, but quality of MRA images is also somewhat less. The image quality is however generally adequate for aneurysm detection. ${ }^{5-10}$ The value of MRA has been established in screening for asymptomatic cerebral aneurysms ${ }^{11}$ and for assessing aneurysm occlusion after endovascular coiling. ${ }^{12-14}$ When a patient presents with a subarachnoid hemorrhage (SAH) and MRA fails to reveal a cerebral aneurysm as the cause of bleeding, a DSA study is indicated to confirm the normal findings.

First-pass or contrast enhanced magnetic resonance angiography (CEMRA) has shorter acquisition times than flow dependent MRA sequences and does not suffer from signal loss due to turbulent or slow flow or as a result from spin saturation in larger scan volumes which might improve diagnostic accuracy. ${ }^{6,8,9,15-17}$ The present study deals with the assessment of CEMRA for the detection and characterization of cerebral aneurysms.

The diagnostic work up of patients suspected of harboring an intracranial aneurysm comprises more than only detecting the aneurysm. The morphology of the aneurysm must be ascertained in order to determine its suitability for the preferred endovascular treatment, its "coilability". Criteria determining the feasibility of endovascular coiling are the neck-to-dome ratio of the aneurysm as well as the absolute size of the neck, and the absence of branch vessels at the neck of the aneurysm. Aneurysms which are not suitable for coiling on the basis of these morphological criteria, are referred for surgical clipping if possible.

If an aneurysm is classified incorrectly on the basis of the CEMRA findings the consequences may be as follows:

- When the aneurysm is mistakenly regarded as being suitable for endovascular coiling this will result in an unsuccessful attempt to coil aneurysm under general anesthesia.

- When the aneurysm is mistakenly regarded as being unsuitable for endovascular coiling and the patient is referred for neurosurgical clipping while in fact the aneurysm is suitable for coiling, the patient is denied the benefits of endovascular treatment as documented in the International Subarachnoid Aneurysm Trial (ISAT). ${ }^{18}$

If CEMRA were to replace completely the more costly and invasive DSA examination, its performance in detection and morphologic assessment of cerebral aneurysms would need to be fully equivalent to that of DSA. As this is presently not the case, strategies will need to be devised in which CEMRA can be employed as initial study, followed if necessary by DSA, with the aim being to reduce as much as 
possible the number of DSA examinations performed in these patients while maintaining an acceptable level of diagnostic accuracy for aneurysm detection as well as assessment of suitability of the aneurysm for endovascular coiling. Beside the reduction of risk, when CEMRA is used, there is also a cost saving. ${ }^{13,19}$

In the present study four diagnostic scenarios employing various combinations of CEMRA and DSA are compared with regard to diagnostic accuracy as well as costs.

\section{Materials and Methods}

\section{Study design}

The study made use of the CEMRA and DSA imaging data which had been acquired in 75 consecutive patients presenting with a SAH, in a study assessing the validity of CEMRA in the detection and workup to treatment of patients suspected of harboring an intracranial aneurysm (see Chapters 2 and 3 ).

In the study the following four scenarios are compared with regard to firstly the effect of each scenario on treatment, and secondly to the costs generated by the different scenarios:

Scenario 1: All patients undergo only DSA. Selection of best treatment (endovascular coiling or surgical clipping) is based on the DSA findings.

Scenario 2: All patients first undergo CEMRA, and the selection of best treatment is based on the CEMRA findings. Only if no aneurysm is found will additional DSA be performed.

Scenario 3: All patients first undergo CEMRA. If no aneurysm is found or if there is doubt about the best treatment on the basis of CEMRA findings, additional DSA will be performed.

Scenario 4: All patients first undergo CEMRA. If no aneurysm is found or if there is doubt about the best treatment in the group allocated to surgical clipping, additional DSA will be performed in this group. All patients allocated to endovascular coiling on the basis of the CEMRA findings will go directly for coiling. To assess these four scenarios we asked two observers, a neuro-interventionist and a neurosurgeon, both experienced in treating cerebral aneurysms, to evaluate jointly the CEMRA studies of the patients harboring one or more aneurysms. The observers were asked to make a decision in consensus about the feasibility of endovascular treatment of the aneurysm. In a separate session all the DSA studies performed in these patients, either before treatment or as part of the coiling procedure, had previously also been blindly evaluated by the two observers in consensus. These DSA findings were regarded as the standard of reference. If the quality of the CEMRA study in a given patient was insufficient or if for other reasons the observers were not sure about their decision they could request access to the findings of the "gold standard" DSA study performed in that patient.

In this way the four scenarios could be simulated with the same observers evaluating both modalities.

\section{Patients}

Patient characteristics are described in Chapter 2. There are two alterations in the number of aneurysms that are described in Chapter 2. One aneurysm had been detected by CEMRA but the finding was not confirmed at the first DSA study because of temporary aneurysm thrombosis, and therefore regarded as a false positive CEMRA finding. A second DSA examination however confirmed the CEMRA finding of an 
aneurysm, which was considered as a true aneurysm in the present study and therefore presented to the observers for assessment of its coilability. In another patient a small right internal carotid artery aneurysm, additional to a larger ruptured left ophthalmic artery aneurysm, was not presented to the observers in this study because no treatment was considered for this aneurysm.

\section{Techniques}

MRA:

MRA was performed on a 1.5 Tesla system using a dedicated head coil (Intera; Philips Medical Systems, Best, the Netherlands). The scan protocol included an ultra-short first-pass CEMRA sequence with concentric k-space filling. Scan parameters were: parallel imaging (SENSE), TR 5.4 / TE 1.68 ms, flip angle $35 \mathrm{deg}$, FOV $256 \mathrm{~mm}$ (rectangular FOV 65\%), matrix 512, ${ }^{2}$ slice thickness $0.4 \mathrm{~mm}$, coronal orientation (parallel to basilar artery), one stack. The contrast medium employed was: gadopentetate dimeglumine (Magnevist ${ }^{\circledR}$, Bayer Schering Pharma, Leverkusen, Germany) $35 \mathrm{ml} \mathrm{IV,} 3 \mathrm{ml} / \mathrm{s}$ (2 $\mathrm{ml}$ for a timing sequence and $33 \mathrm{ml}$ for the CE-MRA sequence), flushed with $25 \mathrm{ml} \mathrm{NaCl} \mathrm{0,9 \%}$ at $3 \mathrm{ml} / \mathrm{s}$.

The MRA studies were post-processed and evaluated by the observers using a dedicated workstation (Vitrea; Vital Images, Minnetonka, Minnesota, USA).

DSA:

All four feeding arteries to the brain were catheterized and imaged in our angiography suite (Integris; Philips Medical Systems, Best, the Netherlands), except for two patients in whom, due to patient unrest, only the vessel which harbored the suspected aneurysm could be catheterized. A 4 or $5 \mathrm{~F}$ catheter system was used for diagnostic DSA and a $6 \mathrm{~F}$ system in cases where immediate endovascular treatment was anticipated. Contrast injections were performed by power injector (Medrad Inc., Warrendale PA, USA), delivering $9 \mathrm{ml}$ iobitridol $350 \mathrm{mg} / \mathrm{ml}$ (Xenetix ${ }^{\circledR}$, Guerbet, Villepinte, France) at $5 \mathrm{ml} / \mathrm{s}$ for the carotid arteries and $8 \mathrm{ml}$ at $4 \mathrm{ml} / \mathrm{s}$ for the vertebral arteries. Internal carotid arteries were imaged in antero-posterior, lateral and oblique projections and the vertebral arteries in antero-posterior and lateral projections. Additional angiographic projections were obtained if necessary, of the vessels that harbored an aneurysm, for better visualization of the aneurysm, its neck and the surrounding arteries.

\section{Image interpretation and statistical analysis}

The CEMRA data were post-processed and the images jointly evaluated on the workstation by the two observers. Scoring criteria were: quality of images, size of the aneurysm, feasibility of endovascular treatment. Quality of images was rated on a three point scale: 'poor', 'moderate' and 'good'. Size of the aneurysm was rated on a four point scale: small $(<5 \mathrm{~mm})$, medium $(5-15 \mathrm{~mm})$, large $(15-25 \mathrm{~mm})$ and giant $(>25 \mathrm{~mm})$. Feasibility of endovascular treatment was rated on a two point scale (yes/no) by the observers. Sensitivity and specificity for prediction of coilability were calculated on a per aneurysm basis.

For cost calculation the costs of MRA and DSA are derived from the Dutch hospital cost reimbursement system. ${ }^{20}$ Because controversy exists about the difference in costs of coiling and clipping, ${ }^{21}$ the cost effect of an incorrect decision with regard to coiling or clipping is not taken into account. 


\section{Results}

In this population of 75 patients, 58 patients harbored 65 aneurysms: 52 patients with one aneurysm, five patients with two aneurysms and one patient with three aneurysms.

Forty-three of the 58 CEMRA studies that were studied by the two observers were regarded as of good quality, eight as moderate and seven as poor.

Forty of the aneurysms measured on the CEMRA images were small (less than $5 \mathrm{~mm}$ in diameter), 20 were of medium size (between 5 and $15 \mathrm{~mm}$ ) and five were large (between 15 and $25 \mathrm{~mm}$ ). There were no giant (>25 $\mathrm{mm}$ ) aneurysms.

Results for prediction of coilability of the 65 aneurysms are given in Table 1.

Table 1. Coilability of all 65 aneurysms

\begin{tabular}{|c|c|c|c|c|}
\hline & & \multicolumn{2}{|c|}{ Coilable? (DSA) } & \multirow[b]{2}{*}{ Total } \\
\hline & & no & yes & \\
\hline Coilable? & no & 24 & 6 & 30 \\
\hline (CEMRA) & yes & 3 & 32 & 35 \\
\hline \multicolumn{2}{|c|}{ Total } & 27 & 38 & 65 \\
\hline
\end{tabular}

Sensitivity of CEMRA for prediction of coilability was $84.2 \%$ (95\% confidence interval (Cl) $72.6-95.8 \%$ ) and specificity was $88.9 \%$ (95\% Cl $77.0-100 \%)$. Negative predictive value (NPV) and positive predictive value (PPV) were $80 \%$ (95\% Cl 65.7 - 94.3\%) and 91.4\% (95\% Cl 82.1 - 100\%) respectively.

In 37 patients harboring 40 of the 65 aneurysms (61.5\%) the observers had been confident enough about their prediction of coilability by CEMRA to state that no additional DSA was needed. For 21 patients harboring 25 of the 65 aneurysms (38.5\%) access to the DSA study of the aneurysm was considered necessary before a definite decision on coilability could be made.

If in this last group a decision were to be made solely on the CEMRA images, five of the 15 coil able aneurysms would have been judged as not coilable, and of the ten aneurysms which were not coilable, two would have been considered coilable (Table 2).

Table 2. Coilability of the aneurysms for which an additional DSA was requested by the observers.

\begin{tabular}{|c|c|c|c|c|}
\hline \multicolumn{2}{|c|}{} & \multicolumn{2}{c|}{ Coilable? (DSA) } \\
\cline { 3 - 5 } \\
\cline { 3 - 5 } $\begin{array}{l}\text { Coilable? } \\
\text { (CEMRA) }\end{array}$ & no & 8 & 5 & 13 \\
& Total & 2 & 10 & 12 \\
\hline
\end{tabular}

The cost of an MRA study as calculated from the Dutch reimbursement system ${ }^{20}$ is $€ 252$, and for a diagnostic DSA study the cost is $€ 725$.

The total 'diagnostic costs' for the 75 patients in Scenario 1 is $75 x € 725=€ 54,375$. For Scenario 2 this would be $75 x € 252+16 x € 725=€ 30,500$. For Scenario 3 the costs amount to $75 x € 252+37 x € 725$ $=€ 45,725$ and for Scenario 4 the costs are $75 x € 252+29 x € 725=€ 39,925$ (see Table 3). 
Table 3. Consequences of the four different scenarios.

\begin{tabular}{|c|c|c|c|c|}
\hline Scenario & $\mathbf{1}$ & $\mathbf{2}$ & $\mathbf{3}$ & $\mathbf{4}$ \\
\hline Patients undergoing DSA & 75 & 16 & 37 & 29 \\
\hline Diagnostic costs (€) & 54,375 & 30,500 & 45,725 & 39,925 \\
\hline Unjustified clipping (pt) & 0 & 6 & 1 & 1 \\
\hline Unsuccessful coiling (pt) & 0 & 1 & 0 & 1 \\
\hline
\end{tabular}

\section{Discussion}

The least costly of the four scenarios which were studied is Scenario 2, in which all patients underwent CEMRA and only the 16 patients with normal CEMRA findings would undergo additional diagnostic DSA. In this scenario however, of the 65 aneurysms which were present in our patient group, three aneurysms in two patients would have been assigned to a coiling procedure which, according to the DSA findings, would not have proved to be possible. One of those three was a left middle cerebral artery (MCA) aneurysm additional to a left posterior inferior cerebellar artery (PICA) aneurysm. This PICA aneurysm was judged coilable on both MRA and DSA, and was successfully coiled. So in this patient no unfruitful attempt at coiling would have been undertaken and the DSA study performed during the coiling of the PICA aneurysm would show the true nature and non-coilability of the MCA aneurysm. The other two aneurysms were a small lobulated right posterior communicating (PCom) aneurysm and a small left PCom aneurysm, both in the same patient. This patient would have undergone an unsuccessful attempt at coiling of the two aneurysms under general anesthesia in Scenario 2. Another six aneurysms would have been referred for surgery while coiling of the aneurysm was in fact possible, depriving the patients of the benefit of the preferred coiling procedure, if this scenario had been implemented. Four of these aneurysms were anterior communicating (ACom) aneurysms, three small and one large. The other two were a small left and a medium sized right MCA aneurysm.

Scenario 3 in this group of 75 patients would result in the performance of 75 CEMRA studies and an additional 37 DSA studies. The total diagnostic costs per patient in this scenario are lower than those of the first scenario, as 38 patients would not need to undergo DSA in the diagnostic phase. In this scenario one aneurysm was considered not coilable on the basis of the CEMRA images but proved to be coilable on the "gold standard" DSA images, though in this case DSA had not been requested by the observers. This was a left small MCA aneurysm (Figure 1). The observers reported a wide neck and uncertainty about the relation of the MCA branches to the neck of the aneurysm.

One aneurysm was judged to be coilable on the CEMRA images, but proved to be not coilable on the "gold standard" DSA images, in a case in which no additional DSA had been considered necessary by the observers. This aneurysm was the left MCA aneurysm also described above in Scenario 2, which was additional to a coilable PICA aneurysm. Again this would not have resulted in an unnecessary procedure as explained above.

Altogether Scenario 3 would have resulted in a saving of 38 diagnostic DSA studies at the cost of one aneurysm being clipped although a coiling procedure would in fact have been possible. 
In Scenario 4 only the patients in whom no aneurysm could be detected by CEMRA as well as those who had been allocated to surgery but in whom doubt remained about the best mode of treatment, would undergo DSA and all the patients allocated to coiling would go directly for coiling under general anesthesia. This would prevent another eight diagnostic DSA studies at the cost of one patient - the individual with two PCom aneurysms mentioned in Scenario 2- undergoing a procedure under general anesthesia where the non-coilable nature of the two aneurysms would be revealed.

The costs of the four scenarios are summarized in Table 3.

Scenario 1, in which all patients undergo only the standard of reference DSA examination, is the most expensive and invasive one.

Scenario 2, in which only patients with a negative CEMRA study undergo DSA, generates the least costs, but is associated with a number of classification errors which is prohibitively high.

In Scenario 3 only CEMRA findings which fail to detect an aneurysm or those which leave doubt with regard to the best treatment (clipping or coiling) are verified by DSA. This strategy leads to only a single misclassification but cost savings are not great.

In Scenario 4 the role of DSA is further limited to CEMRA studies with negative findings and those in which doubt remains only in the subgroup assigned to surgical clipping. Cost savings are more substantial here, but at the price of one further misclassification.
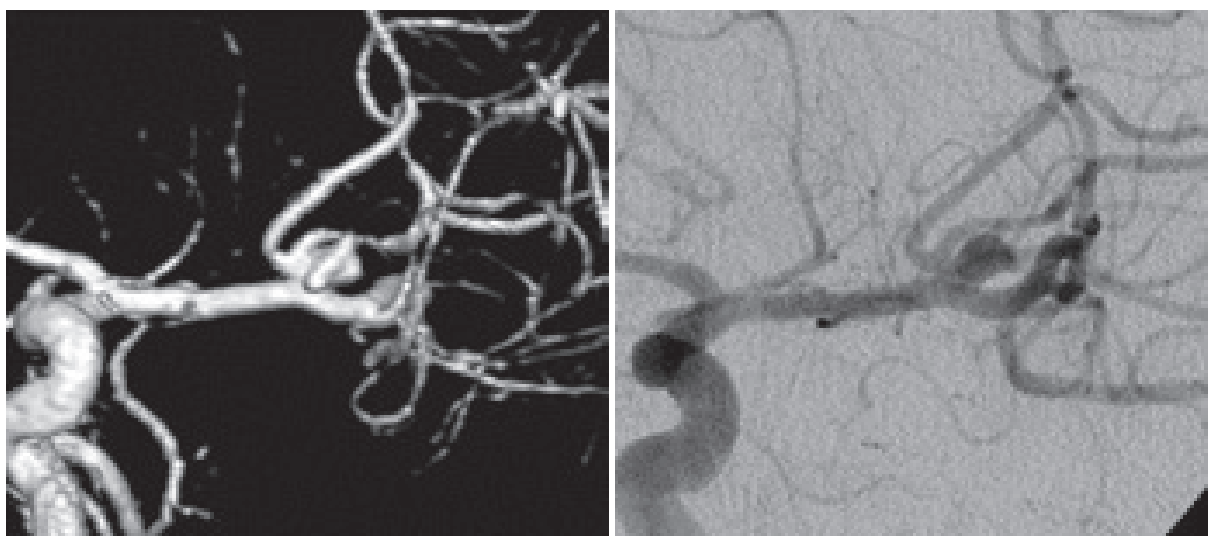

Figure 1. Patient with left middle cerebral artery aneurysm. a: Volume rendered reconstruction of CEMRA study. The observers considered this aneurysm as not suitable for coiling due to wide neck and branch arising from the neck of the aneurysm. No additional DSA was required by the observers. b: Oblique projection of DSA study. The aneurysm was considered suitable for coiling. The neck appears smaller than on CEMRA. The aneurysm was successfully coiled.

With regard to the effects of misclassification the results of ISAT ${ }^{18}$ have shown a slightly but significantly better clinical outcome for patients treated by endovascular coiling compared with surgical clipping, at one year after treatment. The differences in outcome are smaller after a longer period ${ }^{22,23}$ and some authors even state that coiling and clipping should be considered as equivalent for results in the long term. ${ }^{24}$ Therefore the negative effect of a surgical clipping procedure where endovascular coiling would also have been feasible, is likely to be limited. 
On the other hand, when a coiling procedure is unsuccessfully attempted for an aneurysm which is in fact not suitable for endovascular treatment, the patient undergoes a procedure under general anesthesia which would not have been necessary if a diagnostic DSA study had been performed earlier. With regard to the risk of DSA, these studies pose relatively little hazard to the patient, with morbidity and mortality rates of 0.14 and $0.06 \%$ respectively (although the presence of SAH has been associated with an increased risk). ${ }^{3}$

Only a few reports on cerebral aneurysm detection by CEMRA have been published ${ }^{6,7,9,25,26}$ and to our knowledge no study has been published to date addressing the question whether CEMRA can be used for treatment planning.

An alternative technique to CEMRA is CTA. This technique has some disadvantages compared to CEMRA, as ionizing radiation is employed, while X-ray contrast media are considered to be more invasive than MR contrast media. The accuracy of aneurysm detection by CTA has been described in two metaanalyses. $^{27,28}$

There are few reports in the literature describing the accuracy CTA in deciding whether endovascular treatment is possible. ${ }^{29-32}$ One study, using CTA as the only pretreatment modality for aneurysm detection and treatment planning, states that in only $18 \%$ (41/223) of patients with an aneurysm was an additional DSA study needed for treatment planning. ${ }^{30}$ The report does not mention however whether all the decisions on treatment mode made on the basis of CTA were correct. Other studies report strategies using CTA as a pretreatment modality, ${ }^{33-37}$ but none specify the accuracy in guiding the decision whether to perform endovascular treatment or not.

CTA has the logistical advantage that it can be performed directly following a diagnostic CT study aimed at detecting the presence of blood in the subarachnoid cisterns, without the need to transport the patient.

\section{Conclusion}

Diagnostic strategy in patients who have undergone a SAH and are suspected of harboring an intracranial aneurysm must focus on accurate detection and reliable morphologic classification of the aneurysm in order to assist selection of the preferred type of treatment: endovascular coiling or surgical clipping. Given the higher cost and more invasive nature of DSA, several strategies using a technique such as CEMRA can be employed. The present study indicates that acceptable results can be achieved by performing CEMRA as the first study, and reserving DSA for cases in which CEMRA produces a negative result or leaves room for doubt in patients who are to be referred for surgical clipping.

\section{References}

1 Dawkins, A. A. et al. Complications of cerebral angiography: a prospective analysis of 2,924 consecutive procedures. Neuroradiology 49, 753-759, (2007).

2 Fifi, J. T. et al. Complications of modern diagnostic cerebral angiography in an academic medical center. $J$ Vasc Interv Radiol 20, 442-447, (2009). 
Kaufmann, T. J. et al. Complications of diagnostic cerebral angiography: evaluation of 19,826 consecutive patients. Radiology 243, 812-819, (2007).

Willinsky, R. A. et al. Neurologic complications of cerebral angiography: prospective analysis of 2,899 procedures and review of the literature. Radiology 227, 522-528, (2003). with subarachnoid haemorrhage. Eur Radiol, (2012).

Metens, T. et al. Intracranial aneurysms: detection with gadolinium-enhanced dynamic three-dimensional MR angiography-initial results. Radiology 216, 39-46, (2000).

Nael, K. et al. 3-T contrast-enhanced MR angiography in evaluation of suspected intracranial aneurysm: comparison with MDCT angiography. AJR Am J Roentgenol 190, 389-395, (2008).

Nael, K. et al. Contrast-enhanced MR angiography at 3T in the evaluation of intracranial aneurysms: a comparison with time-of-flight MR angiography. AJNR Am J Neuroradiol 27, 2118-2121, (2006).

Unlu, E., Cakir, B., Gocer, B., Tuncbilek, N. \& Gedikoglu, M. The role of contrast-enhanced MR angiography in the assessment of recently ruptured intracranial aneurysms: a comparative study. Neuroradiology 47, 780-791, (2005).

10 Zwam, W. H. v. et al. Diagnostic performance of contrast enhanced magnetic resonance angiography in detecting intracranial aneurysms in patients presenting with subarachnoid haemorrhage. EJMINT, (2012). Raaymakers, T. W. et al. MR angiography as a screening tool for intracranial aneurysms: feasibility, test characteristics, and interobserver agreement. AJR Am J Roentgenol 173, 1469-1475, (1999).

Bakker, N. A. et al. Feasibility of magnetic resonance angiography (MRA) follow-up as the primary imaging modality after coiling of intracranial aneurysms. Acta Radiol 51, 226-232, (2010).

Schaafsma, J. D. et al. Cost-effectiveness of magnetic resonance angiography versus intra-arterial digital subtraction angiography to follow-up patients with coiled intracranial aneurysms. Stroke 41, 1736-1742, (2010).

Schaafsma, J. D. et al. Intracranial aneurysms treated with coil placement: test characteristics of follow-up MR angiography--multicenter study. Radiology 256, 209-218, (2010).

Gottschalk, S. et al. [Contrast-enhanced intracranial 3 D MR angiography (CE-MRA) in assessing arterial stenoses and aneurysms]. Rofo 174, 704-713, (2002).

16 Sungarian, A., Rogg, J. \& Duncan, J. A., 3rd. Pediatric intracranial aneurysm: a diagnostic dilemma solved with contrast-enhanced MR imaging. AJNR Am J Neuroradiol 24, 370-372, (2003).

Isoda, H. et al. Contrast-enhanced three-dimensional MR angiography with an elliptical centric view for the evaluation of intracranial aneurysms. Eur Radiol 17, 1221-1225, (2007).

Molyneux, A. et al. International Subarachnoid Aneurysm Trial (ISAT) of neurosurgical clipping versus endovascular coiling in 2143 patients with ruptured intracranial aneurysms: a randomised trial. Lancet 360, 1267-1274, (2002).

Hay, J. W. et al. Cost impact of diagnostic imaging for lower extremity peripheral vascular occlusive disease. Value Health 12, 262-266, (2009).

20 dbc-tarieven.nza.nl, <http://dbc-tarieven.nza.nl/Nzatarieven/top.do> (2011).

21 Lawson, M. F. \& Hoh, B. L. Clipping versus coiling: the total hospital cost of aneurysm treatment. World Neurosurg 73, 430-431, (2010).

22 Molyneux, A. J. et al. Risk of recurrent subarachnoid haemorrhage, death, or dependence and standardised mortality ratios after clipping or coiling of an intracranial aneurysm in the International Subarachnoid Aneurysm Trial (ISAT): long-term follow-up. Lancet Neurol 8, 427-433, (2009). Qureshi, A. I., Janardhan, V., Hanel, R. A. \& Lanzino, G. Comparison of endovascular and surgical treatments for intracranial aneurysms: an evidence-based review. Lancet Neurol 6, 816-825, (2007). Bakker, N. A., Metzemaekers, J. D., Groen, R. J., Mooij, J. J. \& Van Dijk, J. M. International subarachnoid aneurysm trial 2009: endovascular coiling of ruptured intracranial aneurysms has no significant advantage over neurosurgical clipping. Neurosurgery 66, 961-962, (2010). Jager, H. R. et al. Contrast-enhanced MR angiography of intracranial giant aneurysms. AJNR Am J Neuroradiol 21, 1900-1907, (2000).

26 Suzuki, I. M. et al. Contrast-enhanced MR angiography (enhanced 3-D fast gradient echo) for diagnosis of cerebral aneurysms. Neuroradiology 44, 17-20, (2002).

27 Westerlaan, H. E. et al. Intracranial aneurysms in patients with subarachnoid hemorrhage: CT angiography as a primary examination tool for diagnosis--systematic review and meta-analysis. Radiology 258, 134145, (2011).

28 White, P. M., Wardlaw, J. M. \& Easton, V. Can noninvasive imaging accurately depict intracranial aneurysms? A systematic review. Radiology 217, 361-370, (2000). 
29 Chen, W., Yang, Y., Xing, W., Qiu, J. \& Peng, Y. Application of multislice computed tomographic angiography in diagnosis and treatment of intracranial aneurysms. Clin Neurol Neurosurg 112, 563-571, (2010).

30 Hoh, B. L. et al. Results of a prospective protocol of computed tomographic angiography in place of catheter angiography as the only diagnostic and pretreatment planning study for cerebral aneurysms by a combined neurovascular team. Neurosurgery 54, 1329-1340; discussion 1340-1322, (2004). Papke, K. et al. Intracranial aneurysms: role of multidetector CT angiography in diagnosis and endovascular therapy planning. Radiology 244, 532-540, (2007).

32 Westerlaan, H. E. et al. Multislice CT angiography in the selection of patients with ruptured intracranial aneurysms suitable for clipping or coiling. Neuroradiology 49, 997-1007, (2007).

33 Anderson, G. B., Steinke, D. E., Petruk, K. C., Ashforth, R. \& Findlay, J. M. Computed tomographic angiography versus digital subtraction angiography for the diagnosis and early treatment of ruptured intracranial aneurysms. Neurosurgery 45, 1315-1320; discussion 1320-1312, (1999).

34 Boet, R., Poon, W. S., Lam, J. M. \& Yu, S. C. The surgical treatment of intracranial aneurysms based on computer tomographic angiography alone--streamlining the acute mananagement of symptomatic aneurysms. Acta Neurochir (Wien) 145, 101-105; discussion 105, (2003).

35 Matsumoto, M. et al. Three-dimensional computerized tomography angiography-guided surgery of acutely ruptured cerebral aneurysms. J Neurosurg 94, 718-727, (2001). Velthuis, B. K. et al. Subarachnoid hemorrhage: aneurysm detection and preoperative evaluation with CT angiography. Radiology 208, 423-430, (1998).

37 Zouaoui, A. et al. Three-dimensional computed tomographic angiography in detection of cerebral aneurysms in acute subarachnoid hemorrhage. Neurosurgery 41, 125-130, (1997). 


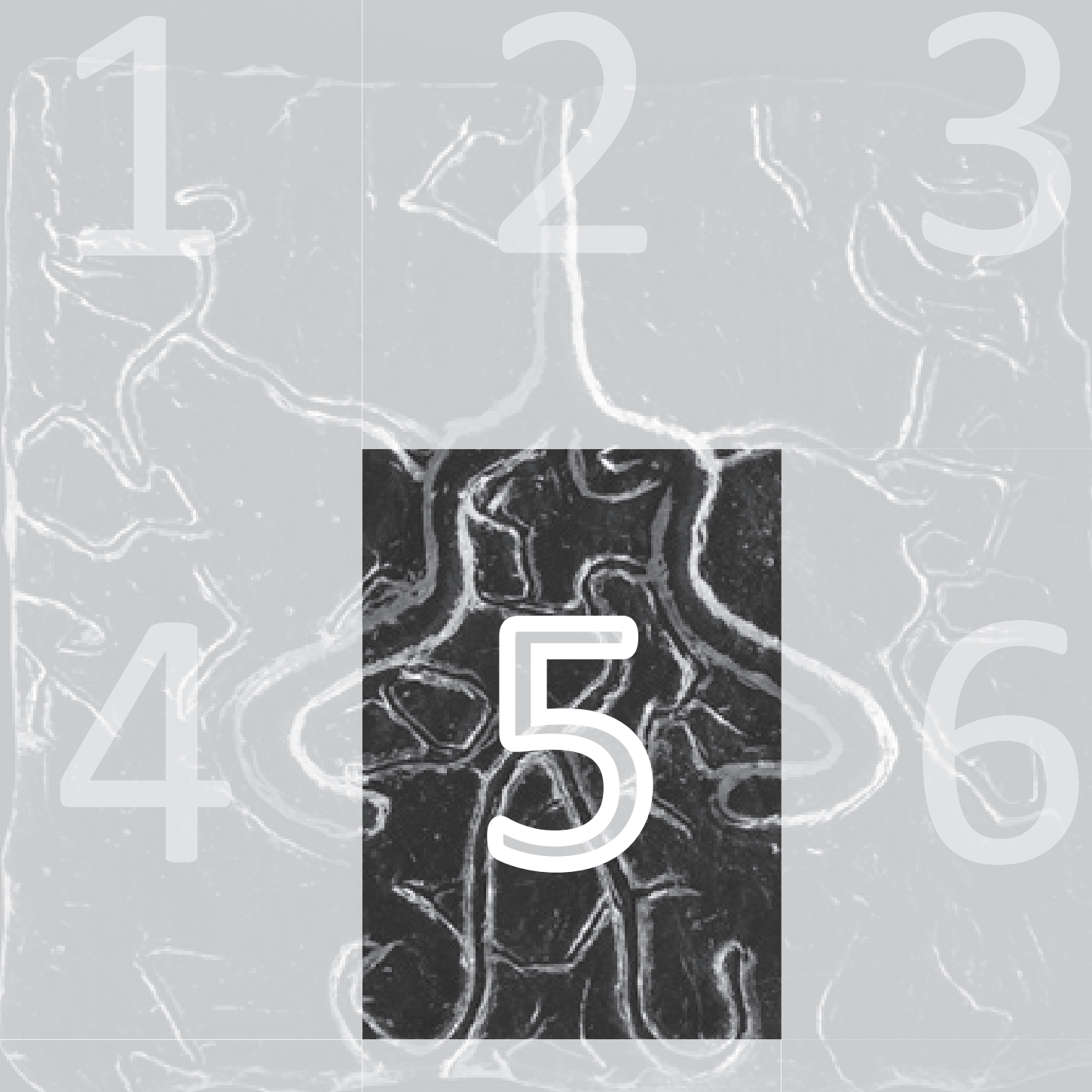




\section{Chapter 5}

Single center experience of surgical and endovascular treatment of ruptured cerebral aneurysms

E.G. Klompenhouwer

J.T.A. Dings

R.J. van Oostenbrugge

S. Oei

J.T. Wilmink

W.H. van Zwam

Published in the American Journal of Neuroradiology (AJNR) 2011 Mar;32(3):570-5. Epub 2011 Feb 24 


\section{Abstract}

Background and purpose: The International Subarachnoid Aneurysm Trial (ISAT) provided valuable data on patient outcome after endovascular coiling and surgical clipping of ruptured aneurysms. The purpose of this study was to retrospectively review the $\geq 1$-year outcome (in terms of survival, independence, and rebleeding) of patients who were treated in a routine clinical setting

Material and methods: Records of patients presenting with a subarachnoid hemorrhage (SAH) from a ruptured aneurysm between 2000 and 2008 were reviewed. The 403 patients who met the inclusion criteria harbored 443 treated aneurysms; 173 were managed surgically and 230 by endovascular means. Mean clinical follow-up was 33.9 months (range, 12-106 months).

Results: The pretreatment clinical condition according to the Hunt and Hess grading scale (HH) was significantly better in the surgically treated patients $(p=0.018)$. Death occurred in $11.6 \%$ after surgery and in $17.4 \%$ after endovascular treatment $(p=0.104)$. Of the surviving patients in the surgical and endovascular groups, $80.3 \%$ and $87.2 \%$, respectively, were able to live independently with grades 0-2 on the modified Rankin scale (mRS) ( $p=0.084)$. Complete aneurysm occlusion was achieved significantly more often after surgical treatment ( $<$ 0.001). Rebleeding occurred in $3.1 \%$ and $2.3 \%$ of the patients after surgical treatment and endovascular coiling, respectively. The occurrence of a residual aneurysm at the end of a coiling procedure was significantly related to the frequency of rebleeding $(p=0.007)$.

Conclusion: The management of patients with intracranial aneurysms in a routine clinical setting shows good and comparable rates of mortality and independence. Coiling results in lower rates of complete aneurysm occlusion. Postcoiling angiography showing a residual aneurysm is a good predictor of the risk of rebleeding. 


\section{Introduction}

Intracranial aneurysms are an important health problem worldwide, affecting about $2 \%$ of the population. ${ }^{1}$ Treatment consists of the exclusion of the malformation from the intracranial circulation to eliminate the risk of bleeding or rebleeding. Intracranial aneurysms can be treated by endovascular coiling or by surgical clipping. Since the introduction of the Guglielmi Detachable Coils (GDCs), ${ }^{1-3}$ endovascular treatment of intracranial aneurysms has evolved rapidly as an alternative to microsurgical clipping. Coiling has become the preferential treatment since the International Subarachnoid Aneurysm Trial (ISAT) demonstrated its clinical superiority over clipping in patients with a ruptured aneurysm who were eligible for both treatment types. ${ }^{4-6}$ However, many aneurysms are preferentially treated by either neurosurgery (eg, middle cerebral artery (MCA) aneurysms) or by endovascular treatment (eg, posterior circulation aneurysms). ${ }^{7}$ Moreover, coiling achieves lower rates of complete occlusion compared with microsurgical clipping, which may affect the long-term stability and rates of rebleeding. ${ }^{8-11}$ The results of ISAT were based on a selected patient population with aneurysms suitable for both endovascular and surgical treatment in a trial setting. Few data are available on the outcome of patients who are either endovascularly or surgically treated in a routine clinical practice. In our center, intracranial aneurysms are treated either by surgical or by endovascular means, according to a decision reached by a multidisciplinary team that includes a neurologist, neurosurgeon, and interventional radiologist.

Therefore, the purpose of the present study was to review the outcomes in a consecutive cohort of patients who were either endovascularly or surgically treated for a ruptured intracranial aneurysm in a routine clinical setting. The outcome was determined by rates of survival, independence, retreatment, and rebleeding after $\geq 1$ year of clinical follow-up.

\section{Materials and methods}

\section{Patients}

Between 2000 and 2008, 531 patients harboring one or more intracranial aneurysms were admitted to our institution. We retrospectively reviewed the medical reports, imaging studies, and reports of endovascular and surgical procedures of these patients.

Subarachnoid hemorrhage (SAH) was diagnosed by cerebral CT or CSF examination. The aneurysmal origin of the SAH was confirmed by computed tomographic angiography (CTA), magnetic resonance angiography (MRA), or digital subtraction angiography (DSA). The clinical status of the patient was rated by using the Hunt and Hess grading scale $(\mathrm{HH}) .{ }^{12}$ All patients received calcium channel blockers.

Figure 1 shows the flow diagram of our patient selection. Patients were included in our analysis if they had a ruptured intracranial aneurysm and underwent either surgical or endovascular treatment. Patients were excluded from this analysis if they met any of the following criteria: 1) presenting with non-ruptured intracranial aneurysm, 2) $\geq 1$ aneurysm treated in another center, 3) both surgical and endovascular treatment applied in the same patient, and 4) aneurysms treated by parent vessel occlusion. One hundred and twenty-eight patients were excluded from the analysis: Forty-nine patients 
did not receive an intervention, and 79 were treated but did not meet the inclusion criteria (Fig 1). The remaining 403 patients presenting with a ruptured aneurysm were included in this study.

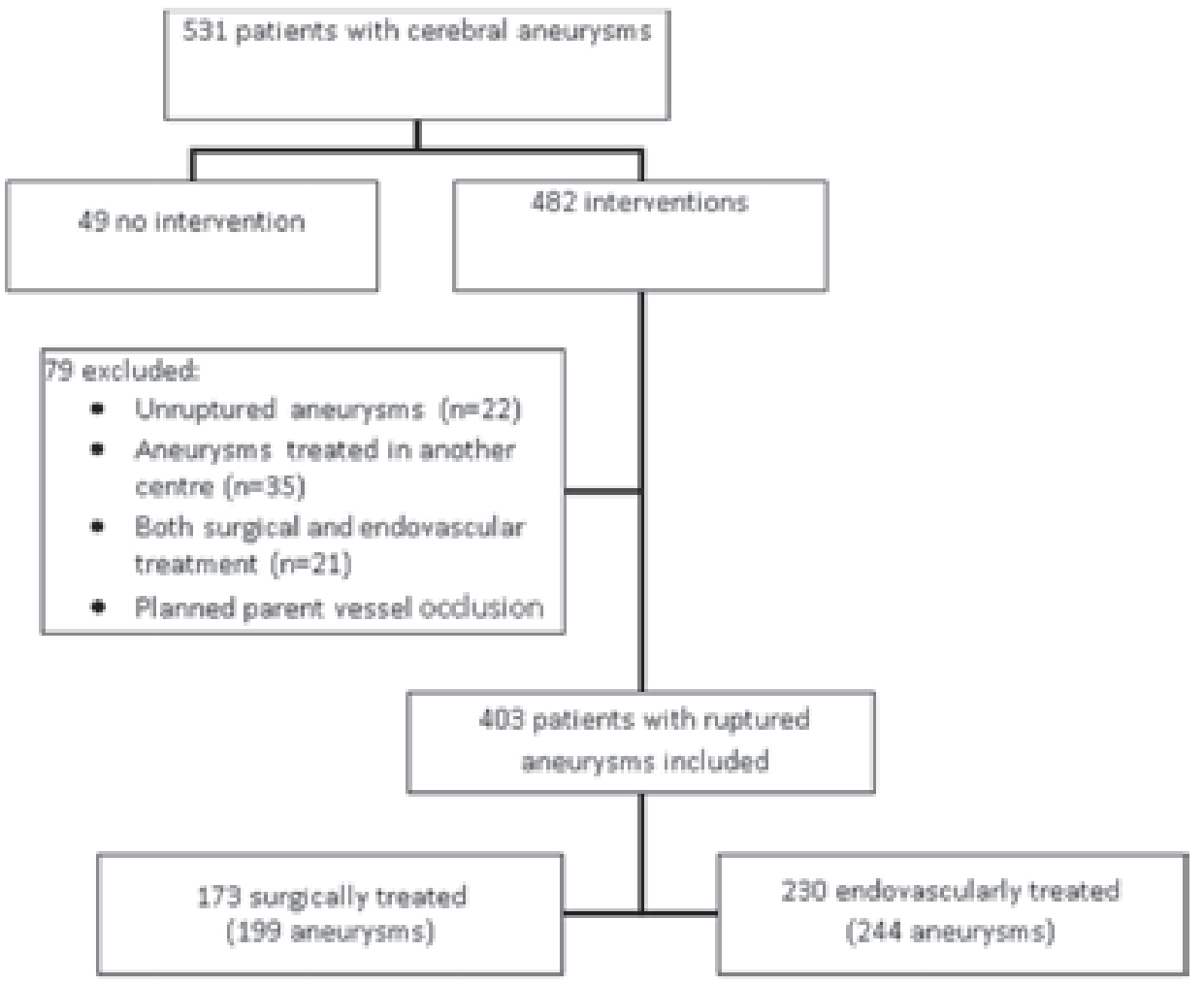

Figure 1. Flow diagram of patient selection

\section{Treatment protocol}

Patient selection for either endovascular coiling or surgical clipping was made by a multidisciplinary team, including a neurologist, neurosurgeon, and interventional radiologist. Endovascular coiling was the preferential treatment for all patients admitted to our institution; surgery was limited to those cases not suitable for coiling. Patients presenting with $\mathrm{HH}$ 4-5 following a ruptured aneurysm were not eligible for surgical treatment. However, in case of an emergency craniotomy for intracranial decompression in this group of patients, surgical clipping could also be performed. $\mathrm{HH} 4$ or 5 was usually not considered to be a contraindication for endovascular treatment.

Endovascular treatment was performed by an interventional neuroradiologist, with the patient under general anesthesia. We used mainly GDCs (Boston Scientific, Natick, Massachusetts). Use of the balloonassisted technique or TriSpan coils (Boston Scientific) was restricted to patients with aneurysms that were not suitable for neurosurgical treatment and when the aneurysm could not be coiled successfully without these additional devices. 
Coil placement was continued until complete angiographic obliteration was achieved or no more coils could be placed safely in the aneurysm. All patients received $5000 \mathrm{IU}$ heparin during the procedure. Postoperative patients were treated with a therapeutic dose of low-molecular-weight heparin for 2 days. Thereafter, patients were prescribed antiplatelet therapy.

Surgical treatment was performed by a neurosurgeon and consisted of direct clipping of the aneurysm neck. Wrapping and coagulation of the aneurysm were performed if the aneurysm neck was not suitable for clipping. Temporary clipping of the parent artery was performed at the discretion of the surgeon. Flow measurements were performed if possible.

\section{Series}

Four hundred and three patients harboring 443 treated aneurysms were included in this study; 173 patients harboring 199 aneurysms underwent surgical treatment. Clipping was performed in 190 aneurysms, 2 of which had additional wrapping; 9 underwent primary coagulation and wrapping without clips being placed. Two hundred and thirty patients harboring 244 aneurysms underwent endovascular treatment; the balloon-assisted technique was used in only 4 aneurysms, and the TriSpan coil, in 1 aneurysm.

Table 1 shows the patient and aneurysm characteristics. The distribution of age, sex, number of aneurysms treated, size, and morphology was very similar in both groups. Aneurysm locations are given in Table 2. The MCA was the only location in which more cases were treated by surgery than by endovascular techniques. This was mainly because of the anatomic characteristics of these aneurysms, which often have wide necks and incorporation of MCA branches. Aneurysms of the posterior circulation, however, were treated more frequently by endovascular coiling than by surgery.

Table 1. Patient and aneurysm characteristics

\begin{tabular}{|c|c|c|}
\hline & $\begin{array}{l}\text { Surgical group } \\
\text { Number (\%) }\end{array}$ & $\begin{array}{c}\text { Endovascular group } \\
\text { Number (\%) }\end{array}$ \\
\hline Number of patients & $173(42.9)$ & $230(57.1)$ \\
\hline Sex: male/female & $52(30.1) / 121$ (69.9) & $68(29.6) / 162(70.4)$ \\
\hline Age years (mean) & $17-77(53.1)$ & $16-97(53.6)$ \\
\hline Number of aneurysm treated & 199 & 244 \\
\hline $\begin{array}{r}\text { Number of aneurysms treated } \\
\text { per patient } \\
1 \\
2 \\
3 \\
5\end{array}$ & $\begin{array}{r}153(88.4) \\
16(9.2) \\
3(1.7) \\
1(0.6)\end{array}$ & $\begin{array}{r}218(94.8) \\
10(4.3) \\
2(0.9) \\
-\end{array}$ \\
\hline $\begin{array}{rr}\text { Size of treated aneurysm } \\
-\quad \text { Small }(<5 \mathrm{~mm}) \\
-\quad \text { Medium }(5-15 \mathrm{~mm}) \\
-\quad \text { Large }(15-25 \mathrm{~mm})\end{array}$ & $\begin{array}{r}96(48.2) \\
90(45.2) \\
13(6.5)\end{array}$ & $\begin{array}{r}98(40.2) \\
136(55.7) \\
10(4.1) \\
\end{array}$ \\
\hline $\begin{array}{rr}\text { Aneurysm morphology } \\
-\quad \text { Saccular } \\
-\quad \text { Dissecting } \\
-\quad \text { Fusiform }\end{array}$ & $\begin{array}{r}198(99.5) \\
- \\
1(0.5)\end{array}$ & $\begin{array}{r}242(99.2) \\
1(0.4) \\
1(0.4)\end{array}$ \\
\hline
\end{tabular}


Table 2. Aneurysm location

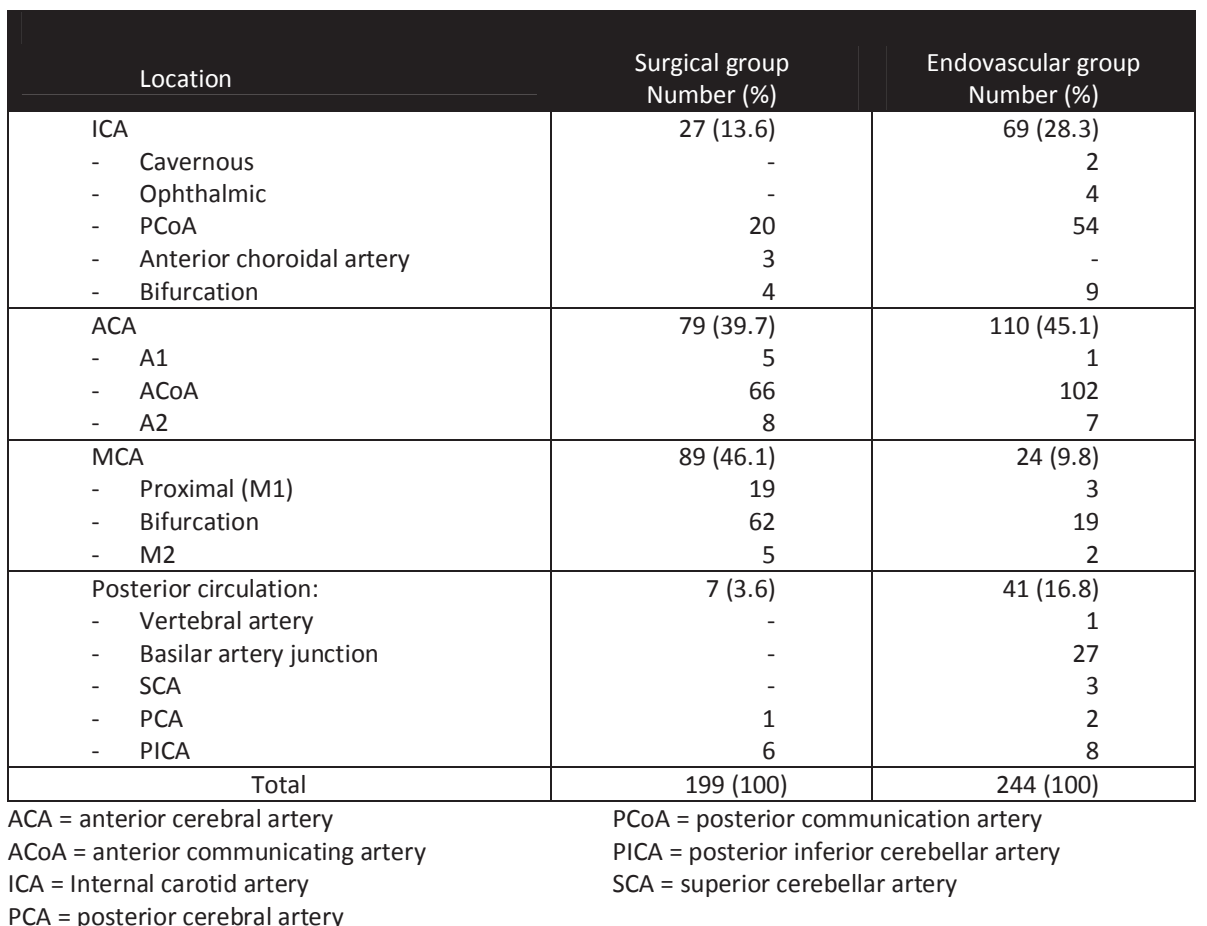

Regarding the mean clinical grading specified in Table 3, the clinical condition before treatment in the surgical group was significantly better than that in the group undergoing endovascular treatment $(p=0.018)$.

Table 3. Clinical grading at presentation

\begin{tabular}{|c|c|c|}
\hline HH & $\begin{array}{c}\text { Surgical group } \\
\text { Number (\%) }\end{array}$ & $\begin{array}{c}\text { Endovascular group } \\
\text { Number (\%) }\end{array}$ \\
\hline 1 & $64(37.0)$ & $65(28.2)$ \\
\hline 2 & $56(32.4)$ & $65(28.2)$ \\
\hline 3 & $17(9.8)$ & $42(18.3)$ \\
\hline 4 & $23(13.3)$ & $29(12.6)$ \\
\hline 5 & $13(7.5)$ & $29(12.6)$ \\
\hline Total & 173 & 230 \\
\hline
\end{tabular}

\section{Follow-up}

Clinical follow-up was performed in the endovascular and surgical groups during outpatient clinic visits. The report of the outpatient visits was missing in 43 patients. In those patients the clinical follow-up was obtained by structured telephone interviews, and by information provided by the general practitioner. Patients with a clinical follow-up period of less than one year were considered to be lost to follow-up. The clinical outcome was determined according to the following modified Rankin scale (mRS) $\mathrm{criteria}^{13}$ $0=$ no symptoms, 1 = no significant disability, despite symptoms, 2 = slight disability, $3=$ moderate 
disability, 4=moderately severe disability, $5=$ severe disability and $6=$ death. Clinically suspected rebleeding was confirmed by a CT scan of the brain.

Angiographic post-procedural follow-up was performed using DSA. The completeness of aneurysm occlusion was assessed using the Raymond classification (complete aneurysm occlusion, residual neck or residual aneurysm). ${ }^{14}$ In the endovascular treatment group, a post-procedural angiogram was always performed at the end of the coiling procedure. Imaging follow-up of coiled aneurysms was routinely carried out at 6 and 24 months after treatment. In case of increasing coil compaction angiographic follow-up was performed more frequently. Imaging follow-up was performed by DSA (62.4\%), and MRA (37.6\%).

Post-procedural angiography after neurosurgery was not standard practice, but was performed if the neurosurgeon found it necessary. This follow-up was performed by DSA (63.2\%), MRA (10.5\%) or CTA (26.3\%).

In case of coil compaction the problem was discussed in a multidisciplinary team including a neurologist, neurosurgeon, and interventional radiologist. An increasing size of the aneurysm remnant was only retreated if this was considered necessary and safe by the multidisciplinary team.

\section{Statistics}

Continuous variables are presented with means and ranges. Categorical data are given as frequencies and percentages and analyzed by T-test, Fisher's exact test or Chi square test accordingly. A p-value of $\leq$ 0.05 was considered to be statistically significant.

\section{Results}

\section{Clinical}

During the follow-up period, 20 patients (11.6\%) died after surgical treatment, 10 (50\%) of whom were graded $\mathrm{HH} 4$ or 5 at the time of presentation. Of these 20 deaths, 17 were related to the SAH or treatment of the cerebral aneurysm. The other three patients died of a pancreatic carcinoma $(n=1)$ or myocardial infarction $(n=2)$. In the endovascular group 40 patients $(17.4 \%)$ had died by the end of the follow-up period, 26 of whom (65\%) were graded 4 or 5 on the $\mathrm{HH}$ at the time of presentation. Thirtyeight deaths were related to the SAH or the coiling of the intracranial aneurysm. One patient died of a lung carcinoma and one died due to cardiac failure. Of the 38 deaths related to the SAH or coiling 10 patients developed vasospasm during the procedure; 6 patients had a thromboembolic complication during the procedure, and 5 patients died after rebleeding. In the other 17 patients, no complications occurred, and they died of a serious preprocedural clinical condition.

Clinical follow-up (mean 33.9 months, range 12-106 months) was completed in 339 of the 343 surviving patients (98.9\%). Follow-up information was missing for 1 and 3 patients in the surgical and endovascular groups, respectively. Three patients were foreigners, visiting the Netherlands at the time of SAH, and one patient had moved away after the SAH period. The clinical outcome of the surviving patients as expressed by mRS is shown in Table 4. In the surgical and endovascular groups respectively, $122(80.3 \%)$ and 163 (87.2\%) were able to live independently (mRS 0-2). 
More patients died after endovascular treatment $(p=0.104)$ and fewer people were able to live independently after surgical treatment $(p=0.084)$. However these differences were not statistically significant.

Table 4. Clinical outcome

\begin{tabular}{|c|c|c|}
\hline Surgical group Number (\%) & $\begin{array}{c}\text { Endovascular group } \\
\text { Number (\%) }\end{array}$ \\
\hline 0 & & $53(28.3)$ \\
\hline 1 & $39(25.7)$ & $52(27.8)$ \\
\hline 2 & $34(22.4)$ & $58(31.0)$ \\
\hline 3 & $49(32.2)$ & $10(5.3)$ \\
\hline 4 & $17(11.2)$ & $7(3.7)$ \\
\hline 5 & $9(5.9)$ & $7(3.7)$ \\
\hline Total & $4(2.6)$ & 187 \\
\hline
\end{tabular}

\section{Imaging}

Table 5 shows the findings of post-procedural imaging. In the surgical group follow-up imaging was performed in 126 (63.3\%) aneurysms, most of these within a year after surgery (88.9\%). Post-procedural angiography showed complete occlusion in 101 (80.2\%) aneurysms after surgical treatment, a residual neck in 17 (13.5\%) and a residual aneurysm in 8 (6.3\%) aneurysms.

All aneurysms treated by endovascular therapy underwent postprocedural imaging at the end of the procedure. In 149 (61.1\%) of these aneurysms complete occlusion was demonstrated, in 60 (24.6\%) a residual neck, and in 35 (14.3\%) a residual aneurysm. Complete aneurysm occlusion occurred significantly more often after surgical treatment compared to endovascular treatment $(p<0.001)$.

Table 5. Post-procedural angiography

\begin{tabular}{|l|c|c|}
\hline & $\begin{array}{c}\text { Surgical group } \\
\mathbf{n = 1 9 9} \text { Number (\%) }\end{array}$ & $\begin{array}{c}\text { Endovascular group } \\
\mathbf{n = 2 4 4} \text { Number (\%) }\end{array}$ \\
\hline No. of aneurysms with imaging & $126(64.8)$ & $244(100)$ \\
\hline Complete occlusion & $101(80.2)$ & $149(61.1)$ \\
\hline Residual neck & $17(13.5)$ & $60(24.6)$ \\
\hline Residual aneurysms & $8(6.3)$ & $35(14.3)$ \\
\hline No. of aneurysms without imaging & $73(35.2)$ & $0(0)$ \\
\hline
\end{tabular}

Late imaging follow-up was available for a group of 38 surgically treated patients $(24.8 \%$ of those surviving), harboring 50 aneurysms. The average interval between treatment and the last angiographic follow-up was 35.5 months (range, 10.3-105.5 months). Aneurysm regrowth was observed in 6 aneurysms (12.0\%) after surgical treatment. Three of these cases had demonstrated a known residual aneurysm at earlier post-operative imaging. Four of these aneurysms had been primarily or additionally treated by coagulation or wrapping. Retreatment was performed in 4 of 199 (2.0\%) aneurysms, in all cases after rebleeding. Because only a small group of surgically treated patients had follow-up imaging, no further results were obtained from this follow-up. 
Table 6 shows the findings at follow-up imaging in aneurysms which had undergone endovascular treatment. Follow-up angiography was available for 181 surviving patients (95.3\%, harboring 189 aneurysms). The average interval between treatment and the last angiographic follow-up was 29.1 months (range 4.8-102.8 months). Increasing compaction of the coil mass was observed in 72 aneurysms (38.1\%); this occurred more often in the group that showed a residual aneurysm at the end of the procedure $(52.0 \%)$ than in those with complete occlusion (36.8\%) or a residual neck (34.0\%) determined at post-procedural angiography. However, this difference was not statistically significant $(p=0.124)$.

Table 6. Angiographic FU after endovascular treatment by post-procedural angiographic results

\begin{tabular}{|l|r|r|r|}
\hline $\begin{array}{c}\text { Post procedural angiographic } \\
\text { results }\end{array}$ & $\begin{array}{c}\text { No changes } \\
\text { Number (\%) }\end{array}$ & $\begin{array}{c}\text { Improvement } \\
\text { Number (\%) }\end{array}$ & $\begin{array}{c}\text { Increased } \\
\text { recanalization } \\
\text { Number (\%) }\end{array}$ \\
\hline Complete occlusion $(n=114)$ & $72(63.2)$ & - & $42(36.8)$ \\
\hline Residual neck $(n=50)$ & $24(48.0)$ & $9(18.0)$ & $17(34.0)$ \\
\hline Residual aneurysm ( $n=25)$ & $12(48.0)$ & - & $13(52.0)$ \\
\hline Total 189 & $108(57.1)$ & $9(4.8)$ & $72(38.1)$ \\
\hline
\end{tabular}

Re-treatment was performed in 16 aneurysms in the endovascular group, 2 after rebleeding and 14 without rebleeding. At the end of the first procedure 10 of these showed a residual aneurysm, 4 aneurysms a residual neck, and 2 were completely occluded after coiling.

\section{Rebleeds}

After the procedure, rebleeding from the target aneurysm occurred in 12 aneurysms. Six (2.5\%) occurred after endovascular treatment, and 6 (3.0\%) after surgical treatment. This difference is not statistically significant ( $p=0.769)$.

Four patients from the endovascular treatment group had a residual aneurysm shown by postprocedural imaging, and 2 had a residual neck. In the endovascular group the presence of a residual neck after coiling was not related to rebleeding $(p=0.085)$. The presence of a residual aneurysm after coiling was statistically significantly related to rebleeding $(p=0.001)$.

One of the surgically treated patients mentioned above had a residual aneurysm; the other 5 did not undergo post-procedural angiography. Because of the missing data no analysis could be performed on the surgically treated aneurysms. Outcome of rebleeds was poor (Table 7). 
Table 7. Data on patients with rebleeding after procedure

\begin{tabular}{|c|c|c|c|c|c|c|c|}
\hline $\begin{array}{l}\text { Age/ } \\
\text { sex }\end{array}$ & Location & $\begin{array}{l}\text { Size } \\
(\mathrm{mm})\end{array}$ & $\begin{array}{l}\text { Initial } \\
\text { intervention }\end{array}$ & $\begin{array}{l}\text { Post procedural } \\
\text { imaging results }\end{array}$ & $\begin{array}{l}\text { Time to } \\
\text { rebleed (days) }\end{array}$ & $\begin{array}{l}\text { Interven- } \\
\text { tion }\end{array}$ & $\mathrm{mRS}$ \\
\hline $48 / F$ & MCA bifurcation & 8 & Coiling & Residual aneurysm & 1 & None & 6 \\
\hline $56 / F$ & $\mathrm{ACOA}$ & 7 & Coiling & Residual neck & 2 & None & 6 \\
\hline $63 / \mathrm{M}$ & ACoA & 2 & Coiling & Residual aneurysm & 1562 & None & 6 \\
\hline $49 / F$ & MCA M2 & 2 & Coiling & Residual neck & 43 & None & 6 \\
\hline $48 / F$ & ACoA & 4 & Coiling & Residual aneurysm & 83 & Recoiling & 4 \\
\hline $70 / F$ & $\mathrm{ACoA}$ & 10 & Coiling & Residual aneurysm & 3373 & Recoiling & 6 \\
\hline $44 / F$ & ACoA & 3 & Coagulation & Aneurysm regrowth & 1396 & Reclipping & 2 \\
\hline $40 / F$ & PCoA & 5 & Clipping & $?^{\mathrm{a}}$ & 1 & None & 6 \\
\hline $65 / M$ & AcoA & 5 & Clipping & Clip slipped $^{b}$ & 57 & Coiling & 2 \\
\hline $40 / F$ & AcoA & 15 & Clipping & $?^{a}$ & 2 & None & 6 \\
\hline $47 / M$ & MCA bifurcation & 6 & Clipping & Residual aneurysm & 507 & Coiling & 3 \\
\hline $49 / F$ & AcoA & 4 & Clipping & Clip slipped $^{b}$ & 12 & Reclipping & 0 \\
\hline
\end{tabular}

\section{Discussion}

The primary goal of aneurysm treatment is to prevent aneurysm bleeding or rebleeding, and thereby decrease the risk of death and dependency. This study presents the results of both types of treatment of intracranial aneurysms in symptomatic patients in a routine clinical setting.

After a median follow-up period of 33.9 months, $11.6 \%$ of the surgically treated and $17.4 \%$ of the endovascularly treated patients had died. ISAT reported different mortality rates after a follow-up period of 5 years: $11 \%$ after coiling and $14 \%$ after surgical treatment. ${ }^{6}$ These differences can be explained by the inclusion criteria and the clinical status at presentation. In our study, all patients presenting with an intracranial aneurysm were analyzed. In the group undergoing endovascular treatment only $56.4 \%$ had a good clinical grading at presentation (HH 1-2), in the surgically treated patients this was $69.4 \%$. ISAT included only patients whose clinical condition was suitable for both coiling and surgical clipping. A clinical grading of $\mathrm{HH} 1-2$ at presentation was seen in $88 \%$ of these patients. ${ }^{4-6}$

At the end of the follow-up period $80.3 \%$ and $87.2 \%$ of the surviving patients in the surgical and endovascular group respectively were living independently (mRS 1-2). These results are comparable with the ISAT study, which describes a good clinical outcome (mRS 1-2) in $82 \%$ and $83 \%$ of the surviving patients after surgery and coiling respectively. ${ }^{6}$

The overall risk of rebleeding tends to be greater after coiling compared to surgical clipping. ${ }^{4,6,15}$ In ISAT and other published studies, rebleeding rates after surgical treatment varied from $1.1 \%$ to $3.2 \%$, while after endovascular treatment the rates varied from $2.1 \%$ to $3.5 \%$, depending on the occlusion rates and on the follow-up period. ${ }^{4,6,15-22}$ In the present study, rebleeding occurred with approximately equal frequency after surgery compared to endovascular treatment, $3.0 \%$ and $2.5 \%$ respectively. Coiling is known to result in lower rates of complete occlusion compared to microsurgical clipping, which may affect the long-term stability and rates of rebleeding. ${ }^{8-11}$ In the present study a residual aneurysm was 
seen at post-procedural imaging in $14.2 \%$ of the patients having undergone endovascular treatment and in $4.3 \%$ of those treated by surgery. This group of neurosurgically treated aneurysms probably forms a selected population because post-treatment imaging was not standard procedure in the first years of inclusion. In case of doubt as to whether the aneurysm had been occluded satisfactorily or in patients with multiple aneurysms when one or more aneurysms had remained untreated, post-clipping imaging was more likely to be performed. Even in this selected population, complete aneurysm occlusion occurred significantly more often after surgical treatment compared to endovascular treatment $(p<0.001)$.

Progressive coil compaction after endovascular treatment was seen more often when a residual aneurysm was present at post-procedural imaging compared to completely occluded aneurysms and residual necks at post-procedural imaging; however, this difference was not statistically significant $(p=0.35)$. The presence of a residual aneurysm was significantly related to rebleeding $(p=0.007)$. These results are supported by other studies. The Cerebral Aneurysm Rerupture After Treatment (CARAT) study found the degree of aneurysm occlusion to be highly predictive of the risk for re-rupture. ${ }^{15}$ Willinsky et al found significantly more frequent recanalization in cases with a residual aneurysm, though the rebleeding rates did not show a difference for completely occluded aneurysms or for aneurysms with a neck or residual aneurysm. ${ }^{16}$

\section{Study limitations}

The primary goal of the present study was to assess how patient outcome in routine clinical practice relates to those reported in the literature. However, our study was not a randomized trial; therefore, a direct comparison of outcomes of between endovascular and surgical treatment is not strictly valid.

The number of patients presenting in our center with an SAH from a ruptured aneurysm is relatively small, but has grown in the past few years.

The clinical loss to follow-up in our study is very low (1.1\%). However, in 43 patients the clinical followup was obtained from structured telephone interviews, and by information provided by the general practitioner. This may make the clinical outcome graded by the mRS less reliable.

Postprocedural imaging was available for all patients after endovascular treatment. However postprocedural angiography after surgery was only available for $64.8 \%$ of the patients.

The use of balloon or Trispan coils in our clinic was low. This treatment was restricted to patients with aneurysms that were not suitable for neurosurgical treatment, and when the aneurysm could not be treated endovascularly without these additional devices. We think that the risk of complications in most cases where an additional device is needed for endovascular treatment is higher than the risk of neurosurgical clipping, while the outcome in the long term is nearly the same. ${ }^{23,24}$

\section{Conclusion}

The outcome of management of patients with intracranial aneurysms in a routine clinical setting according to a decision reached by a multidisciplinary team confirms the efficacy of such a policy. Mortality rates are comparable with those in the literature when the frequently poor clinical condition 
of patients at the time of presentation is taken into account. Furthermore, the rates of dependency are low in both treatment groups. Coiling results in lower rates of complete aneurysm occlusion compared with surgical treatment. Post-coiling angiography showing a residual aneurysm is a good predictor of the risk of rebleeding.

\section{References}

1 Rinkel, G. J., Djibuti, M., Algra, A. \& van Gijn, J. Prevalence and risk of rupture of intracranial aneurysms: a systematic review. Stroke 29, 251-256, (1998).

2 Guglielmi, G., Vinuela, F., Dion, J. \& Duckwiler, G. Electrothrombosis of saccular aneurysms via endovascular approach. Part 2: Preliminary clinical experience. J Neurosurg 75, 8-14, (1991).

3 Guglielmi, G., Vinuela, F., Sepetka, I. \& Macellari, V. Electrothrombosis of saccular aneurysms via endovascular approach. Part 1: Electrochemical basis, technique, and experimental results. J Neurosurg 75, 1-7, (1991).

4 Molyneux, A. et al. International Subarachnoid Aneurysm Trial (ISAT) of neurosurgical clipping versus endovascular coiling in 2143 patients with ruptured intracranial aneurysms: a randomised trial. Lancet 360, 1267-1274, (2002).

5 Molyneux, A. J. et al. Risk of recurrent subarachnoid haemorrhage, death, or dependence and standardised mortality ratios after clipping or coiling of an intracranial aneurysm in the International Subarachnoid Aneurysm Trial (ISAT): long-term follow-up. Lancet Neurol 8, 427-433, (2009).

6 Molyneux, A. J. et al. International subarachnoid aneurysm trial (ISAT) of neurosurgical clipping versus endovascular coiling in 2143 patients with ruptured intracranial aneurysms: a randomised comparison of effects on survival, dependency, seizures, rebleeding, subgroups, and aneurysm occlusion. Lancet 366, 809817, (2005).

7 Raja, P. V. et al. Microsurgical clipping and endovascular coiling of intracranial aneurysms: a critical review of the literature. Neurosurgery 62, 1187-1202; discussion 1202-1183, (2008).

8 Grunwald, I. Q. et al. Recanalization after endovascular treatment of intracerebral aneurysms. Neuroradiology 49, 41-47, (2007).

9 Holmin, S. et al. Intradural saccular aneurysms treated by Guglielmi detachable bare coils at a single institution between 1993 and 2005: clinical long-term follow-up for a total of 1810 patient-years in relation to morphological treatment results. Stroke 39, 2288-2297, (2008).

10 Lot, G., Houdart, E., Cophignon, J., Casasco, A. \& George, B. Combined management of intracranial aneurysms by surgical and endovascular treatment. Modalities and results from a series of 395 cases. Acta Neurochir (Wien) 141, 557-562, (1999).

11 Raymond, J. et al. Long-term angiographic recurrences after selective endovascular treatment of aneurysms with detachable coils. Stroke 34, 1398-1403, (2003).

12 Hunt, W. E. \& Hess, R. M. Surgical risk as related to time of intervention in the repair of intracranial aneurysms. J Neurosurg 28, 14-20, (1968).

13 Kasner, S. E. Clinical interpretation and use of stroke scales. Lancet Neurol 5, 603-612, (2006).

14 Roy, D., Milot, G. \& Raymond, J. Endovascular treatment of unruptured aneurysms. Stroke 32, 1998-2004, (2001).

15 Johnston, S. C. et al. Predictors of rehemorrhage after treatment of ruptured intracranial aneurysms: the Cerebral Aneurysm Rerupture After Treatment (CARAT) study. Stroke 39, 120-125, (2008).

16 Willinsky, R. A. et al. Clinical and angiographic follow-up of ruptured intracranial aneurysms treated with endovascular embolization. AJNR Am J Neuroradiol 30, 1035-1040, (2009).

17 Aikawa, H. et al. Rebleeding after endovascular embolization of ruptured cerebral aneurysms. Neurol Med Chir (Tokyo) 47, 439-445; discussion 446-437, (2007).

18 Sluzewski, M. \& van Rooij, W. J. Early rebleeding after coiling of ruptured cerebral aneurysms: incidence, morbidity, and risk factors. AJNR Am J Neuroradiol 26, 1739-1743, (2005).

19 Sluzewski, M., van Rooij, W. J., Beute, G. N. \& Nijssen, P. C. Late rebleeding of ruptured intracranial aneurysms treated with detachable coils. AJNR Am J Neuroradiol 26, 2542-2549, (2005).

20 Tsutsumi, K., Ueki, K., Usui, M., Kwak, S. \& Kirino, T. Risk of recurrent subarachnoid hemorrhage after complete obliteration of cerebral aneurysms. Stroke 29, 2511-2513, (1998). 
21 Wermer, M. J., Greebe, P., Algra, A. \& Rinkel, G. J. Incidence of recurrent subarachnoid hemorrhage after clipping for ruptured intracranial aneurysms. Stroke 36, 2394-2399, (2005).

22 David, C. A. et al. Late angiographic follow-up review of surgically treated aneurysms. J Neurosurg 91, 396-401, (1999).

23 Piotin, M. et al. Stent-assisted coiling of intracranial aneurysms: clinical and angiographic results in 216 consecutive aneurysms. Stroke 41, 110-115, (2010).

24 Sluzewski, M., van Rooij, W. J., Beute, G. N. \& Nijssen, P. C. Balloon-assisted coil embolization of intracranial aneurysms: incidence, complications, and angiography results. J Neurosurg 105, 396-399, (2006). 


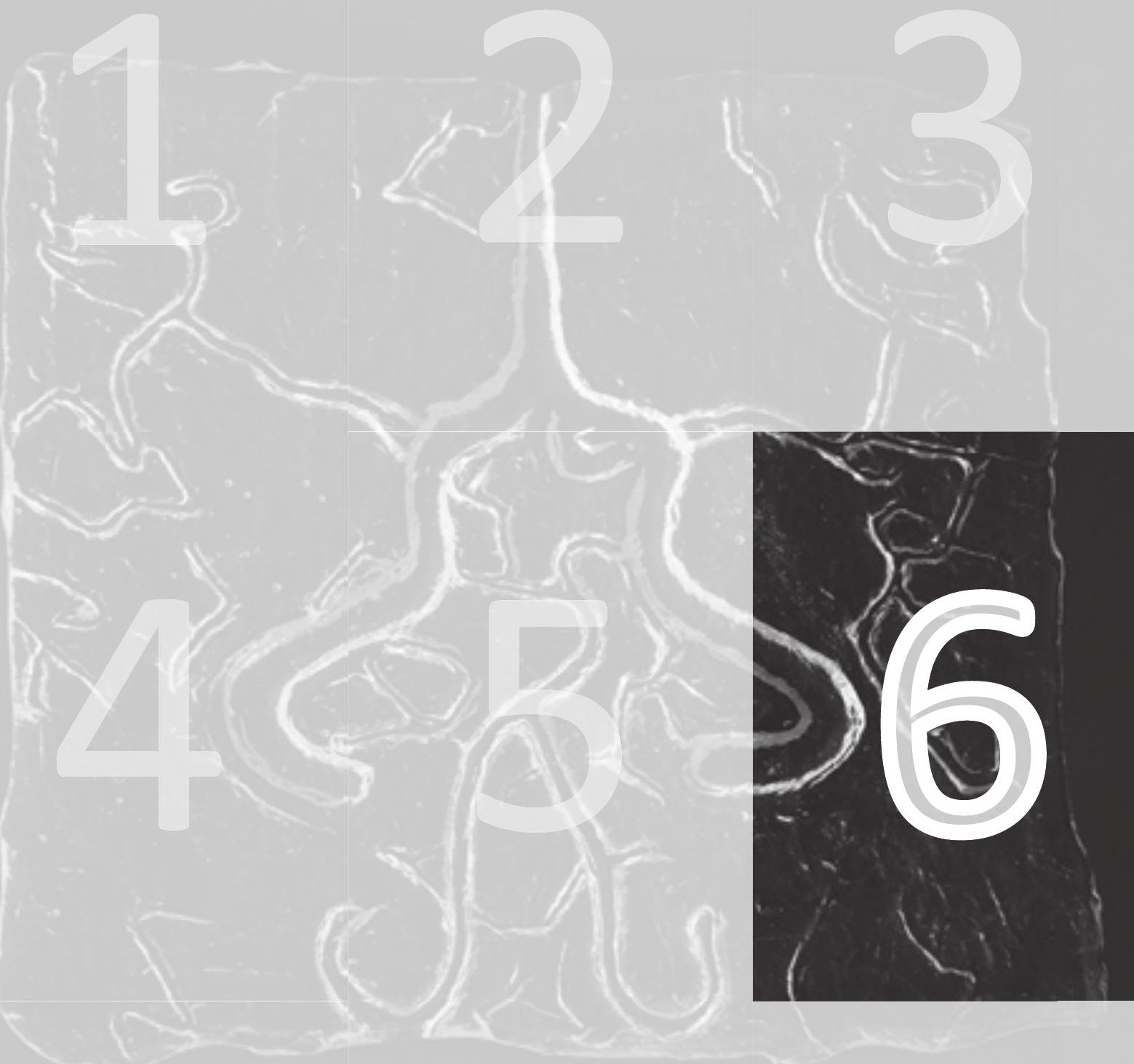




\section{Chapter 6}

Follow-up of coiled intracranial aneurysms with contrast enhanced MRA with digital subtraction angiography as standard of reference.

W.H. van Zwam

P.A.M. Hofman

A.G. Kessels

T.K. Oei

J.T. Wilmink 


\section{Abstract}

Objective: To evaluate the performance of contrast enhanced MRA (CEMRA) at 1.5T in the follow-up of coiled intracranial aneurysms, with digital subtraction angiography (DSA) as the standard of reference.

Materials and methods: This is a single-center study, including patients who had been treated by endovascular coiling of one or more intracranial aneurysms and were scheduled for routine follow-up. In addition to the scheduled DSA study participants all underwent CEMRA after giving written informed consent. The interval between DSA and CEMRA was less than 24 hours. Test characteristics of CEMRA were calculated for assessing the occlusion grade of aneurysms according to the Roy and Raymond $(R \& R)$ classification, with DSA as the standard of reference. Change in aneurysm occlusion grade in comparison with the initial post-coiling result was evaluated. CEMRA studies were evaluated by two independent observers interactively on a dedicated workstation. In case of discordant results, consensus was reached after joint re-evaluation by both observers.

Results: Sixty-nine patients with 74 aneurysms were included. Fourteen of these patients, harboring 17 aneurysms, were studied at six months as well as eighteen months after coiling, resulting in a total of 91 aneurysm assessments. Adequate aneurysm occlusion (Roy and Raymond (R\&R) class 1 and 2) was seen at DSA in 69 assessments (75.8\%).

Sensitivity with $95 \%$ confidence interval $(\mathrm{Cl})$ for detecting inadequate aneurysm occlusion (R\&R class 3 ) was $81.8 \%$ (95\% Cl: $65.7-97.9)$, specificity was 55.1 (95\% Cl: $43.4-66.8$ ) and negative and positive predictive values were $90.5 \%(95 \% \mathrm{Cl}: 81.6-99.4)$ and $36.7 \%(95 \% \mathrm{Cl}: 23.2-50.2)$ respectively. Linear weighted Kappa for interobserver agreement was 0.57 ( $95 \% \mathrm{Cl}: 0.43-0.72$ ).

The results did not differ significantly when calculated for detecting any aneurysm remnant (R\&R class 2 and 3), nor when calculated for only a single follow-up assessment per patient.

Conclusion: CEMRA can be used for the follow-up of coiled aneurysms. When CEMRA shows complete aneurysm occlusion a recanalization of the aneurysm can be confidently excluded. As a consequence of the low positive predictive value however, additional DSA may be necessary in case of incomplete occlusion seen on CEMRA.

The results of this assessment employing CEMRA are not better than those published in the literature employing time-of-flight (TOF) MRA in this patient population. 


\section{Introduction}

In centers where intracranial aneurysms are treated, the preferred method in most cases is by endovascular coiling. ${ }^{1-4}$ Follow-up of these coiled aneurysms is necessary because in around $20 \%$ of aneurysms coiled with initial success recanalization of the aneurysm lumen occurs over time due to compaction of the coils, growth of the aneurysm or migration of coils into intraluminal thrombus. ${ }^{5-9}$ Additional treatment is reported to be necessary in about half of these recanalyzed aneurysms. ${ }^{6,10}$ Intra-arterial digital subtraction angiography (DSA) has until recently been the standard follow-up modality but this is an invasive procedure with a risk of complications, and with relatively high costs. ${ }^{11,12}$ Magnetic resonance angiography (MRA) appears to be a less invasive and less expensive alternative. In two meta-analyses ${ }^{13,14}$ and several other studies published since, ${ }^{15-20}$ the value of this technique has been proven. Non-contrast enhanced time-of-flight MRA (TOF-MRA) was used in most of these studies and the additional value of contrast enhanced MRA (CEMRA) is still under study. ${ }^{16,18,19,21,22}$

The purpose of this study is to evaluate the performance of CEMRA in the follow-up of coiled intracranial aneurysms, with DSA as the standard of reference.

\section{Materials and Methods}

\section{Participants}

Patients were recruited in the Maastricht University Medical Centre (MUMC). The institutional review board of this center approved the study and all patients provided written informed consent.

For patients who have been treated by endovascular coiling, follow-up DSA examinations are routinely scheduled at 6 and 24 months after treatment. Patients due to undergo their regular follow-up DSA were asked to participate in the study, and to undergo an additional CEMRA examination. Patients could be recruited for either the 6-month or 24-month follow-up study or for both. Participants underwent the additional MRA study within 24 hours before or after DSA.

\section{CEMRA}

MRA was performed on a 1.5 Tesla Philips system using a dedicated head coil (Intera; Philips, Best, The Netherlands). The scan protocol included an ultra-short first-pass CEMRA sequence with concentric k-space filling. The scan parameters were as follows: parallel imaging (SENSE, factor 2), TR 5.4 / TE 1.68 ms, flip angle 35 degrees, FOV 256 mm (rectangular FOV 65\%), matrix 512, slice thickness 0.4 mm, coronal orientation (parallel to basilar artery), one stack. Contrast medium: gadopentetate dimeglumine (Magnevist ${ }^{\oplus}$, Bayer Schering Pharma, Leverkusen, Germany) $35 \mathrm{ml} \mathrm{IV}$, at $3 \mathrm{ml} / \mathrm{s}(2 \mathrm{ml}$ for a timing sequence and $33 \mathrm{ml}$ for the CE-MRA sequence), flushed with $25 \mathrm{ml} \mathrm{NaCl} 0,9 \%$ at $3 \mathrm{ml} / \mathrm{s}$.

CEMRA studies were post-processed and evaluated by two observers on a dedicated workstation (Vitrea; Vital Images, Minnetonka, Minnesota, USA). 
DSA

All patients underwent catheter DSA (Integris; Philips Medical Systems, Best, the Netherlands). A 4- or $5 \mathrm{~F}$ catheter was used to perform contrast injections by a power injector (Medrad Inc., Warrendale PA, USA): of $9 \mathrm{ml}$ iobitridol $350 \mathrm{mg} / \mathrm{ml}$ (Xenetix ${ }^{\circledR}$, Guerbet, Villepinte, France) at $5 \mathrm{ml} / \mathrm{s}$ for the internal carotid arteries and $8 \mathrm{ml}$ at $4 \mathrm{ml} / \mathrm{s}$ for the vertebral arteries. Intracranial branches of the internal carotid arteries were imaged in antero-posterior, lateral and oblique projections and the vertebrobasilar arteries and their branches in antero-posterior and lateral projections. Additional angiographic projections were obtained, if necessary, of the vessels that harbored the aneurysm(s), for better visualization of an eventual recanalization of the aneurysm(s)

\section{Evaluation of CEMRA images}

CEMRA images were independently evaluated by two neuroradiologists experienced in evaluating both MRA and DSA images of coiled aneurysms. They were unaware of the parallel DSA results but the initial DSA images made during the endovascular treatment were at their disposal. The CEMRA acquisition could be interactively assessed on a dedicated workstation (Vitrea; Vital Images, Minnetonka, Minnesota, USA).

Scoring criteria were: occlusion status, change compared with initial post-coiling occlusion status, size of recanalization when present, and diagnostic confidence.

Occlusion status was graded on the three-point scale described by Roy and Raymond (R\&R) ${ }^{23}$ as follows:

R\&R Class 1: Complete aneurysm obliteration. R\&R Class 2: Residual aneurysm neck. R\&R Class 3 : residual aneurysm lumen.

Discrepancies between the two observers in assessing occlusion status were resolved by joint reassessment to reach consensus.

The CEMRA images were compared with the initial post-coiling DSA images to decide whether the occlusion had changed, using a three-point scale: New or increased recanalization (category 1). No change (category 2). Disappearance of, or decrease of remnant (category 3 ).

Confidence of the scoring was given on a three-point scale: 'poor', 'moderate' and 'good'.

\section{Evaluation of DSA images}

The report by the radiologist who had performed the follow-up DSA study was used as the standard of reference. Usually the three-point R\&R scale was mentioned; if the radiological report did not indicate a specific grading on this scale, the images were re-assessed by a neuro-interventional radiologist and an $R \& R$ class was assigned. Size of the aneurysm remnant was estimated by comparison with known diameters of adjacent intracranial arteries.

For the assessment of the post-coiling DSA study the same procedure was followed using the original report made by the neuro-interventional radiologist who performed the treatment.

\section{Statistical analysis}

Interobserver agreement was assessed for all CEMRA ratings by kappa statistics with linear weighting for the three-point scale categories. 
To determine test characteristics for CEMRA the ratings of the aneurysm occlusion status were first dichotomized. R\&R class 1 and 2 are regarded as adequately occluded, not requiring retreatment; class 3 is regarded as inadequately occluded, requiring retreatment. Calculations were repeated after dichotomization between complete aneurysm occlusion (R\&R class 1 ) on the one hand, and incomplete occlusion (R\&R class 2 and 3 ) on the other. Calculations were also performed using only the ratings of a single follow-up study, in patients who had undergone two CEMRA follow-ups. Sensitivity, specificity, negative and positive predictive values (NPV and PPV) were calculated with $95 \%$ confidence intervals $(\mathrm{Cl})$, using the DSA ratings as standard of reference.

Analysis of the results of the comparison with initial occlusion status was done after dichotomization between "new or increased recanalization" (category 1) on the one hand, and "no change" and "disappeared or decreased remnant" (categories 2 and 3 ) on the other.

\section{Results}

Seventy-one patients were included in the study. There were 69 patients with one aneurysm, one patient with two aneurysms and one patient with three aneurysms. 14 patients were included two times, the first time at six months follow-up and the second time at 24 months follow-up; among these 14 were the two patients with multiple aneurysms, thus resulting in a total of 91 aneurysm assessments. There were no stent-assisted coilings.

For four patients with four aneurysms the initial post-coiling DSA images were not available. Patient characteristics are given in Table 1.

Complete occlusion of the aneurysm was found at follow-up DSA (the standard of reference) in 39 of 91 aneurysm assessments (42.9\%), while a neck remnant was found in $30(33.0 \%)$ and incomplete occlusion of the aneurysm lumen was found in $22(24.2 \%)$ assessments.

Compared with the initial post-coiling DSA study increased aneurysm remnant or new recanalization was found in 36 of 87 assessments (41.4\%), occlusion was unchanged in $45(51.7 \%)$ and the aneurysm remnant had decreased in $6(6.9 \%)$ aneurysms at follow-up DSA.

Confidence in scoring per aneurysm was very good: the first observer scored 'good' confidence in 89 aneurysm assessments, 'moderate' in 1 and 'poor' confidence in 1 assessment. For the second observer these figures were 79 , ten and two, respectively.

Linear weighted Kappa for interobserver agreement in assessing occlusion status was $0.57(95 \% \mathrm{Cl}$ : $0.43-0.72$ ). For data dichotomized between adequate occlusion (R\&R 1 and 2) and inadequate occlusion ( $R \& R$ 3) Kappa was 0.52 (95\% Cl: $0.35-0.69)$; if the data were dichotomized between complete (R\&R 1) and incomplete occlusion (R\&R 2 and 3), Kappa was $0.65(95 \% \mathrm{Cl}: 0.49-0.82)$. 
Table 1: Characteristics of included patients and aneurysms

\begin{tabular}{|c|c|}
\hline & $\mathbf{N} \quad(\%)$ \\
\hline Female & $50 \quad(70.4)$ \\
\hline Age Mean (SD) & $52.7(5.7)$ \\
\hline Age Range & $19-85$ \\
\hline Unruptured aneurysms & $\begin{array}{ll}9 & (12.2)\end{array}$ \\
\hline Location of aneurysm & \\
\hline ICA, PCom, OphthA & $21 \quad(28.4)$ \\
\hline ACom, ACA & $25 \quad(33.8)$ \\
\hline MCA & $(8.1)$ \\
\hline Vertebrobasilar & (29.7) \\
\hline (of which BATip & $15 \quad(20.3)$ \\
\hline Initial aneurysm size: & \\
\hline Mean (SD) & $6.2(0.7)$ \\
\hline $5 \mathrm{~mm}$ or smaller & $29 \quad(39.2)$ \\
\hline $5-15 \mathrm{~mm}$ & $43 \quad(58.1)$ \\
\hline Larger than $15 \mathrm{~mm}$ & (2.7) \\
\hline Initial occlusion status & \\
\hline Complete occlusion ( $R \& R$ class 1 ) & (59.5) \\
\hline Residual neck (R\&R class 2 ) & $18 \quad(24.3)$ \\
\hline Incomplete occlusion (R\&R class 3 ) & (16.2) \\
\hline Number of patients at 6 month follow-up & 50 \\
\hline Number of patients at 12 month follow-up & 35 \\
\hline (Number of patients both 6 and 12 month follow-up & 14) \\
\hline
\end{tabular}

$S D=$ Standard deviation. $R \& R=$ Roy and Raymond. $I C A=$ Internal carotid artery. $P C o m=$ Posterior communicating artery. OphtA = Ophtalmic artery. ACom = Anterior communicating artery. ACA = Anterior cerebral artery. MCA = Middle cerebral artery. BAtip $=$ tip of basilar artery.

Test characteristics for both dichotomizations are also given in Table 2.

Table 2. Test characteristics of CEMRA in the follow-up of coiled aneurysms for two different dichotomizations in the three-point Roy and Raymond classification.

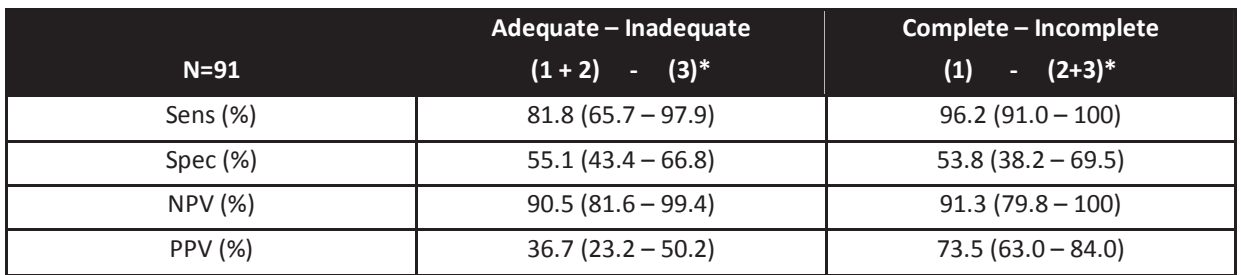

Figures between brackets are $95 \%$ Cl's

* Roy and Raymond classification 
If only one follow-up per patient was assessed in the 14 patients who had follow-up at both six and 24 months, the results did not differ substantially from those also containing the data of the second study (Table 3).

Table 3. Test characteristics of CEMRA in the follow-up of coiled aneurysms for two different dichotomizations in the three-point Roy and Raymond classification, only one follow-up assessment per patient.

\begin{tabular}{|c|c|c|}
\hline & dequate - Inadequate & Complete - Incomplete \\
\hline $\mathrm{N}=74$ & $(1+2)-(3)^{*}$ & $-(2+3)^{*}$ \\
\hline Sens (\%) & $78.9(60.6-97.3)$ & $95.5(89.4-100)$ \\
\hline Spec (\%) & 52.7 (39.5 - 65.9) & $53.3(35.5-71.2)$ \\
\hline NPV (\%) & $87.9(76.8-99.0)$ & $88.9(74.4-100)$ \\
\hline PPV (\%) & $36.6(21.9-51.3)$ & $75.0(63.7-86.3)$ \\
\hline
\end{tabular}

Linear weighted Kappa for interobserver agreement in comparing occlusion status at follow-up with initial occlusion status at DSA after treatment was only 0.40 (95\% Cl: $0.18-0.54)$.

Sensitivity and specificity for new or increased recanalization compared with initial occlusion status were 80.6 (95\% Cl: 67.6 - 93.5) and 64.7\% (95\% Cl: 51.6 - 77.8) respectively for the first observer and $77.8(95 \% \mathrm{Cl}: 64.2-91.4)$ and $64.7 \%(95 \% \mathrm{Cl}: 51.6-77.8)$ for the second observer. PPV was 61.7 (95\% Cl: 47.8 - 75.6) and 60.9 (95\% Cl: 46.8 - 75.0) for the first and second observer respectively and NPV 82.5 (95\% Cl: $70.7-94.3)$ and 80.5 (95\% Cl: $86.4-92.6)$ respectively.

\section{Discussion}

Most test characteristics dealing with occlusion status in this study show lower values than those previously published. In the two meta-analyses of Kwee and Kwee ${ }^{13}$ and Weng et al ${ }^{14}$ pooled sensitivities and specificities were calculated out of 16 studies in both cases, partly overlapping. Pooled sensitivities for detecting any residual flow (incomplete occlusion, R\&R class 2 and 3) were 83.3\% and 90\% respectively, and specificities $90.6 \%$ and $95 \%$ respectively. However, the studies in these meta-analyses were very heterogeneous because different analyzing methodologies were used.

A more recent multi-center study as well as some smaller single center studies used the same methodology as we did. ${ }^{16-19,24}$

Kappa values are comparable with those in our study, ranging from 0.49 to 0.57 for studies employing CEMRA, and from 0.55 to 0.64 for those in which TOF-MRA was used. The NPV for inadequate occlusion (R\&R class 3 ) is also in the same range: NPV 92\% in two studies evaluating CEMRA ${ }^{17,18}$ and NPV ranging from $85 \%$ to $94 \%$ in the studies evaluating TOF-MRA. ${ }^{17-19,24}$ For detecting any degree of recanalization (R\&R class 2 and 3 ) the NPV in the present study is even better than in the other studies (72 and $81 \%$ in the CEMRA studies and $68-87 \%$ in the TOF MRA studies).

Sensitivity in our study for detecting both inadequate and incomplete occlusion was $82 \%$, and this is higher (though not significantly so) than in the above-mentioned studies, where sensitivity for detecting 
inadequate occlusion ranged from 50 to $82 \%$ For detecting incomplete occlusion sensitivity was $96 \%$ in our study, ranging from 65 to $90 \%$ in the other studies. ${ }^{16-19,24}$

On the other hand specificity and PPV are lower in our study. The PPV for inadequate occlusion is $36.7 \%$ : this is significantly lower than in the other studies (range $67-90 \%$ ), while the PPV for incomplete occlusion ( $74 \%$ in this study) was similar to that in the other studies, which values range from 67 to $86 \%$ One difference with these other studies is the standard of reference: In the study presented here, DSA is not assessed in a research setting but in a clinical setting. Class 3 in the R\&R classification is used to describe an aneurysm in which a degree of recanalization has been demonstrated which would require retreatment. However, the decision to re-treat depends not only on the recanalization and its configuration in respect to the parent vessel, which determine its suitability for endovascular treatment, but also on secondary factors such as age and comorbidity of the patient. Therefore in a clinical setting the physician may be more reluctant to award a rating of R\&R class 3 than when in a research setting, thus leading to the lower specificity and PPV for detecting inadequate occlusion status with CEMRA which was found in this study. The fact that Kappa is only moderate (0.52) underlines the uncertainty in deciding whether an aneurysm is adequately occluded or not. This uncertainty in deciding whether retreatment of coiled and recanalized aneurysms is necessary, is known and well described by Daugherty et al. ${ }^{25}$

The mean size of the initial aneurysms in this study is less than in the study by Schaafsma et al. (6.2 versus $7 \mathrm{~mm}$ ). The decision whether a recanalization should be categorized as R\&R class 2 or class 3 can depend on the size of the initial aneurysm: in a $15 \mathrm{~mm}$ aneurysm a $1 \mathrm{~mm}$ contrast collection at the neck would most likely be regarded as a small class 2 neck remnant, while a similar collection in a $3 \mathrm{~mm}$ aneurysm could easily be classified as a class 3 recanalization. In smaller aneurysms the distinction between class 2 and class 3 recanalization is therefore likely to be more difficult than in larger aneurysms (see figures $1-4$ ).

Another difference in our study compared with some others is the use of MRA at 1.5T instead of 3T. However the added value of $3 \mathrm{~T}$ in this setting has not been established. ${ }^{16,19,26-28}$ In the second study of Pierot $^{24}$ and in the studies of Kaufmann ${ }^{16}$ and Schaafsma ${ }^{19}, 1.5 T$ and 3T MRA studies were evaluated without significant differences being found.

The high number of (apparent) false positive results in this study as well as in previous studies can probably be explained in part by the fact that a residual aneurysm lumen is sometimes masked by the surrounding coil mesh on DSA, a so called 'helmet configuration' which is impenetrable to X-rays. This is a recognized pitfall of DSA. ${ }^{29}$ In these cases the CEMRA results are in fact true positives, but are counted as false positives because DSA is considered the standard of reference.

The dichotomization between ratings of aneurysms which are completely occluded (R\&R class 1 ) on the one hand, and those which present a residual neck (R\&R class 2 ) or a residual aneurysm (R\&R class 3 ) on the other, leads to slightly less discordant results between observers, and better test results in our study than when the choice has to be made between adequately ( $R \& R$ class 1 and 2 ) and inadequately ( $R \& R$ class 3) coiled aneurysms. The clinical consequences of this differentiation between R\&R class 1 and class 2, however, appears minimal, as additional treatment is not considered necessary in both these classes. 

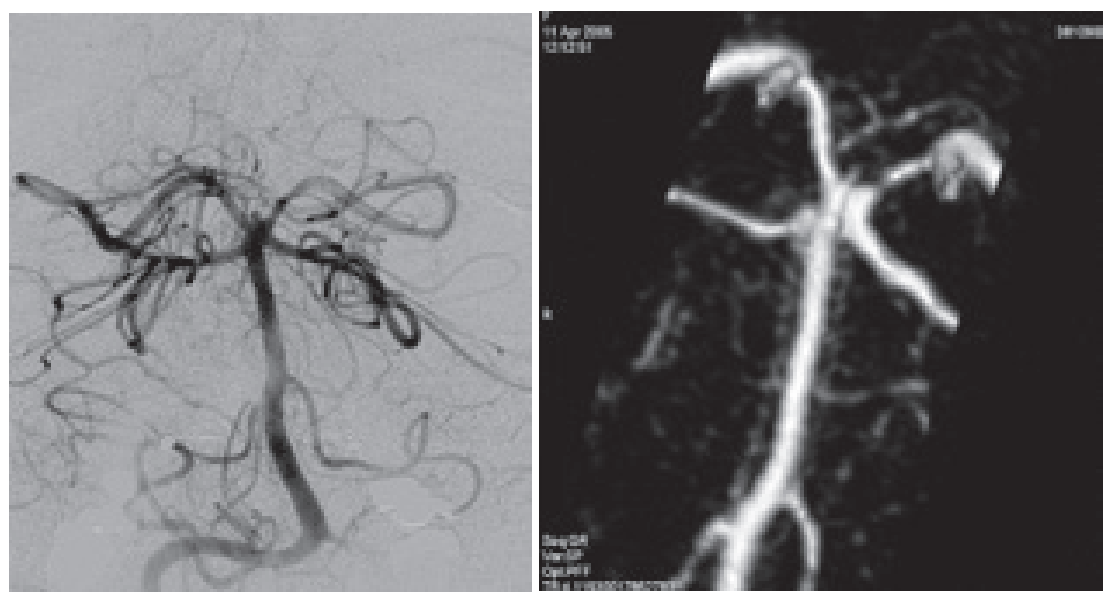

Figure 1. 45 year old female with coiled small $(2 \times 3 \mathrm{~mm})$ basilar tip aneurysm. Initially complete occlusion. Images at 24 months follow-up. a. DSA revealing a small neck remnant (R\&R class 2). b. MRA was scored by observer 1 as completely occluded (R\&R class 1 ) and by observer 2 as recanalization ( $R \& R$ class 3).

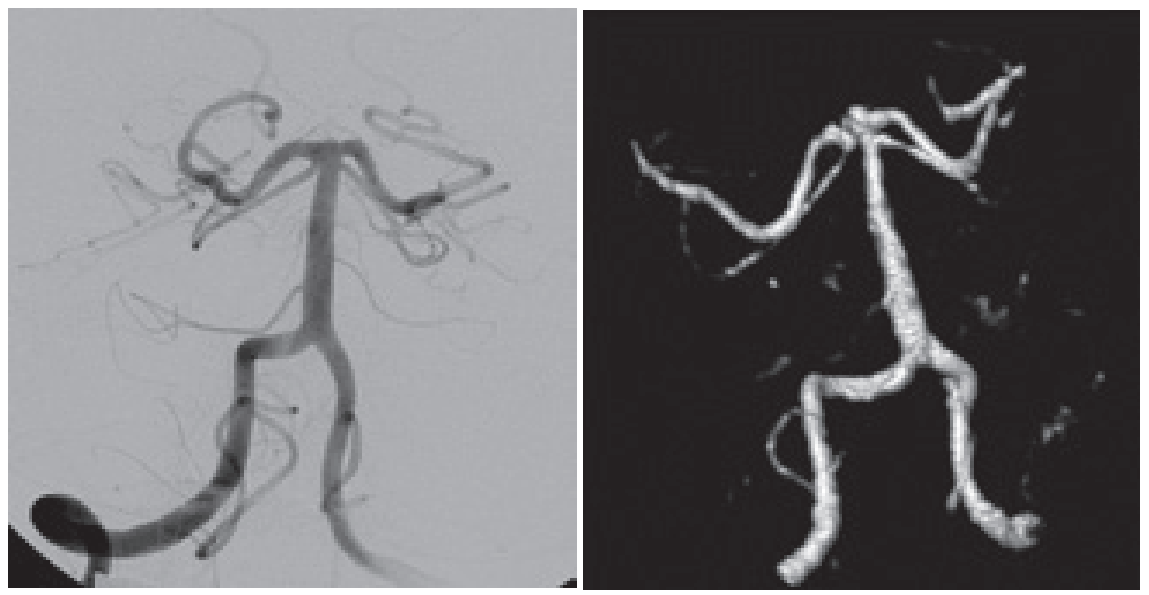

Figure 2. 62 year old female with a coiled $4 \mathrm{~mm}$ basilar tip aneurysm. a. DSA at 6 months follow up shows a stable complete occlusion (R\&R class 1 ). b. MRA at 6 months: observer 2 considered this as a recanalization, $R \& R$ class 3 , while observer 1 considered this as stable and completely occluded ( $R \& R$ class 1) 


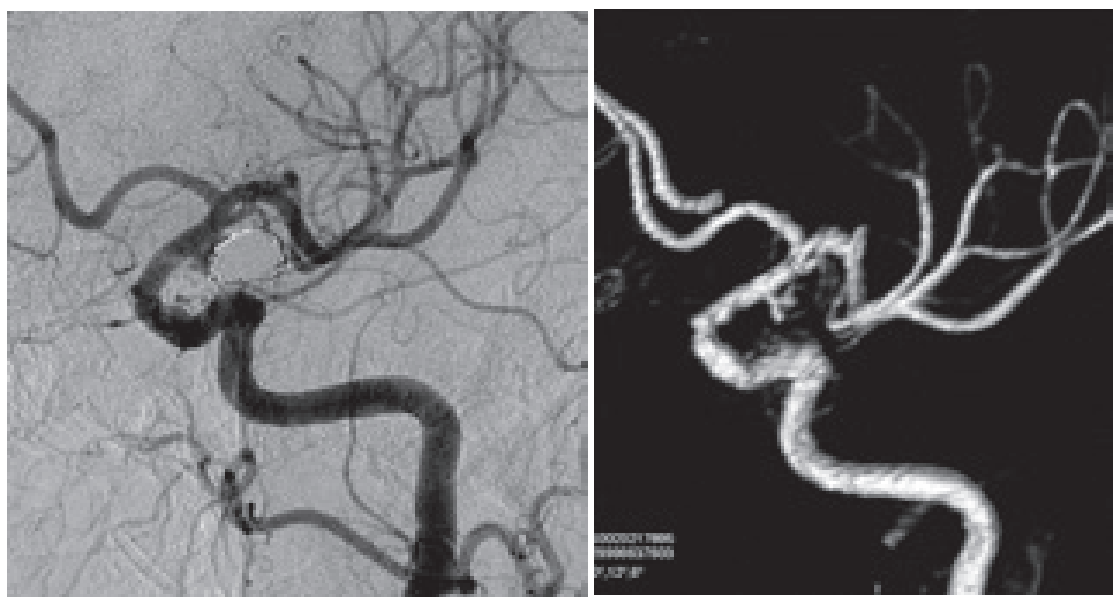

Figure 3. 63 year old female with coiled $6 \times 10 \mathrm{~mm}$ right posterior communicating artery aneurysm. Initial occlusion was 100\%. a. DSA at 6 months shows a recanalization at the neck, R\&R class 2. b. MRA at 6 months: Observer 1 considered this a recanalization R\&R class 3, while observer 2 thought that this was no recanalization at all.
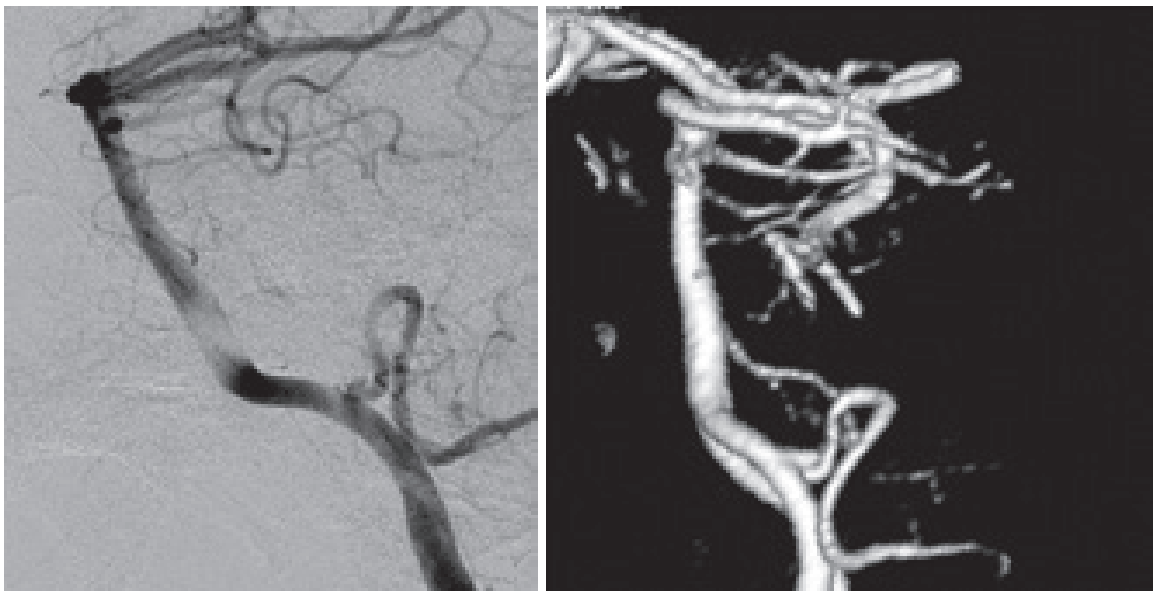

Figure 4. 55 year old female with coiled $3 \mathrm{~mm}$ small left posterior inferior cerebellar artery aneurysm. Initially complete occlusion. a. Follow-up DSA at 24 months shows small recanalization in the neck, R\&R class 2. b. MRA at 24 months: observer 1 did not see a recanalization, while observer 2 considered this a $R \& R$ class 3 recanalization.

Assessing change in aneurysm occlusion compared with initial post coiling DSA could give additional information for cases that leave doubt whether re-treatment is indicated or not. Comparing MRA with DSA images, however, is less accurate, which is probably one of the reasons the test characteristics of this comparison are lower than those of the recanalization assessment. 


\section{Conclusion}

The aim of the present study was to evaluate the diagnostic performance of CEMRA in the follow-up of cerebral aneurysms treated by endovascular coiling. The results are not better than those reported in studies employing TOF-MRA, but they do support the conclusion drawn by Schaafsma et al. that MRA can be used for the follow-up of coiled aneurysms. ${ }^{19}$ The high NPV warrants a confident exclusion of recanalization with MRA. But, as a consequence of the low PPV, additional DSA may be necessary in case of incomplete occlusion seen on CEMRA, to assess whether repeat treatment is necessary.

\section{References}

1 Bradac, O., Hide, S., Mendelow, D. A. \& Benes, V. Aneurysm treatment in Europe 2010: an internet survey. Acta Neurochir (Wien) 154, 971-978, (2012).

2 Cognard, C., Pierot, L., Anxionnat, R. \& Ricolfi, F. Results of embolization used as the first treatment choice in a consecutive nonselected population of ruptured aneurysms: clinical results of the Clarity GDC study. Neurosurgery 69, 837-841; discussion 842, (2011).

3 Smith, G. A., Dagostino, P., Maltenfort, M. G., Dumont, A. S. \& Ratliff, J. K. Geographic variation and regional trends in adoption of endovascular techniques for cerebral aneurysms. J Neurosurg 114, 1768-1777, (2011).

4 Spiotta, A. M., Hui, F. K. \& Moskowitz, S. I. Trends in device-assisted aneurysm treatment at a single highvolume tertiary care center. J Neurointerv Surg, (2012).

5 Johnston, S. C. et al. Predictors of rehemorrhage after treatment of ruptured intracranial aneurysms: the Cerebral Aneurysm Rerupture After Treatment (CARAT) study. Stroke 39, 120-125, (2008).

6 Ferns, S. P. et al. Coiling of intracranial aneurysms: a systematic review on initial occlusion and reopening and retreatment rates. Stroke 40, e523-529, (2009).

7 Murayama, Y. et al. Guglielmi detachable coil embolization of cerebral aneurysms: 11 years' experience. J Neurosurg 98, 959-966, (2003).

8 Raja, P. V. et al. Microsurgical clipping and endovascular coiling of intracranial aneurysms: a critical review of the literature. Neurosurgery 62, 1187-1202; discussion 1202-1183, (2008).

9 Sluzewski, M., van Rooij, W. J., Rinkel, G. J. \& Wijnalda, D. Endovascular treatment of ruptured intracranial aneurysms with detachable coils: long-term clinical and serial angiographic results. Radiology 227, 720-724, (2003).

10 Campi, A. et al. Retreatment of ruptured cerebral aneurysms in patients randomized by coiling or clipping in the International Subarachnoid Aneurysm Trial (ISAT). Stroke 38, 1538-1544, (2007).

11 Fifi, J. T. et al. Complications of modern diagnostic cerebral angiography in an academic medical center. J Vasc Interv Radiol 20, 442-447, (2009).

12 Kaufmann, T. J. et al. Complications of diagnostic cerebral angiography: evaluation of 19,826 consecutive patients. Radiology 243, 812-819, (2007).

13 Kwee, T. C. \& Kwee, R. M. MR angiography in the follow-up of intracranial aneurysms treated with Guglielmi detachable coils: systematic review and meta-analysis. Neuroradiology 49, 703-713, (2007).

14 Weng, H. H., Jao, S. Y., Yang, C. Y. \& Tsai, Y. H. Meta-analysis on Diagnostic Accuracy of MR Angiography in the Follow-Up of Residual Intracranial Aneurysms Treated with Guglielmi Detachable Coils. Interv Neuroradiol 14 Suppl 2, 53-63, (2008).

15 Ferre, J. C. et al. Time-of-flight MR angiography at 3T versus digital subtraction angiography in the imaging follow-up of 51 intracranial aneurysms treated with coils. Eur J Radiol 72, 365-369, (2009).

16 Kaufmann, T. J. et al. A prospective trial of 3T and 1.5T time-of-flight and contrast-enhanced MR angiography in the follow-up of coiled intracranial aneurysms. AJNR Am J Neuroradiol 31, 912-918, (2010).

17 Lavoie, P. et al. Residual flow after cerebral aneurysm coil occlusion: diagnostic accuracy of MR angiography. Stroke 43, 740-746, (2012).

18 Pierot, L., Portefaix, C., Boulin, A. \& Gauvrit, J. Y. Follow-up of coiled intracranial aneurysms: comparison of 3D time-of-flight and contrast-enhanced magnetic resonance angiography at $3 \mathrm{~T}$ in a large, prospective series. Eur Radiol, (2012). 
19 Schaafsma, J. D. et al. Intracranial aneurysms treated with coil placement: test characteristics of follow-up MR angiography--multicenter study. Radiology 256, 209-218, (2010).

20 Serafin, Z., Strzesniewski, P., Lasek, W. \& Beuth, W. Follow-up after embolization of ruptured intracranial aneurysms: A prospective comparison of two-dimensional digital subtraction angiography, three-dimensional digital subtraction angiography, and time-of-flight magnetic resonance angiography. Neuroradiology, (2012).

21 Sprengers, M. E. et al. Evaluation of the occlusion status of coiled intracranial aneurysms with MR angiography at 3T: is contrast enhancement necessary? AJNR Am J Neuroradiol 30, 1665-1671, (2009).

22 Wikstrom, J., Ronne-Engstrom, E., Gal, G., Enblad, P. \& Tovi, M. Three-dimensional time-of-flight (3D TOF) magnetic resonance angiography (MRA) and contrast-enhanced MRA of intracranial aneurysms treated with platinum coils. Acta Radiol 49, 190-196, (2008).

23 Roy, D., Milot, G. \& Raymond, J. Endovascular treatment of unruptured aneurysms. Stroke 32, 1998-2004, (2001).

24 Pierot, L., Portefaix, C., Gauvrit, J. Y. \& Boulin, A. Follow-Up of Coiled Intracranial Aneurysms: Comparison of 3D Time-of-Flight MR Angiography at $3 \mathrm{~T}$ and $1.5 \mathrm{~T}$ in a Large Prospective Series. AJNR Am J Neuroradiol, (2012).

25 Daugherty, W. P. et al. Observer agreement regarding the necessity of retreatment of previously coiled recurrent cerebral aneurysms. AJNR Am J Neuroradiol 32, 566-569, (2011).

26 Buhk, J. H., Kallenberg, K., Mohr, A., Dechent, P. \& Knauth, M. No advantage of time-of-flight magnetic resonance angiography at 3 Tesla compared to 1.5 Tesla in the follow-up after endovascular treatment of cerebral aneurysms. Neuroradiology 50, 855-861, (2008).

27 Anzalone, N. et al. Follow-up of coiled cerebral aneurysms at 3T: comparison of 3D time-of-flight MR angiography and contrast-enhanced MR angiography. AJNR Am J Neuroradiol 29, 1530-1536, (2008).

28 Majoie, C. B. et al. MR angiography at 3T versus digital subtraction angiography in the follow-up of intracranial aneurysms treated with detachable coils. AJNR Am J Neuroradiol 26, 1349-1356, (2005).

29 Agid, R., Willinsky, R. A., Lee, S. K., Terbrugge, K. G. \& Farb, R. I. Characterization of aneurysm remnants after endovascular treatment: contrast-enhanced $M R$ angiography versus catheter digital subtraction angiography. AJNR Am J Neuroradiol 29, 1570-1574, (2008). 

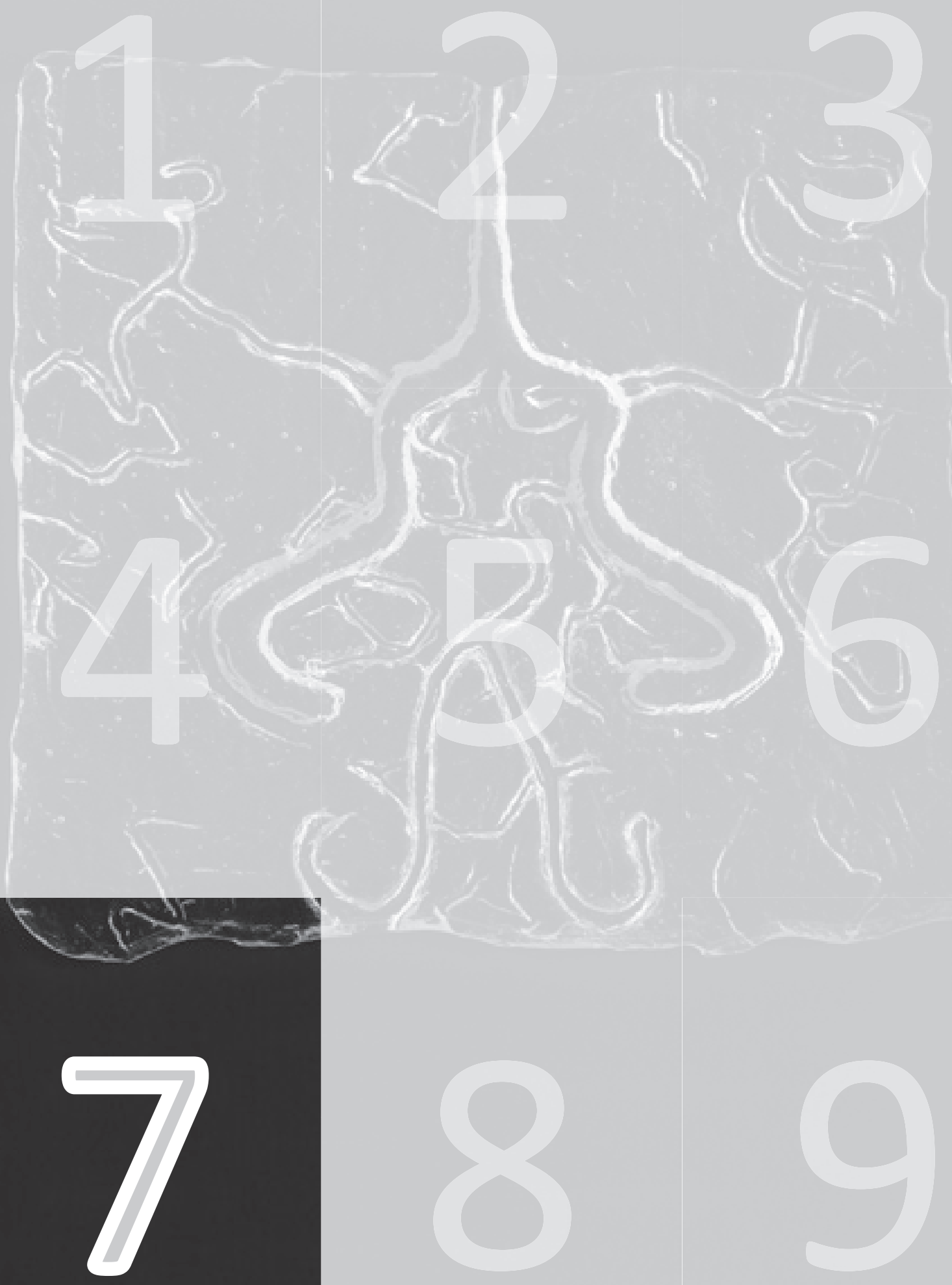


\section{Chapter 7}

Late recanalization of adequately coiled intracranial aneurysms.

W.H. van Zwam

S.P. Ferns

Adapted from 'Late reopening of adequately coiled intracranial aneurysms: frequency and risk factors in 400 patients with 440 aneurysms'. by S.P. Ferns et al. Stroke. 2011 May;42(5):1331-7. Epub 2011 Mar 31. 


\section{Abstract}

Background and Purpose In a large multicenter study (the LOTUS study) the frequency of late recanalization of aneurysms more than five years after initially successful endovascular coiling was assessed, and possible risk factors for such recurrence were studied. ${ }^{1}$ In this chapter the data from the patients included by the Maastricht University Medical Centre (MUMC) are separately evaluated. The predictive value of the presence of a residual neck in a coiled aneurysm at six months follow-up, for late recanalization, is investigated.

Methods From December 1997 to June 2005, 202 intracranial aneurysms were coiled in 180 patients in the MUMC. At 6 month angiographic follow-up, 150 aneurysms in 138 patients were judged to be still adequately occluded. After a mean period of 7.9 years after coiling, 62 of these 150 patients, harboring 72 aneurysms, underwent MR angiography (MRA) at $3 T$ to assess the occlusion status of the aneurysms. Percentages and corresponding 95\% confidence intervals (Cl) of aneurysm recanalization and retreatment were calculated. Risk factors for late recanalization were assessed by univariable and multivariable logistic regression analysis, including patient gender, rupture status of aneurysms, initial aneurysm occlusion status, aneurysm size $\geq 10 \mathrm{~mm}$ and aneurysm location. Occlusion status at six months follow-up was retrieved from patients treated in the MUMC and from the patients included in the LOTUS in whom this was documented according to the Roy and Raymond (R\&) classification. ${ }^{2}$ Correlation between this classification and late recanalization was evaluated.

Results In 3 of our 62 patients (4.8\%, 95\% Cl: 1.3-14.4\%) with 71 aneurysms (2.5\%, 95\% Cl: 1.1-12.7\%) late recanalization had occurred; none of these reopened aneurysms were retreated $(0.0 \%, 95 \% \mathrm{Cl}$ : 0.0-6.4\%). In the total group of 400 patients harboring 440 aneurysms, included in the LOTUS study, independent predictors for late recanalization were aneurysm size $\geq 10 \mathrm{~mm}$ (Odds Ratio (OR) $4.7,95 \% \mathrm{Cl}$ : 1.3-16.3), and location on basilar tip (OR 3.9, 95\% Cl: 1.1-14.6). There were no cases of late recanalization in 143 anterior cerebral artery aneurysms. ${ }^{1}$ No correlation was found between residual neck at six months follow-up and late recanalization.

Conclusions In patients with aneurysms that are adequately occluded at 6 months, the yield of longterm MRA follow-up for detection of recanalized aneurysms that require retreatment is very low. Longer-term follow -up may be considered in potential higher risk patients, such as patients with large or basilar tip aneurysms. Presence of a residual neck at six months follow-up has no predictive value for late recanalization. 


\section{Introduction}

Endovascular coiling has become an established treatment for intracranial aneurysms. ${ }^{3,4}$ A shortcoming of coiling is the possibility of aneurysm recanalization over time due to coil compaction, aneurysm growth, coil migration into intraluminal thrombus or resolution of intraluminal thrombus. Recanalization or reopening occurs in approximately $20 \%$ of coiled aneurysms, and about half of these recanalized aneurysms are retreated. ${ }^{5}$ Currently, it is not known for how long and how frequently coiled aneurysms need to be followed and whether certain subgroups carry a higher risk for late recanalization.

Known risk factors for aneurysm recanalization are large aneurysm size and low coil packing density. ${ }^{6,7}$ Longer passage of time after coiling as a risk factor for recanalization is under debate: some studies have reported more aneurysm recanalization with longer follow-up and therefore prolonged imaging followup has been recommended. ${ }^{7,8}$ However, there is a wide variety in these studies of time intervals between coiling and first follow-up angiography. Recanalization detected on first follow-up angiography some years after coiling, could therefore have developed much earlier. Longer follow-up duration was not associated with more frequent aneurysm recanalization in a systematic review and in studies with fixed follow-up intervals. ${ }^{5,9,10}$

We determined the incidence of late aneurysm recanalization in 62 patients harboring 71 aneurysms that were treated in the MUMC, with adequate occlusion at 6 months angiographic follow-up. This was a subgroup of a multicenter study (the LOTUS study) which included 400 patients harboring 440 aneurysms. In the LOTUS study possible risk factors for recanalization were also assessed.

\section{Materials and Methods}

\section{Patients}

The Institutional Review Board of the Maastricht University Medical Centre approved the study protocol. Participants provided written informed consent.

We retrieved the data from patients with a ruptured or unruptured intracranial aneurysm treated by endovascular coiling between December 1997 and June 2005 and who had adequate aneurysm occlusion - complete aneurysm obliteration or only a small residual aneurysm neck - at 6 months angiographic follow-up according to occlusion status recorded in the databases and radiological reports. Inclusion criteria were: follow-up duration > 4.5 years after coiling, current age between 18 and 70 years, living independently (Glasgow Outcome Scale 4 and 5) ${ }^{11}$ and no contra-indications for magnetic resonance imaging at 3 Tesla. The upper age limit of 70 years was chosen because it was not considered likely that a patient over 70 years of age would be subjected to retreatment if an aneurysm recanalization were to be found. Firstly there is an increased risk of treatment complications in these patients, and secondly the anticipated annual risk, and thus the lifetime risk of rupture from an aneurysm reopening in these elderly patients is low. ${ }^{12}$

We contacted the general practitioners of all eligible patients to ascertain whether the patient was still alive. If a patient had died, we retrieved the date and cause of death. The surviving patients received an invitation letter to participate in this long-term magnetic resonance angiography (MRA) follow-up study, 
with background information. Patients who did not respond to the invitation letter were contacted by telephone.

\section{MR Imaging follow-up protocol}

MR imaging examinations were performed on 3T systems (Intera R10; Philips Healthcare, Best, The Netherlands) by using the sensitivity encoding (SENSE) phased-array head coil (MR Imaging Devices, Gainesville, FL, USA). The MR imaging protocol included axial T2-weighted fast spin echo and multiple overlapping thin slab acquisition 3D time-of-flight (MOTSA 3D-TOF) MRA sequences. Imaging parameters for the T2-weighted fast spin-echo sequence were the following: TR/TE, 3394/80 ms; $400 \mathrm{x}$ 400 matrix (reconstructed to $512 \times 512$ ); FOV, 230-mm; 70\% rectangular FOV; 5-mm-thick sections with a $0.5-\mathrm{mm}$ gap. The volume of the MOTSA 3D-TOF MRA was localized on a sagittal 2D phase-contrast scout image. A presaturation band was applied above the imaging volume to saturate incoming venous blood. For the MOTSA 3D-TOF MR imaging, the parameters were the following: a 3D fast-field echo T1weighted sequence; TR/TE, 21/4 ms; flip angle, 20; matrix, 512 x 512 (reconstructed to $1024 \times 1024$ ); FOV, $200 \mathrm{~mm}$; 85\% rectangular FOV; 1.0- $\mathrm{mm}$ thick sections, interpolated to $0.5 \mathrm{~mm} ; 160$ sections acquired in 8 chunks. The measured voxel size of the MOTSA 3D-TOF MR image was $0.39 \times 0.61 \times 1 \mathrm{~mm}$, and the reconstructed voxel size was $0.2 \times 0.2 \times 0.5 \mathrm{~mm}$. The acquisition time of the high-resolution MOTSA 3DTOF sequence was reduced by SENSE parallel imaging. Total MR imaging examination time was 20 minutes. Images were processed into maximum intensity projections and volume rendered 3D images of the circle of Willis. This 3T MRA protocol for follow-up of coiled intracranial aneurysms has been validated in a previous study. ${ }^{13}$

\section{MR imaging evaluation}

MRI and MRA images were independently evaluated by 2 experienced neuroradiologists. Discrepancies were resolved in consensus. All MRA studies were scored using the Roy and Raymond (R\&R) classification as follows: complete aneurysm obliteration ( $R \& R$ class 1 ); residual aneurysm neck (R\&R class 2 ), and residual aneurysm lumen (R\&R class 3 ). ${ }^{2}$ In order to optimize interobserver agreement these ratings were dichotomized as follows: adequately occluded aneurysm (R\&R class 1 and 2 ) on the one hand, and inadequately occluded aneurysm (R\&R class 3 ) on the other. ${ }^{14}$

In inadequately occluded R\&R class 3 aneurysms, the residual aneurysm lumen was measured in 2 directions. In the case of a de novo aneurysm at the site of the coiled aneurysm, this was not considered a recurrence of the coiled aneurysm.

\section{Statistical analysis}

Percentages with $95 \%$ confidence intervals $(\mathrm{Cl})$ were calculated for aneurysms that had recanalized. We calculated inter-observer agreement of the dichotomized scores (adequate and inadequate occlusion) per aneurysm in percentages.

Correlation between near complete (R\&R class 2 ) initial occlusion status and inadequate occlusion at long term follow-up was calculated for the MUMC cohort and for those patients from the multicenter 
cohort of whom the initial R\&R occlusion status had been specified in the report. The OR with its $95 \% \mathrm{Cl}$ was calculated and the association was tested using a chi square test or Fisher exact if appropriate.

In the 400 patients of the multicenter LOTUS study odds ratios (OR) with $95 \% \mathrm{Cl}$ were calculated for binary outcome measures: patient gender, rupture status of aneurysms, aneurysm size $\geq 10 \mathrm{~mm}$, posterior circulation aneurysms and basilar tip aneurysms. Subsequently, risk factors with a P-value $\leq 0.10$ were included in a multivariate logistic regression model. A backward selection strategy was used and odds ratios with $95 \% \mathrm{Cl}$ were calculated.

\section{Results}

\section{Baseline patient and aneurysm characteristics}

Sixty-two patients with 71 coiled aneurysms, treated between December 1997 and June 2005, were included. During this period, 202 intracranial aneurysms in 180 patients had been treated by coiling in the MUMC. Of 180 patients, 173 with 195 aneurysms had six months follow-up angiography and 150 (77\%) aneurysms in 138 patients proved to be adequately occluded at this six month angiographic follow-up. Of 138 eligible patients with 150 aneurysms, 36 could not be included (1 patient with clipped aneurysm, 35 patients $>70$ yrs of age) and twenty-two patients were lost to follow-up (12\%). We invited 80 patients to participate in the study, but 18 declined (participation grade $77.5 \%$ ) (Figure 1).

Comparison of patient- and aneurysm characteristics of the 62 patients from the MUMC with all patients included in the LOTUS multicenter study did not show any significant difference (Table 1).

Table 1. Patient- and aneurysm characteristics of all participants in long-term MRA follow-up in the multicenter study (left column) and of MUMC patients in the present study (middle column).

\begin{tabular}{|c|c|c|c|}
\hline & $\begin{array}{l}400 \text { patients/ } \\
440 \text { aneurysms } \\
\text { with long-term } \\
\text { MRA follow-up }\end{array}$ & $\begin{array}{l}62 \text { patients/ } \\
71 \text { aneurysms } \\
\text { of the MUMC }\end{array}$ & OR $(95 \% \mathrm{Cl}), \mathrm{p}$ \\
\hline Women & $276(69 \%)$ & $47(76 \%)$ & $1.41(0.76-2.61), 0.28$ \\
\hline Mean age (yrs) & 54.5 & 54.7 & - \\
\hline median, range & $55,23-70$ & $56,23-70$ & - \\
\hline Ruptured aneurysms & $344(78 \%)$ & $60(84 \%)$ & $1.52(0.77-3.01), 0.24$ \\
\hline Mean size $(\mathrm{mm})$ & 6.5 & 6.1 & - \\
\hline median, range & $6.0,2-20$ & $5.0,2-18$ & - \\
\hline Size $\geq 10 \mathrm{~mm}$ & $66(15 \%)$ & $8(11 \%)^{*}$ & $0.72(0.33-1.57), 0.41$ \\
\hline \multicolumn{4}{|l|}{ Aneurysm location } \\
\hline Anterior circulation & $327(74 \%)$ & $54(76 \%)$ & - \\
\hline$A C A$ & 143 & 25 & - \\
\hline$M C A$ & 44 & 3 & - \\
\hline$I C A$ & 140 & 26 & - \\
\hline Posterior circulation & $113(26 \%)$ & $17(24 \%)+$ & $0.91(0.51-1.64), 0.75$ \\
\hline Basilar tip & 61 & $10^{+}$ & $1.02(0.49-2.09), 0.96$ \\
\hline
\end{tabular}

MRA: Magnetic Resonance Angiography; OR: Odds Ratio; ACA: anterior cerebral artery; MCA: middle cerebral artery; ICA: internal carotid artery; - : not calculated. 


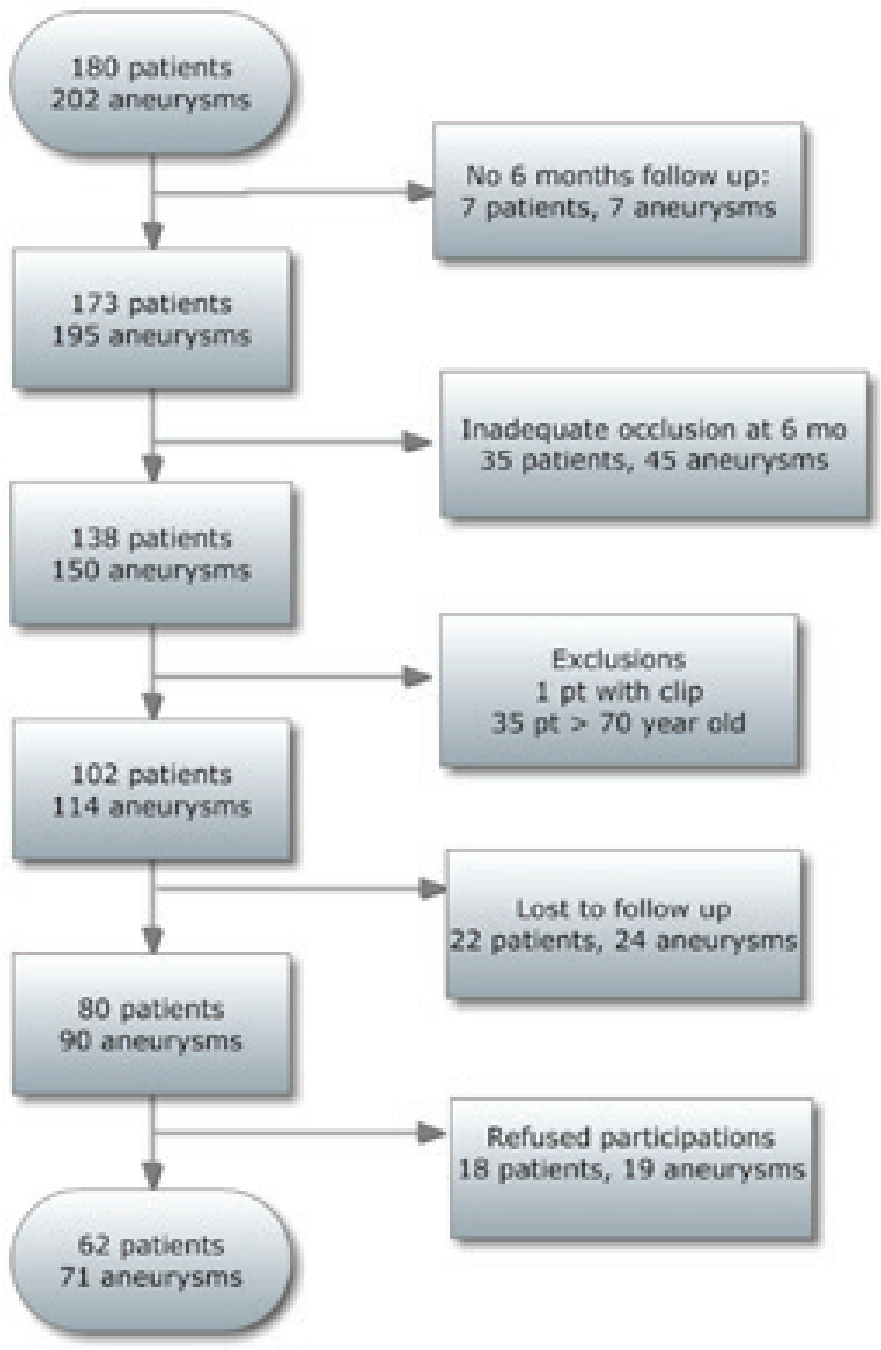

Figure 1. Flow chart showing patient and aneurysm selection

Aneurysm reopening on long-term follow-up MRA

Mean duration of follow-up was 7.9 years (median 8.3, range 4.5-12.2 yrs). There was agreement between observers with regard to occlusion status of the aneurysms in 66 of 71 aneurysms (92.9\%). Late reopening occurred in 3 of 62 patients $(4.8 \%, 95 \% \mathrm{Cl} 1.3-14.4 \%)$ with 71 aneurysms $(2.5 \%, 95 \% \mathrm{Cl}$ 1.1-12.7\%). Characteristics of patients and aneurysms with recanalization are displayed in Table 2. 
Table 2. Patient- and aneurysm characteristics of all participants in the multicenter study (left column) and of patients with aneurysm recanalization (middle column).

\begin{tabular}{|l|l|l|l|}
\hline & $\begin{array}{l}400 \text { patients/ } \\
440 \text { aneurysms } \\
\text { with long-term } \\
\text { MRA follow-up }\end{array}$ & $\begin{array}{l}11 \text { patients/ } \\
11 \text { aneurysms } \\
\text { with aneurysm } \\
\text { reopening }\end{array}$ & OR (95\% Cl), p \\
\hline Women & $276(69 \%)$ & $10(91 \%)$ & $4.66(0.59-36.82), 0.14$ \\
\hline Ruptured aneurysms & $344(78 \%)$ & $9(81 \%)$ & $1.26(0.27-5.94), 0.77$ \\
\hline Size $\geq 10 \mathrm{~mm}$ & $66(15 \%)$ & $5(45 \%) *$ & $5.13(1.52-17.32), 0.01 \ddagger$ \\
\hline Posterior circulation & $113(26 \%)$ & $5(45 \%)+$ & $2.51(0.75-8.38), 0.14$ \\
\hline Basilar tip & 61 & $4 \dagger$ & $3.73(1.06-13.14), 0.04 \ddagger$ \\
\hline
\end{tabular}

MRA: Magnetic Resonance Angiography; OR: Odds Ratio; ACA: anterior cerebral artery; MCA: middle cerebral artery; ICA: internal carotid artery.

* For calculation of OR for aneurysm reopening of aneurysms $\geq 10 \mathrm{~mm}$, aneurysms $<10 \mathrm{~mm}$ were used as reference group.

† For calculation of OR for aneurysm reopening of posterior circulation aneurysms, anterior circulation aneurysms were used as reference group. For calculation of OR for aneurysm reopening of basilar tip aneurysms, aneurysms on all other locations were used as reference group.

‡ Statistically significant

None of the three aneurysms with late recanalization were subjected to re-coiling $(0.0 \%, 95 \% \mathrm{Cl}$ 0.0-6.4\%). Two patients with aneurysm recanalization refused retreatment. In both patients a recanalization of the aneurysm had already been seen at the 24 month follow-up study, and the late follow-up study showed a very subtle enlargement of the recanalization (Figure 2 and 3 ). In the third patient, an interval follow-up MRA, performed 4.5 years after coiling, had still shown complete occlusion of the aneurysm. The late follow-up MRA that was done for this study, 9 years after the coiling procedure, showed a small recanalization at the wall of the aneurysm (Figure 4). In a multidisciplinary conference retreatment of the aneurysm was considered not indicated (Table 3).
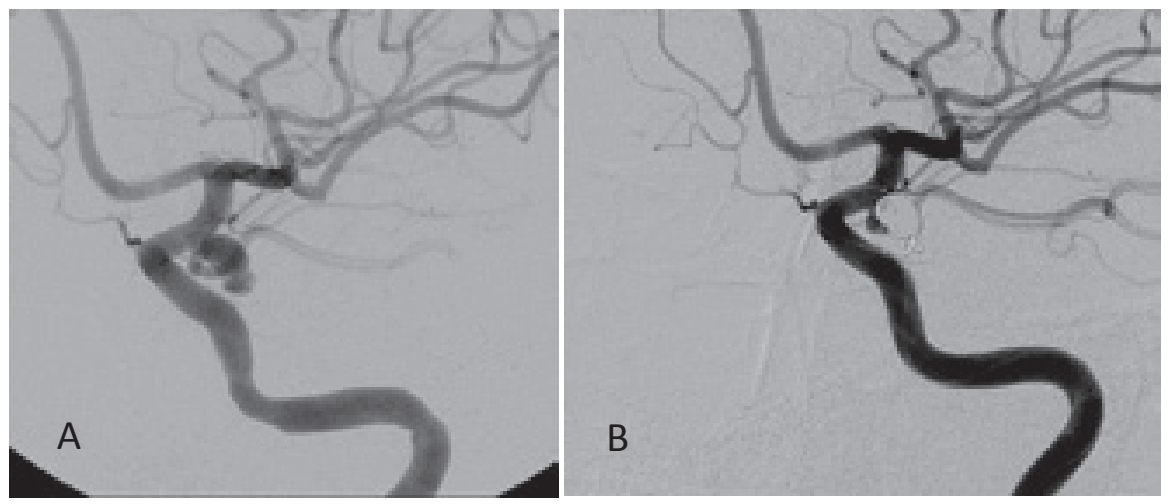

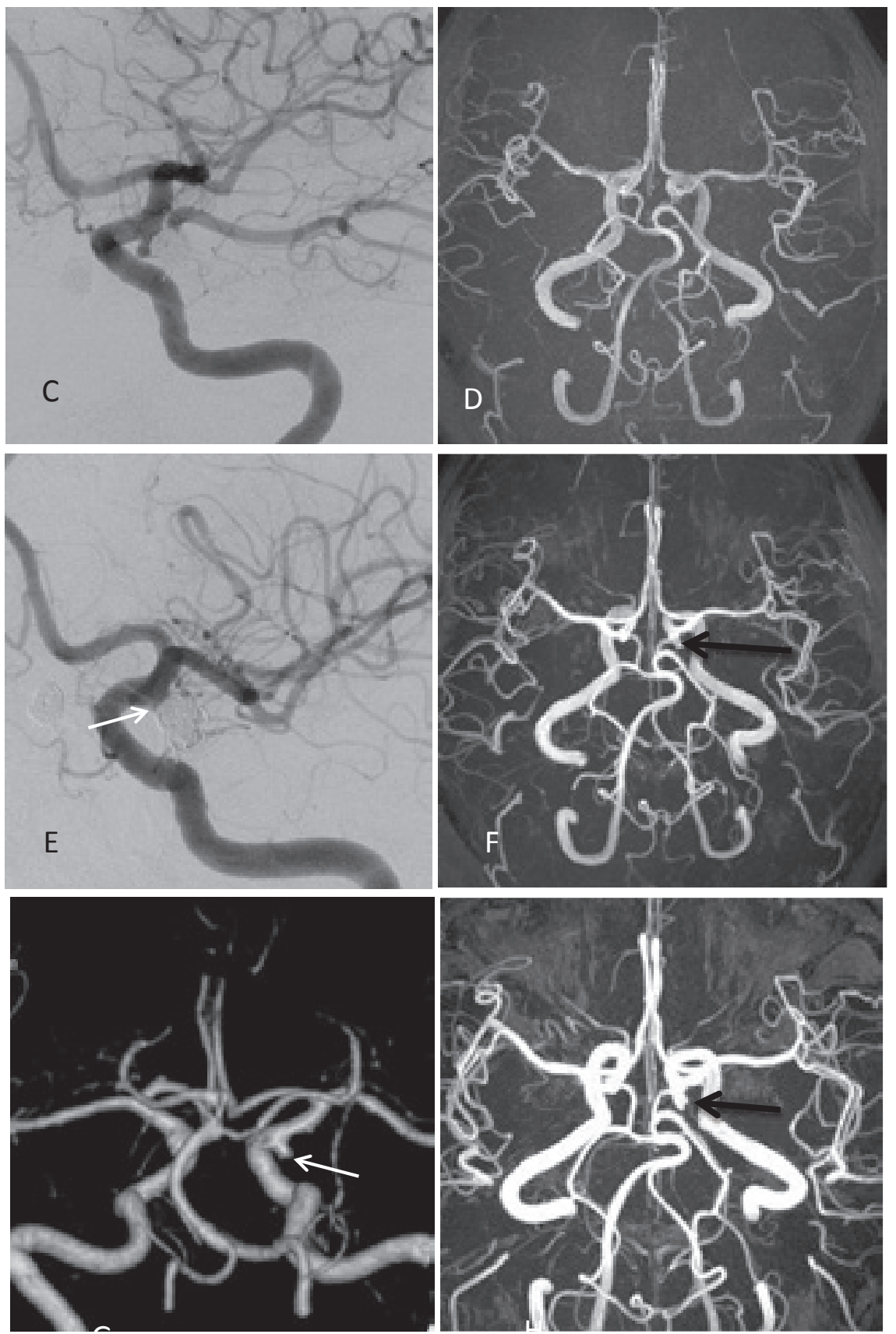

Figure 2. 41 year old woman with late reopening of a previously ruptured left posterior communicating (PCom) artery aneurysm. Patient refused treatment which was proposed by the multidisciplinary treatment team.

A. Lateral projection of DSA at presentation shows a $7 \mathrm{~mm}$ long aneurysm at the left PCom artery

B. Immediate post coiling result shows adequate occlusion of the aneurysm 
C and D. DSA and maximum intensity (MIP) reconstruction of the MRA at six months both show a stable occlusion of the aneurysm

$E$ and F. DSA and MIP reconstruction of the MRA at 24 months show a small recanalization in the neck of the aneurysm (arrow)

$\mathrm{G}$ and $\mathrm{H}$. 3D volume rendering and MIP reconstruction of the MRA at 75 months show a subtle enlargement of the recanalization (arrow)

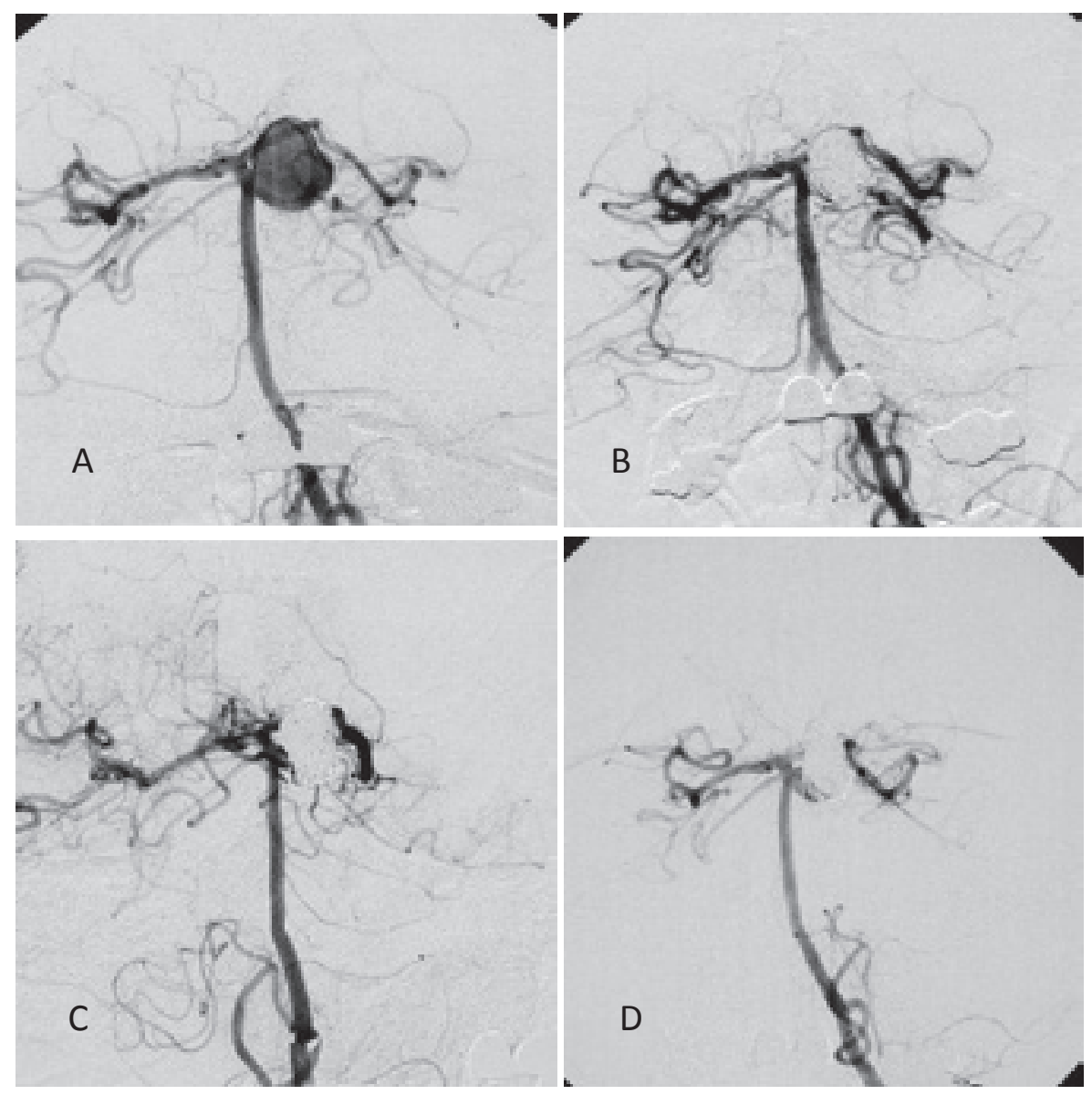



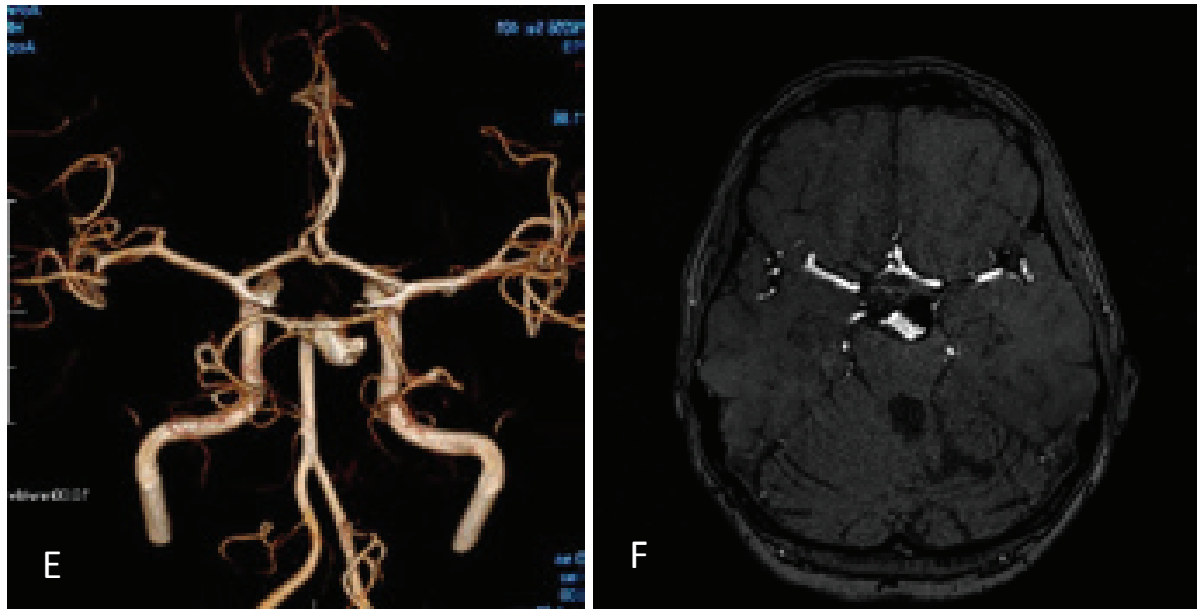

Figure 3. 60 year old woman with late reopening of a previously ruptured left superior cerebellar artery aneurysm. The patient refused the proposed treatment.

A. Anteroposterior projection of the DSA at presentation shows a $1 \mathrm{~cm}$ large left superior cerebellar artery aneurysm.

B. Immediate post coiling DSA image shows an adequately occluded aneurysm.

C. DSA at 6 months follow-up shows that the aneurysm is still completely occluded.

D. DSA at 24 months shows a displacement of the coils and recanalization at the neck and in the caudal part of the aneurysm

$E$ and F. 3D reconstructed and source images of the MRA at 59 months. The recanalization appears to have increased compared with the 24 months DSA
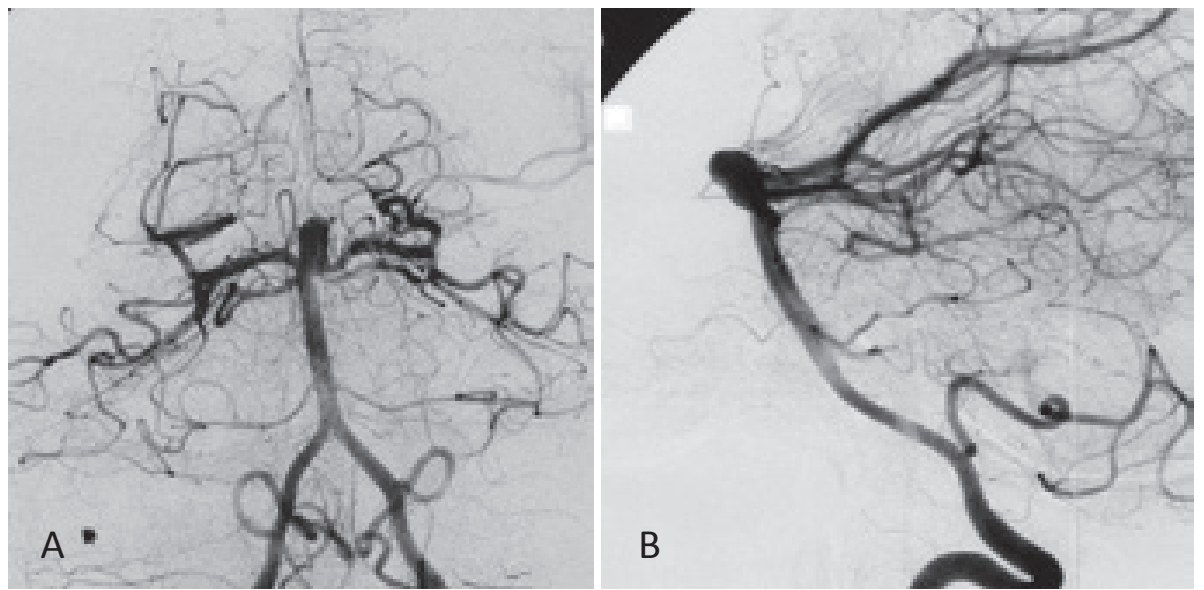

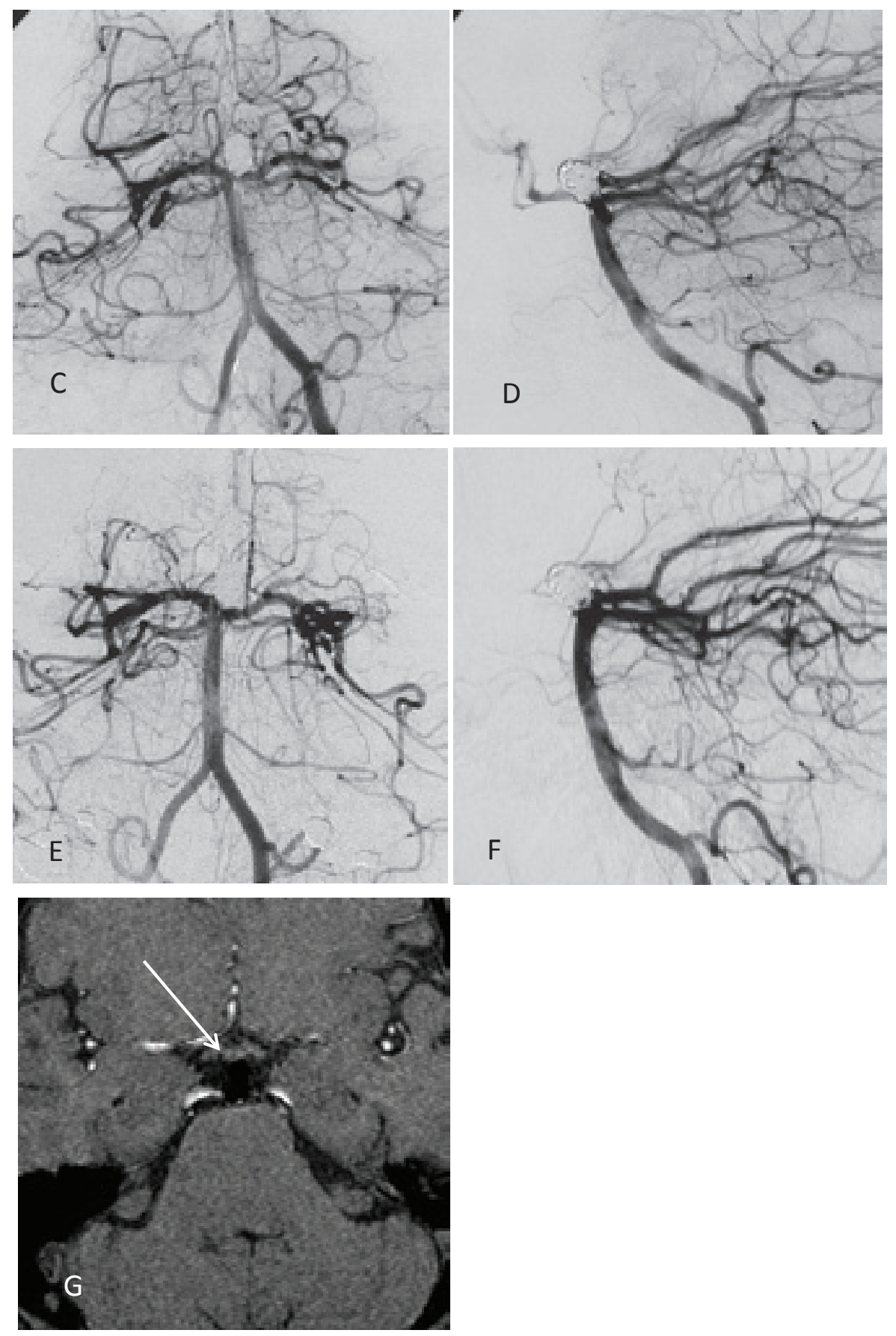

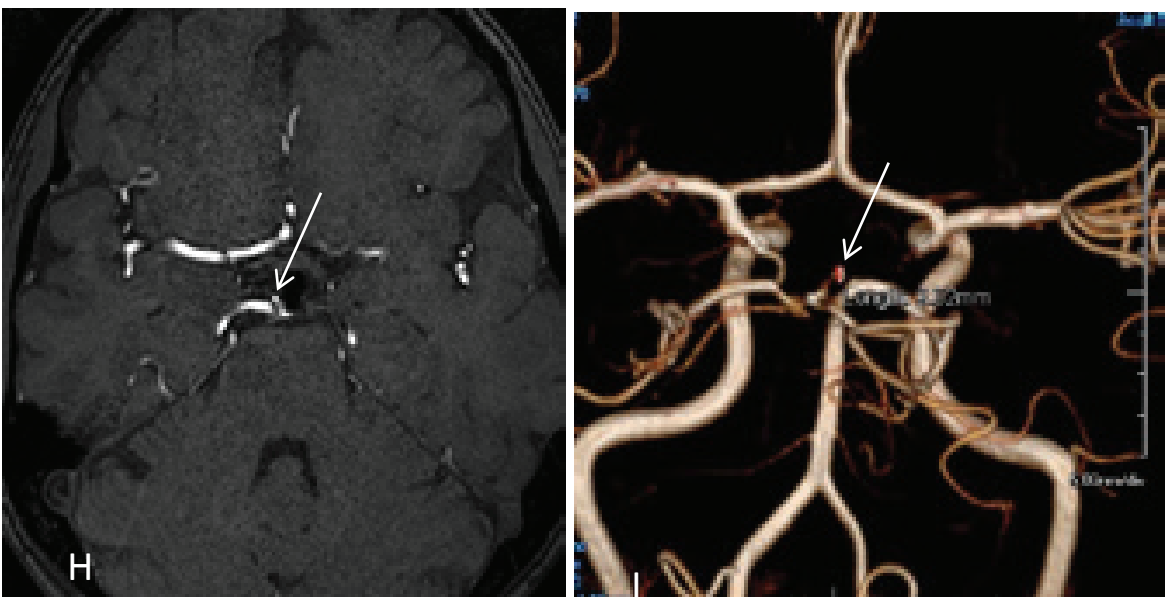

Figure 4. 45-year-old woman with late reopening of a previously ruptured basilar tip aneurysm.

$\mathrm{A}$ and B. Anteroposterior and lateral DSA projection at presentation shows a 6-mm basilar tip aneurysm $C$ and D. Directly after coiling DSA shows adequate aneurysm occlusion

E and F. Stable complete occlusion at 6-month follow-up DSA

G. MRA 5 years after coiling still shows a complete occlusion of the aneurysm, with signal loss due to coil mass (arrow)

$\mathrm{H}$ and I. Source image and volume rendered 3D image of MRA 9 years after coiling shows $2 \mathrm{~mm}$ aneurysm reopening at right of coil mass (arrow)

Table 3. Details of MUMC patients and aneurysms in present study with late reopening

\begin{tabular}{c|c|c|c|c|c|c|c|} 
No & M/F & Age & $\begin{array}{c}\text { Aneurysm } \\
\text { location }\end{array}$ & $\begin{array}{c}\text { Size } \\
\mathrm{mm}\end{array}$ & $\begin{array}{c}\text { Previous } \\
\text { rupture }\end{array}$ & $\begin{array}{c}\text { Size } \\
\text { reopening (mm) }\end{array}$ & $\begin{array}{c}\text { Retreat- } \\
\text { ment }\end{array}$ \\
\hline 1 & $\mathrm{~F}$ & 42 & PcomA & 5 & $\mathrm{Y}$ & $4 \times 3$ & $\mathrm{~N} \S$ \\
\hline 2 & $\mathrm{~F}$ & 61 & $\mathrm{SCA}$ & 10 & $\mathrm{Y}$ & $9 \times 7$ & $\mathrm{~N} \S$ \\
\hline 3 & $\mathrm{~F}$ & 45 & Basilar tip & 7 & $\mathrm{Y}$ & $1 \times 2$ & $\mathrm{~N}^{*}$ \\
\hline
\end{tabular}

PcomA: Posterior Communicating Artery, SCA: Superior Cerebellar Artery, Y: yes, N: no

$\S$ Patient refused retreatment

* Retreatment not judged indicated by multidisciplinary team

All three recanalized aneurysms had been judged as completely occluded at the end of the coiling procedure and at six months follow-up. None of the 17 residual neck aneurysms seen at six months follow-up showed further recanalization at late follow-up (Table 4).

Table 4. Two by two table comparing aneurysm occlusion status (R\&R class) at six months follow-up with adequacy of occlusion at long term follow-up in the present study.

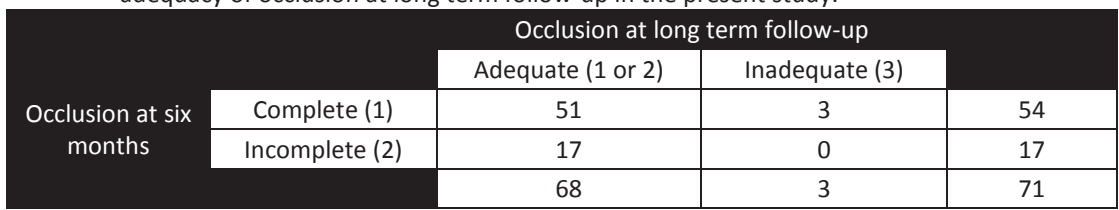

This is in concordance with the data from the multicenter LOTUS study: of 325 aneurysms the initial and six months occlusion status were specified according to the R\&R classification. (Table 5). No correlation 
between the aneurysms with a neck remnant (R\&R class 2 ) after coiling or at six months on the one hand, and inadequate occlusion (R\&R class 3 ) at late follow-up on the other, was found (OR 0.45, $95 \% \mathrm{Cl}: 0.05-3.79, \mathrm{p}=0.46)$, as these differences in proportion can easily be explained by chance.

Table 5. Two by two table comparing occlusion status (R\&R class) at six months follow-up with adequacy of occlusion at long term follow-up for 325 patients of the multicenter study. ${ }^{1}$

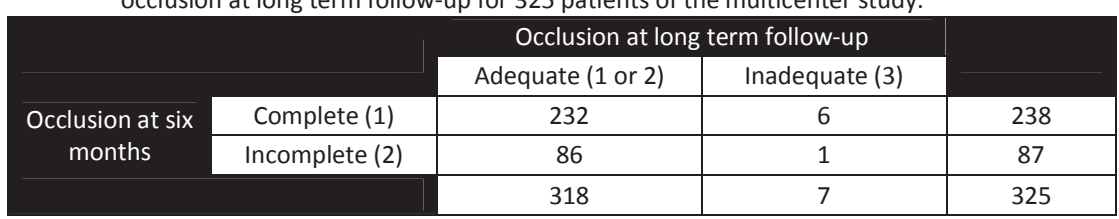

\section{Risk factors for late aneurysm reopening}

The number of recanalizations in the MUMC cohort was too small to assess risk factors.

In the larger LOTUS cohort of 400 patients with 440 aneurysms, ${ }^{1}$ of which our population was a subgroup, risk factors for late aneurysm recanalization are summarized in Table 2. In uni- and multivariable regression analysis, two factors were identified as both dependent and independent risk factors for late reopening: aneurysm size $\geq 10 \mathrm{~mm}$ (multivariable analysis: OR 4.7, 95\% Cl: 1.3-16.3, $\mathrm{p}=0.016)$ and location on the basilar tip (OR 3.9, $95 \% \mathrm{Cl}: 1.1-14.6, \mathrm{p}=0.042)$.

Two of the three recanalized aneurysms in our series were at or near the basilar tip (Figure 3 and 4), and one of these was $10 \mathrm{~mm}$ in diameter at presentation (Figure 3).

\section{Discussion}

Our study confirms that the great majority of coiled intracranial aneurysms that are adequately occluded at six months follow-up remain adequately occluded, at least during the following five years. ${ }^{1}$ First appearance of recanalization long after coiling occurred only occasionally and these recanalized aneurysms were not retreated for a variety of reasons. Our results indicate that for coiled aneurysms with adequate occlusion at 6 months, the yield of long-term MRA follow-up is very low.

Apart from the risk of aneurysm recanalization, a concern in patients with treated aneurysms is the frequent presence of small untreated aneurysms and the risk to develop de novo aneurysms over time. Imaging follow-up may be indicated to timely detect new aneurysms and growth of untreated additional aneurysms. The results of previous large follow-up studies addressing these issues indicate that in the first five years after coiling (and probably also in the first ten years), both the risk of de novo aneurysm formation and the risk of growth of existing untreated aneurysms is low and the risk of SAH from such aneurysms is extremely low. . $^{10,15,16}$

With such low additional risk of hemorrhage from de novo or untreated additional aneurysms the total risk of late hemorrhage in patients with adequately coiled aneurysms at six months, is expected to be very low. This has been confirmed in previous studies that focused on the recurrent hemorrhage rate in a comparable subgroup of patients with adequately coiled ruptured aneurysms at six months. In those 
studies, the incidence of recurrent subarachnoid hemorrhage after adequate coiling was significantly lower than after surgical clipping. ${ }^{17,18}$

The first imaging follow-up at six months appears to take place at a crucial point in time: if the coiled aneurysm is adequately occluded at this time, it is very likely that it will remain stable., ${ }^{1,9,10,19,20}$ However, extended imaging follow-up may be considered in patients with aneurysms larger than $10 \mathrm{~mm}$, with aneurysms located on the basilar tip and with partially thrombosed aneurysms. ${ }^{21}$ Other factors may also play a role in decision making, such as young patient age, the presence of multiple aneurysms or family history of cerebral aneurysms.

Since its introduction by Roy and Raymond in 2001, their three-point scale for describing the occlusion status of coiled aneurysms has been generally accepted. ${ }^{2}$ It served a simple purpose: to differentiate between complete occlusion (class 1 ), incomplete occlusion that does not require further treatment (class 2), and incomplete occlusion that may require further treatment, depending on other factors (class 3). The practical significance of making a distinction between R\&R class 1 and class 2 is unclear although in many studies this level is used as cut-off point for dichotomized analyses. ${ }^{22,23}$ Only in some more recent publications have analyses been done with dichotomization between adequately occluded ( $R \& R$ class 1 and 2 ) and inadequately occluded (R\&R class 3 ) aneurysms. ${ }^{24-27}$

Only if R\&R class 2 occlusions have a predictive value for later recanalization is there a rationale for this distinction. In this study and in the larger multicenter LOTUS study we did not find this predictive value.

\section{Conclusion}

Prolonged imaging follow-up within the first 5-10 years after coiling does not seem beneficial in patients with coiled aneurysms that are adequately occluded at 6 months, in terms of detecting recanalized aneurysms that need retreatment. Whether patients might benefit from screening beyond the 5 - to $10-$ year interval is not yet clear.

Occlusion status at six months follow-up of coiled aneurysms can be described as adequate or inadequate.

\section{References}

Ferns, S. P. et al. Late reopening of adequately coiled intracranial aneurysms: frequency and risk factors in 400 patients with 440 aneurysms. Stroke 42, 1331-1337, (2011).

Roy, D., Milot, G. \& Raymond, J. Endovascular treatment of unruptured aneurysms. Stroke 32, 1998-2004, (2001).

Molyneux, A. et al. International Subarachnoid Aneurysm Trial (ISAT) of neurosurgical clipping versus endovascular coiling in 2143 patients with ruptured intracranial aneurysms: a randomised trial. Lancet 360, 1267-1274, (2002).

Wiebers, D. O. et al. Unruptured intracranial aneurysms: natural history, clinical outcome, and risks of surgical and endovascular treatment. Lancet 362, 103-110, (2003).

Ferns, S. P. et al. Coiling of intracranial aneurysms: a systematic review on initial occlusion and reopening and retreatment rates. Stroke 40, e523-529, (2009).

Sluzewski, M. et al. Relation between aneurysm volume, packing, and compaction in 145 cerebral aneurysms treated with coils. Radiology 231, 653-658, (2004). 
Campi, A. et al. Retreatment of ruptured cerebral aneurysms in patients randomized by coiling or clipping in the International Subarachnoid Aneurysm Trial (ISAT). Stroke 38, 1538-1544, (2007). Raymond, J. et al. Long-term angiographic recurrences after selective endovascular treatment of aneurysms with detachable coils. Stroke 34, 1398-1403, (2003).

Sluzewski, M., van Rooij, W. J., Rinkel, G. J. \& Wijnalda, D. Endovascular treatment of ruptured intracranial aneurysms with detachable coils: long-term clinical and serial angiographic results. Radiology 227, 720724, (2003).

10 Gallas, S. et al. Long-term follow-up of 1036 cerebral aneurysms treated by bare coils: a multicentric cohort treated between 1998 and 2003. AJNR Am J Neuroradiol 30, 1986-1992, (2009).

11 Sprengers, M. E. et al. Stability of intracranial aneurysms adequately occluded 6 months after coiling: a 3T MR angiography multicenter long-term follow-up study. AJNR Am J Neuroradiol 29, 1768-1774, (2008). Jennett, B. \& Bond, M. Assessment of outcome after severe brain damage. Lancet 1, 480-484, (1975).

13 Majoie, C. B. et al. MR angiography at 3T versus digital subtraction angiography in the follow-up of intracranial aneurysms treated with detachable coils. AJNR Am J Neuroradiol 26, 1349-1356, (2005). Cloft, H. J., Kaufmann, T. \& Kallmes, D. F. Observer agreement in the assessment of endovascular aneurysm therapy and aneurysm recurrence. AJNR Am J Neuroradiol 28, 497-500, (2007). Wermer, M. J. et al. Follow-up screening after subarachnoid haemorrhage: frequency and determinants of new aneurysms and enlargement of existing aneurysms. Brain 128, 2421-2429, (2005). Sprengers, M. E. et al. MR angiography follow-up 5 years after coiling: frequency of new aneurysms and enlargement of untreated aneurysms. AJNR Am J Neuroradiol 30, 303-307, (2009). Schaafsma, J. D. et al. Long-term recurrent subarachnoid hemorrhage after adequate coiling versus clipping of ruptured intracranial aneurysms. Stroke 40, 1758-1763, (2009). Wermer, M. J., Greebe, P., Algra, A. \& Rinkel, G. J. Incidence of recurrent subarachnoid hemorrhage after clipping for ruptured intracranial aneurysms. Stroke 36, 2394-2399, (2005). standardised mortality ratios after clipping or coiling of an intracranial aneurysm in the International Subarachnoid Aneurysm Trial (ISAT): long-term follow-up. Lancet Neurol 8, 427-433, (2009).

20 Holmin, S. et al. Intradural saccular aneurysms treated by Guglielmi detachable bare coils at a single institution between 1993 and 2005: clinical long-term follow-up for a total of 1810 patient-years in relation to morphological treatment results. Stroke 39, 2288-2297, (2008).

21 Ferns, S. P., van Rooij, W. J., Sluzewski, M., van den Berg, R. \& Majoie, C. B. Partially thrombosed intracranial aneurysms presenting with mass effect: long-term clinical and imaging follow-up after endovascular treatment. AJNR Am J Neuroradiol 31, 1197-1205, (2010).

22 Kwee, T. C. \& Kwee, R. M. MR angiography in the follow-up of intracranial aneurysms treated with Guglielmi detachable coils: systematic review and meta-analysis. Neuroradiology 49, 703-713, (2007). Weng, H. H., Jao, S. Y., Yang, C. Y. \& Tsai, Y. H. Meta-analysis on Diagnostic Accuracy of MR Angiography in the Follow-Up of Residual Intracranial Aneurysms Treated with Guglielmi Detachable Coils. Interv Neuroradiol 14 Suppl 2, 53-63, (2008).

24 Kaufmann, T. J. et al. A prospective trial of 3T and 1.5T time-of-flight and contrast-enhanced MR angiography in the follow-up of coiled intracranial aneurysms. AJNR Am J Neuroradiol 31, 912-918, (2010). Lavoie, P. et al. Residual flow after cerebral aneurysm coil occlusion: diagnostic accuracy of MR angiography. Stroke 43, 740-746, (2012).

26 Pierot, L., Portefaix, C., Boulin, A. \& Gauvrit, J. Y. Follow-up of coiled intracranial aneurysms: comparison of 3D time-of-flight and contrast-enhanced magnetic resonance angiography at $3 \mathrm{~T}$ in a large, prospective series. Eur Radiol, (2012).

27 Schaafsma, J. D. et al. Intracranial aneurysms treated with coil placement: test characteristics of follow-up MR angiography--multicenter study. Radiology 256, 209-218, (2010). 


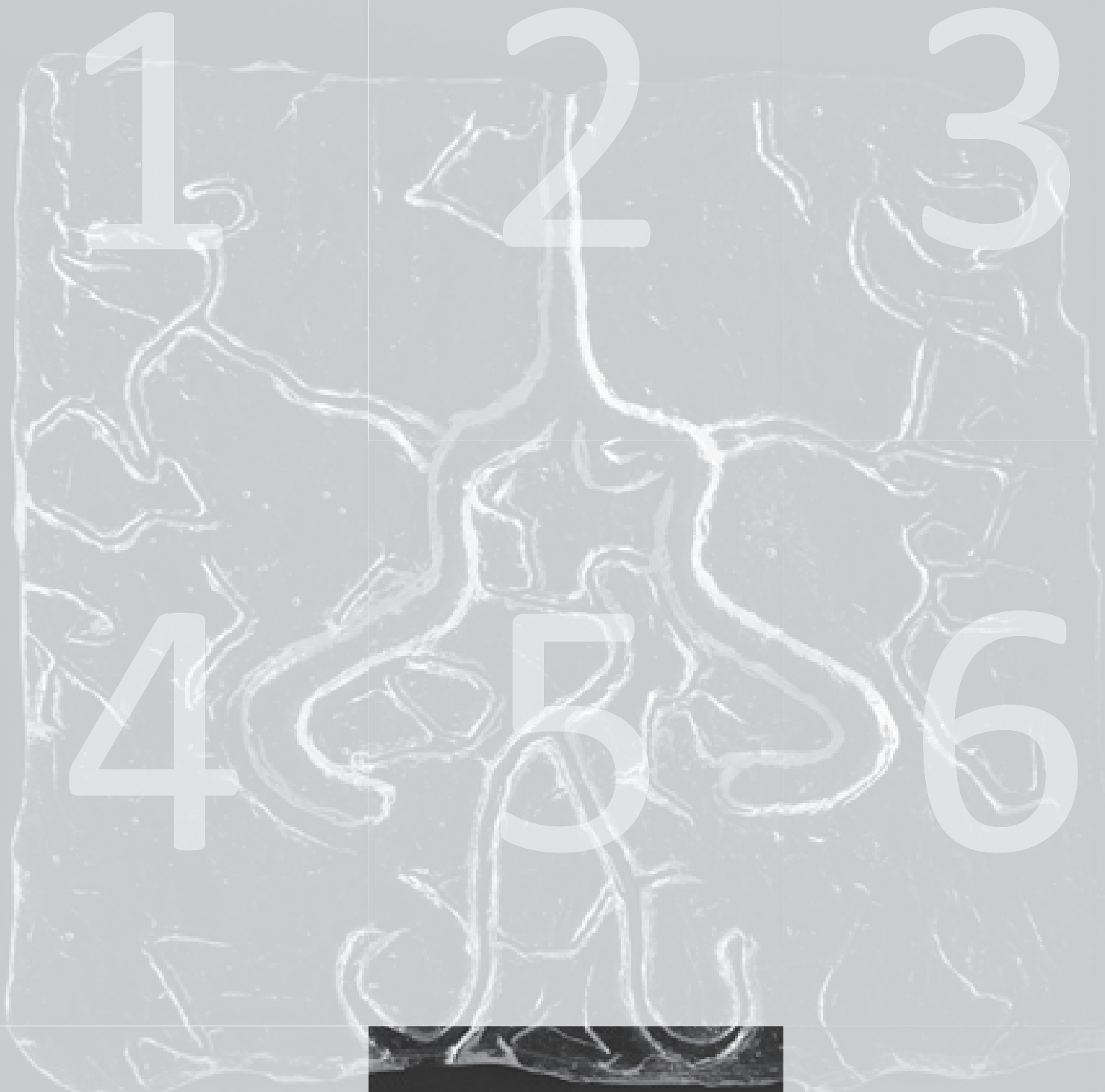




\section{Chapter 8}

Cost-effectiveness of CTA, MRA and DSA in patients with non-traumatic subarachnoid hemorrhage.
A.M.H. Sailer
J.P.C. Grutters
J.E. Wildberger
P.A.M. Hofman
J.T. Wilmink
W.H. van Zwam

Submitted to European Radiology. 


\section{Abstract}

Purpose: Intra-arterial digital subtraction angiography (DSA) is the standard of reference for detection of ruptured intracranial aneurysms and determination of suitable treatment. Contrast enhanced magnetic resonance angiography (MRA) and computed tomographic angiography (CTA) are non-invasive alternatives. If imaging deems no feasibility of endovascular treatment, surgical clipping is an alternative with higher costs and less favorable outcome. Goal of this study was to compare the cost-effectiveness of MRA, CTA and DSA respectively in non-traumatic subarachnoid hemorrhage.

Materials and Methods: A decision model was used to calculate costs and benefits (in quality-adjusted life-years [QALYs]) that accrued to cohorts of 1000 patients during one year. Costs and characteristics of diagnostic tests, therapy, patients' quality of life and associated costs were taken into account. In a scenario analysis a strategy was examined where in each patient, for whom coiling was not deemed feasible on the basis of CTA or MRA, DSA was performed.

Results DSA was the most effective diagnostic option, yielding on average 0.6039 QALYS (SD 0.0148) per patient, followed by CTA 0.5983 QALYs (SD 0.0146) and MRA 0.5947 QALYS (SD 0.0146). Cost was lowest for DSA (€39,808; SD €1,384), followed by CTA (€40,748; SD €1,510) and MRA (€41,814; SD €1,644). The strategy that included DSA for each patient for whom coiling was not deemed feasible showed CTA being most cost-effective.

Conclusion: DSA is more cost-effective than MRA and CTA. A strategy where CTA is followed by DSA if aneurysm coiling is not deemed feasible, is found to be the most cost-effective option. 


\section{Introduction}

Rupture of an intracranial aneurysms is a major cause of death and disability with an overall incidence of approximately 9 out of $100.000 .^{1}$ In the group of patients who survived initial bleed, the risk of rebleeding without treatment would be $1-2 \%$ per day for the first four weeks with a $70 \%$ case fatality rate. $^{2,3}$

To prevent rebleeding from ruptured aneurysms, treatment is performed as soon as feasible in order to exclude the aneurysm from the arterial circulation. ${ }^{2,4,5}$ Treatment options are either neurosurgical clipping via craniotomy or endovascular aneurysm occlusion by detachable platinum coils. The ISAT trial demonstrated better clinical outcome and significant risk reduction for endovascular treatment. Coiling is the preferred option in patients where both treatments are feasible. ${ }^{2,6-9}$ Total treatment costs were found to be slightly higher for surgical clipping compared to endovascular coiling. ${ }^{10-13}$ Non-traumatic subarachnoid hemorrhage (SAH) is caused in about $85 \%$ of cases by a ruptured intracranial aneurysm. ${ }^{14}$ Diagnostic imaging is required to fulfill two tasks: 1 . To detect the presence of intracerebral aneurysms. 2. To determine the most suitable treatment: endovascular coiling or surgical clipping.

DSA is the reference standard for detecting aneurysms and determing the feasibility of coiling. Nevertheless this invasive and labor intensive technique is relatively expensive and carries discomforts and potential risks. ${ }^{15-18}$ Promising noninvasive and less costly diagnostic alternatives are CTA and MRA. CTA is easily available and can be rapidly performed in an acute setting. The main benefits of MRA are the fact that no ionizing radiation is used, and the contrast medium injected has less nephrotoxic complications.

Although costs and characteristics of diagnostic tests and treatment have been reported, we found no studies determining the optimal diagnostic pathway in patients with suspected ruptured intracranial aneurysms. The goal of our study was to compare the cost-effectiveness of MRA, CTA and DSA in these patients for the first year's period after the bleed. Cost-effectiveness of diagnostic tests in follow-up of coiled aneurysm has previously been evaluated by Schaafsma et al. ${ }^{19}$

\section{Materials and Methods}

The results of Chapter 2 and 3 of this thesis are used as input parameters. 75 patients with nontraumatic SAH were included. ${ }^{20}$ For all patients, MRA, CTA and DSA had been performed. Details of the patient population and scan parameters can be found in Chapter 2. For each diagnostic test, two experienced observers determined the presence of an aneurysm and feasibility of endovascular coiling. The observers were blinded to the parallel imaging modality and to the results of each other's findings. Pooled sensitivity of CTA for detection of aneurysms was $91.5 \%$ (95\% Cl: 85.0-95.5) and specificity was 94.4\% (95\% Cl: 79.0-99.0). Pooled sensitivity of MRA for detection of aneurysms was $95.4 \%$ (95\% $\mathrm{Cl}$ : 89.8-98.1) and specificity was $83.3 \%(95 \% \mathrm{Cl}$ : 66.5-93.0). Pooled sensitivity of CTA in determining feasibility of endovascular coiling was $71.9 \%(95 \% \mathrm{Cl}: 59.0-82.1)$ and specificity was $75.4 \%(95 \% \mathrm{Cl}$ : $62.0-85.5)$. Pooled sensitivity of MRA in determining feasibility of endovascular coiling was $60.6 \%(95 \%$ 
$\mathrm{Cl}: 48.2-71.7)$ and specificity was $81.4 \%$ (95\% Cl: 68.7-89.9). DSA as standard of reference was regarded to have a sensitivity and specificity for aneurysm detection and determination of treatment of $100 \%$.

\section{Evaluation of costs and benefits: A decision tree}

A decision tree (using Excel Software) was developed to determine differences in health benefits and costs in patients with ruptured aneurysms for each diagnostic pathways. ${ }^{21}$ For patients with acute nontraumatic $\mathrm{SAH}$, the decision tree delivers different health states due to characteristics of diagnostic imaging and choice of therapy. Health states were based on whether patients were alive and, when they were alive, whether they were well or disabled. Figure 1 shows the decision tree for MRA. A hypothetical cohort of patients passes through the model based on a one year period. This allowed us to evaluate health costs of diagnostic test and treatment as well as related quality of life and associated costs determined by diagnostic decision. A health care perspective was used, which included only direct health care costs.

\section{Basic model and scenario model}

In the basic model, patients underwent either DSA, MRA or CTA. Following our standard clinical practice, if no aneurysm was detected on CTA or MRA, an additional DSA study was performed. Patients without an intracranial aneurysm were not treated. In patients in whom an aneurysm was detected, feasibility of coiling of the aneurysm was determined. Depending on the result of each test, either a coiling or clipping procedure was initiated. In cases where false positive feasibility of coiling was determined, angiography during the coiling procedure would show no feasibility, and transfer to surgical clipping would have been performed. In case of false negative determination of coiling, surgical clipping would have been performed although coiling would have been feasible.

In a scenario analysis in each patient in whom an aneurysm was detected which was deemed not suitable for coiling by MRA or CTA, an additional DSA study was considered to be performed.

\section{Model parameters}

Sensitivity and specificity of the diagnostic test for detection of aneurysms and determination of treatment possibility from our prior study, as described in Chapter 2 and 3, were taken as input parameters to the decision model. For the costs of DSA, MRA and CTA, standard prices from the Dutch manual for cost research were used. ${ }^{22}$ Total one year costs of surgical clipping and endovascular coiling were derived from a literature search for western countries. ${ }^{13}$ Health outcome after one year of treatment was derived from the ISAT trial. ${ }^{7,8}$

Input parameters for related utilities ${ }^{23}$ and $\operatorname{costs}^{19,22,24}$ as well as health risk of DSA are based on available literature. ${ }^{15,16}$ All costs were updated to 2010 by means of national price index figures ${ }^{25}$ and converted to Euro $(1 \$=1,37 €)$. Standard discount rates of $1.5 \%$ for effects and $4 \%$ for costs according to Dutch guidelines were used. ${ }^{22}$ Table 1 shows the model input parameters and their sources.

\section{Model assumptions}

We assumed that DSA as standard of reference has a sensitivity and specificity of $100 \%$ in detecting aneurysms and determining feasibility of coiling. Furthermore we assumed no significant gender or age 

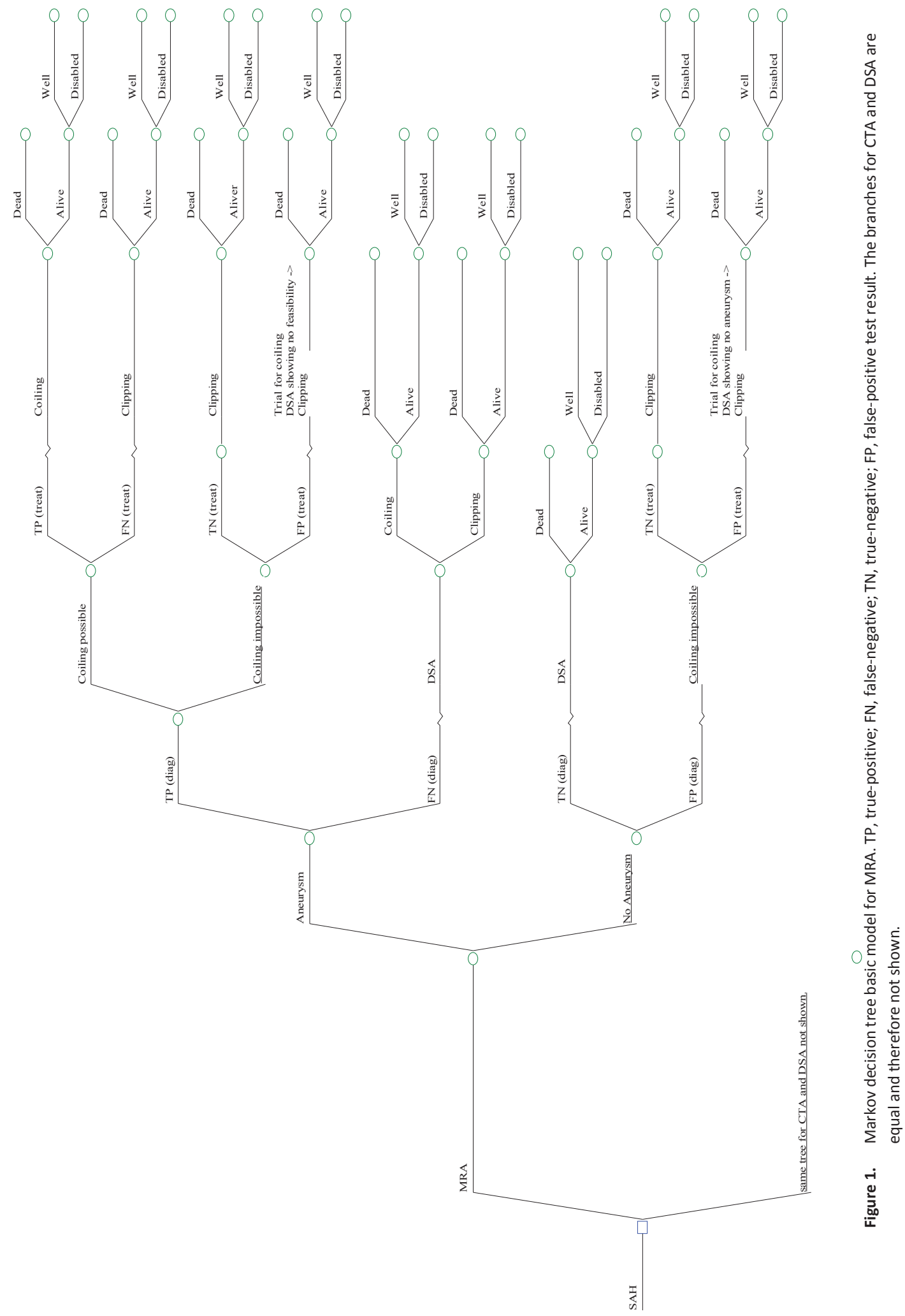
related differences in outcome as well as no influence due to aneurysm size or location. Patients presenting with acute SAH without presence of a ruptured aneurysm were assumed to have no other intracranial vascular pathology to be treated.

\section{Model simulation and outcome measures}

In our model, we evaluated the outcome of diagnostic pathways based on the input parameters in table 1. Simulation was performed for a hypothetical cohort of 1000 patients. We compared total one-year costs of diagnostic test, treatment option and health state to one year's health benefits in terms of QALYs. Incremental cost-effectiveness ratios (ICERs) were calculated from each model, by dividing the incremental costs by the incremental QALYs. Whether a treatment is deemed cost-effective depends on how much society is willing to pay for a QALY gained. The simulation was repeated with the scenario analysis in which for all patients DSA was performed in case an aneurysm was visible but coiling was deemed not feasible.

\section{Sensitivity analysis}

Uncertainty regarding the model input parameters was explored with a probabilistic sensitivity analysis using Monte Carlo simulation. ${ }^{21,26}$ With Monte Carlo simulation, different samples ( $\left.N=1000\right)$ are taken from parameter distributions for the hypothetical cohort to examine uncertainty in cost-effectiveness estimation. ${ }^{19}$ All assigned distributions are listed in table 1.

Table 1. Model input parameters

\begin{tabular}{|c|c|c|c|c|}
\hline Model Parameter & Value & $\begin{array}{l}\text { SD / } \\
\text { range }\end{array}$ & Distribution & Source \\
\hline \multicolumn{5}{|l|}{ Discount rates } \\
\hline cDR (Cost discount rate) & $4 \%$ & & fixed & 22 \\
\hline oDR (Outcome discount rate) & $1.5 \%$ & & fixed & 22 \\
\hline \multicolumn{5}{|l|}{ Treatment independent parameters } \\
\hline \multicolumn{5}{|l|}{ Probabilities $(p)$} \\
\hline pAneurysm in case of non traumatic SAH & 0.85 & & beta & 14 \\
\hline \multicolumn{5}{|l|}{ Costs $(€)$} \\
\hline \multicolumn{5}{|l|}{ Diagnostics } \\
\hline cDSA & $725 €$ & & & 22 \\
\hline CMRA & $252 €$ & & & 22 \\
\hline cCTA & $197 €$ & & & 22 \\
\hline \multicolumn{5}{|l|}{ Treatment } \\
\hline cCoiling & $28,870 €$ & $1,833 €$ & gamma & 13 \\
\hline cClipping & $31,739 €$ & $2,503 €$ & gamma & 13 \\
\hline \multicolumn{5}{|l|}{ Health state costs } \\
\hline number of days in nursing home per year (d) & 365 & & & \\
\hline costs per day in nursing home $(€ / d)$ & $241 €$ & & & \\
\hline cDisability & $87,975 €$ & & & 22 \\
\hline \multicolumn{5}{|l|}{ Event costs } \\
\hline cDeath & $2,741 €$ & & & 19,24 \\
\hline \multicolumn{5}{|l|}{ Utilities } \\
\hline uWell & 0.78 & 0.019 & beta & 19,23 \\
\hline uWell after SAH & 0.72 & $0.65-0.80$ & triangular & 19,23 \\
\hline
\end{tabular}


Table 1 continued

\begin{tabular}{|c|c|c|c|c|}
\hline uDis & 0.25 & $0.21-0.30$ & triangular & 19,23 \\
\hline \multicolumn{5}{|l|}{ clinical outcome propabilities } \\
\hline Probability of being well after clipping & 0.69 & 0.014 & beta & 8 \\
\hline Probability of being disabled after clipping & 0.21 & 0.013 & beta & 8 \\
\hline pClipdead & 0.10 & 0.009 & beta & 8 \\
\hline pClipwell (probability of being well after survived clipping) & 0.77 & & & 8 \\
\hline Probability of being well after coiling & 0.76 & 0.013 & beta & 8 \\
\hline Probability of being disabled after coiling & 0.16 & 0.011 & beta & 8 \\
\hline pCoildead & 0.08 & 0.008 & beta & 8 \\
\hline pCoilwell (probability of being well after survived coiling) & 0.83 & & & 8 \\
\hline Probability of being well after DSA & 0.998 & 0.001 & beta & 15,16 \\
\hline Probability of being disabled after DSA & 0.002 & 0.001 & beta & 15,16 \\
\hline pDSAwell (probability of being well after survived DSA) & 0.998 & & & \\
\hline \multicolumn{5}{|l|}{ probability of being dead/disabled after surgery without aneurysm } \\
\hline pSurgdead & 0.025 & 0.004 & beta & 27 \\
\hline pSurgdisab & 0.132 & 0.008 & beta & 27 \\
\hline pCoilTP (probability coiling is feasible in true positive aneurysm) & 0.585 & 0.061 & beta & $*$ \\
\hline pCoilFP (probability coiling is feasible in false positive aneurysm) & 0 & & fixed & * \\
\hline \multicolumn{5}{|l|}{ Treatment dependent parameters } \\
\hline \multicolumn{5}{|l|}{ Probabilities } \\
\hline pMRAtpD (Sensitivity MRA in diagnosing aneurysm) & 0.954 & 0.018 & beta & 20 \\
\hline pMRAtnD (Specificity MRA in diagnosing aneurysm) & 0.833 & 0.061 & beta & 20 \\
\hline pCTAtpD (Sensitivity CTA in diagnosing aneurysm) & 0.915 & 0.024 & beta & 20 \\
\hline pCTAtnD (Specificity CTA in diagnosing aneurysm) & 0.944 & 0.038 & beta & 20 \\
\hline $\begin{array}{l}\text { pMRAtpT (Sensitivity MRA in determining whether coiling is } \\
\text { feasible) }\end{array}$ & 0.606 & 0.058 & beta & * \\
\hline $\begin{array}{l}\text { pMRAtnT (Specificity MRA in determining whether coiling is } \\
\text { feasible) }\end{array}$ & 0.816 & 0,050 & beta & * \\
\hline pCTAtpT (Sensitivity CTA in determining whether coiling is feasible) & 0.719 & 0.056 & beta & * \\
\hline pCTAtnT (Specificity CTA in determining whether coiling is feasible) & 0.754 & 0.057 & beta & * \\
\hline pDSAtpD (Sensitivity DSA in diagnosing aneurysm) & 1 & & fixed & * \\
\hline pDSAtnD (Specificity DSA in diagnosing aneurysm) & 1 & & fixed & * \\
\hline $\begin{array}{l}\text { pDSAtpT (Sensitivity DSA in determining whether coiling is } \\
\text { feasible) }\end{array}$ & 1 & & fixed & * \\
\hline $\begin{array}{l}\text { pDSAtnT (Specificity DSA in determining whether coiling is } \\
\text { feasible) }\end{array}$ & 1 & & fixed & * \\
\hline
\end{tabular}

To illustrate the results of the simulation, cost-effectiveness acceptability curves (CEACS) were calculated. ${ }^{28}$ CEACs show the probability that a strategy is cost-effective, given different values of willingness to pay for a QALY.

Simulation was also repeated with univariate sensitivity analyses for costs of DSA, MRA and CTA as well as for costs of coiling and clipping to determine association between model parameters and uncertainty in cost-effectiveness outcome. 


\section{Results}

\section{Basic model}

Comparing average one year health benefits, DSA was the most effective diagnostic option, yielding 0.6039 QALYS (SD 0.0148), followed by CTA yielding 0.5983 QALYS (SD 0.0146) and MRA yielding 0.5947 QALYS (SD 0.0146). The total one year health costs were lowest for DSA (€39,808; SD €1,384), followed by CTA (€40,748; SD €1,510) and MRA (€41,814; SD €1,644). Initial diagnostic costs were highest for DSA while therapy and health state related costs were lowest for DSA, resulting in an overall less costly management. CTA as diagnostic test resulted in 128 out of 1,000 patients being referred for clipping although coiling would have been feasible. With MRA, 187 patients out of 1,000 were treated surgically although endovascular treatment would have been feasible. DSA was both more effective and less costly over one year and dominated CTA and MRA. CTA was more effective and less costly and thus dominated MRA. Table 2 shows costs and QALYs for the three diagnostic tests.

Table 2. Related one-year costs and QALYS for MRA, CTA and DSA per patient in the basic model

\begin{tabular}{|l|rr|r|r|rc|}
\hline & \multicolumn{2}{|c|}{ MRA } & \multicolumn{2}{c|}{ CTA } & \multicolumn{2}{c|}{ DSA } \\
\cline { 2 - 7 } & Costs (€) & QALYs & Costs (€) & QALYs & Costs (€) & QALYs \\
\hline MRA resp. CTA & 252 & 0,5947 & 197 & 0,5983 & & 0,6039 \\
DSA & $* 168$ & & $* 214$ & & 725 & 725 \\
Total diagnostic & 420 & & 411 & & 25.552 \\
Treatment & 26.734 & & 26.119 & & 205 \\
Death & 217 & & 213 & & 13.324 & \\
Disability costs & 14.443 & & 14.005 & & 39.808 & 0,6039 \\
\hline Total & 41.814 & 0,5947 & 40.748 & 0,5983 & & \\
\hline
\end{tabular}

* average costs per patient for DSA performed in case CTA / MRA showing no aneurysm

\section{Scenario model}

The strategy that included DSA for every patient for whom coiling was not deemed feasible on the basis of CTA and MRA, led to equal effectiveness for DSA, MRA and CTA (0,6039 QALYs each). In this approach no patient was treated surgically unless coiling was no option. In this scenario, CTA was less costly reaching a total average one year's cost per patient of $€ 39,767$, and therefore cost-effective compared to MRA and DSA which reached costs of $€ 39,851$ and $€ 39,808$ respectively. Table 3 shows total one year's costs and QALYs as well as incremental costs and QALYs for diagnostic tests in the scenario analysis and basic model.

Table 3. Total one year's outcome and incremental cost-effectiveness ratio (ICER) for basic and scenario models.

\begin{tabular}{|c|c|c|c|c|c|c|}
\hline & Costs (€) & QALYS & Comparator & $\begin{array}{c}\text { Incremental } \\
\text { Costs }(€)\end{array}$ & $\begin{array}{c}\text { Incremental } \\
\text { QALYs }\end{array}$ & $\begin{array}{c}\text { ICER } \\
\text { (€ per QALY) }\end{array}$ \\
\hline $\begin{array}{l}\text { Base case analysis } \\
\text { DSA } \\
\text { CTA } \\
\text { MRA }\end{array}$ & $\begin{array}{l}39.808 \\
40.748 \\
41.814 \\
\end{array}$ & $\begin{array}{l}0,6039 \\
0,5983 \\
0,5947\end{array}$ & $\begin{array}{l}\text { DSA } \\
\text { DSA }\end{array}$ & $\begin{array}{r}940 \\
1.066 \\
\end{array}$ & $\begin{array}{l}-0,004 \\
-0,009\end{array}$ & $\begin{array}{l}\text { Dominated } \\
\text { Dominated }\end{array}$ \\
\hline $\begin{array}{l}\text { Base case analysis } \\
\text { DSA } \\
\text { CTA } \\
\text { MRA }\end{array}$ & $\begin{array}{l}39.808 \\
39.767 \\
39.851\end{array}$ & $\begin{array}{l}0,6039 \\
0,6039 \\
0,6039\end{array}$ & $\begin{array}{l}\text { DSA } \\
\text { CTA }\end{array}$ & $\begin{array}{r}-41 \\
84\end{array}$ & $\begin{array}{l}0,000 \\
0,000\end{array}$ & $\begin{array}{l}\text { Dominant } \\
\text { Dominated }\end{array}$ \\
\hline
\end{tabular}


In a sensitivity analysis, results remained stable also for assumption of equal treatment cost for coiling and clipping. Furthermore results remained stable for the assumption of higher costs of DSA up to factor 2.8. Higher sensitivity and specificity for detection of aneurysms and determination of feasibility of coiling for CTA and MRA up to $96 \%$ also yielded stable results. The probabilistic sensitivity analysis showed that in the base case analysis, DSA had a $98-100 \%$ probability of being cost-effective. In the scenario analysis, CTA had the highest probability of being cost-effective (91\%), followed by DSA (9\%) and MRA (0\%). Because in the scenario analysis effectiveness is equal for all strategies, these percentages are constant over the different values of willingness to pay for a QALY.

\section{Discussion}

When a patient presents with a suspected ruptured intracranial aneurysm, imaging is a challenge. Due to high risk of case fatality of ruptured intracranial aneurysms, timely detection of a causative aneurysm and determination of treatment are mandatory. Based on imaging results, patients are either left untreated, clipped surgically or receive endovascular treatment. In the last decades, much research has been done on evaluating best treatment options and imaging modalities. Especially the role and necessity of DSA in this patient population is widely discussed. ${ }^{29-32}$ No paper has yet evaluated the best diagnostic pathway based on cost-effectiveness. Our paper, comparing MRA, CTA and DSA, is a contribution to this field.

Our analysis is based on a one-year horizon. This holds potential conflict concerning the long term validity of the results. This matter can be addressed looking at the ISAT trial which was based on a one year's model and validity of results was proclaimed to be stable for up to 7 years. ${ }^{8}$ Incomplete occlusion and refilling of the aneurysm is a complication occurring mainly in coiling which can cause rebleeding, resulting in a higher rate of follow up imaging costs and re-interventions in the endovascular group. The rate of recanalization is highest in the first months and decreases significantly over time. ${ }^{33-36}$ Follow-up for detection of recanalization after 6 months may not be necessary. ${ }^{35}$

Wolstenholme et al. determined cost of coiling and clipping in the first year for western countries. ${ }^{13}$ Calculation of total costs for both treatment options included not only cost for material, intensive care and standard unit days, and medication, but also cost of follow-up imaging and re-intervention for the first year. Taking the results from literature, we can assume that validity of our data will be stable for the following years.

Our results show that DSA is the most cost-effective imaging modality and is superior to both MRA and CTA. Although initial test costs are about three times higher than those of MRA and CTA, optimal detection of aneurysms and determination of treatment in DSA yields lower overall one year's costs per patient and the highest QALYs. We assumed DSA to be standard of reference with sensitivity and specificity for detection and determination of treatment of $100 \%$. In cases where coiling was performed, costs for diagnostic DSA were accounted for separately. Costs of imaging were put to $€ 725$, following the Dutch healthcare costs guideline. ${ }^{22}$ It is debatable to state that sensitivity and specificity of DSA are $100 \%$ in an acute setting. ${ }^{37}$ Also actual costs of DSA might be higher than in our model. We therefore performed sensitivity analysis showing stable results even for assumption of $80 \%$ sensitivity in aneurysm 
detection as well as costs up to $€ 2.000$ for DSA. The test characteristics for CTA and MRA are based on our study performed with 75 patients. In literature, meta-analyses of test characteristics of CTA, as well as other studies, show higher sensitivity and specificity for CTA and MRA in detection of aneurysms and determination of treatment compared to our study. ${ }^{38-40}$ Since our data are stable in sensitivity analysis with assumption of up to $96 \%$ sensitivity and specificity for aneurysm detection and determination of treatment for CTA and MRA, we can assume that our conclusions are valid in a broad range of diagnostic performance. In the scenario model sensitivity analysis, increasing sensitivity and specificity for CTA and MRA shows even increasing preference of our imaging strategy starting with non-invasive imaging compared to only DSA.

Comparing the two non-invasive imaging modalities, CTA was superior to MRA because it dominated in the basic model analysis. This was mainly due to lower sensitivity in determination of feasibility of coiling in MRA. We did not sub-specialize between size of aneurysm nor certainty of the observer which could have allowed a better differentiation in results.

Our scenario model with initial CTA followed by DSA in case an aneurysm is detected but deemed not suitable for coiling, was found to be the most cost-effective imaging strategy. The cost savings to only DSA for all patients were $€ 41$ per patient, which is marginal in comparison to overall one year's costs. In case of suspected SAH, standard diagnostic imaging is non-contrast enhanced CT, followed by examination of CSF, obtained by lumbar puncture, if $\mathrm{CT}$ is negative. ${ }^{41}$ In case $\mathrm{SAH}$ is detected, performing an additional CTA study can be assumed to be less expensive than the cost that is used as input parameter in our model since labor costs for moving the patient can be neglected and only additional contrast application need to be accounted. We therefore can assume that the real cost advantage will most likely be higher.

There are heated discussions about whether or not to always perform DSA in patient with suspected ruptured intracranial aneurysms. ${ }^{42-51}$ Our study contributes to this discussion with two important findings. First, DSA is both more effective, yielding higher QALYs, and less costly in overall costs than CTA and MRA. DSA is therefore superior to the non-invasive imaging modalities. Second, we analyzed a scenario that combines invasive and non-invasive diagnostic tests. We found the most efficient diagnostic approach overall to be a strategy starting with CTA as first examination, followed by DSA if no aneurysm is found or coiling of a detected aneurysm is not deemed feasible. This means that every patient undergoes an additional DSA unless an aneurysm has been detected and deemed suitable for endovascular coiling. In this case coiling under general anesthesia is planned without preliminary diagnostic DSA. This strategy yields the same amount of QALYs compared to DSA in all patients and results in slightly lower costs.

Besides representing the most cost-effective approach overall, we believe that the strategy of combining CTA and DSA also represents the most practical approach in routine clinical practice. For patients with suspected SAH, we therefore recommend performing a non-contrast enhanced CT scan first. If a SAH is demonstrated, CTA is directly performed. When CTA shows no aneurysm, or shows an aneurysm which is not suitable for coiling, an additional DSA study should be performed. 


\section{Conclusion}

Comparing DSA, CTA and MRA to each other on the basis of case cost-effectiveness analysis shows that DSA is superior to both MRA and CTA due to higher quality of life and less overall one-year costs. Comparing the two non-invasive diagnostic tests, CTA is superior to MRA. A scenario strategy where CTA was followed by DSA if endovascular coiling was not deemed feasible, was found to be the most costeffective diagnostic option in patients with suspected ruptured intracranial aneurysm.

\section{References}

1 de Rooij, N. K., Linn, F. H., van der Plas, J. A., Algra, A. \& Rinkel, G. J. Incidence of subarachnoid haemorrhage: a systematic review with emphasis on region, age, gender and time trends. J Neurol Neurosurg Psychiatry 78, 1365-1372, (2007).

2 Connolly, E. S., Jr. et al. Guidelines for the Management of Aneurysmal Subarachnoid Hemorrhage: A Guideline for Healthcare Professionals From the American Heart Association/American Stroke Association. Stroke, (2012).

3 Starke, R. M. \& Connolly, E. S., Jr. Rebleeding after aneurysmal subarachnoid hemorrhage. Neurocrit Care 15, 241-246, (2011).

4 de Gans, K., Nieuwkamp, D. J., Rinkel, G. J. \& Algra, A. Timing of aneurysm surgery in subarachnoid hemorrhage: a systematic review of the literature. Neurosurgery 50, 336-340; discussion 340-332, (2002).

5 Weil, A. G. \& Zhao, J. Z. Treatment of Ruptured Aneurysms: Earlier is Better. World Neurosurg 77, 263-265, (2012).

6 Klompenhouwer, E. G. et al. Single-center experience of surgical and endovascular treatment of ruptured intracranial aneurysms. AJNR Am J Neuroradiol 32, 570-575, (2011).

7 Molyneux, A. et al. International Subarachnoid Aneurysm Trial (ISAT) of neurosurgical clipping versus endovascular coiling in 2143 patients with ruptured intracranial aneurysms: a randomised trial. Lancet 360, 1267-1274, (2002).

8 Molyneux, A. J. et al. International subarachnoid aneurysm trial (ISAT) of neurosurgical clipping versus endovascular coiling in 2143 patients with ruptured intracranial aneurysms: a randomised comparison of effects on survival, dependency, seizures, rebleeding, subgroups, and aneurysm occlusion. Lancet 366, 809$817,(2005)$.

9 van der Schaaf, I. et al. Endovascular coiling versus neurosurgical clipping for patients with aneurysmal subarachnoid haemorrhage. Cochrane Database Syst Rev, CD003085, (2005).

10 Bairstow, P., Dodgson, A., Linto, J. \& Khangure, M. Comparison of cost and outcome of endovascular and neurosurgical procedures in the treatment of ruptured intracranial aneurysms. Australas Radiol 46, 249-251, (2002).

11 Hoh, B. L., Chi, Y. Y., Lawson, M. F., Mocco, J. \& Barker, F. G., 2nd. Length of stay and total hospital charges of clipping versus coiling for ruptured and unruptured adult cerebral aneurysms in the Nationwide Inpatient Sample database 2002 to 2006. Stroke 41, 337-342, (2010).

12 Lawson, M. F. \& Hoh, B. L. Clipping versus coiling: the total hospital cost of aneurysm treatment. World Neurosurg 73, 430-431, (2010).

13 Wolstenholme, J. et al. Treatment pathways, resource use, and costs of endovascular coiling versus surgical clipping after aSAH. Stroke 39, 111-119, (2008).

14 van Gijn, J., Kerr, R. S. \& Rinkel, G. J. Subarachnoid haemorrhage. Lancet 369, 306-318, (2007).

15 Willinsky, R. A. et al. Neurologic complications of cerebral angiography: prospective analysis of 2,899 procedures and review of the literature. Radiology 227, 522-528, (2003).

16 Cloft, H. J., Joseph, G. J. \& Dion, J. E. Risk of cerebral angiography in patients with subarachnoid hemorrhage, cerebral aneurysm, and arteriovenous malformation: a meta-analysis. Stroke 30, 317-320, (1999).

17 Kaufmann, T. J. et al. Complications of diagnostic cerebral angiography: evaluation of 19,826 consecutive patients. Radiology 243, 812-819, (2007).

$18 \mathrm{Fifi}$, J. T. et al. Complications of modern diagnostic cerebral angiography in an academic medical center. J Vasc Interv Radiol 20, 442-447, (2009). 
19 Schaafsma, J. D. et al. Cost-effectiveness of magnetic resonance angiography versus intra-arterial digital subtraction angiography to follow-up patients with coiled intracranial aneurysms. Stroke 41, 1736-1742, (2010).

20 Zwam, W. H. v. et al. Diagnostic performance of contrast enhanced magnetic resonance angiography in detecting intracranial aneurysms in patients presenting with subarachnoid haemorrhage. EJMINT, 1240000078, (2012).

21 Briggs, A. \& Sculpher, M. An introduction to Markov modelling for economic evaluation. Pharmacoeconomics 13, 397-409, (1998).

22 Hakkaart, L. T., S. Bouwmans, C. in Amstelveen: Dutch Health Care Insurance Board (2010).

23 Post, P. N., Stiggelbout, A. M. \& Wakker, P. P. The utility of health states after stroke: a systematic review of the literature. Stroke 32, 1425-1429, (2001).

24 Buskens, E. et al. Imaging of carotid arteries in symptomatic patients: cost-effectiveness of diagnostic strategies. Radiology 233, 101-112, (2004).

25 Statline. Access date 05/06/2012., <http://statline.cbs.nl> (2012).

26 Ades, A. E., Claxton, K. \& Sculpher, M. Evidence synthesis, parameter correlation and probabilistic sensitivity analysis. Health Econ 15, 373-381, (2006).

27 Higashida, R. T. et al. Treatment of unruptured intracranial aneurysms: a nationwide assessment of effectiveness. AJNR Am J Neuroradiol 28, 146-151, (2007).

28 van Hout, B. A., Al, M. J., Gordon, G. S. \& Rutten, F. F. Costs, effects and C/E-ratios alongside a clinical trial. Health Econ 3, 309-319, (1994).

29 Agid, R., Willinsky, R. A., Farb, R. I. \& Terbrugge, K. G. Life at the end of the tunnel: why emergent CT angiography should be done for patients with acute subarachnoid hemorrhage. AJNR Am J Neuroradiol 29, e45; author reply e46-47, (2008).

30 Fox, A. J., Symons, S. P. \& Aviv, R. I. CT angiography is state-of-the-art first vascular imaging for subarachnoid hemorrhage. AJNR Am J Neuroradiol 29, e41-42; author reply e46-47, (2008).

31 Livingston, R. R. Regarding the risk of death from CT angiography in patients with subarachnoid hemorrhage. AJNR Am J Neuroradiol 29, e44; author reply e46-47, (2008).

32 Moran, C. J. Aneurysmal subarachnoid hemorrhage: DSA versus CT angiography--is the answer available? Radiology 258, 15-17, (2011).

33 Raymond, J. et al. Long-term angiographic recurrences after selective endovascular treatment of aneurysms with detachable coils. Stroke 34, 1398-1403, (2003).

34 Ries, T. et al. Long-term follow-up of cerebral aneurysms after endovascular therapy prediction and outcome of retreatment. AJNR Am J Neuroradiol 28, 1755-1761, (2007).

35 Sluzewski, M., van Rooij, W. J., Rinkel, G. J. \& Wijnalda, D. Endovascular treatment of ruptured intracranial aneurysms with detachable coils: long-term clinical and serial angiographic results. Radiology 227, 720-724, (2003).

36 Sprengers, M. E. et al. Stability of intracranial aneurysms adequately occluded 6 months after coiling: a 3T MR angiography multicenter long-term follow-up study. AJNR Am J Neuroradiol 29, 1768-1774, (2008).

37 DeLaPaz, R. L. et al. ACR Appropriateness Criteria(R) on cerebrovascular disease. J Am Coll Radiol 8, 532-538, (2011).

38 Chen, Y. C. et al. The clinical value of MRA at 3.0 T for the diagnosis and therapeutic planning of patients with subarachnoid haemorrhage. Eur Radiol, (2012).

39 Menke, J., Larsen, J. \& Kallenberg, K. Diagnosing cerebral aneurysms by computed tomographic angiography: meta-analysis. Ann Neurol 69, 646-654, (2011).

40 Westerlaan, H. E. et al. Intracranial aneurysms in patients with subarachnoid hemorrhage: CT angiography as a primary examination tool for diagnosis--systematic review and meta-analysis. Radiology 258, 134-145, (2011).

41 Bederson, J. B. et al. Guidelines for the management of aneurysmal subarachnoid hemorrhage: a statement for healthcare professionals from a special writing group of the Stroke Council, American Heart Association. Stroke 40, 994-1025, (2009).

42 Agid, R., Lee, S. K., Willinsky, R. A., Farb, R. I. \& terBrugge, K. G. Acute subarachnoid hemorrhage: using 64-slice multidetector CT angiography to "triage" patients' treatment. Neuroradiology 48, 787-794, (2006).

43 Chen, W., Yang, Y., Xing, W., Qiu, J. \& Peng, Y. Application of multislice computed tomographic angiography in diagnosis and treatment of intracranial aneurysms. Clin Neurol Neurosurg 112, 563-571, (2010).

44 Dehdashti, A. R., Rufenacht, D. A., Delavelle, J., Reverdin, A. \& de Tribolet, N. Therapeutic decision and management of aneurysmal subarachnoid haemorrhage based on computed tomographic angiography. $\mathrm{Br} J$ Neurosurg 17, 46-53, (2003).

45 Gonzalez-Darder, J. M., Pesudo-Martinez, J. V. \& Feliu-Tatay, R. A. Microsurgical management of cerebral aneurysms based in CT angiography with three-dimensional reconstruction (3D-CTA) and without preoperative cerebral angiography. Acta Neurochir (Wien) 143, 673-679, (2001). 
46 Jayaraman, M. V., Haas, R. A., Do, H. M. \& Meyers, P. M. Should CT Angiography Be Routinely Used in Patients Suspected of Having Aneurysmal Subarachnoid Hemorrhage? No! Radiology 254, 314-315, (2010).

47 Kallmes, D. F., Layton, K., Marx, W. F. \& Tong, F. Death by nondiagnosis: why emergent CT angiography should not be done for patients with subarachnoid hemorrhage. AJNR Am J Neuroradiol 28, 1837-1838, (2007).

48 Kaufmann, T. J. \& Kallmes, D. F. Diagnostic cerebral angiography: archaic and complication-prone or here to stay for another 80 years? AJR Am J Roentgenol 190, 1435-1437, (2008).

49 Papke, K. et al. Intracranial aneurysms: role of multidetector CT angiography in diagnosis and endovascular therapy planning. Radiology 244, 532-540, (2007).

50 Villablanca, J. P. et al. Aneurysms of the posterior circulation: detection and treatment planning using volumerendered three-dimensional helical computerized tomography angiography. J Neurosurg 103, 1018-1029, (2005).

51 Westerlaan, H. E. et al. Multislice CT angiography in the selection of patients with ruptured intracranial aneurysms suitable for clipping or coiling. Neuroradiology 49, 997-1007, (2007). 



\section{Chapter 9}

General discussion

W.H. van Zwam 
Since the first description of a patient with an aneurysmal subarachnoid hemorrhage (SAH) was published 250 years ago, ${ }^{1}$ prospects for survival of these patients have significantly improved, thanks to diagnostic improvements and treatment innovation. In addition, the management of these patients, laid out in different guidelines, has evolved over time, based on continuous research. ${ }^{2-5}$

This thesis centers on the various diagnostic aspects of aneurysmal subarachnoid hemorrhage. Based on available literature and the work carried out for this thesis, we have several proposals pertaining to the diagnosis, treatment and follow-up of patients with an aneurysmal SAH.

\section{Diagnosis of SAH}

The first problem to be addressed in the diagnosis of SAH is that of establishing the presence of SAH. In the most recent guidelines, lumbar puncture CSF examination is still recommended. ${ }^{3}$ However, based on the evidence in the available literature described in Chapter 1 , there are compelling arguments for the use of CT and CT angiography (CTA) as the first examination of patients presenting with clinical signs of $\mathrm{SAH} .^{6-8}$

Proposal 1. NECT and CTA should be performed in all patients with clinical suspicion of SAH. A subsequent lumbar puncture is unnecessary.

Despite some promising results in previous studies the role of MRI in diagnosing SAH appeared very limited in this acute setting. ${ }^{9}$

\section{DSA in CTA-negative SAH}

Conform all guidelines, catheter digital subtraction angiography (DSA) should be performed - preferably using rotational 3D technique - if the diagnosis of SAH is established by non-contrast enhanced CT (NECT), and CTA does not show an aneurysm as the cause of the hemorrhage. ${ }^{3,10}$

If the first DSA study does not show an aneurysm, repeat DSA is recommended. ${ }^{3}$ However, recent studies show that the yield of repeat DSA is low if the distribution pattern of the SAH is clearly perimesencephalic. ${ }^{9,11-13}$

Proposal 2. If NECT shows SAH, and CTA does not show an aneurysm, 3D DSA is recommended. If the first DSA study is negative, repeat DSA is recommended only if the pattern of SAH is nonperimesencephalic.

Some caution is necessary here, because the diagnosis of a perimesencephalic SAH on the basis of its distribution pattern is not always straightforward. ${ }^{14-16}$

It is recommended that a second DSA study in case of a negative first DSA should be performed within a week after the first study; delayed repeat DSA appears to have very little extra diagnostic value. ${ }^{12}$

Additional MRI of the cervical spine to rule out spinal vascular malformations may be considered, although this too has a low diagnostic yield. ${ }^{17}$

\section{MRA in patients with SAH}

The use of MR angiography as the primary diagnostic modality seems attractive because no potentially harmful X-rays and iodinated contrast media are used. However, there are logistic disadvantages: MRI is less readily available than $\mathrm{CT}$, and the lengthy $\mathrm{MRI}$ acquisitions are more susceptible to patient motion than $\mathrm{CT}$. Because the diagnosis $\mathrm{SAH}$ is generally established by $\mathrm{CT}$, the patient will need to be 
transferred from the CT scanner to the MRI system for an MRA study. Therefore, only if MRA can be shown to possess a better diagnostic performance than CTA will its use be recommended in the detection of intracranial aneurysms.

Our study, described in Chapter 2, has shown no benefit of contrast enhanced MRA (CEMRA) over CTA.

Proposal 3. CEMRA has no benefit over CTA in the detection of intracranial aneurysms in patients with a possible aneurysmal SAH, and CTA should be used as the primary imaging modality in these patients.

\section{CTA for treatment planning}

After CTA shows an aneurysm to be the cause of SAH, a treatment strategy must be selected. The goal of the treatment is to prevent a rebleed from the aneurysm in question, or a new bleed from other existing aneurysms. Since the publication of the results of the International Subarachnoid Aneurysm Trial (ISAT), endovascular coiling is the preferred treatment method. ${ }^{18,19}$ As a consequence, images acquired by any given diagnostic modality should enable assessment of endovascular coiling feasibility, or "coilability" of the aneurysm. If coiling is not possible, neurosurgical clipping is the other treatment option. ${ }^{3}$

In the majority of cases, CTA images are sufficient to assess whether an aneurysm can be coiled or not. ${ }^{20-25}$ Aneurysms considered suitable for coiling through CTA findings will later be subjected to DSA imaging at the onset of the coiling procedure. If, at this point, the aneurysm proves unsuitable for coiling, the patient can be scheduled for a surgical clipping procedure. The drawback of this approach is that the patient has undergone an unnecessary procedure under general anesthesia.

Another drawback of basing the decision to treat endovascularly or not only on CTA findings is that, if an aneurysm is considered unsuitable for endovascular treatment, surgical clipping will be performed where possible; if this decision is later proved to be incorrect, and the aneurysm was in fact coilable, the preferred endovascular treatment will have been unjustly withheld.

From our cost-effectiveness study (Chapter 8 ) it appears that the most cost-effective diagnostic strategy is to base the choice of treatment on CTA images, and to perform additional DSA only when an aneurysm is considered unsuitable for endovascular coiling. In the simulation study (Chapter 4) we further fine-tune this strategy, limiting additional DSA studies to cases thought not suitable for endovascular coiling based on CTA but with some doubt about this decision. If the neuro-interventionist is confident about his decision not to coil the aneurysm, no additional DSA is required (Fig 1).

We did not test this strategy in our cost-effectiveness analyses, as it was not possible to define the level of uncertainty for the decision not to coil an aneurysm in the Markov-model. The clinical difference in outcome between this fine-tuned strategy and the strategy tested in our Markov model is that, in the cohort of 75 patients included in our simulation study, 13 patients would have undergone additional diagnostic DSA, which would have led to the transfer of one patient from the clipping group to the group assigned to a coiling procedure. Considering the minimal difference in outcome for patients that are clipped or coiled, ${ }^{19,26}$ and the existing controversies in total costs of endovascular and neurosurgical treatment, ${ }^{27-35}$ we consider it justifiable to use the following diagnostic strategy (See Box 4 and Figure 1).

Proposal 4. Additional DSA is recommended only for those aneurysms appearing unsuitable for endovascular coiling based on CTA in which some doubt of this unsuitability exists. 


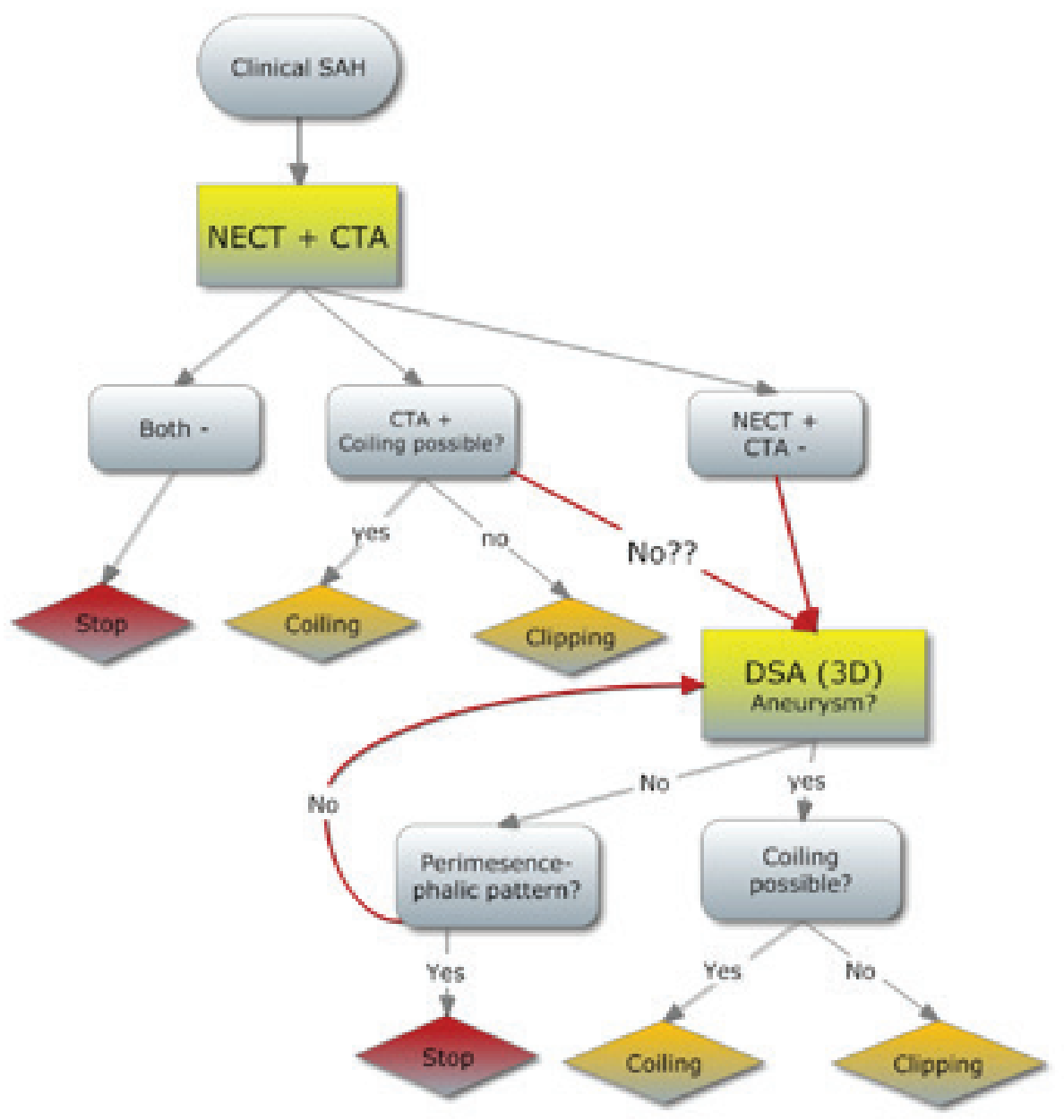

No?? = Coiling not suitable but with uncertainty about this unsuitability.

Figure 1. Diagnostic flow chart for patients presenting with a SAH

\section{MRA for treatment planning}

If MRA were to perform better than CTA in determining the coilability of an aneurysm this would be a reason to use MRA in the work-up of patients presenting with aneurysmal SAH. Despite a few promising results reported in the studies reviewed in Chapter $1,^{36-40}$ in our study CEMRA at 1.5T yielded no better results than CTA in the assessment of coilability of aneurysms (see Chapter 3 ). However, advances have been made in both CT and MR imaging techniques since this study was performed. MRA systems operating at 3T have become widely available, but the advantage of imaging at 3T over 1.5T is not clear; very few direct comparisons are available in this patient population. ${ }^{41}$ Current data implies that the main advantage of 3 T MRA lies in the detection of very small $(<3 \mathrm{~mm})$ aneurysms, and not so much in the characterization of aneurysms as suitable or unsuitable for endovascular coiling. ${ }^{37,42}$ The evolution of CT technology, on the other hand, from the 2- and 4-detector-row scanners used in our study to 16- ,64- or 
even more detector-row scanners, has led to a clear improvement in image quality. ${ }^{43}$ It is therefore unlikely that MRA, at the present state of the art, will produce better results than CTA.

Proposal 5. CEMRA has no benefit over CTA for assessing coilability of intracranial aneurysms in patients with $\mathrm{SAH}$, and CTA should be used as the primary imaging modality in these patients.

It must be noted that our single-center study, with a relatively small patient cohort, is one of many similar studies. While several meta-analyses have been carried out in order to assess the value of CTA in the detection of intracranial aneurysms, ${ }^{43-47}$ the only meta-analysis assessing the value of MRA in this patient population dates from the year $2000 .{ }^{47}$

\section{Treatment}

The suitability of an aneurysm for endovascular coiling depends on the morphology of the aneurysm and its relation to the parent vessel and side branches. A wide neck, or the presence of branches originating from the aneurysm, makes the prospect of successful endovascular treatment less likely. With the use of remodeling balloons, neck-bridging stents and flow diverters, nearly all intracranial aneurysms can be treated nowadays, but with increased -and sometimes unacceptable- risks. ${ }^{48,49}$ Furthermore, there is little scientific evidence that the increased use of these tools results in better patient outcome after endovascular treatment. ${ }^{50}$ For some aneurysms, though, these tools were very welcome. For example, aneurysms located at the basilar tip are difficult to approach surgically and, at present, only very skilled and experienced neurosurgeons will treat these. ${ }^{51-53}$ In the majority of centers, such aneurysms are preferentially treated using endovascular coiling, with the support of balloons and/or stents where necessary. ${ }^{53}$ Most aneurysm locations require both a neuro-interventionist and a neurosurgeon to make a decision on whether to coil or clip, depending on their experience. Other factors such as age and comorbidity of the patient will also play a role in this decision. In Chapter 5 we showed that this joint decision making in the management of patients presenting with aneurysmal SAH in our hospital leads to satisfactory results.

Proposal 6. The preferred treatment of intracranial aneurysms is endovascular coiling, but if additional balloon remodeling or stents are required a multidisciplinary discussion should determine the optimal treatment, being either endovascular or surgical. Aneurysms of the basilar tip are primarily treated by endovascular means with balloon remodeling or stent placement where needed.

\section{Treatment in high volume centers}

High volume centers for treating intracranial aneurysms generally have lower mortality and lower poor outcome rates as compared to low volume centers. ${ }^{54-56}$ Although this is clearly described in the literature and summarized in Chapter 1, no cut off point between "low" and "high" volume in this perspective is defined. In the survey by Bradac et al. a low volume center was defined as one treating less than 31 ruptured aneurysms per year..$^{53}$ In the United States $82 \%$ of hospitals treat fewer than 18 cases per year and these are considered low-volume centers in the study of Vespa. ${ }^{56}$ In the guidelines of the American Heart Association (AHA) a low volume center is defined as a center treating less than 10 aneurysmal SAH cases per year. ${ }^{3}$ Our hospital, which admits around $70-80$ patients with ruptured aneurysms per year, would be considered a high volume center in the US and a medium volume center by Bradac et al., in which high volume centers are defined as those treating more than 100 ruptured 
aneurysms per year. ${ }^{53}$ High volume centers in Europe treat a larger percentage of aneurysms through coiling than medium- and low volume centers. ${ }^{53}$ Brinjikji et al. showed that centers treating a higher percentage of unruptured aneurysms with coiling than with clipping achieve markedly lower rates of morbidity and mortality. ${ }^{57}$ From a cost-effectiveness perspective, Bardach et al. determined that patients in the US benefited from transfer from low-volume centers to high-volume centers with a net gain of roughly $\$ 2,200 /$ quality life year. ${ }^{58}$

These findings have prompted the amendment of the AHA guidelines for the management of aneurysmal SAH: 'Low volume hospitals should consider early transfer of patients with aneurysmal SAH to high volume centres...'. ${ }^{3}$

Proposal 7. Patients with intracranial aneurysms should preferably be treated in centers with the highest possible volume where both endovascular and neurosurgical treatment options are available on a $24 / 7$ basis.

\section{Follow-up}

As pointed out in Chapter 6, follow-up of coiled intracranial aneurysms can be done reliably with MRA. Although the advantages of contrast enhanced MRA (CEMRA) have not (yet) been convincingly demonstrated, we use both time of flight (TOF-MRA) and CEMRA sequences in our hospital. When a recanalization is found which may require retreatment, an additional DSA study is performed in most cases in order to confirm the recanalization and guide further management (retreatment or prolonged follow-up). In addition, we perform a scheduled follow-up of all coiled aneurysms at six and 24 months after treatment.

From the many studies presented in Chapter 1 it becomes clear that the first follow-up at six months is crucial: the majority of recanalizations and rebleeds occur within this time frame. ${ }^{59-62}$ Later rebleeds are rare and incomplete occlusion of the coiled aneurysm directly after coiling is a strong predictor of recanalization and rebleed after the follow-up at six months. ${ }^{19,63-66}$ The risk of a late rebleed, either from the treated aneurysm or from additional or de novo aneurysms, is very low in patients with aneurysms that are adequately occluded at six months. ${ }^{19,63,67-72}$ The yield of long term follow-up of patients with adequately occluded aneurysms at six months, in terms of recanalizations needing treatment, is very low. ${ }^{73}$ Even before the results of the LOTUS study were known, the suggestion arose to limit prolonged follow-up to patients with an incomplete aneurysm occlusion at six months. ${ }^{74}$ The results of the LOTUS study strongly supported this limitation.

Proposal 8 . Coiled aneurysms that are adequately occluded at six months do not require longer follow-up.

The mean length of follow-up in the LOTUS study was six years. ${ }^{73}$ We cannot yet predict if the risk of new aneurysm formation or recanalization of the treated aneurysm increases after this period.

Thus it appears that evaluation at six months should define future patient management. Based on the findings at six months, it must be decided whether any aneurysm needs further treatment, whether the patient should be followed for a longer period or whether the patient is stable and does not need further surveillance. In addition, new aneurysms and growing additional aneurysms must be detected and treated or must receive prolonged surveillance. ${ }^{75,76}$ 
Can we reliably determine whether a treated aneurysm is 'adequately' occluded and longer follow-up not required? The classification of Roy and Raymond $(R \& R)^{77}$ (figure 2 ) is used in nearly all studies to describe the occlusion status of coiled aneurysms.

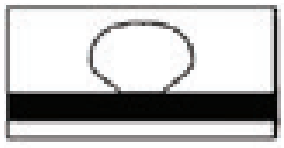

R\&R Class 1

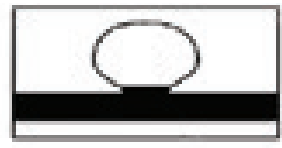

R\&R Class 2

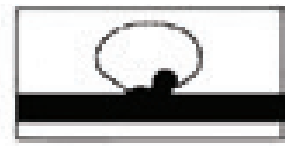

R\&R Class 3

Figure 2 Aneurysm occlusion classification by Roy and Raymond

The relationship between this classification, based on morphology, and risk of late rebleed or recanalization requiring retreatment, is not clearly defined. A pragmatic use of the $R \& R$ classification could be as follows:

Class 1: stable, follow-up no longer needed;

Class 2: small neck remnant, no need for treatment but prolonged follow-up required;

Class 3: recanalization requiring treatment.

This is not the way the R\&R classification is interpreted in the studies described in Chapter 1 and in the LOTUS study: class 2 is mostly considered as 'stable' or 'adequate', while class 3 is used for 'unstable' or 'inadequate' occlusions. About half of these inadequately occluded aneurysms are treated in practice, ${ }^{78}$ and the other half probably need prolonged follow-up. ${ }^{74}$ The R\&R class 2 occlusions only require longer follow-up if there is a tendency to recanalize or rebleed at a later stage. As described in Chapter 7, we found no correlation in our data or in the LOTUS study data between R\&R class 2 occlusion status and later recanalization. These findings are in line with other studies comparing six to 18 or 24 months follow-up results. ${ }^{62,79}$ Thus, we conclude that aneurysms with occlusion status R\&R class 1 or 2 at six months are adequately occluded and do not need prolonged follow-up.

Contrary to R\&R class 1 and 2 occlusion, the distinction between R\&R class 2 and 3 occlusion remains significant. A problem with such morphologic classifications however, lies in the initial size of the aneurysm. For example, if there is a large aneurysm with a small remnant after coiling this will usually be regarded as class 2 . If the initial aneurysm was small (say 3 or $4 \mathrm{~mm}$ ), the same remnant will appear proportionally much larger, and may be classified as Class 3 .

Based on our findings described in Chapter 7 we suggest a simplification of occlusion classification of coiled aneurysms at six months follow-up.

Proposal 9. Occlusion status of coiled aneurysms at six months follow-up can be described as adequate (class 1 or 2 of Roy and Raymond classification) or inadequate (class 3). Inadequately occluded aneurysms at six months require either retreatment or prolonged follow-up.

\section{Cost-effectiveness}

The Markov decision model can be used to calculate quality-adjusted life-years (QALYs) as outcome for different management strategies. Using costs as input parameters in this model, the effects of different management strategies on total costs can be calculated as well. ${ }^{80-82}$ In Chapter 8 we used both these outcomes to compare the cost-effectiveness of different imaging strategies in patients with a SAH.

In an earlier study, Schaafsma et al. compared the cost-effectiveness of MRA versus DSA in the followup of patients with coiled intracranial aneurysms. ${ }^{83}$ This cost-effectiveness study supports our 
conclusion that CTA should be used as the primary imaging modality in patients presenting with a SAH, and that MRA should be the imaging modality of choice in the follow-up of coiled aneurysms.

In Chapter 1 we noted that most cost-effectiveness studies in patients with intracranial aneurysms focused on treatment of the aneurysms, and few on screening for unruptured aneurysms. Wermer et al. assessed the yield of screening for new aneurysms after treatment for SAH, with the Markov model, ${ }^{84}$ and in a later paper these same authors assessed the cost-effectiveness of screening patients using CTA every five years after being clipped for a ruptured intracranial aneurysm. ${ }^{85}$ For this patient population in general, screening for new aneurysms did not lead to an increase in QALY's, nor was it cost-effective. Screening was found to save costs and increase QALYs in patients with a relatively high risk of both aneurysm formation and rupture, however, and to increase QALYs at acceptable costs in patients with a higher risk of recurrence. ${ }^{85}$ There have been no cost-effectiveness studies published on the follow-up of coiled aneurysms. In view of our proposal 8 above, that prolonged follow-up is not recommended in patients with an adequately occluded aneurysm at six months after coiling, it would be interesting to see whether a cost-effectiveness study would support this.

\section{Future research}

Many aspects of imaging in patients presenting with SAH have been addressed in the past, as described in Chapter 1, and are still being addressed in on-going research. For detection of aneurysms as well as for follow-up of treated aneurysms, most diagnostic modalities have been tested on all levels necessary for proper evaluation of a diagnostic test. ${ }^{86,87}$

However, this thesis has shown the necessity for several studies to be carried out in the near future:

- A systematic review and meta-analysis of MRA for the detection of intracranial aneurysms based on recent literature, with separate analyses for CEMRA and TOF-MRA and for ruptured and unruptured aneurysms.

- Confirmation or rejection of our proposal that the three-point R\&R classification can be reduced to a two-point classification: adequately or inadequately occluded. This should ideally be done in a prospective study. However, if existing studies have used the R\&R classification correctly, a retrospective analysis of these data could be useful, as the one we carried out on the LOTUS data.

- Cost-effectiveness studies of different follow-up strategies are required in order to define the optimal timing of follow-up, and clarify whether prolonged follow-up of all coiled aneurysms with MRA is cost-effective.

- The yield of ultra-long follow-up (>10 yrs) has yet to be assessed. Plans for such a study (LOTUS III) have been made.

Preferably, all the above studies should meet the Standards for Reporting of Diagnostic Accuracy (STARD) criteria, ${ }^{88}$ as this will improve and simplify the comparison and pooling of data.

\section{References}

1 Holmes, T. Aneurysms of the internal carotid artery in the cavernous sinus. Trans Pathol Soc London 12, 61, (1860).

2 Bederson, J. B. et al. Guidelines for the management of aneurysmal subarachnoid hemorrhage: a statement for healthcare professionals from a special writing group of the Stroke Council, American Heart Association. Stroke 40, 994-1025, (2009). 
3 Connolly, E. S., Jr. et al. Guidelines for the Management of Aneurysmal Subarachnoid Hemorrhage: A Guideline for Healthcare Professionals From the American Heart Association/American Stroke Association. Stroke, (2012).

4 Johnston, S. C. et al. Recommendations for the endovascular treatment of intracranial aneurysms: a statement for healthcare professionals from the Committee on Cerebrovascular Imaging of the American Heart Association Council on Cardiovascular Radiology. Stroke 33, 2536-2544, (2002).

5 Mayberg, M. R. et al. Guidelines for the management of aneurysmal subarachnoid hemorrhage. A statement for healthcare professionals from a special writing group of the Stroke Council, American Heart Association. Stroke 25, 2315-2328, (1994).

6 Carstairs, S. D. et al. Computed tomographic angiography for the evaluation of aneurysmal subarachnoid hemorrhage. Acad Emerg Med 13, 486-492, (2006).

7 Gee, C. et al. Sensitivity of Newer-generation Computed Tomography Scanners for Subarachnoid Hemorrhage: A Bayesian Analysis. J Emerg Med, (2012).

8 McCormack, R. F. \& Hutson, A. Can computed tomography angiography of the brain replace lumbar puncture in the evaluation of acute-onset headache after a negative noncontrast cranial computed tomography scan? Acad Emerg Med 17, 444-451, (2010).

9 Maslehaty, H., Petridis, A. K., Barth, H. \& Mehdorn, H. M. Diagnostic value of magnetic resonance imaging in perimesencephalic and nonperimesencephalic subarachnoid hemorrhage of unknown origin. $J$ Neurosurg 114, 1003-1007, (2011).

10 van Rooij, W. J., Sprengers, M. E., de Gast, A. N., Peluso, J. P. \& Sluzewski, M. 3D rotational angiography: the new gold standard in the detection of additional intracranial aneurysms. AJNR Am J Neuroradiol 29, 976-979, (2008).

11 Agid, R. et al. Negative CT angiography findings in patients with spontaneous subarachnoid hemorrhage: When is digital subtraction angiography still needed? AJNR Am J Neuroradiol 31, 696-705, (2010).

12 Delgado Almandoz, J. E. et al. Diagnostic Yield of Repeat Catheter Angiography in Patients with Catheter and CT Angiography Negative Subarachnoid Hemorrhage. Neurosurgery, (2011).

13 Huttner, H. B. et al. Repeated digital substraction angiography after perimesencephalic subarachnoid hemorrhage? J Neuroradiol 33, 87-89, (2006).

14 Alen, J. F. et al. Comparison between perimesencephalic nonaneurysmal subarachnoid hemorrhage and subarachnoid hemorrhage caused by posterior circulation aneurysms. J Neurosurg 98, 529-535, (2003).

15 Brinjikji, W. et al. Inter- and intraobserver agreement in CT characterization of nonaneurysmal perimesencephalic subarachnoid hemorrhage. AJNR Am J Neuroradiol 31, 1103-1105, (2010).

16 Dupont, S. A., Lanzino, G., Wijdicks, E. F. \& Rabinstein, A. A. The use of clinical and routine imaging data to differentiate between aneurysmal and nonaneurysmal subarachnoid hemorrhage prior to angiography. Clinical article. J Neurosurg 113, 790-794, (2010).

17 Little, A. S. et al. Evaluation of patients with spontaneous subarachnoid hemorrhage and negative angiography. Neurosurgery 61, 1139-1150; discussion 1150-1131, (2007).

18 Molyneux, A. et al. International Subarachnoid Aneurysm Trial (ISAT) of neurosurgical clipping versus endovascular coiling in 2143 patients with ruptured intracranial aneurysms: a randomised trial. Lancet 360, 1267-1274, (2002).

19 Molyneux, A. J. et al. Risk of recurrent subarachnoid haemorrhage, death, or dependence and standardised mortality ratios after clipping or coiling of an intracranial aneurysm in the International Subarachnoid Aneurysm Trial (ISAT): long-term follow-up. Lancet Neurol 8, 427-433, (2009).

20 Agid, R., Lee, S. K., Willinsky, R. A., Farb, R. I. \& terBrugge, K. G. Acute subarachnoid hemorrhage: using 64slice multidetector CT angiography to "triage" patients' treatment. Neuroradiology 48, 787-794, (2006).

21 Chen, W., Yang, Y., Xing, W., Qiu, J. \& Peng, Y. Application of multislice computed tomographic angiography in diagnosis and treatment of intracranial aneurysms. Clin Neurol Neurosurg 112, 563-571, (2010).

22 Dehdashti, A. R., Rufenacht, D. A., Delavelle, J., Reverdin, A. \& de Tribolet, N. Therapeutic decision and management of aneurysmal subarachnoid haemorrhage based on computed tomographic angiography. $\mathrm{Br} J$ Neurosurg 17, 46-53, (2003).

23 Papke, K. et al. Intracranial aneurysms: role of multidetector CT angiography in diagnosis and endovascular therapy planning. Radiology 244, 532-540, (2007).

24 Villablanca, J. P. et al. Aneurysms of the posterior circulation: detection and treatment planning using volume-rendered three-dimensional helical computerized tomography angiography. J Neurosurg 103, 10181029, (2005).

25 Westerlaan, H. E. et al. Multislice CT angiography in the selection of patients with ruptured intracranial aneurysms suitable for clipping or coiling. Neuroradiology 49, 997-1007, (2007). 
26 Bakker, N. A., Metzemaekers, J. D., Groen, R. J., Mooij, J. J. \& Van Dijk, J. M. International subarachnoid aneurysm trial 2009: endovascular coiling of ruptured intracranial aneurysms has no significant advantage over neurosurgical clipping. Neurosurgery 66, 961-962, (2010).

27 Niskanen, M., Koivisto, T., Ronkainen, A., Rinne, J. \& Ruokonen, E. Resource use after subarachnoid hemorrhage: comparison between endovascular and surgical treatment. Neurosurgery 54, 1081-1086; discussion 1086-1088, (2004).

28 Bairstow, P., Dodgson, A., Linto, J. \& Khangure, M. Comparison of cost and outcome of endovascular and neurosurgical procedures in the treatment of ruptured intracranial aneurysms. Australas Radiol 46, 249-251, (2002).

29 Ballet, A. C. et al. [Neurosurgical and endovascular treatment of intracranial aneurysms: a cost analysis of two different strategies at the University Hospital of Bordeaux (France)]. Neurochirurgie 48, 419-425, (2002).

30 Halkes, P. H., Wermer, M. J., Rinkel, G. J. \& Buskens, E. Direct costs of surgical clipping and endovascular coiling of unruptured intracranial aneurysms. Cerebrovasc Dis 22, 40-45, (2006).

31 Hoh, B. L., Chi, Y. Y., Dermott, M. A., Lipori, P. J. \& Lewis, S. B. The effect of coiling versus clipping of ruptured and unruptured cerebral aneurysms on length of stay, hospital cost, hospital reimbursement, and surgeon reimbursement at the university of Florida. Neurosurgery 64, 614-619; discussion 619-621, (2009).

32 Javadpour, M. et al. Analysis of cost related to clinical and angiographic outcomes of aneurysm patients enrolled in the international subarachnoid aneurysm trial in a North American setting. Neurosurgery 56, 886894; discussion 886-894, (2005).

33 Lawson, M. F. \& Hoh, B. L. Clipping versus coiling: the total hospital cost of aneurysm treatment. World Neurosurg 73, 430-431, (2010).

34 Maud, A. et al. Cost-effectiveness analysis of endovascular versus neurosurgical treatment for ruptured intracranial aneurysms in the United States. J Neurosurg 110, 880-886, (2009).

35 Wolstenholme, J. et al. Treatment pathways, resource use, and costs of endovascular coiling versus surgical clipping after aSAH. Stroke 39, 111-119, (2008).

36 Adams, W. M., Laitt, R. D. \& Jackson, A. The role of MR angiography in the pretreatment assessment of intracranial aneurysms: a comparative study. AJNR Am J Neuroradiol 21, 1618-1628, (2000).

37 Chen, Y. C. et al. The clinical value of MRA at 3.0 T for the diagnosis and therapeutic planning of patients with subarachnoid haemorrhage. Eur Radiol, (2012).

38 Chung, T. S., Joo, J. Y., Lee, S. K., Chien, D. \& Laub, G. Evaluation of cerebral aneurysms with high-resolution MR angiography using a section-interpolation technique: correlation with digital subtraction angiography. AJNR Am J Neuroradiol 20, 229-235, (1999).

39 Mallouhi, A. et al. Detection and characterization of intracranial aneurysms with MR angiography: comparison of volume-rendering and maximum-intensity-projection algorithms. AJR Am J Roentgenol 180, 55-64, (2003).

40 Westerlaan, H. E. et al. Magnetic resonance angiography in the selection of patients suitable for neurosurgical intervention of ruptured intracranial aneurysms. Neuroradiology 46, 867-875, (2004).

41 Gibbs, G. F., Huston, J., 3rd, Bernstein, M. A., Riederer, S. J. \& Brown, R. D., Jr. Improved image quality of intracranial aneurysms: 3.0-T versus 1.5-T time-of-flight MR angiography. AJNR Am J Neuroradiol 25, 84-87, (2004).

42 Kapsalaki, E. Z., Rountas, C. D. \& Fountas, K. N. The Role of 3 Tesla MRA in the Detection of Intracranial Aneurysms. Int J Vasc Med 2012, 792834, (2012).

43 Menke, J., Larsen, J. \& Kallenberg, K. Diagnosing cerebral aneurysms by computed tomographic angiography: meta-analysis. Ann Neurol 69, 646-654, (2011).

44 Chappell, E. T., Moure, F. C. \& Good, M. C. Comparison of computed tomographic angiography with digital subtraction angiography in the diagnosis of cerebral aneurysms: a meta-analysis. Neurosurgery 52, 624-631; discussion 630-621, (2003).

45 van Gelder, J. M. Computed tomographic angiography for detecting cerebral aneurysms: implications of aneurysm size distribution for the sensitivity, specificity, and likelihood ratios. Neurosurgery 53, 597-605; discussion 605-596, (2003).

46 Westerlaan, H. E. et al. Intracranial aneurysms in patients with subarachnoid hemorrhage: CT angiography as a primary examination tool for diagnosis--systematic review and meta-analysis. Radiology 258, 134-145, (2011).

47 White, P. M., Wardlaw, J. M. \& Easton, V. Can noninvasive imaging accurately depict intracranial aneurysms? A systematic review. Radiology 217, 361-370, (2000).

48 Piotin, M. et al. Stent-assisted coiling of intracranial aneurysms: clinical and angiographic results in 216 consecutive aneurysms. Stroke 41, 110-115, (2010). 
49 Sluzewski, M., van Rooij, W. J., Beute, G. N. \& Nijssen, P. C. Balloon-assisted coil embolization of intracranial aneurysms: incidence, complications, and angiography results. J Neurosurg 105, 396-399, (2006).

50 Kurre, W. \& Berkefeld, J. Materials and techniques for coiling of cerebral aneurysms: how much scientific evidence do we have? Neuroradiology 50, 909-927, (2008).

51 Sanai, N., Tarapore, P., Lee, A. C. \& Lawton, M. T. The current role of microsurgery for posterior circulation aneurysms: a selective approach in the endovascular era. Neurosurgery 62, 1236-1249; discussion 1249-1253, (2008).

52 Tenjin, H. et al. Treatment selection for ruptured aneurysm and outcomes: clipping or coil embolization. Neurol Med Chir (Tokyo) 51, 23-29, (2011).

53 Bradac, O., Hide, S., Mendelow, D. A. \& Benes, V. Aneurysm treatment in Europe 2010: an internet survey. Acta Neurochir (Wien) 154, 971-978, (2012).

54 Bardach, N. S., Zhao, S., Gress, D. R., Lawton, M. T. \& Johnston, S. C. Association between subarachnoid hemorrhage outcomes and number of cases treated at California hospitals. Stroke 33, 1851-1856, (2002).

55 Cross, D. T., 3rd et al. Mortality rates after subarachnoid hemorrhage: variations according to hospital case volume in 18 states. J Neurosurg 99, 810-817, (2003).

56 Vespa, P. \& Diringer, M. N. High-volume centers. Neurocrit Care 15, 369-372, (2011).

57 Brinjikji, W., Rabinstein, A. A., Lanzino, G., Kallmes, D. F. \& Cloft, H. J. Patient outcomes are better for unruptured cerebral aneurysms treated at centers that preferentially treat with endovascular coiling: a study of the national inpatient sample 2001-2007. AJNR Am J Neuroradiol 32, 1065-1070, (2011).

58 Bardach, N. S. et al. Regionalization of treatment for subarachnoid hemorrhage: a cost-utility analysis. Circulation 109, 2207-2212, (2004).

59 Cho, Y. D. et al. Early recurrent hemorrhage after coil embolization in ruptured intracranial aneurysms. Neuroradiology, (2011).

60 Jartti, P. et al. Early rebleeding after coiling of ruptured intracranial aneurysms. Acta Radiol 51, 1043-1049, (2010).

61 Sluzewski, M. \& van Rooij, W. J. Early rebleeding after coiling of ruptured cerebral aneurysms: incidence, morbidity, and risk factors. AJNR Am J Neuroradiol 26, 1739-1743, (2005).

62 Sluzewski, M., van Rooij, W. J., Rinkel, G. J. \& Wijnalda, D. Endovascular treatment of ruptured intracranial aneurysms with detachable coils: long-term clinical and serial angiographic results. Radiology 227, 720-724, (2003).

63 CARAT-investigators. Rates of delayed rebleeding from intracranial aneurysms are low after surgical and endovascular treatment. Stroke 37, 1437-1442, (2006).

64 Sluzewski, M., van Rooij, W. J., Beute, G. N. \& Nijssen, P. C. Late rebleeding of ruptured intracranial aneurysms treated with detachable coils. AJNR Am J Neuroradiol 26, 2542-2549, (2005).

65 Ries, T. et al. Long-term follow-up of cerebral aneurysms after endovascular therapy prediction and outcome of retreatment. AJNR Am J Neuroradiol 28, 1755-1761, (2007).

66 Johnston, S. C. et al. Predictors of rehemorrhage after treatment of ruptured intracranial aneurysms: the Cerebral Aneurysm Rerupture After Treatment (CARAT) study. Stroke 39, 120-125, (2008).

67 Ferns, S. P. et al. De novo aneurysm formation and growth of untreated aneurysms: a 5-year MRA follow-up in a large cohort of patients with coiled aneurysms and review of the literature. Stroke 42, 313-318, (2011).

68 Schaafsma, J. D. et al. Long-term recurrent subarachnoid hemorrhage after adequate coiling versus clipping of ruptured intracranial aneurysms. Stroke 40, 1758-1763, (2009).

69 Lindvall, P., Borota, L., Birgander, R., Jonasson, P. \& Ridderheim, P. A. Long-term follow-up of intracranial aneurysms treated with endovascular coiling: experience from one institution. Vasc Endovascular Surg 46, 325-328, (2012).

70 Choi, D. S., Kim, M. C., Lee, S. K., Willinsky, R. A. \& Terbrugge, K. G. Clinical and angiographic long-term followup of completely coiled intracranial aneurysms using endovascular technique. J Neurosurg 112, 575-581, (2010).

71 Pyysalo, L. M., Keski-Nisula, L. H., Niskakangas, T. T., Kahara, V. J. \& Ohman, J. E. Long-term follow-up study of endovascularly treated intracranial aneurysms. Interv Neuroradiol 16, 361-368, (2010).

72 Plowman, R. S., Clarke, A., Clarke, M. \& Byrne, J. V. Sixteen-year single-surgeon experience with coil embolization for ruptured intracranial aneurysms: recurrence rates and incidence of late rebleeding. Clinical article. J Neurosurg 114, 863-874, (2011).

73 Ferns, S. P. et al. Late reopening of adequately coiled intracranial aneurysms: frequency and risk factors in 400 patients with 440 aneurysms. Stroke 42, 1331-1337, (2011).

74 van Rooij, W. J. \& Sluzewski, M. Opinion: imaging follow-up after coiling of intracranial aneurysms. AJNR Am J Neuroradiol 30, 1646-1648, (2009). 
75 Bruneau, M. et al. Long-term follow-up survey reveals a high yield, up to $30 \%$ of patients presenting newly detected aneurysms more than 10 years after ruptured intracranial aneurysms clipping. Neurosurg Rev 34, 485-496, (2011).

76 Wermer, M. J. et al. Follow-up screening after subarachnoid haemorrhage: frequency and determinants of new aneurysms and enlargement of existing aneurysms. Brain 128, 2421-2429, (2005).

77 Roy, D., Milot, G. \& Raymond, J. Endovascular treatment of unruptured aneurysms. Stroke 32, 1998-2004, (2001).

78 Ferns, S. P. et al. Coiling of intracranial aneurysms: a systematic review on initial occlusion and reopening and retreatment rates. Stroke 40, e523-529, (2009).

79 Tailor, J. et al. Stability of ruptured intracranial aneurysms treated with detachable coils: is delayed follow-up angiography warranted? Br J Neurosurg 24, 405-409, (2010).

80 Bala, M. V. \& Mauskopf, J. A. Optimal assignment of treatments to health states using a Markov decision model: an introduction to basic concepts. Pharmacoeconomics 24, 345-354, (2006).

81 Briggs, A. \& Sculpher, M. An introduction to Markov modelling for economic evaluation. Pharmacoeconomics 13, 397-409, (1998).

82 Sonnenberg, F. A. \& Beck, J. R. Markov models in medical decision making: a practical guide. Med Decis Making 13, 322-338, (1993).

83 Schaafsma, J. D. et al. Cost-effectiveness of magnetic resonance angiography versus intra-arterial digital subtraction angiography to follow-up patients with coiled intracranial aneurysms. Stroke 41, 1736-1742, (2010).

84 Wermer, M. J., Buskens, E., van der Schaaf, I. C., Bossuyt, P. M. \& Rinkel, G. J. Yield of screening for new aneurysms after treatment for subarachnoid hemorrhage. Neurology 62, 369-375, (2004).

85 Wermer, M. J., Koffijberg, H. \& van der Schaaf, I. C. Effectiveness and costs of screening for aneurysms every 5 years after subarachnoid hemorrhage. Neurology 70, 2053-2062, (2008).

86 Schaafsma, J. D., van der Graaf, Y., Rinkel, G. J. \& Buskens, E. Decision analysis to complete diagnostic research by closing the gap between test characteristics and cost-effectiveness. J Clin Epidemiol 62, 12481252, (2009).

87 Van den Bruel, A., Cleemput, I., Aertgeerts, B., Ramaekers, D. \& Buntinx, F. The evaluation of diagnostic tests: evidence on technical and diagnostic accuracy, impact on patient outcome and cost-effectiveness is needed. $J$ Clin Epidemiol 60, 1116-1122, (2007).

88 Bossuyt, P. M. et al. Towards complete and accurate reporting of studies of diagnostic accuracy: the STARD initiative. AJR Am J Roentgenol 181, 51-55, (2003). 


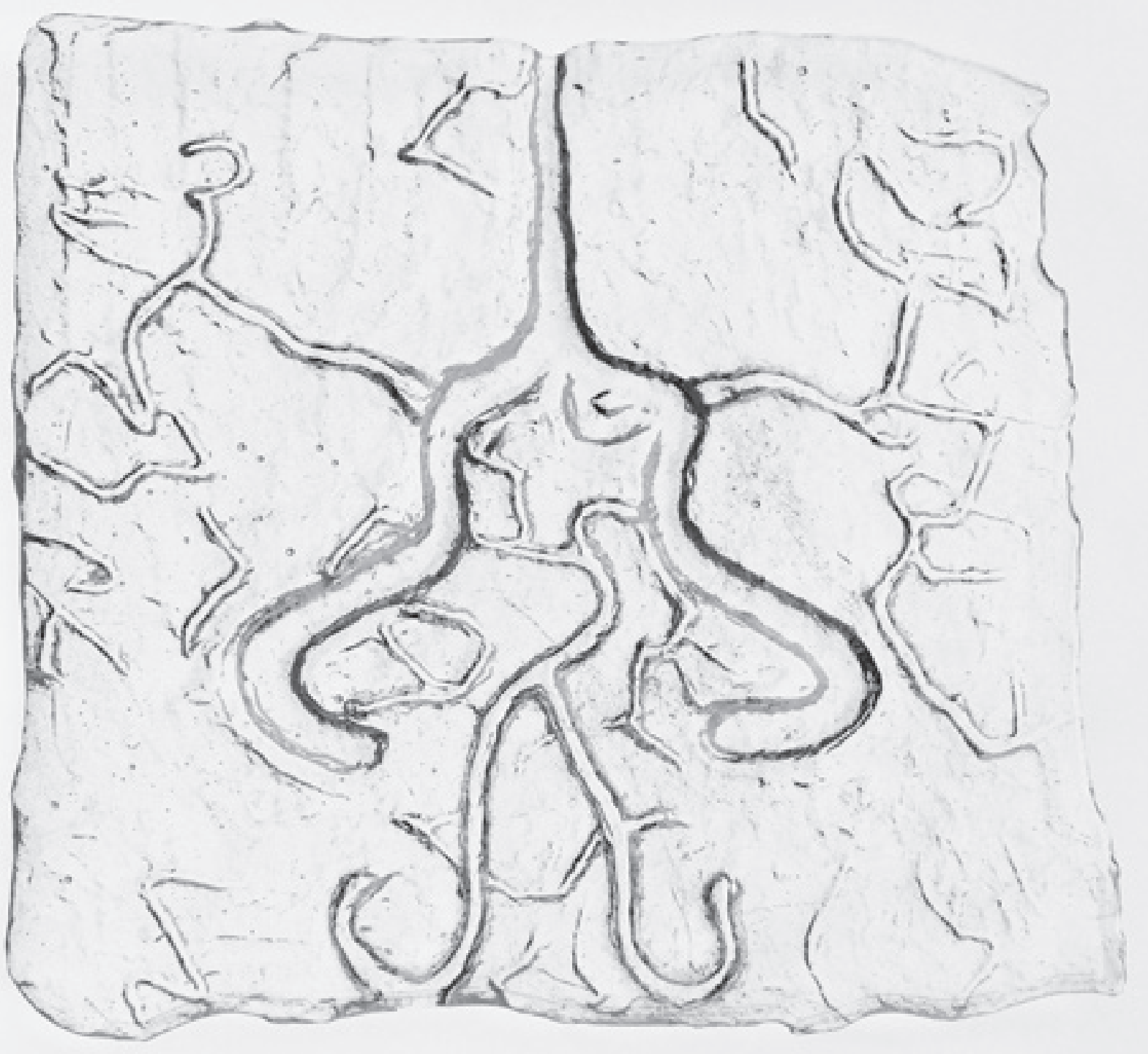

Summary 


\section{Summary}

Patients with subarachnoid haemorrhage $(\mathrm{SAH})$ need immediate diagnostic imaging and treatment where indicated. This poses a big challenge for physicians involved. Fortunately, spectacular improvements in both imaging and treatment have been achieved in the last two decades, and these have been thoroughly evaluated resulting in hundreds of articles being published on the subject.

Chapter 1 of this thesis takes you on a journey from the first description of a SAH to current scientific activities in this field. If you read nothing else, reader of this Summary, I invite you to at least read the highly interesting story that is Chapter 1.

Although this thesis, on the whole, focuses on diagnostic imaging, the evolution of SAH therapy is addressed as well. However, the concurrent development of different diagnostic modalities and the studies concerning these developments are elaborated on more extensively.

Despite the fact that all steps taken in diagnostic tests have been, at least partially, investigated in the past few years, there are still gaps in our knowledge. In addition, the rapid development of diagnostic techniques requires continuous research. In subsequent chapters we present our work in this field, which fills some of the gaps.

In 2002 we designed a study called 'Magnetic resonance Angiography with Contrast for the detection of Cerebral Aneurysms' (MACCA). The rationale behind the study was that magnetic resonance angiography (MRA) has large advantages in not involving patient exposure to either ionising radiation or iodinated contrast material. Furthermore, contrast enhanced MRA (CEMRA, using non-iodinated contrast material) was expected to give better quality images than non-contrast-enhanced MRA. A disadvantage of MRA is that patients must be transferred to a MR-suite after the standard non-contrastenhanced CT made to detect the SAH, whereas computed tomographic angiography (CTA) can be performed directly without need for such a transfer. MRA would therefore be preferable only if it performed better than CTA in aneurysm detection or in determining optimal treatment.

For the MACCA study 75 patients presenting with SAH underwent an additional MRA on top of the standard CTA and digital subtraction angiography (DSA), DSA serving as standard of reference. Due to logistics inclusion of patients took longer than expected, but in 2006 the last patient was included. Chapter 2 describes the MACCA study results with respect to aneurysm detection, showing that performance of CEMRA and CTA in detecting intracranial aneurysms does not significantly differ.

The second part of the MACCA study evaluated the performance of CEMRA and CTA in assessing suitability of endovascular coiling - or 'coilability'- of detected aneurysms. Results are described in Chapter 3. We found no significant difference in the performance of CEMRA and CTA in assessing coilability. 
The assessment of coilability itself is difficult because no definite criteria for coilability exist. Although a wide neck of the aneurysm or vessels originating from the aneurysm are generally factors leading to preference for surgical treatment, the choice of treatment remains subjective depending on skills and experiences of the treating neuro-interventionalist or neurosurgeon. In Chapter 3 this is demonstrated by the low interobserver agreement we found in the evaluation of the standard of reference, DSA, by two experienced neuro-interventionalists with respect to coilability (Kappa 0.41). Despite this obvious difficulty in assessing coilability of an aneurysm, the results of the study remain valid as long as no better way of evaluating the performance of imaging modalities with respect to coilability of intracranial aneurysms exists.

Since MRA appears to perform equally to CTA at best, the latter must remain the preferred imaging modality for patients with $\mathrm{SAH}$. This is even truer now that CT technique has considerably improved since the inclusion of our study took place, as can be read in Chapter 1, whilst technical developments in MRI during this period are limited and the same MRA at 1.5 Tesla is still widely used.

Potential consequences of using different imaging strategies in choice of treatment of SAH can be identified by running a simulation which evaluates the effects of different imaging strategies on both patient treatment and diagnostic costs. Chapter 4 describes our simulation study in which, using the images from the MACCA-study, different combinations of CEMRA and DSA were tried. We found that non-invasive imaging like CEMRA as first line modality is safe and less expensive than performing diagnostic DSA in all patients, reserving additional diagnostic DSA for those patients in whom no aneurysm is found or harboring an aneurysm that is probably not suitable for endovascular treatment. In our study group of 75 patients this imaging strategy would save 46 diagnostic DSA's translating to a total of approximately 14,500 Euro in diagnostic costs. On the other hand, it would also lead to one patient undergoing surgical clipping of an aneurysm that was coilable based on DSA, and to one patient undergoing an unsuccessful coiling attempt under general anaesthesia. In view of the small difference in outcome after coiling versus clipping, however, and the small additional risk of general anaesthesia during a DSA, this disadvantage is deemed acceptable.

For the assessment of coilability one should consider the background of the centres in which the assessment is carried out: it is probable that centres where more than $90 \%$ of intracranial aneurysms are treated by endovascular means use different coilability criteria than centres treating the majority of aneurysms by surgical clipping. Chapter 5 gives an overview of our neuro-interventional practice from 2000 to 2008 , elucidating the clinical background of the studies in previous chapters. In this overview we evaluated 443 ruptured aneurysms in 403 patients treated in our hospital in that time-period: 173 patients (42.9\%) harbouring 199 aneurysms underwent surgical treatment, and 244 (55.1\%) aneurysms were coiled in 230 patients. During an average follow-up period of 33.9 months (range 12 - 106), rebleeding occurred in $3.1 \%$ of patients after surgical treatment, and in $2.3 \%$ after endovascular treatment. Total mortality (related and unrelated to the SAH) in this follow-up period was $11.6 \%$ after surgery, and $17.4 \%$ after coiling $(p=0.104)$, but pretreatment clinical condition according to Hunt and Hess grading scale $(\mathrm{HH})$ was significantly better in surgically treated patients $(p=0.018)$. These figures are comparable with other publications, taking into account the frequently poor clinical condition of 
patients at the time of presentation, and affirms the efficacy of our centre's policy of letting a multidisciplinary team decide what type of treatment is given to patients with a ruptured intracranial aneurysm.

When an intracranial aneurysm has been coiled, follow-up is recommended because recanalization of a coiled aneurysm occurs regularly. In our own population, increasing compaction of the coil mass was observed in 38.1\% during follow-up (72 of 189 aneurysms for which a follow-up study was available), and $16(22 \%)$ of these were retreated. DSA has been used for many years now to assess recanalization of coiled aneurysms at follow-up. Recent studies, however, have shown MRA to be a good alternative. Most of these studies use a flow dependent MRA sequence for recanalization assessment. In order to assess the performance of CEMRA in detecting recanalization, we carried out a prospective study using CEMRA in the follow-up of coiled aneurysms, with DSA as standard of reference, and compared the results with those from studies using flow dependent MRA. The results are described in Chapter 6. We found a sensitivity of $81.8 \%$ and negative predictive value of $90.5 \%$ for CEMRA, which does not differ from values published in the literature for flow dependent MRA sequences. This study shows that CEMRA can be used in the follow-up of coiled aneurysms, but because CEMRA has such a low positive predictive value (36.7\%), additional DSA may be required where incomplete occlusion is seen on CEMRA images.

The first follow-up study is usually performed at six months after treatment. In our centre it is standard procedure to follow-up a second time 24 months after treatment. Recently the question was raised in the literature whether prolonged follow-up, when an aneurysm is adequately occluded at six months, yields any advantages. Adequately occluded aneurysms are those that are completely occluded or show a small neck remnant (Class 1 and Class 2 of the Roy and Raymond classification (R\&R)). We performed a long-term follow-up study of a group of patients with aneurysms that were adequately occluded at six months follow-up, and investigated the relation between Class 2 R\&R at six months and late recanalization. We compared our results to those obtained from the Ferns et al. LOTUS study, of which our group of patients was a subset. This we describe in Chapter 7. Three of our 62 patients (4.8\%, 95\% Confidence Interval $(\mathrm{Cl}) 1.3-14.4 \%)$ with a total of 71 aneurysms (2.5\%, 95\% $1.1-12.7 \%)$ showed late recanalization; none of these reopened aneurysms were retreated however $(0.0 \%, 95 \% \mathrm{Cl} 0.0-6.4 \%)$. All three of the recanalized aneurysms had been classified as completely occluded (Class 1 ) at the end of the coiling procedure, and at six months follow-up. These results are comparable to those of the LOTUS study, leading to the conclusion that prolonged follow-up, within the first 5-10 years after coiling, is not beneficial in in terms of detecting recanalized aneurysms requiring retreatment in patients with coiled aneurysms that are adequately occluded at 6 months. Furthermore, no relationship was found between Class 2 R\&R and late recanalization, and thus a simplification of occlusion classification can be introduced: coiling of aneurysms at 6 months can be described as 'adequate' or 'inadequate'.

Chapter 8 describes a study assessing cost-effectiveness of different imaging modalities in patients with non-traumatic SAH. CTA, MRA and DSA and combinations of CTA or MRA with DSA are evaluated, using a decision model that calculates costs and benefits in quality-adjusted life-years (QALYs) accruing to 
cohorts of 1000 patients in the duration of one year. Differences in cost - benefit balance are mostly due to the varying costs of imaging modalities set against their sensitivity and specificity in both aneurysm detection and coilability assessment. Our model shows that a diagnostic DSA in all patients is more costeffective than CTA or MRA as single diagnostic modality before treatment, but that a combination of CTA with DSA, where DSA is performed when CTA detects no aneurysm or finds an aneurysm not suitable for endovascular treatment, is marginally more cost-effective than a diagnostic DSA in all patients. The difference in cost between this combination and a diagnostic DSA in all patients may appear minimal (0.1\%: 41 Euro on top of a total one year estimated cost of nearly 40,000 Euro), but we expect this difference to be bigger in practice, as we explain in Chapter 8.

Finally in Chapter 9 we make nine proposals for treatment and assessment of SAH, based on the results from our own research in combination with results from the published research described in Chapter 1. These proposals provide a basis for discussion and future research, for which we give a few suggestions at the end of chapter 9. 


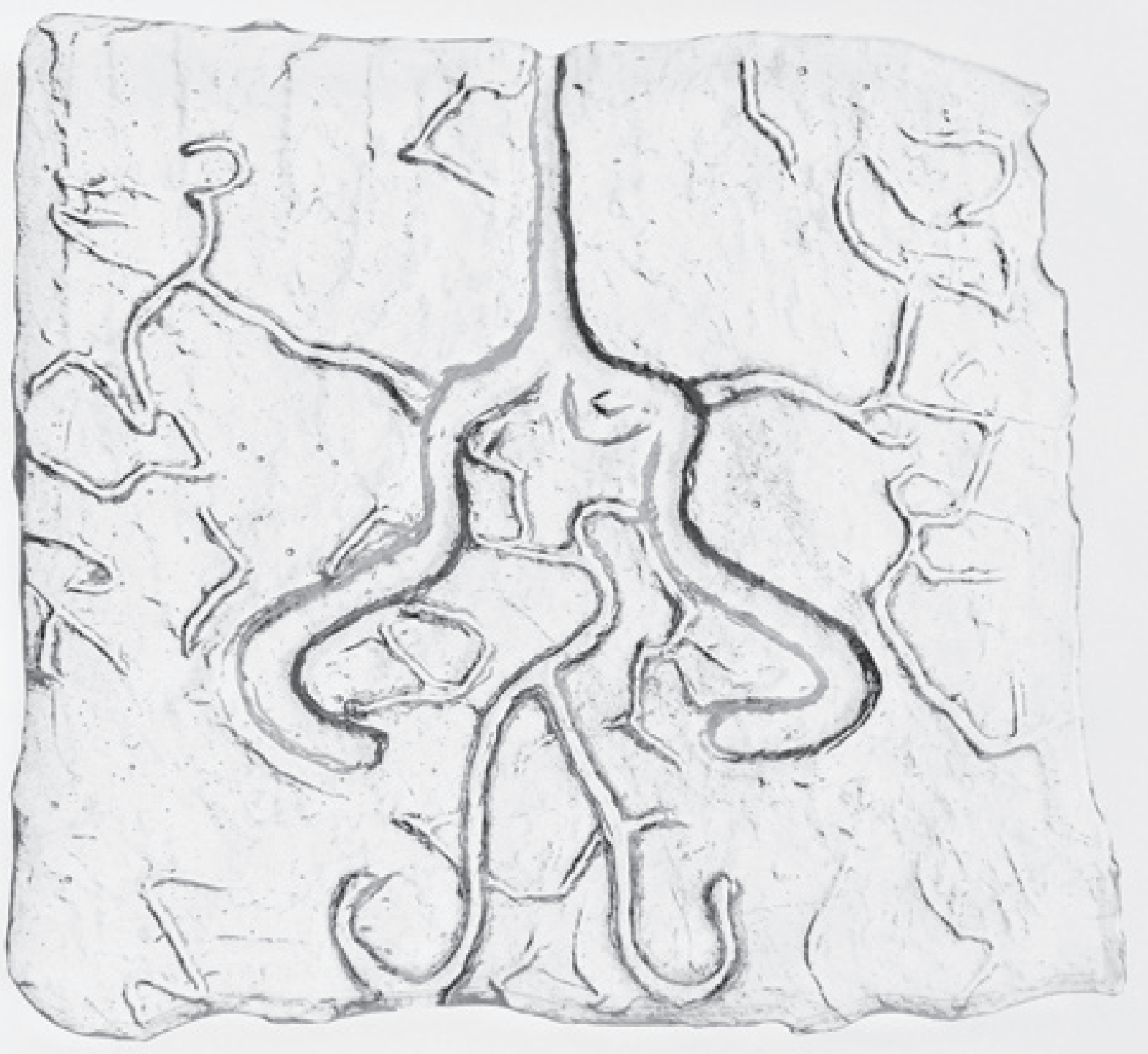

Samenvatting 


\section{Samenvatting}

Snelle, adequate diagnostiek en behandeling van patiënten met een subarachnoïdale bloeding (SAB) vormt een uitdaging voor iedere arts die met deze patiënten geconfronteerd wordt. In de afgelopen decennia hebben er spectaculaire ontwikkelingen plaatsgevonden in zowel beeldvormende diagnostiek als in therapie, en deze nieuwe ontwikkelingen zijn uitgebreid onderzocht, wat terug te vinden is in de honderden publicaties in recente medische literatuur.

Hoofdstuk 1 van dit proefschrift beschrijft de geschiedenis vanaf de eerste beschrijving van een SAB tot aan de recente ontwikkelingen, en ik zou u, lezer van deze samenvatting, van harte willen aanbevelen op zijn minst deze bijzondere geschiedenis te lezen.

Hoewel dit proefschrift de beeldvormende diagnostiek van de patiënt met een SAB behandelt, wordt in dit eerste hoofdstuk ook de evolutie in de behandeling beschreven. De nadruk ligt echter op het onderzoek naar de verschillende diagnostische mogelijkheden.

Ondanks het feit dat alle stappen die nodig zijn voor compleet onderzoek naar diagnostische testen geheel of gedeeltelijk - zijn doorlopen, zijn er altijd facetten waar onze kennis nog onvoldoende is. Bovendien gaan de ontwikkelingen in diagnostische technieken zo snel dat continue onderzoek noodzakelijk blijft. In de volgende hoofdstukken presenteren we onze bijdragen in dit onderzoeksveld.

In 2002 werd de MACCA studie (Magnetic resonance Angiography with Contrast for the detection of Cerebral Aneurysms) ontworpen. De idee achter deze studie was dat magnetische resonantie angiografie (MRA) een aantal voordelen heeft ten opzichte van CT angiografie (CTA) en digitale subtractie angiografie (DSA), aangezien geen ioniserende straling en geen jodiumhoudend contrastmiddel wordt gebruikt. Contrast versterkte MRA (CEMRA, waarbij een niet-jodiumhoudend contrastmiddel wordt gebruikt) zou bovendien theoretisch kwalitatief betere beelden opleveren dan de flow-afhankelijke MRA sequenties. Een nadeel van het gebruik van MRA als diagnostische modaliteit is echter dat patiënten dienen te worden overgebracht van de CT, waar de SAB wordt gediagnostiseerd, naar de MRI-ruimte, terwijl een CTA direct aansluitend aan de standaard CT kan worden verricht, zonder dat een verplaatsing van de patiënt nodig is. MRA zou derhalve slechts dan te prefereren zijn als het significant betere resultaten zou opleveren in het detecteren van intracraniële aneurysmata of voor het bepalen van de optimale behandeling van deze aneurysmata.

Voor de MACCA studie ondergingen 75 patiënten met een SAB een extra CEMRA naast de standaard uitgevoerde CTA. Bovendien ondergingen al deze patiënten een DSA, welke als gouden standaard werd gebruikt. Inclusie van patiënten nam meer tijd in beslag dan verwacht, maar uiteindelijk werd in 2006 de laatste patiënt geïncludeerd. In Hoofdstuk 2 worden de resultaten beschreven van de MACCA studie met betrekking tot aneurysma detectie. Er werd geen statistisch significant verschil gevonden in aneurysma detectie tussen CEMRA en CTA. 
In het tweede deel van de MACCA studie werd in deze zelfde patiëntengroep onderzocht in hoeverre men op basis van de CEMRA- en CTA-beelden kon bepalen of een aneurysma endovasculair te behandelen zou zijn (de 'coilbaarheid' van een aneurysma), met DSA of de uiteindelijke klinische coilbaarheid als gouden standaard. De resultaten worden beschreven in Hoofdstuk 3. Ook hier werd geen statistisch significant verschil tussen CTA en CEMRA gevonden. Het bepalen van coilbaarheid is lastig aangezien er geen harde criteria voor bestaan. Hoewel aneurysmata met een brede hals of met takken welke ontspringen uit de basis van het aneurysma bij voorkeur chirurgisch worden behandeld, berust in veel gevallen de keuze op de voorkeuren en ervaringen van de behandelend neurointerventionalist of neurochirurg. In Hoofdstuk 3 blijkt deze subjectiviteit uit de lage interobserver overeenkomst wanneer de gouden standaard (DSA) wordt beoordeeld door twee onafhankelijke ervaren beoordelaars (Kappa $=0,41$ ). Ondanks deze wat onzekere gouden standaard blijven de resultaten van dit deel van de studie van waarde, zolang er geen betere methode is om coilbaarheid vast te stellen.

Aangezien CEMRA niet beter blijkt te presteren dan CTA in detectie van aneurysmata of bepalen van coilbaarheid, behoudt CTA de voorkeur als diagnostische modaliteit bij patiënten met een SAB. Dit zal zeker niet veranderd zijn nu, sinds ons onderzoek, de CT techniek een enorme vooruitgang heeft geboekt, terwijl de ontwikkelingen in MRA in deze periode slechts beperkt zijn geweest: 1,5 Tesla MRI scanners worden nog altijd veel gebruikt, terwijl de 2- en 4- detectorring CT scanners, gebruikt in ons onderzoek, ondertussen allen vervangen zijn door 16-, 64- of meer detectorring CT scanners.

Eventuele klinische en financiële gevolgen van de keuze voor een bepaalde modaliteit kunnen onderzocht worden door middel van een simulatiestudie. In Hoofdstuk $\mathbf{4}$ wordt een studie beschreven waarin we, op basis van de onderzoeken verricht in de MACCA studie, verschillende combinaties van CEMRA en DSA simuleerden en de klinische en financiële gevolgen evalueerden. Het gebruik van een non-invasieve modaliteit als CEMRA als eerste onderzoek gevolgd door een aanvullend DSA als geen aneurysma gevonden werd of als een aneurysma niet coilbaar leek, bleek veilig, en goedkoper dan alle patiënten direct een DSA laten ondergaan. In onze studie groep van 75 patiënten zou met deze strategie 46 patiënten een diagnostisch DSA bespaard blijven wat een kosten reductie van ongeveer 14.500 Euro zou opleveren. Het zou echter ook resulteren in één chirurgische clipping procedure van een aneurysma welke op basis van de DSA beelden gecoild had kunnen worden, en in één coiling procedure onder algehele anaesthesie, waar de DSA bij aanvang zou aantonen dat het aneurysma niet coilbaar was. Deze klinische consequenties zijn acceptabel in het licht van de geringe verschillen in uitkomst na coilen en na clippen, zoals beschreven in de International Aneurysm Treatment Study (ISAT), en gezien de huidige geringe risico's van algehele narcose.

Zoals eerder beschreven is 'coilbaarheid' een enigszins subjectief gegeven, en ook afhankelijk van de context waarin deze beoordeling plaatsvindt: in centra waar meer dan $90 \%$ van de intracraniële aneurysmata gecoild wordt zal men andere criteria voor coilbaarheid hanteren dan in centra waar het merendeel van deze aneurysmata geclipt wordt. De context van de in dit boek beschreven studies wordt gegeven in Hoofdstuk 5, waar een overzicht van onze neurovasculaire praktijk met betrekking tot geruptureerde aneurysmata wordt beschreven in de periode van 2000 tot 2008 . Van de geëvalueerde 
443 aneurysmata in 403 patiënten werden er $244(55,1 \%)$ in 230 patiënten gecoild, en 173 patiënten (42,9\%) met 199 aneurysmata werden geopereerd. Gedurende een gemiddelde follow-up van 33,9 maanden (range 12 -106) werd een nieuwe SAB ('rebleed') gezien in 3,1\% van de chirurgisch behandelde patiënten en in 2,3\% van de endovasculair behandelde patiënten. Totale mortaliteit (zowel gerelateerd als onafhankelijk van de $\mathrm{SAB}$ ) in deze vervolgperiode was $11,6 \%$ na operatie en $17,4 \%$ na endovasculaire behandeling $(P=0,018)$. Deze getallen zijn vergelijkbaar met die in andere publicaties, rekening houdend met de slechte klinische conditie van een relatief groot deel van onze patiëntengroep ten tijde van binnenkomst, en ze ondersteunen ons beleid waarbij een multidisciplinair team beslist welke behandeling het beste is voor een patiënt met een geruptureerd intracranieel aneurysma.

Follow-up van gecoilde aneurysmata is nodig omdat heropening of rekanalisatie van een gecoild aneurysma regelmatig voorkomt. In onze onderzochte groep kwam dit voor in 38,1\% (72 van 189 aneurysmata waarvan een follow-up onderzoek beschikbaar was) en 16 van deze 72 (22\%) werden opnieuw behandeld.

DSA was lange tijd de het meest geschikte onderzoek voor follow-up van gecoilde aneurysmata. MRA bleek in recente studies echter een goed alternatief. In de meeste van deze studies werd een flow gewogen MRA sequentie gebruikt. Om de kwaliteit van Contrast Enhanced MRA (CEMRA) in het beoordelen van rekanalisties van gecoilde aneurysmata te evalueren hebben we een prospectieve studie uitgevoerd waarin patiënten een CEMRA onderzoek naast de standaard DSA ondergingen voor follow-up van een gecoild aneurysma. De DSA fungeerde als gouden standaard. De resultaten werden vergeleken met andere studies waar flow gewogen sequenties werden gebruikt. De resultaten van onze studie zijn beschreven in Hoofdstuk 6. CEMRA had een sensitiviteit van $81,8 \%$ en een negatief voorspellende waarde van 90,5\%, wat niet veel anders is dan in de literatuur beschreven voor flow gewogen MRA sequenties. Onze studie toont aan dat CEMRA gebruikt kan worden voor de follow-up van gecoilde intracraniële aneurysmata, maar dat de lage positief voorspellende waarde $(36,7 \%)$ een DSA nodig maakt bij aneurysmata waar een rekanalisatie is waargenomen met CEMRA.

In het algemeen wordt een eerste follow-up zes maanden na de behandeling gedaan. In onze kliniek wordt standaard een follow-up onderzoek gedaan zes maanden en 24 maanden na de behandeling. Recent is de vraag gerezen of langere follow-up nodig is voor aneurysmata welke adequaat geoccludeerd zijn bij de eerste controle na zes maanden. Adequaat geoccludeerde aneurysmata zijn deze welke volledig geoccludeerd zijn of een kleine opening in de hals van het aneurysma vertonen (Klasse 1 en 2 van de Roy en Raymond classificatie (R\&R)). In een groep patiënten met adequaat geoccludeerde aneurysmata na zes maanden hebben we gekeken naar de occlusie status op lange termijn en onderzochten de relatie tussen Klasse 2 R\&R occlusie bij zes maanden en late rekanalisatie. We vergeleken onze resultaten met die van de grotere multicenter LOTUS studie van Ferns et al, waar onze patiënten deel van uitmaakten. In Hoofdstuk 7 zijn deze resultaten beschreven. Drie van de 62 onderzochte patiënten (4,8\%, 95\% Confidence Interval ( $\mathrm{Cl})$ 1,3-14,4\%) met in totaal 71 aneurysmata $(2,5 \%, 95 \% \mathrm{Cl} 1,1-12,7 \%)$ vertoonden late rekanalisatie. Geen van deze drie gerekanaliseerde aneurysmata is echter opnieuw behandeld $(0,0 \%, 95 \% \mathrm{Cl} 0,0-6,4 \%)$. Alle drie de aneurysmata waren volledig geoccludeerd (Klasse $1 \mathrm{R} \& \mathrm{R}$ ) aan het eind van de coiling procedure en bij follow-up na zes 
maanden. Deze resultaten waren vergelijkbaar met die van de LOTUS studie, wat leidde tot de conclusie dat lange termijn follow-up, althans tussen vijf en tien jaar na behandeling, niet efficiënt is met betrekking tot het ontdekken van een behandeling vergende rekanalisatie van een gecoild aneurysma, voor patiënten die adequaat geoccludeerde aneurysmata bij zes maands follow-up hebben. Bovendien: aangezien er geen relatie gevonden kon worden tussen Klasse 2 R\&R en late rekanalisatie zou de beoordeling van de occlusiestatus bij follow-up eenvoudigweg gegeven kunnen worden als 'adequaat' of 'inadequaat'.

In Hoofdstuk 8 wordt een kosteneffectiviteit studie beschreven van verschillende beeldvormende modaliteiten bij patiënten met een non-traumatische SAB. CTA, CEMRA en DSA en combinaties van CTA of CEMRA met DSA werden geëvalueerd met behulp van een beslissingsmodel dat de kosten en de effectiviteit in 'quality adjusted life years' (QALY's) voor een cohort van 1000 patiënten berekent voor een periode tot één jaar na behandeling. Verschillen in kosten en effectiviteit worden verklaard door de kosten van de beeldvormende modaliteit en door de effecten van verschil in sensitiviteit en specificiteit van deze modaliteiten voor de detectie van aneurysmata en het bepalen van coilbaarheid. Ons model toont aan dat DSA als diagnostische modaliteit kosteneffectiever is dan alleen CTA of CEMRA voorafgaand aan een behandeling. Maar een strategie waarbij CTA gevolgd wordt door DSA indien geen aneurysma gevonden wordt of indien een aneurysma op CTA niet coilbaar lijkt, is iets kosteneffectiever dan DSA alleen. Het verschil in kosten van deze strategie met DSA alleen lijkt minimaal (0,1\%: 41 Euro extra op totale één jaars kosten van bijna 40.000 Euro), maar zal in de praktijk hoger zijn zoals in Hoofdstuk 8 wordt uitgelegd.

De resultaten van in dit boek beschreven onderzoeken en de resultaten uit andere publicaties als beschreven in Hoofdstuk 1 leiden in Hoofdstuk 9 tot negen voorstellen met betrekking tot diagnostiek en behandeling van patiënten met een SAB. Deze voorstellen staan open voor discussie en kunnen een basis vormen voor verder onderzoek. Enkele suggesties voor zulk onderzoek worden aan het eind van Hoofdstuk 9 gegeven. 


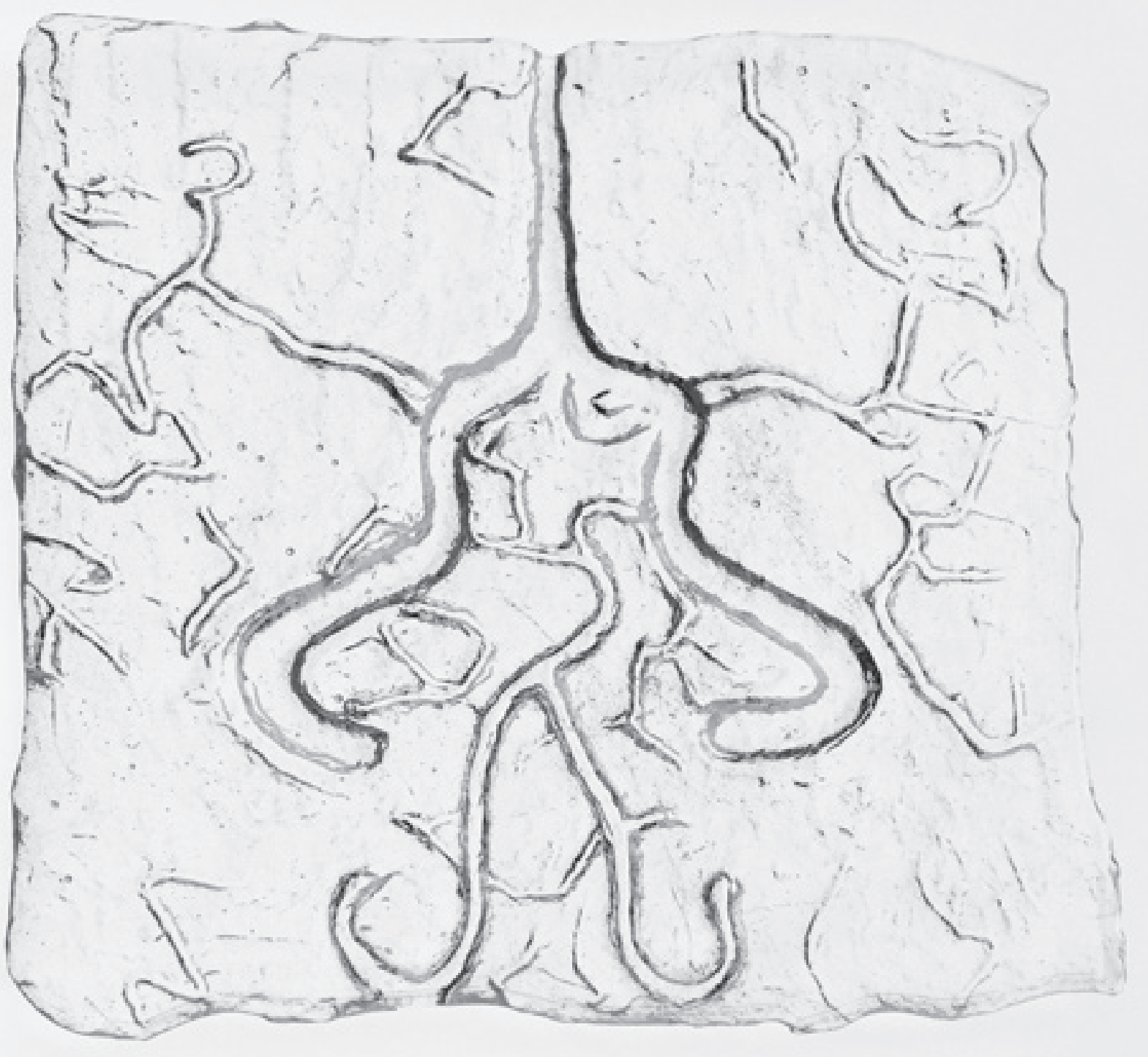

\section{Acknowledgements}




\title{
Acknowledgements
}

\author{
Cast \\ In order of appearance
}

Susanne Besseling Love of my life Jos van Engelshoven Previous head of Radiology department, mentor Michiel de Haan Head of 'Angio Suite', A\&I teacher and buddy

Jan Wilmink. Promotor, initiator, tutor, co-author Paul Hofman Co-promotor, mental coach, co-author Thoen Kiam Oei Neuro-interventional trailblazer, co-author

Fons Kessels Statistician, bridge-partner, inspirator, co-author

Willem-Jan van Rooij, Menno Sluzewski Neuro-intervention teachers Roel Heijboer Co-author, (neuro)interventional radiologist Geert Spincemaille Co-author, neurosurgeon Robert van Oostenbrugge, .Co-author, neurologist Jim Dings Co-author, neurosurgeon Stanley Oei. Co-author, radiologist Lisa Klompenhouwer. Paranymph, co-author, Muse 1 Rick de Graaf. Sparring partner, roommate Anni Sailer Paranymph, co-author, Muse 2 Joachim Wildberger Promotor, head of Radiology Dept, motivator, co-author Sandra Ferns Co-author, Muse 3 Janneke Grutters Epidemiologist, co-author Estelle Nijssen Text corrector, Muse 4 


\section{Special thanks}

Patients

Radiology technicians

Radiology secretariat 


\section{Author's career in a nutshell}

Born on July $1^{\text {st }} 1961$ in Geleen, the Netherlands

Secondary school: Christelijk Lyceum Arnhem

Studied one year electrical engineering at the Technical University Enschede before entering the medical study at the Free University in Amsterdam. Noteworthy internships: tropical medicine in the Kakamega Provincial Hospital in Kenya and gynaecology / obstetrics in the Diaconessen Hospital in Paramaribo, Surinam.

Attended the Dutch Tropical Course for physicians at the Royal Dutch Tropical Institute in Amsterdam after finishing a special residency for tropical medicine at the Slotervaart Hospital in Amsterdam.

Worked for Medécins Sans Frontieres in Somalia, Laos and Sri Lanka.

Acted one year as resident gynaecology / obstetrics in the Maastricht University Medical Centre, followed by the residency of Radiology in the same hospital.

Trained for interventional radiology at the University hospital in Leuven, Belgium, and for neurointerventional radiology in the Elisabeth Gasthuis in Tilburg, the Netherlands and the Alfried Krupp Hospital in Essen, Germany.

Achieved a Master of Science degree in Interventional Neurosurgery at the University of Paris-Sud, France. 
